Universidade de São Paulo

Instituto de Astronomia, Geofísica e Ciências Atmosféricas

Departamento de Astronomia

Oscar Cavichia de Moraes

\title{
Abundâncias químicas de nebulosas planetárias na conexão bojo-disco
}

São Paulo

2008 

Oscar Cavichia de Moraes

\section{Abundâncias químicas de nebulosas planetárias na conexão bojo-disco}

Dissertação apresentada ao Departamento de Astronomia do Instituto de Astronomia, Geofísica e Ciências Atmosféricas da Universidade de São Paulo como requisito parcial para a obtenção do título de Mestre em Ciências.

Área de Concentração: Astronomia

Orientador: Prof. Dr. Roberto D. Dias da Costa

São Paulo

2008 



\section{Agradecimentos}

Gostaria de agradecer primeiramente aos meus pais pela oportunidade a mim dada de prosseguir nos estudos.

À FAPESP pela bolsa de estudos processo 05/03194-4 e ao CNPQ.

Ao meu orientador, Dr. Roberto Costa, que, desde a iniciação científica, sempre esteve disposto a me ajudar nos momentos que precisei.

Ao Dr. Walter J. Maciel pelas pertinentes discussões a respeito do projeto.

Ao Dr. Jacques Lépine por seus comentários e discussões.

Ao colega de sala Juan Luna por sua ajuda com o IRAF.

À Tatiana Laganá por sua paciência ao me ajudar com o IDL.

Aos amigos do IAG: Felipe, Raimundo, $\mathrm{Marcio}^{2}$, Vinicius Placco, Tiago Ricci, Alessandro, Tatiana, Patricia, Graziela, Sergio², Monica, Pedro, Pamela, entre outros, pelos momentos de descontração.

Ao pessoal do LNA pelo suporte técnico nas observações.

Ao pessoal do IAG: informática, secretaria, biblioteca, limpeza, café, segurança, gráfica.

A todos que de uma certa forma me ajudaram neste projeto.

Muito obrigado!

Esta dissertação foi escrita em LATEX com a classe IAGTESE, para teses e dissertações do IAG. 

"I have a limited intelligence and I use it in a particular direction."

Richard P. Feynman (1918-1988) 



\section{Resumo}

Este trabalho constituiu-se da análise de abundâncias químicas de nebulosas planetárias localizadas na conexão bojo-disco, onde se dá o encontro das características do bojo, tais como a diversidade de abundâncias, com as do disco, tais como o limite interno do gradiente radial de abundâncias. Em particular, o estudo de nebulosas planetárias nesta região traz informações importantes a respeito das abundâncias de elementos tais como He, O, Ne, Ar, S e de sua evolução associada à evolução das estrelas de massa intermediária.

Novas abundâncias foram derivadas a partir de observações espectrofotométricas no telescópio Perkin-Elmer de 1.60 m do Laboratório Nacional de Astrofísica (LNA) em Minas Gerais, Brasil. Foram observadas nebulosas planetárias selecionadas através da localização na direção do centro da Galáxia, diâmetro angular no óptico e fluxo em rádio. A comparação entre as abundâncias obtidas neste trabalho com outros trabalhos da literatura mostrou que as distribuições das abundâncias são compatíveis.

Para o estudo da distribuição das abundâncias na conexão utilizou-se as escalas de distância de Maciel e Pottasch (1980), Cahn et al. (1992), e Zhang (1995). A separação das nebulosas planetárias do bojo e do disco mostrou que em média as do bojo apresentam menores abundâncias se comparadas as disco interno, para as escalas de Cahn et al. (1992) e Zhang (1995). Contudo esta separação não é superior aos erros na obtenção das abundâncias, indicando apenas uma tendência. Através deste estudo encontrou-se uma distância de separação entre as propriedades químicas destas regiões. Para a primeira escala esta distância é de $2.9 \mathrm{kpc}$ e para a segunda de $1.5 \mathrm{kpc}$. Sendo que o valor de 2.9 kpc concorda com resultados independentes. A escala de Maciel e Pottasch (1980) não apresentou resultados conclusivos a respeito da distribuição das abundâncias entre estas estruturas. 



\section{Abstract}

This project consisted in a spectrophotometric investigation of planetary nebulae located at the bulge-disk connection of the Milk Way, where the bulge and disk characteristics such as chemical and kinematic properties should intersect. In particular, the study of planetary nebulae in the bulge-disk connection brings important informations about the chemical abundances of elements such as He,N,O,S,Ar,Ne and the evolution of these abundances, associated with the evolution of intermediate-mass stars, as well as for the chemical evolution of the Galaxy.

New abundances were derived from spectrophotometric observations at the PerkinElmer 1.6 m telescope of Laboratório Nacional de Astrofísica - Brazil. The objects were selected according to their location toward the Galactic center, angular diameter, and radio flux. The data show a good agreement with some other results in the literature, in the sense that the distribution of the abundances is similar to those works.

Statistical distance scales from Maciel e Pottasch (1980), Cahn et al. (1992), and Zhang (1995) were used to study the distribution of chemical abundances in the bulge-disk connection. Making use of Cahn et al. (1992) and Zhang (1995) scales, the separation between PNe belonging to the disk and bulge showed that on the average those from the bulge have a slight underabundance compared to those from the inner disk. Nevertheless this separation is not larger than the errors in the abundance determinations, showing only a tendency. This study allowed to find the distance in which the chemical properties of these regions are distinct. For the former scale the distance is $2.9 \mathrm{kpc}$ and for the latter is $1.5 \mathrm{kpc}$. The value of $2.9 \mathrm{kpc}$ agree with other results for the disk-bulge separation. The same study with Maciel e Pottasch (1980) distance scale did not show any conclusive result about the distribution of chemical abundances between these structures. 



\section{Lista de Figuras}

1.1 Principais componentes da estrutura da Via Láctea. . . . . . . . . . . . . . 22

1.2 Imagem do bojo no infravermelho obtida pelo satélite COBE/DIRBE. . . . 23

1.3 Diagrama HR mostrando a evolução de uma estrela de baixa massa. . . . . 27

1.4 Estrutura de camadas do interior de uma estrela no AGB. . . . . . . . . . 28

2.1 Visão esquemática do espectrógrafo Cassegrain. . . . . . . . . . . . . . . . 31

2.2 Contornos do bojo galáctico em $2.2 \mu \mathrm{m} . \quad \ldots \ldots \ldots$. . . . . . . . . . . . . . 32

2.3 Diagrama de níveis para os íons OII e SII. . . . . . . . . . . . . . . . . . 39

2.4 Diagrama de níveis para os íons OIII e NII. . . . . . . . . . . . . . . . . . 41

3.1 Distribuição das NPs observadas neste projeto. . . . . . . . . . . . . . . . 49

3.2 Comparação entre as distribuições das abundâncias de hélio. . . . . . . . . . 52

3.3 Comparação entre as abundâncias de hélio. . . . . . . . . . . . . . . . . . 53

3.4 Histogramas comparando as distribuições das abundâncias de nitrogênio. 55

3.5 Comparação das abundâncias de nitrogênio com dados da literatura. . . . . 56

3.6 Comparação entre as distribuições das abundâncias de oxigênio. . . . . . 57

3.7 Comparação entre as abundâncias de oxigênio . . . . . . . . . . . . . . 58

3.8 Distribuição das abundâncias químicas do enxofre . . . . . . . . . . . . . . 59

3.9 Comparação entre as abundâncias químicas do enxofre. . . . . . . . . . . . 60

3.10 Distribuição da abundância de argônio. . . . . . . . . . . . . . . . . . . . . 61

3.11 Comparação entre as abundâncias de argônio. . . . . . . . . . . . . . . . . 62

3.12 Histograma das abundâncias de neônio. . . . . . . . . . . . . . . . . . . 63

3.13 Comparação entre as abundâncias de neônio. . . . . . . . . . . . . . . . . . 64

$3.14 \log (N / O)$ como função de He/H. . . . . . . . . . . . . . . . . . 65 
3.15 Variação da abundância de nitrogênio com a abundância de oxigênio. 66

3.16 Correlação entre as abundâncias de oxigênio e neônio. . . . . . . . . . . . . 67

3.17 Correlação entre as abundâncias de argônio e oxigênio. . . . . . . . . . . . 68

3.18 Correlação entre as abundâncias de neônio e oxigênio. . . . . . . . . . . . . 68

4.1 Histograma da distância de MP80 . . . . . . . . . . . . . . . . 73

4.2 Distribuição no plano do céu dos objetos da amostra de M84. . . . . . . . 74

4.3 Histograma da amostra selecionada do catálogo de M84 sem LL. . . . . . . 74

4.4 Distribuição das distâncias de MP80 multiplicadas por um fator de escala. 75

4.5 Distribuição no plano do céu dos objetos selecionados da amostra de Zhang1995. 78

4.6 Histograma da distância heliocêntrica obtida através da escala de Zhang1995. 79

4.7 Distribuição no plano do céu dos objetos selecionados da amostra de CKS92. 80

4.8 Distribuição da distância obtida através do método de CKS92. . . . . . . . 81

4.9 Distribuição radial para a escala de MP80 e um campo de 50x20. . . . . . 85

4.10 Distribuição radial para a escala de MP80 e um campo de 20x20. . . . . . 86

4.11 Distribuição radial para a escala de MP80 e um campo de 10x10. . . . . . 87

4.12 Distribuição radial para MP80 sem escalonar e um campo de 50x20 . . . . 88

4.13 Distribuição radial para a escala de Zhang95 e um campo de 50x20 . . . . . 90

4.14 Distribuição radial para a escala de Zhang95 e um campo de 20x20 . . . . . 91

4.15 Distribuição radial para a escala de Zhang95 e um campo de 10x10 . . . . . 92

4.16 Distribuição radial para a escala de CKS92 e um campo de 50x20 . . . . . . 94

4.17 Distribuição radial para a escala de CKS92 e um campo de 20x20 . . . . . . 95

4.18 Distribuição radial para a escala de CKS92 e um campo de 10x10. . . . . . 96

4.19 Teste KS aplicado à escala de Zhang95 para um campo de 50x20 graus. . . 97

4.20 Teste KS aplicado à escala de Zhang95 para um campo de 20x20 graus. . . 98

4.21 Teste KS aplicado à escala de Zhang95 para um campo de 10x10 graus. . . 98

4.22 Teste KS aplicado à escala de CKS92 para um campo de 50x20 graus. . . . 99

4.23 Teste KS aplicado à escala de CKS92 para um campo de 20x20 graus. . . . 100

4.24 Teste KS aplicado à escala de CKS92 para um campo de 10x10 graus. . . . 100

4.25 Teste KS aplicado à escala de MP80 para um campo de 50x20 graus. . . . 101

4.26 Teste KS aplicado à escala de MP80 para um campo de 20x20 graus. . . . 102

4.27 Teste KS aplicado à escala de MP80 para um campo de 10x10 graus. . . . 102 
4.28 Histogramas dos grupos I e II para Zhang95 e um campo de 50x20. . . . . 104

4.29 Histogramas dos grupos I e II para Zhang95 e um campo de 20x20. . . . . 105

4.30 Histogramas dos grupos I e II para Zhang95 e um campo de 10x10. . . . . 106

4.31 Histogramas dos grupos I e II para CKS92 e um campo de 50x20 . . . . . 107

4.32 Histogramas dos grupos I e II para CKS92 e um campo de 20x20. . . . . . 108

4.33 Histogramas dos grupos I e II para CKS92 e um campo de 10x10. . . . . . 109

4.34 Histogramas dos grupos I e II para MP80 e um campo de 50x20 . . . . . . 110

4.35 Histogramas dos grupos I e II para MP80 e um campo de 20x20. . . . . . . 111

4.36 Histogramas dos grupos I e II para MP80 e um campo de 10x10. . . . . . . 112

4.37 Distribuição radial das metalicidades de estrelas de Tiede e Terndrup (1999).115

4.38 Densidade radial de gás observada e a SFR ao longo do disco. . . . . . . . 116

4.39 Densidade radial de gás observada e distribuição de $\epsilon(\mathrm{O})$ ao longo do disco. 117 



\section{Lista de Tabelas}

2.1 Registro das observações. . . . . . . . . . . . . . . . . . . . . 33

2.2 Parâmetros físicos dos objetos observados em 2006 e 2007. . . . . . . . . . 42

2.3 Abundâncias químicas dos objetos observados. . . . . . . . . . . . . . . 47

A.1 Fluxos desavermelhados observados em junho de 2006 relativos a $\mathrm{H} \beta$, sendo $\mathrm{F}(\mathrm{H} \beta)=100 \ldots \ldots \ldots \ldots \ldots \ldots \ldots$

A.1 Continuação . . . . . . . . . . . . . . . . . . . . . . . . 139

A.1 Continuação . . . . . . . . . . . . . . . . . . . . . . . . 140

A.2 Fluxos desavermelhados dos objetos observados em junho de 2007. Os fluxos são relativos a $\mathrm{H} \beta$ sendo $\mathrm{F}(\mathrm{H} \beta)=100 \ldots \ldots$. . . . . . . . . . . . 141

A.2 Continuação . . . . . . . . . . . . . . . . . . . . . . 142

A.2 Continuação . . . . . . . . . . . . . . . . . . . . . . . . 143

A.2 Continuação . . . . . . . . . . . . . . . . . . . . . . . . . . . . 144 



\section{Sumário}

1. Introdução . . . . . . . . . . . . . . . . . . . . . . . . . . . . . . . 21

1.1 Estrutura da Galáxia . . . . . . . . . . . . . . . . . . . . . . . 21

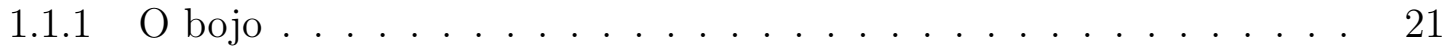

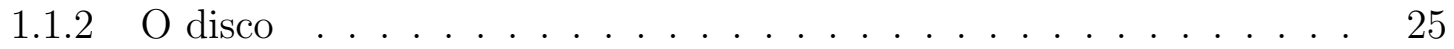

1.2 Nebulosas Planetárias e evolução química da Galáxia . . . . . . . . . . . . 25

1.3 Objetivos do trabalho . . . . . . . . . . . . . . . . . . . . . . . . 29

2. Observação e redução dos dados . . . . . . . . . . . . . . . . . . . . . 31

2.1 Observação . . . . . . . . . . . . . . . . . . . . . . 31

2.2 Redução dos dados . . . . . . . . . . . . . . . . . . . . . . . . . . . 34

2.2.1 Bias e flat field . . . . . . . . . . . . . . . . . . 34

2.2.2 Extração do espectro . . . . . . . . . . . . . . . . . . 35

2.2.3 Calibração em comprimento de onda. . . . . . . . . . . . . . . . 36

2.2.4 Calibração em fluxo. . . . . . . . . . . . . . . . . 36

2.2.5 Correção da extinção interestelar . . . . . . . . . . . . . . . . . 37

2.3 Diagnóstico de plasma . . . . . . . . . . . . . . . . . . . . . . . . . 37

2.3.1 Densidade eletrônica . . . . . . . . . . . . . . . . . . 38

2.3.2 Temperatura eletrônica . . . . . . . . . . . . . . . . . . 40

2.4 Cálculo das abundâncias . . . . . . . . . . . . . . . . . . . . . . . 44

2.4 .1 Abundâncias iônicas . . . . . . . . . . . . . . . . . . . . . . 44

2.4.2 Abundâncias elementais . . . . . . . . . . . . . 45 
3. Resultados observacionais . . . . . . . . . . . . . . . . . . . 49

3.1 Distribuição da amostra . . . . . . . . . . . . . . . . . . . . . . . . 49

3.2 Análise das abundâncias químicas . . . . . . . . . . . . . . . 50

3.2 .1 Hélio . . . . . . . . . . . . . . . . . . . . . . . 52

3.2 .2 Nitrogênio . . . . . . . . . . . . . . . . . . . . . . . 54

3.2 .3 Oxigênio . . . . . . . . . . . . . . . . . . . 56

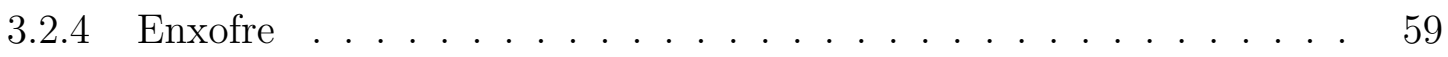

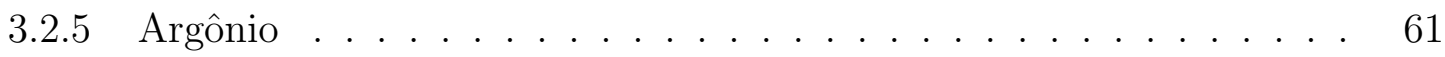

3.2 .6 Neônio . . . . . . . . . . . . . . . . . . . . . . . . . 63

3.3 Correlações entre elementos químicos . . . . . . . . . . . . . . . . . 64

3.3 .1 Correlação entre N/O e hélio . . . . . . . . . . . . . . . 64

3.3 .2 Correlação entre nitrogênio e oxigênio . . . . . . . . . . . . 66

3.3.3 Correlação entre $(\mathrm{S}, \mathrm{Ar}, \mathrm{Ne})$ e oxigênio . . . . . . . . . . . . 66

4. Distâncias estatísticas e abundâncias químicas _. . . . . . . . . . . 69

4.1 Escala de distância de Shklovsky . . . . . . . . . . . . . . . . 70

4.2 Escala de distância de Maciel e Pottasch . . . . . . . . . . . . . . . 71

4.3 Escala de distância de Zhang . . . . . . . . . . . . . . . . . 76

4.4 Escala de distância de Cahn . . . . . . . . . . . . . . . . . . 79

4.5 Abundâncias na conexão bojo-disco ～. . . . . . . . . . . . . . . . . 82

4.5 .1 Escala de Maciel . . . . . . . . . . . . . . . . . . . . . 83

4.5 .2 Escala de Zhang . . . . . . . . . . . . . . . . . . . . . . . . . 89

4.5 .3 Escala de Cahn . . . . . . . . . . . . . . . . . . . . . 93

4.6 Teste de Kolmogorov-Smirnov . . . . . . . . . . . . . . . . . . . 97

4.7 Distribuição das abundâncias ～. . . . . . . . . . . . . . . . . 103

4.8 Comparação com outros trabalhos . . . . . . . . . . . . . . . . . . 114

5. Conclusões. . . . . . . . . . . . . . . . . . . . . . . . . . . . . . . . . . . . 119

5.1 Síntese das conclusões . . . . . . . . . . . . . . . . . . . . . . . 119

5.2 Perspectivas . . . . . . . . . . . . . . . . . . . . . . 121

5.2 .1 Cinemática . . . . . . . . . . . . . . . . . . . . 121

5.2 .2 Modelos Quimiodinâmicos . . . . . . . . . . . . . . . . . 122 
5.2 .3 Novos catálogos . . . . . . . . . . . . . . . . . . . . . . 122

5.2 .4 Espectrógrafo Goodman - SOAR . . . . . . . . . . . . . . 122

5.2 .5 Gaia . . . . . . . . . . . . . . . . . . 123

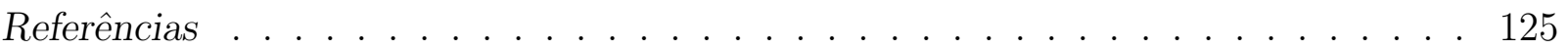

Apêndice 135

A. Tabelas de fluxos . . . . . . . . . . . . . . . . . . . . . . . 137 

Capítulo 1

\section{Introdução}

Neste capítulo é feita uma breve revisão sobre as principais estruturas que compõem a Via Láctea e o papel das nebulosas planetárias na evolução química da Galáxia. Em seguida são apresentados os objetivos desta dissertação de mestrado.

\subsection{Estrutura da Galáxia}

Atualmente nossa concepção da estrutura da Galáxia inclui três componentes principais: o bojo, que contém em seu interior um núcleo, o disco, onde estão localizados os braços espirais, e que inclui um disco fino e um disco espesso, e o halo, onde se distribuem os aglomerados globulares mais velhos. Uma visão de perfil da estrutura da Galáxia é mostrada na figura 1.1. Cada uma destas componentes apresenta características distintas com relação à composição química, cinemática, dinâmica e história evolutiva.

\subsubsection{O bojo}

A estrutura esferoidal central da Via Láctea, denominada bojo, possui uma grande dispersão de metalicidades. O estudo da distribuição de metalicidades através de gigantes $\mathrm{K}$, como feito por Rich (1988), indica um largo intervalo, com valores entre 0.1 a $10 Z_{\odot}$. Posteriormente, McWilliam e Rich (1994) obtiveram espectros com resolução 14 vezes melhor que o estudo anterior e concluíram que Rich (1988) superestimou $[\mathrm{Fe} / \mathrm{H}]$ por $\sim$ 0.3 para a maioria das estrelas mais ricas em metal. Recentemente, Rich e Origlia (2005) encontraram um avanço dos elementos alfa em $[\mathrm{O} / \mathrm{Fe}]=+0.4$ para 13 gigantes com um intervalo de metalicidade estreito ao redor de $[\mathrm{Fe} / \mathrm{H}]=-0.2$. Zoccali et al. (2006) e Lecureur et al. (2007) mediram as abundâncias de oxigênio, magnésio, sódio e alumínio em 


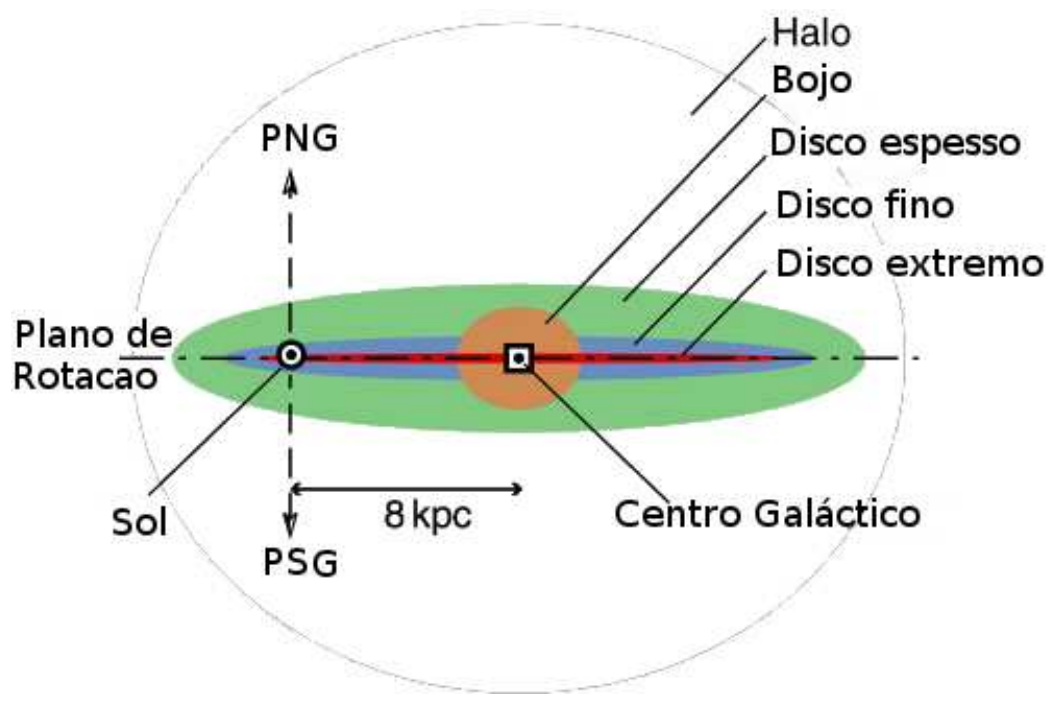

Figura 1.1: Esquema mostrando os principais componentes da estrutura da Via Láctea (visão de perfil). PSG e PNG significam, respectivamente, pólo sul galáctico e pólo norte galáctico.

uma amostra de 50 gigantes $\mathrm{K}$ com $[\mathrm{Fe} / \mathrm{H}]$ cobrindo um largo intervalo de metalicidade, indo de -0.8 a +0.3 . Os resultados mostram que as estrelas do bojo apresentam grandes razões $[\mathrm{O} / \mathrm{Fe}]$ e $[\mathrm{Mg} / \mathrm{Fe}]$ se comparados aos discos fino e espesso. Esta é a assinatura de um enriquecimento químico através de estrelas massivas, progenitoras de supernovas tipo II, e com pouca ou nenhuma contribuição de supernovas tipo Ia, mostrando uma escala de formação curta do bojo com respeito às duas componentes do disco.

Estes resultados concordam com as previsões de recentes modelos de formação do bojo, todos assumindo uma rápida formação em épocas remotas (Ballero et al., 2006; Immeli et al., 2004). Ainda mais importante, eles foram confirmados por grupos diferentes: Fulbright et al. (2007) analisaram 27 gigantes K, e Cunha et al. (2007) observaram 7 gigantes, todas com avanço de oxigênio com respeito a todas as outras componentes Galácticas, em todas as metalicidades.

No entanto, este cenário não combina com os resultados derivados de nebulosas planetárias do bojo tais como os de Ratag et al. (1992), Cuisinier et al. (2000), Escudero e Costa (2001) e Escudero, Costa e Maciel (2004), que obtêm abundâncias análogas às do disco. Os elementos He, O, Si, S, Ar, e Ca mostram um padrão normal de abundâncias, em favor de uma evolução mais lenta.

Em princípio, a partir da distribuição de idades das estrelas do bojo seria possível 
derivar a taxa de formação estelar, e assim responder a questão de quando o bojo se formou. Na prática, a contaminação por estrelas do disco na região de turnoff do diagrama cor-magnitude, acoplada com as dispersões de metalicidade, distância e avermelhamento, não permitem a datação da formação do bojo com uma incerteza menor que 2.5 Ganos. A maioria das estrelas do bojo são velhas, com idade maior que 10 bilhões de anos. Com o advento de câmeras que operam no infra-vermelho (IR), a exploração do centro galáctico tem revelado a presença de estrelas massivas o que indica formação estelar recente (Genzel, Hollenbach e Townes, 1994).

Com relação à cinemática, os objetos do bojo apresentam grandes velocidades com órbitas alongadas e uma grande dispersão, que diminui com a distância galactocêntrica (Minniti, 1996, e referências aí citadas). As cinemáticas são intermediárias entre um sistema puramente rotante tal como o disco da Galáxia, e um sistema quente não rotacional como o halo da Galáxia, que é suportado pela dispersão de velocidades.

A região do bojo é de difícil observação devido à extinção interestelar no plano da Via Láctea (no óptico a extinção pode chegar a 30 magnitudes do centro da galáxia até o Sol). A forma do bojo só pode ser bem definida com observações no infravermelho. Em particular, observações do satélite $\mathrm{COBE}^{1} / \mathrm{DIRBE}^{2}$ em $2.2 \mu \mathrm{m}$ confirmaram a forma achatada do bojo da galáxia (figura 1.2).

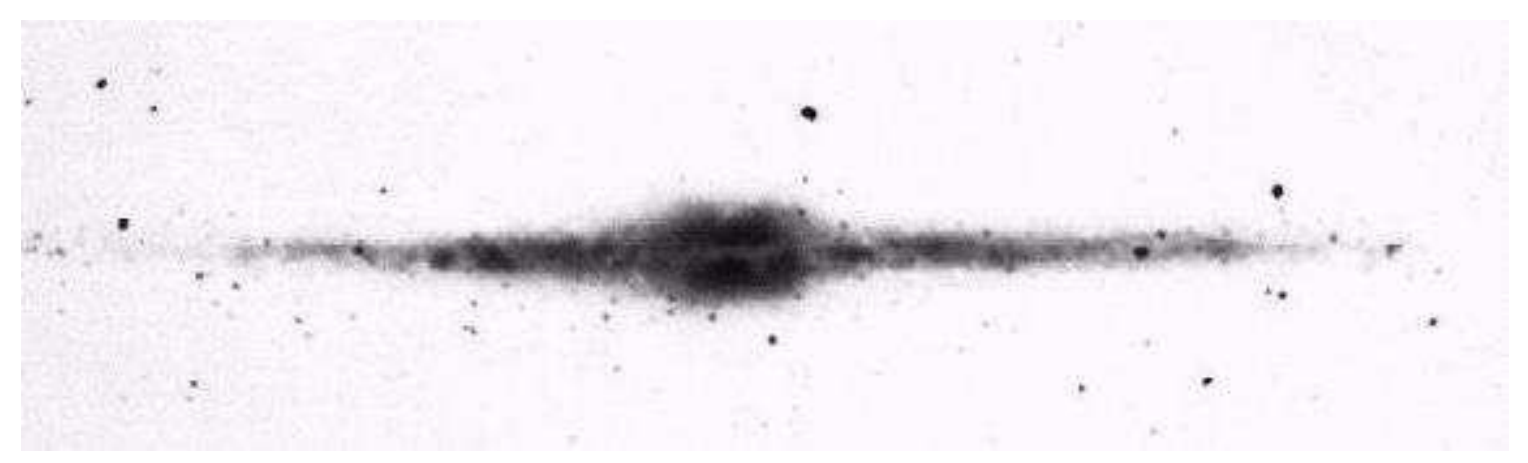

Figura 1.2: Imagem composta infravermelho $(1.25,2.2,3.5 \mu \mathrm{m})$ na direção do centro da galáxia mostrando a assimetria do bojo. A imagem compreende $60^{\circ}$ em longitude galáctica e $20^{\circ}$ em latitude galáctica. Créditos: NASA COBE/DIRBE.

Evidências indicam que bojos com esta forma achatada estão associados a uma estru-

\footnotetext{
${ }^{1}$ Cosmic Background Explorer.

2 Diffuse Infrared Background Experiment.
} 
tura em forma de barra (ver por exemplo Bureau e Freeman, 1999). Porém é difícil uma identificação não ambígua da barra no centro da Galáxia, pois o Sol está localizado no plano da Galáxia e, como mencionado, nossa visão do centro da Galáxia é obscurecida pela poeira do disco. No entanto, são muitas as evidências observacionais apontando para a existência de tal barra no centro da Galáxia, entre elas (para uma lista mais completa ver Gerhard, 2002):

1. de Vaucouleurs (1964) foi o primeiro a constatar que uma barra central é provavelmente responsável pelos movimentos não circulares de HI nas regiões internas da Via Láctea.

2. A assimetria da distribuição da emissão em $2.4 \mu \mathrm{m}$ em longitude derivada por balões atmosféricos indicou que as estrelas nos kpc centrais estão em uma barra com o lado mais próximo em longitudes galácticas positivas.

3. As imagens do satélite COBE/DIRBE confirmaram esta assimetria através da distribuição do brilho superficial no infravermelho próximo, exceto para uma região perto do centro, onde este efeito é invertido (Weiland et al., 1994).

4. Nikolaev e Weinberg (1997) mostraram que a distribuição das populações variáveis no catálogo IRAS é consistente com uma barra com um semi-eixo maior de $3.3 \mathrm{kpc}$ e um ângulo de $24^{\circ} \pm 2^{\circ}$ entre o eixo maior da barra e a linha que une o Sol ao centro da Galáxia, sendo que este ângulo é positivo para uma barra apontando para o quadrante de longitude galáctica positiva.

5. Rohlfs e Kampmann (1993) mostraram que a velocidade terminal HI indica a presença de uma barra com semi-eixo maior de 2-3 kpc e um ângulo por volta de $45^{\circ}$.

6. Binney et al. (1991) usaram a cinemática de CO localizado nas regiões internas da Galáxia para mostrar a presença de uma barra com padrão de velocidade de 63 $\mathrm{kms}^{-1} \mathrm{kpc}^{-1}$, um raio de corrotação de $2.4 \mathrm{kpc}$, e um ângulo de $16^{\circ} \pm 2^{\circ}$. Mais recentemente, estudos da dinâmica de gás (como feitos por Fux, 1999, por exemplo), dão suporte para um raio de corrotação substancialmente maior.

A partir de alguns destes estudos e outros, parece claro que os objetos do bojo de longitudes galácticas positivas são mais brilhantes que aqueles com longitude negativa. 
Isto é geralmente interpretado como a evidência de que os a barra possui um ângulo com a linha de visada, e a extremidade mais próxima da barra está localizada em longitudes positivas. Ainda não há consenso nos parâmetros da barra como o comprimento, velocidade do padrão de rotação, e ângulo.

A barra também pode ter influência sobre a distribuição de abundâncias dos objetos da região central. Efeitos como o aumento de fluxo de gás do disco para o interior do bojo afetam a taxa de formação estelar da região central, além de reduzir a densidade de gás na conexão bojo-disco. Com isso, é de se esperar que as propriedades químicas desta região sofram alterações importantes de ser analisadas.

\subsubsection{O disco}

O disco da Galáxia, como mencionado anteriormente, pode ser dividido em duas componentes: o disco fino e o disco espesso. O disco espesso é composto de estrelas com metalicidade $-1.0 \leq[\mathrm{Fe} / \mathrm{H}] \leq-0.6$ dex, altura do plano galáctico entre 270 e $920 \mathrm{pc}$ e cinemática intermediária entre o halo e o disco fino. As estrelas que compõem o disco fino possuem metalicidades $[\mathrm{Fe} / \mathrm{H}]>-0.6$ dex, altura do plano galáctico inferior a $270 \mathrm{pc}$, órbitas aproximadamente circulares, seguem a rotação do disco e as idades vão desde 9-10 Ganos a poucos milhares de anos.

O disco fino apresenta gradientes radiais de abundâncias químicas encontrados basicamente a partir de estudos de regiões HII e nebulosas planetárias (Pagel e Edmunds, 1981; Faundez-Abans e Maciel, 1986, 1987). Estes gradientes, originalmente encontrados para o oxigênio (Pagel e Edmunds, 1981), se estenderam para outros elementos produzidos por estrelas massivas $(\mathrm{Ne}, \mathrm{S}, \ldots)$, sendo o gradiente similar ao oxigênio, o qual é da ordem de $-0.07 \mathrm{dex} \mathrm{kpc}^{-1}$ (Maciel, 2002b). Recentemente descobriu-se um achatamento temporal deste gradiente em aproximadamente de $-0.11 \mathrm{dex} / \mathrm{kpc}$ a $-0.06 \mathrm{dex} / \mathrm{kpc}$ durante os últimos 9 Ganos, ou de -0.08 dex/kpc a -0.06 dex/kpc nos últimos 5 Ganos (Maciel, Costa e Uchida, 2003; Maciel, Lago e Costa, 2005, 2006), com base na investigação de abundâncias de NPs.

\subsection{Nebulosas Planetárias e evolução química da Galáxia}

Nebulosas Planetárias (NPs) são fundamentais para o estudo da evolução química em galáxias. O entendimento deste estágio de evolução estelar nos permite compreender como 
a Galáxia se originou e desenvolveu. A Galáxia está sujeita a evolução química causada pelo nascimento e morte de estrelas. Durante suas vidas, reações nucleares ocorrendo dentro das estrelas sintetizam a maioria dos elementos que são vistos hoje. Ao final de suas vidas, as estrelas sofrem uma série de episódios de perda de massa, alimentando o meio interestelar a partir do qual futuras gerações de estrelas serão formadas. Sem estes elementos pesados planetas não se formariam e a vida nunca teria se desenvolvido na Terra.

O final da vida das estrelas é portanto de extrema importância para o entendimento completo da evolução estelar e o impacto sobre a evolução química da Galáxia. A maneira a qual as estrelas morrem depende das suas massas originais. Em estrelas de massa intermediária $\left(0.8-8 \mathrm{M}_{\odot}\right)$ a morte é precedida de uma fase chamada nebulosa planetária. Nosso Sol se tornará uma nebulosa planetária em 5 bilhões de anos. Apesar do fato de a maioria das estrelas terem massas abaixo de $8 \mathrm{M}_{\odot}$, uma estrela passa pela fase de nebulosa planetária num tempo relativamente curto, da ordem de 10000 anos. Nesta fase, o material é ionizado pela estrela central que atinge temperaturas da ordem de $100000 \mathrm{~K}$. O material ejetado oferece uma excelente oportunidade para estudar como as estrelas de massa intermediária contribuem para o enriquecimento químico da Galáxia, como estes elementos são produzidos e levados a superfície da estrela, e como a estrela interage com o material previamente ejetado.

A evolução de uma estrela de massa intermediária é mostrada na figura 1.3. As estrela passam a maior parte de suas vidas na seqüencia principal, queimando hidrogênio nos seus núcleos. Quando o hidrogênio no núcleo é exaurido, o núcleo de hélio se contrai e, para estrelas com massas $\leq 2.5 \mathrm{M}_{\odot}$, este núcleo se torna degenerado. A fusão de hidrogênio começa em uma camada ao redor do núcleo e a estrela se move para o ramo das gigantes (RGB na figura). A temperatura no núcleo aumenta e em algum momento se torna quente o suficiente para o início da queima de hélio no núcleo, posicionando a estrela no ramo horizontal (HB). O processo é chamado de flash de He pois, devido à degenerescência, os acréscimos da temperatura devido à queima de hélio levam a uma intensificação do processo triplo- $\alpha$. Quando todo o hélio no núcleo é queimado, ocorre uma nova contração no caroço e expansão do envelope que levam a um aumento da luminosidade e do raio da estrela. A estrela entra no ramo assintótico das gigantes (AGB). Esta fase é caracterizada por duas camadas, uma ao redor do núcleo onde o hélio é queimado, e outra mais externa 


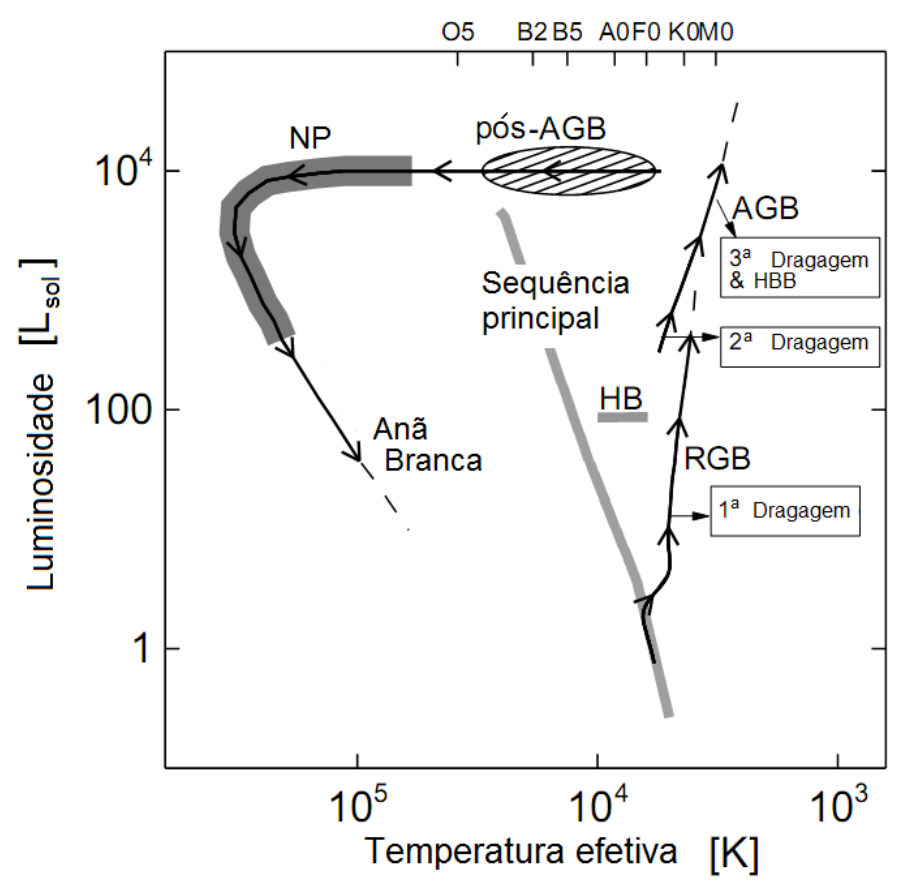

Figura 1.3: Diagrama HR mostrando a evolução de uma estrela de baixa massa. As diferentes fases da evolução estelar são indicadas junto com os principais episódios de mistura. Os acrônimos significam: RGB - ramo das gigantes, AGB - ramo assintótico das gigantes, HB - ramo horizontal, HBB - hot bottom burning, NP - nebulosa planetária.

onde o hidrogênio é queimado. Durante a fase AGB a estrela sofre perda de massa através de um vento não muito intenso $(\sim 10 \mathrm{~km} / \mathrm{s})$. Em algum momento, a estrela apresenta ventos intensos, os chamados superventos, que culmina na ejeção das camadas superficiais da estrela na forma de uma nebulosa planetária. Quando as reações termonucleares param, a estrela central começa a esfriar, não sendo mais capaz de ionizar o material ejetado, até atingir o estágio de uma anã branca. Os restos da nebulosa planetária se misturam com o material presente no meio interestelar, aguardando para a formação de uma nova estrela.

Durante a evolução, as estrelas apresentam uma série de episódios de mistura nos quais o material sintetizado nas regiões mais internas é trazido para a superfície. Estes processos são indicados na figura 1.3 e a estrutura interna de uma estrela que passa por estes processos é mostrada na figura 1.4. A seguir é feito um resumo dos episódios de mistura. 


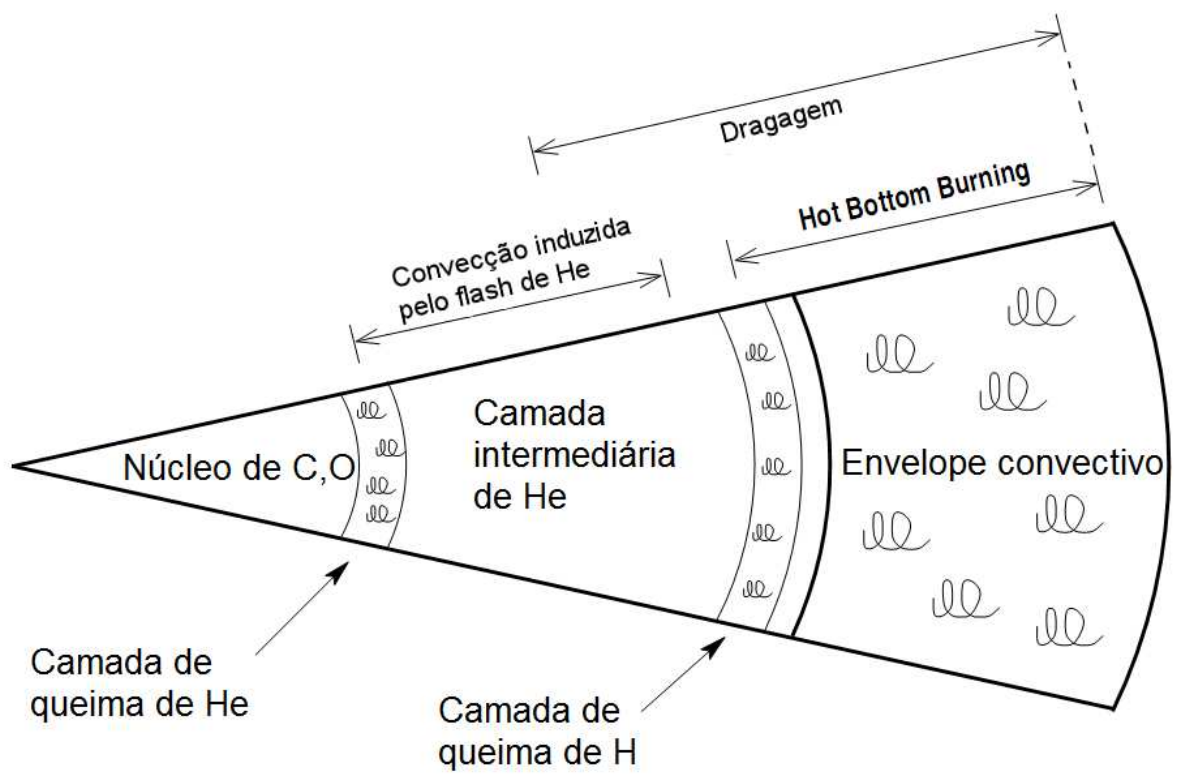

Figura 1.4: Estrutura de camadas do interior de uma estrela no AGB.

- Primeira dragagem. Ao se aproximar do ramo das gigantes, a base da região convectiva superficial se estende até as camadas em que o C foi convertido em N. A abundância superficial de $\mathrm{He}^{4}$ aumenta e a de $\mathrm{H}$ diminui em quantidades detectáveis.

- Segunda dragagem. Para uma estrela com massa acima de $2.3 \mathrm{M}_{\odot}$, quando a abundância do hélio central decresce significativamente, o hélio continua a queimar em uma camada externa que se expande, e o hidrogênio para de queimar. Isto permite que a base do envelope convectivo se estenda até a interface hidrogêniohélio. Conseqüentemente, ${ }^{4} \mathrm{He}$ e ${ }^{14} \mathrm{~N}$ são trazidos para a superfície, aumentando as abundâncias destes elementos e diminuindo as abundâncias de ${ }^{12} \mathrm{C},{ }^{13} \mathrm{C}$ e ${ }^{16} \mathrm{O}$.

- Terceira dragagem. Ocorre durante a fase no ramo assintótico das gigantes e consiste em diversos episódios de mistura. A camada de hélio é termicamente instável e eventualmente produz uma grande quantidade de energia. Estes flashes de hélio são também conhecidos como pulsos térmicos. Isto produz uma zona de convecção induzida pelo flash do hélio, e o ${ }^{12} \mathrm{C}$ produzido na camada de queima do hélio é misturado com aquele produzido na camada intermediária de hélio. A pulsação faz a estrela esfriar e a camada de queima de hidrogênio é extinguida. O envelope convectivo penetra nas regiões mais internas trazendo para a superfície ${ }^{4} \mathrm{He},{ }^{12} \mathrm{C}$, 
e diversos outros elementos ricos em nêutrons que foram sintetizados através da nucleossíntese por captura de nêutrons.

- Hot bottom burning (HBB). Este processo ocorre para as estrelas do ramo assintótico das gigantes com massas acima de 4-4.5 $\mathrm{M}_{\odot}$. Nestas estrelas o envelope convectivo penetra na camada de hidrogênio, e pode ativar a queima do mesmo uma vez que a temperatura da zona de convecção é bastante alta, podendo chegar a $10^{8} \mathrm{~K}$. O HBB pode permitir a queima de $\mathrm{H}$ através do ciclo $\mathrm{CNO}$, convertendo ${ }^{12} \mathrm{C}$ em ${ }^{13} \mathrm{C}$ e ${ }^{14} \mathrm{~N}$. Se a temperatura for alta o suficiente, o ciclo ON é ativado causando a destruição de ${ }^{16} \mathrm{O}$ para a produção de ${ }^{14} \mathrm{~N}$.

Portanto, as abundâncias químicas em NPs traçam as abundâncias do meio interestelar do qual a estrela progenitora nasceu, e também o produto da nucleossíntese que ocorreu durante a evolução da estrela progenitora. Uma vez que He, C, e N são produzidos durante a evolução da estrela mas elementos como O, S, Ar, Ne e elementos do pico do Fe não são sintetizados em estrelas de massa intermediária. Desta forma, determinações precisas das abundâncias químicas em NPs representa uma ferramenta importante para o estudo não somente da evolução estelar e processos de nucleossíntese mas também da evolução química de galáxias.

\subsection{Objetivos do trabalho}

O projeto visa a execução uma investigação espectrofotométrica de nebulosas planetárias localizadas na conexão bojo-disco da Via Láctea. Nesta região deve haver o encontro das características do bojo, tais como a diversidade de abundâncias químicas, com as do disco, como o limite interno do gradiente radial de abundâncias do disco. O objetivo deste projeto é determinar as abundâncias químicas de uma amostra significativa de nebulosas planetárias da conexão bojo-disco, bem como informações sobre sua distribuição. Procedendo assim, pretende-se estabelecer uma distinção entre as populações do bojo e do disco interno, determinando-se a fronteira entre as mesmas e obtendo-se, de maneira independente de modelos, o raio do bojo galáctico.

Tal projeto será executado combinando resultados já disponíveis na literatura com novos dados a serem obtidos através de espectrofotometria. Combinando os resultados, 
poder-se-á modelar com melhor precisão a evolução química tanto do bojo quanto do disco da Galáxia, bem como a interação entre estas estruturas.

Assim, o estudo das abundâncias químicas nesta região deverá prover vínculos observacionais importantes para a modelagem da evolução química da Galáxia. 
Capítulo 2

\section{Observação e redução dos dados}

\subsection{Observação}

As observações deste projeto foram realizadas no telescópio Perkin-Elmer de $1.60 \mathrm{~m}$ do Laboratório Nacional de Astrofísica (LNA) em Minas Gerais, Brasil, nos períodos de 21 a 27 de junho de 2006 e 21 a 26 de junho de 2007.

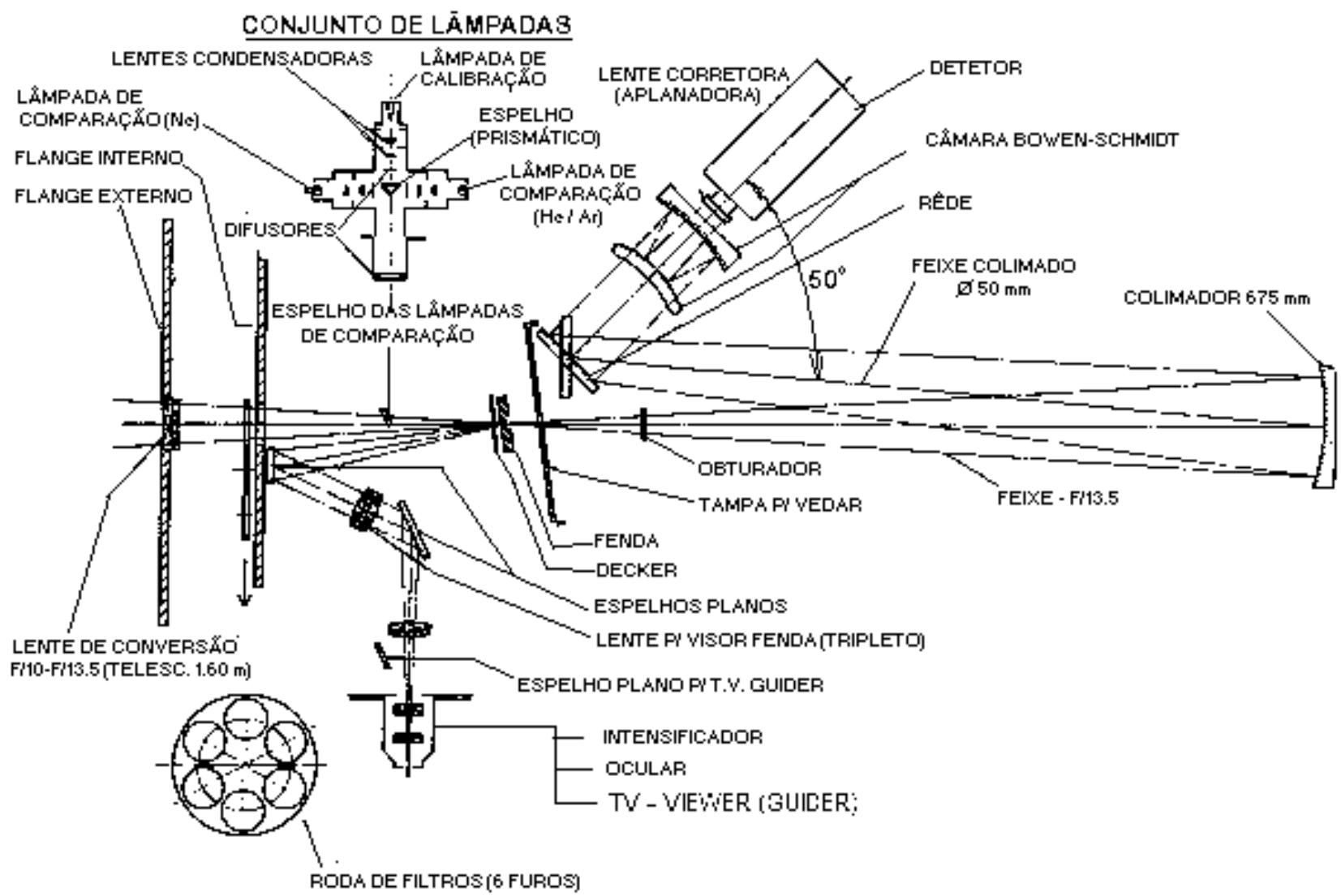

Figura 2.1: Visão esquemática do espectrógrafo Cassegrain. A luz proveniente do telescópio é colimada e direcionada para a rede de difração e em seguida coletada por um detector. 
Utilizou-se para estas observações o espectrógrafo Cassegrain com rede de difração de 300 l/mm e blaze em $640 \mathrm{~nm}$. Tal configuração fornece uma dispersão média de 0.2 $\mathrm{nm} /$ pixel. Um esquema deste espectrógrafo pode ser visto na figura 2.1.

Os objetos foram selecionados a partir do catálogo de Acker et al. (1992) com base em três critérios: coordenadas galácticas compreendidas no intervalo $|\ell| \leq 25^{\circ}$ e $|b| \leq 10^{\circ}$, fluxo em $5 \mathrm{GHz}$ menor que 100 mJy, e diâmetro angular óptico menor que 12 arcsec. A longitude galáctica $(\ell)$ e a latitude galáctica $(b)$ foram usadas para restringir a amostra aos objetos que estão na direção do bojo. Estes intervalos nas coordenadas galácticas se justificam através da análise da figura 2.2, que mostra os contornos da região nuclear do bojo galáctico visto no infravermelho, obtidos pelo satélite COBE/DIRBE. A combinação fluxo em 5 Ghz menor que 100 mJy e diâmetro angular óptico menor que 12 arcsec deve eliminar cerca de 90 a 95\% das nebulosas planetárias que estão na direção do bojo, porém a uma distância menor que $4 \mathrm{kpc}$ do Sol, como pode ser visto em Stasińska et al. (1991). Uma discussão mais detalhada sobre este método será feita no capítulo 4.

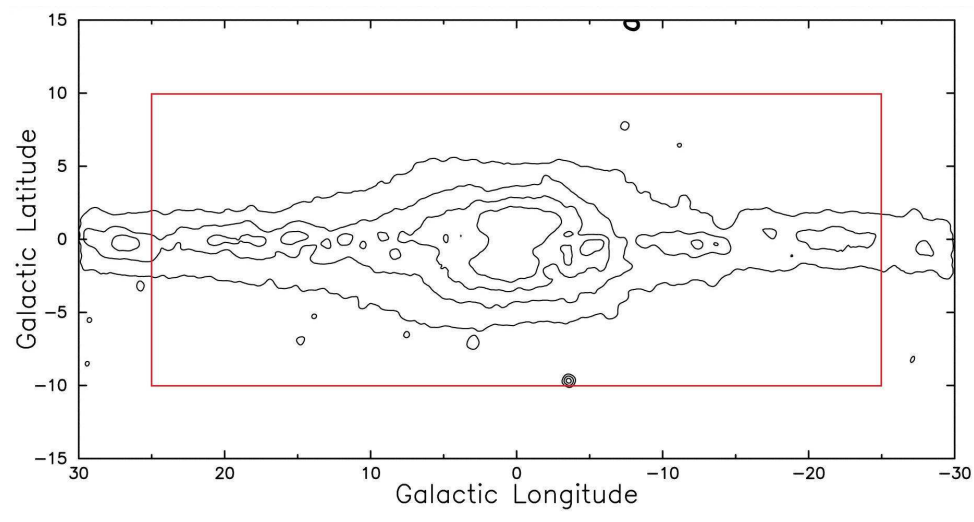

Figura 2.2: Contornos do bojo galáctico em $2.2 \mu \mathrm{m}$. O retângulo na figura delimita a região $|\ell| \leq 25^{\circ}$ e $|b| \leq 10^{\circ}$.

O registro das observações realizadas no LNA é mostrado na tabela 2.1 onde para cada NP é mostrado o número PN G (do inglês Planetary Nebulae Galactic coordinates, introduzido por Acker et al. (1992)), o nome identificador, as coordenadas ascensão reta e declinação (J2000), a data de observação, e o número de exposições juntamente com o tempo de cada exposição. 
Tabela 2.1 - Registro das observações.

\begin{tabular}{|c|c|c|c|c|c|}
\hline PN G & Nome & RA(J2000) & DEC(J2000) & Data de Obs. & Tempo Exp. (s) \\
\hline $000.7-02.7$ & M 2-21 & 175809.57 & -294420.10 & 24-Jun-07 & $2 \times 1200$ \\
\hline $004.0-11.1$ & M 3-29 & 183925.77 & $\begin{array}{lll}-30 & 40 & 36.7\end{array}$ & 24-Jun-06 & $2 \times 1200$ \\
\hline $004.2-04.3$ & H 1-60 & 181225.16 & -272913.00 & 21-Jun-07 & $2 \times 1200$ \\
\hline $004.2-05.9$ & M 2-37 & 181838.35 & -280801.00 & 24-Jun-07 & $1 \times 1200$ \\
\hline $005.2-18.6$ & StWr 2-21 & 191423.33 & -323416.7 & 21-Jun-06 & $3 \times 900$ \\
\hline 006.4-04.6 & Pe $2-13$ & 181813.36 & -253808.90 & 22/23-Jun-07 & $2 \times 1800$ \\
\hline 006.8-03.4 & H 2-45 & 181428.84 & -244338.30 & 23-Jun-07 & $2 \times 900$ \\
\hline $007.0+06.3$ & M 1-24 & 173811.59 & -193737.60 & 24-Jun-07 & $2 \times 1200$ \\
\hline $010.7+07.4$ & Sa $2-230$ & 174202.01 & -155607.5 & 24-Jun-06 & $2 \times 1800$ \\
\hline $011.0-05.1$ & M 1-47 & 182911.15 & -214653.40 & 21-Jun-07 & $2 \times 900$ \\
\hline $011.3+02.8$ & Th 4-11 & 180008.82 & -174043.3 & 24-Jun-06 & $3 \times 600$ \\
\hline 011.7-06.6 & M 1-55 & 183642.55 & -214859.1 & 23-Jun-06 & $2 \times 1200$ \\
\hline 012.6-02.6 & M 1-45 & 182307.98 & -191705.30 & 21-Jun-07 & $2 \times 1200$ \\
\hline 013.8-07.9 & Pc 21 & 184535.22 & -203458.3 & 21-Jun-06 & $2 \times 1200$ \\
\hline $015.9+03.3$ & M 1-39 & 180730.70 & -132847.6 & 23-Jun-06 & $3 \times 600$ \\
\hline 016.4-01.9 & M 1-46 & 182756.34 & -153254.40 & 23-Jun-07 & $3 \times 600$ \\
\hline $19.7-04.5$ & M 1-60 & 184338.11 & -134448.60 & 23-Jun-07 & $3 \times 600$ \\
\hline $019.9+00.9$ & M 3-53 & 182407.89 & -110642.10 & 22-Jun-07 & $2 \times 1800$ \\
\hline $023.0+04.3$ & MA 3 & 181749.38 & -064821.5 & 24-Jun-06 & $3 \times 1200$ \\
\hline 023.3-07.6 & $\mathrm{MaC} 1-16$ & 190121.77 & -115820.0 & 21-Jun-06 & $3 \times 1200$ \\
\hline 023.8-01.7 & K 3-11 & 184107.31 & -085559.00 & 22-Jun-07 & $2 \times 1800$ \\
\hline $024.1+03.8$ & M 2-40 & 182123.85 & -060155.8 & 24-Jun-06 & $2 \times 1200$ \\
\hline 025.9-02.1 & Pe 1-15 & 184624.48 & -071434.60 & 22-Jun-07 & $2 \times 1200$ \\
\hline 335.4-01.1 & Hen 2-169 & 163413.33 & -492113.20 & 23-Jun-07 & $2 \times 1200$ \\
\hline 335.9-03.6 & Mewe 1-7 & 164757.07 & -504248.3 & 21-Jun-06 & $3 \times 1200$ \\
\hline $336.2+01.9$ & Pe 1-6 & 162354.31 & $\begin{array}{lll}-46 & 42 & 15.3\end{array}$ & 22-Jun-07 & $2 \times 1200$ \\
\hline $336.3-05.6$ & Hen 2-186 & 165936.06 & -514206.50 & 25-Jun-07 & $3 \times 600$ \\
\hline $336.9+08.3$ & StWr 4-10 & 160213.04 & -413335.9 & 23-Jun-06 & $2 \times 1200$ \\
\hline $338.8+05.6$ & Hen 2-155 & 161923.10 & -421536.00 & 21-Jun-07 & $3 \times 900$ \\
\hline $340.9-04.6$ & Sa $1-5$ & 171127.37 & -472501.6 & 23-Jun-06 & $2 \times 900$ \\
\hline $342.9-04.9$ & He 2-207 & 171932.97 & -455316.7 & 23-Jun-06 & $3 \times 900$ \\
\hline $343.0-01.7$ & Vd 1-9 & 170538.3 & -435618 & 21-Jun-06 & $2 \times 1200$ \\
\hline $344.2-01.2$ & Н 1-6 & 170658.87 & -424109.75 & 23-Jun-07 & $2 \times 1800$ \\
\hline $344.4+02.8$ & Vd 1-5 & 165133.57 & -400256.0 & 21-Jun-06 & $2 \times 1200$ \\
\hline $344.8+03.4$ & Vd 1-3 & 164932.87 & $\begin{array}{lll}-39 & 21 & 08.9\end{array}$ & 23-Jun-06 & $2 \times 1800$ \\
\hline $345.0+03.4$ & Vd 1-4 & 165025.32 & -390818.9 & 24-Jun-06 & $3 \times 900$ \\
\hline $346.2-08.2$ & IC 4663 & 174528.37 & -445415.90 & 25-Jun-07 & $2 \times 900$ \\
\hline $347.7+02.0$ & Vd 1-8 & 170433.77 & -375314.9 & 24-Jun-06 & $2 \times 1200$ \\
\hline $348.0-13.8$ & IC 4699 & 181832.02 & -455901.7 & 23-Jun-06 & $3 \times 900$ \\
\hline $350.5-05.0$ & H 1-28 & 174254.07 & -393624.00 & 24-Jun-07 & $2 \times 1800$ \\
\hline $350.9+04.4$ & H 2-1 & 170436.26 & -335918.80 & 21-Jun-07 & $4 \times 240,1 \times 120$ \\
\hline $351.6-06.2$ & H 1-37 & 175044.57 & -391726.00 & 24-Jun-07 & $2 \times 900$ \\
\hline
\end{tabular}

Continua na próxima página... 
Tabela 2.1 - Continuação

\begin{tabular}{|c|c|c|c|c|c|}
\hline PN G & Nome & RA(J2000) & DEC(J2000) & Data de Obs. & Tempo Exp. (s) \\
\hline $351.7-10.9$ & Wray 16-385 & 181252.91 & -413026.6 & 21-Jun-06 & $2 \times 1200,1 \times 1800$ \\
\hline $352.6+03.0$ & H $1-8$ & 171442.90 & -332447.20 & 24-Jun-07 & $2 \times 1200$ \\
\hline $355.4-04.0$ & Hf $2-1$ & 175112.15 & -345524.30 & 25-Jun-07 & $2 \times 900$ \\
\hline $356.3-06.2$ & M 3-49 & 180232.11 & -351314.70 & 23-Jun-07 & $2 \times 1800$ \\
\hline $356.8-05.4$ & H 2-35 & 180018.26 & -342739.30 & 21-Jun-07 & $2 \times 1800$ \\
\hline $358.2+03.5$ & H 2-10 & 172732.85 & -283106.90 & 21-Jun-07 & $2 \times 1200$ \\
\hline $358.3+03.0$ & H 1-17 & 172940.59 & -284022.10 & 23-Jun-07 & $3 \times 900$ \\
\hline $358.7+05.2$ & M 3-40 & 172228.27 & -270842.40 & 23-Jun-07 & $2 \times 1200$ \\
\hline $358.8+03.0$ & Th 3-26 & 173109.30 & -281450.40 & 24-Jun-07 & $2 \times 1800$ \\
\hline $359.8+03.7$ & Th 3-25 & 173046.72 & -270559.10 & 22-Jun-07 & $2 \times 1200$ \\
\hline 021.8-00.4 & M 3-28 & 183241.29 & -100550.00 & 22-Jun-07 & $2 \times 1200$ \\
\hline 000.9-04.8 & M 3-23 & 180706.15 & -303417.00 & 21-Jun-07 & $3 \times 1200$ \\
\hline 357.4-04.6 & M 2-22 & 175832.63 & -332836.60 & 22-Jun-07 & $2 \times 1200$ \\
\hline
\end{tabular}

\subsection{Redução dos dados}

Nesta seção são descritos os procedimentos para a redução dos espectros obtidos nas missões observacionais ao LNA. A redução dos dados foi feita através do pacote IRAF ${ }^{1}$.

\subsubsection{Bias e flat field}

O primeiro passo na redução dos dados é corrigir os dados adquiridos pelo CCD de dois tipos de erros: aditivos e multiplicativos. Para corrigir os erros aditivos, que na verdade são originados de ruídos de leitura do CCD, foram feitas exposições de zero segundo com o obturador fechado no começo e no final da missão, o chamado bias. Os CCDs do LNA são resfriados a temperaturas criogênicas $(77 \mathrm{~K})$ e, portanto, os dados não necessitam de correção de dark (corrente de escuro). Posteriormente as imagens bias foram combinadas pela mediana (o valor resultante de um pixel da imagem final é a mediana dos valores daquele mesmo pixel nas imagens de entrada; isto reduz o ruído na imagem de calibração) e esta imagem combinada foi subtraída das imagens científicas.

Os erros multiplicativos podem surgir de várias fontes: diferenças de eficiência quântica, diferenças de iluminação (vignetting), e imagens dos grãos de poeira que estão no espelho

\footnotetext{
${ }^{1}$ Image Reduction and Analysis Facility
} 
do telescópio. Para corrigi-los foram feitas imagens chamadas flat field. Estas imagens são obtidas com o obturador aberto e a luz captada pelo telescópio provém da luz de uma lâmpada, luz esta que é refletida numa tela branca localizada na cúpula do telescópio. Se comparadas com o fundo do céu escuro, estas lâmpadas são usualmente mais vermelhas e possuem uma componente infravermelha significativa. Isto introduz altas contagens na região vermelha do CCD se comparado à região azul. Como as imagens científicas são divididas por estas imagens normalizadas de flat field, isto aumentará as contagens do lado azul do espectro e diminuirá as contagens do lado vermelho. Desta forma, introduz-se erros na calibração. Este efeito é corrigido com uma task do IRAF chamada mkillumflat, que tem como propósito corrigir efeitos de iluminação nas imagens flat field, removendo o padrão de iluminação em grande escala, porém conservando os efeitos de resposta em pequenas escalas, isto é, pixel a pixel.

As estrelas-padrão são muito brilhantes e necessitam de uma fenda mais larga para que todo o fluxo seja registrado, garantindo-se desta forma a precisão da calibração em fluxo. Sendo assim, foi necessário fazer exposições flat field com a fenda estreita $(120 \mu \mathrm{m}$ ou 1.5" projetado no céu) para os objetos de programa e as lâmpadas de calibração e outras exposições com a fenda mais larga $(600 \mu \mathrm{m}$ ou 7.5 " projetado no céu) para as estrelaspadrão. Cada imagem flat field foi dividida pela sua moda (variações na iluminação podem fazer com que o método de combinar pela mediana não seja eficiente para reduzir o ruído), e as imagens resultantes foram combinadas pela mediana. Por último as imagens científicas foram divididas pela imagem flat field combinada.

\subsubsection{Extração do espectro}

$\mathrm{Na}$ espectrofotometria as imagens finais precisam ser bi-dimensionais (comprimento de onda no eixo $x$ e fluxo no eixo $y$ ). Porém as imagens obtidas possuem duas dimensões espaciais e, portanto, é necessário extrair os espectros para se obter imagens com uma dimensão espacial.

Primeiramente é preciso encontrar o espectro na imagem. Isto é feito manualmente, examinando um corte ao longo do eixo espacial e indicando o pico apropriado com o cursor, pois, no caso das NPs estudadas neste projeto, nem sempre o espectro do objeto de interesse é o mais intenso na imagem. Em seguida defini-se a janela de extração e o céu. Na prática 
isto é feito especificando-se o tamanho da janela de extração em termos do número de pixels para a direita e para a esquerda do centro do perfil espacial. Similarmente a região do céu é definida em termos de uma região para a esquerda e para a direita do centro do perfil espacial. Contudo, para NPs na direção do bojo, onde o campo é muito rico em objetos, esta região deve ser definida em pequenas faixas entre os objetos.

Pode-se assumir que o eixo espacial é exatamente ao longo das colunas, porém o espectro não será exatamente perpendicular ao eixo espacial (isto é, o espectro não é exatamente paralelo ao eixo de dispersão teórico definido), pois na maioria das vezes o acoplamento do CCD com o espectrógrafo não está alinhado para tal configuração. Além disso, o centro exato do perfil espacial mudará um pouco ao longo do eixo de dispersão conforme a posição do telescópio, devido os desvios na estrutura óptica do telescópio, do espectrógrafo e da câmara CCD. Portanto é preciso traçar o centro do perfil espacial como função do eixo de dispersão.

Em cada ponto ao longo do eixo de dispersão, as colunas dentro da janela de extração são somadas e o céu é subtraído. Esta soma é feita utilizando-se como peso estatístico a variância, que privilegia os valores com alta razão sinal-ruído. A etapa de subtração do céu não é feita nas lâmpadas de calibração, que são lâmpadas de He-Ar utilizadas na calibração em comprimento de onda.

\subsubsection{Calibração em comprimento de onda.}

Cada objeto teve um espectro de lâmpada de calibração de He-Ar medido. Estas lâmpadas possuem o comprimento de onda das linhas de emissão tabelados, o que permite fazer uma correlação entre o comprimento de onda e o pixel correspondente. Tal correlação foi feita utilizando uma função Chebyshev de ordem entre 4 e 5.

\subsubsection{Calibração em fluxo.}

Os espectros precisam ser calibrados em fluxo, ou seja, o fluxo de energia precisa ser expressado em uma unidade física. Para tal foram observadas no mínimo três estrelaspadrão espectrofotométricas ao longo de cada noite. Estas estrelas possuem os fluxos tabelados, permitindo determinar a função sensibilidade do sistema como uma função do comprimento de onda, ou seja, encontrar uma correlação entre as contagens e o fluxo para 
cada comprimento de onda. Esta função é determinada a partir de uma média entre as funções obtidas para cada estrela-padrão. Na medição de cada objeto utilizou-se sua massa de ar para correção da extinção atmosférica, e a função sensibilidade para a calibração final do fluxo.

\subsubsection{Correção da extinção interestelar}

Os fluxos obtidos necessitam de mais uma correção: a extinção interestelar. Em uma nebulosa planetária, as densidades e temperaturas eletrônicas típicas são da ordem de 5000 partículas $/ \mathrm{cm}^{3}$ e $10000 \mathrm{~K}$, respectivamente. Para estes valores a razão $H \alpha / H \beta$ não varia significativamente com relação às flutuações de densidade e temperatura da região (Osterbrock, 1989), podendo-se adotar 2.85 como um valor típico, de acordo com a teoria de recombinação. A correção da extinção interestelar é feita aplicando-se a relação

$$
\log \left[\frac{\mathrm{F}(\lambda)}{\mathrm{F}(\mathrm{H} \beta)}\right]_{\text {teórico }}=\log \left[\frac{\mathrm{F}(\lambda)}{\mathrm{F}(\mathrm{H} \beta)}\right]_{\text {observado }}+0.4 \mathrm{E}(\mathrm{B}-\mathrm{V})\left[\frac{\mathrm{A}_{\lambda}-\mathrm{A}_{\mathrm{H}_{\beta}}}{\mathrm{E}(\mathrm{B}-\mathrm{V})}\right] .
$$

Com esta expressão o valor do excesso de cor E(B-V) é determinado a partir das razões $\mathrm{H} \alpha / \mathrm{H} \beta$ teórica e observada, aplicando-se a curva de extinção $\left(\mathrm{A}_{\lambda}-\mathrm{A}_{\mathrm{H}_{\beta}}\right) / \mathrm{E}(\mathrm{B}-\mathrm{V})$ dada por Fitzpatrick (1999). Esta curva de extinção é um polinômio de grau 7 da seguinte forma

$$
\begin{aligned}
{\left[\frac{\mathrm{A}_{\lambda}}{\mathrm{E}(\mathrm{B}-\mathrm{V})}\right]=} & 0.00001+0.22707 x+1.95243 x^{2}-2.67596 x^{3}+2.6507 x^{4}- \\
& -1.26812 x^{5}+0.27549 x^{6}-0.02212 x^{7}
\end{aligned}
$$

sendo $x=1 / \lambda\left[\mu \mathrm{m}^{-1}\right]$.

Tendo o excesso de cor para cada objeto, os fluxos foram corrigidos da extinção interestelar. As tabelas A.1 e A.2, que podem ser vistas no apêndice, contêm os fluxos relativos a $H \beta$ corrigidos da extinção interestelar numa escala onde $\mathrm{F}(H \beta)=100$.

\subsection{Diagnóstico de plasma}

Nesta seção são descritos os procedimentos para a determinação dos parâmetros físicos densidade e temperatura eletrônica das NPs a partir da análise das linhas de emissão observadas no espectro óptico. 


\subsubsection{Densidade eletrônica}

No equilíbrio termodinâmico (ET) as densidades relativas de dois níveis de energia $j$ e $k$ podem ser calculadas pela equação de Boltzmann, desde que sejam conhecidos os parâmetros do átomo em questão e a temperatura T. No meio interestelar ocorrem grandes desvios em relação ao ET. Por isto é necessário introduzir os chamados coeficientes de desvio $b_{j}$ e $b_{k}$, os quais dependem dos processos detalhados que provocam a excitação e desexcitação dos diversos átomos e íons. Considerando estes coeficientes, a equação de Boltzmann se torna

$$
\frac{n_{k}}{n_{j}}=\frac{b_{k}}{b_{j}} \frac{g_{k}}{g_{j}} e^{-h \nu_{k j} / k T}
$$

onde $g_{k}$ e $g_{j}$ são os pesos estatísticos dos níveis $j$ e $k$, e $\nu_{k j}$ é a freqüência do fóton emitido na transição dos níveis $k$ para o $j$.

Freqüentemente é usada a aproximação de processos estacionários, em que $n_{j}(t)=n_{j}$, ou seja, a densidade tem um valor constante de equilíbrio e, portanto,

$$
\frac{d n_{j}}{d t}=0
$$

Chamando $\left(R_{j k}\right)_{y}$ a probabilidade por unidade de tempo de que uma partícula no nível $j$ sofra uma transição do nível $j$ para o nível $k$ causada pelo processo $y$, a condição de equilíbrio estatístico pode ser escrita como

$$
\frac{d n_{j}}{d t}=-n_{j} \sum_{y} \sum_{k}\left(R_{j k}\right)_{y}+\sum_{y} \sum_{k} n_{k}\left(R_{k j}\right)_{y}=0 .
$$

Para transições com elétrons, a equação de equilíbrio estatístico pode ser escrita (Maciel, 2002a, p. 124)

$$
n_{j}\left[\sum_{k}\left(n_{e} \gamma_{j k}+B_{j k} u_{\nu}\right)+\sum_{k<j} A_{j k}\right]=\sum_{k} n_{k}\left(n_{e} \gamma_{k j}+B_{k j} u_{\nu}\right)+\sum_{k>j} n_{k} A_{k j}
$$

sendo $\gamma_{j k}$ a taxa de excitação colisional, ou coeficiente de excitação colisional, dada por

$$
\gamma_{j k}=\frac{\left(R_{j k}\right)_{c}}{n_{e}}
$$

$A_{j k}$ o coeficiente de emissão de Einstein, o qual exprime a probabilidade por unidade de tempo de que um átomo no estado de excitação $k$ sofra espontaneamente uma transição 
para o estado $j$, de menor energia, com emissão de um fóton; $B_{j k}$ o coeficiente de absorção de Einstein, e o produto $B_{j k} u_{\nu}$ é a probabilidade por unidade de tempo para que ocorra uma absorção sendo $u_{\nu}$ a densidade de energia; $B_{k j}$ é um outro coeficiente de Einstein, definindo-se $B_{k j} u_{\nu}$ como a probabilidade por unidade de tempo para ocorrer uma emissão estimulada.

Considerando dois níveis de energia $k$ e $j$, com $E_{k}>E_{j}$, o produto $n_{k} A_{k j}$ denota o número de transições espontâneas do nível $k$ para o nível $j$, por unidade de volume, por unidade de tempo. Sendo assim, para um íon com três níveis de energia 1, 2 e 3, como é o caso do $S^{+}\left({ }^{4} S_{3 / 2},{ }^{2} D_{3 / 2}\right.$ e ${ }^{2} D_{5 / 2}$, respectivamente), mostrado na figura 2.3 , tendo em conta apenas colisões com elétrons e desprezando as transições radiativas induzidas, pode-se expressar a razão das intensidades emitidas nas transições $3 \rightarrow 1$ e $2 \rightarrow 1$ como

$$
\frac{I_{31}}{I_{21}}=\frac{n_{3} A_{31} E_{31}}{n_{2} A_{21} E_{21}}=\frac{g_{3} A_{31} \nu_{31}}{g_{2} A_{21} \nu_{21}}\left[\frac{1+\left(A_{21} / n_{e} \gamma_{21}\right)}{1+\left(A_{31} / n_{e} \gamma_{31}\right)}\right] e^{-E_{32} / k T},
$$

onde $E_{k j}=h \nu_{k j}$, a energia do fóton liberado na transição.

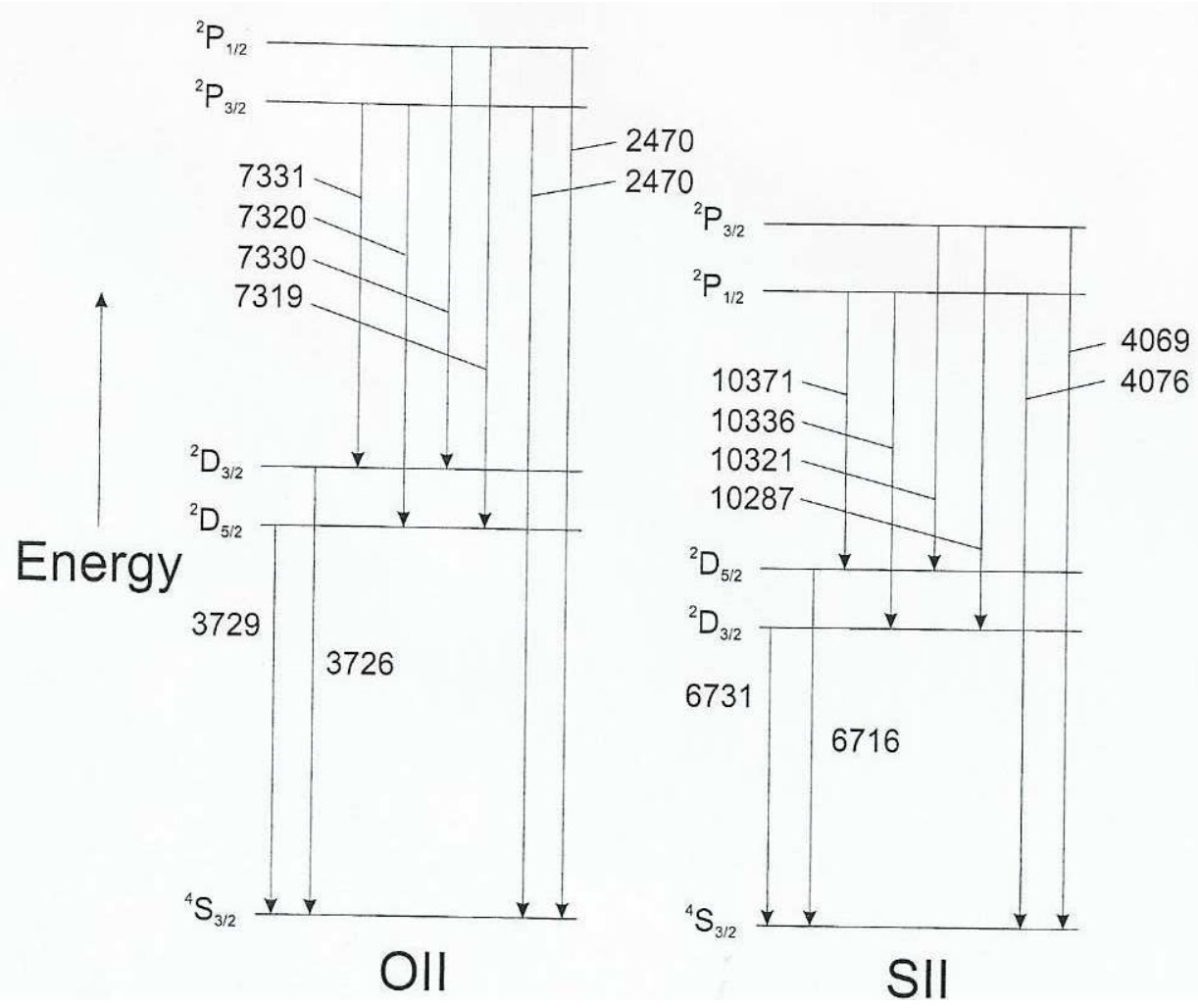

Figura 2.3: Diagrama de níveis para os íons OII e SII. Os comprimentos de onda são indicados em $\stackrel{\circ}{\text {. }}$ 
A diferença de energia entre os níveis ${ }^{2} D_{5 / 2}$ e ${ }^{2} D_{3 / 2}$ é de aproximadamente $0.004 \mathrm{eV}$, e, para um temperatura típica de uma nebulosa planetária da ordem de $10^{4} \mathrm{~K}$, o produto $k T$ é da ordem de $0.86 \mathrm{eV}$. Portanto, o termo exponencial da equação 2.8 é aproximadamente 1. Desta forma, esta equação depende essencialmente da densidade eletrônica e de parâmetros atômicos. Logo, conhecendo-se a razão das intensidades das linhas $671.6 \mathrm{~nm}$ e $673.1 \mathrm{~nm}$, é possível estimar a densidade eletrônica da nebulosa planetária.

O íon OII possui configuração eletrônica semelhante ao SII, como pode ser visto na figura 2.3 e também poderia ser utilizado para estimar a densidade eletrônica. Contudo, a resolução espectral da configuração instrumental empregada não permite resolver as linhas do [OII] $\lambda 372.6 / 372.9$ nm, necessárias para determinar a densidade eletrônica.

\subsubsection{Temperatura eletrônica}

A temperatura eletrônica é encontrada de maneira similar à densidade eletrônica, a partir das razões de linhas do OIII $\lambda 495.9,500.7 / 436.3 \mathrm{~nm}$ ou das razões de linhas do NII $\lambda 654.8,658.4 / 575.4 \mathrm{~nm}$. A figura 2.4 mostra a configuração dos primeiros níveis de energia do OIII e NII.

No limite de baixas densidades, toda excitação colisional resultará na emissão de um fóton, e os estados superiores somente podem ser povoados por excitação colisional a partir do estado fundamental. Neste caso a probabilidade de transição entre os níveis $3 \rightarrow 2,3 \rightarrow 1$, $2 \rightarrow 3,2 \rightarrow 1$ através de excitação colisional é essencialmente zero. Escrevendo as equações de equilíbrio estatístico na condição de baixas densidades, temos

$$
\begin{aligned}
n_{2} A_{21} & =n_{1} n_{e} \gamma_{12} \\
n_{3}\left(A_{31}+A_{32}\right) & =n_{1} n_{e} \gamma_{13} .
\end{aligned}
$$

A solução para este sistema de equações é

$$
\frac{n_{3}}{n_{2}}=\frac{\gamma_{13}}{\gamma_{12}} \frac{A_{21}}{A_{31}+A_{32}} .
$$

A razão entre as intensidades das linhas $500.7+495.9 \mathrm{~nm}$ e $436.3 \mathrm{~nm}$ é dada por

$$
\frac{I(500.7+495.9 \mathrm{~nm})}{I(436.3 \mathrm{~nm})}=\frac{I_{21}}{I_{32}}=\frac{n_{2} \nu_{21} A_{21}}{n_{3} \nu_{32} A_{32}}
$$



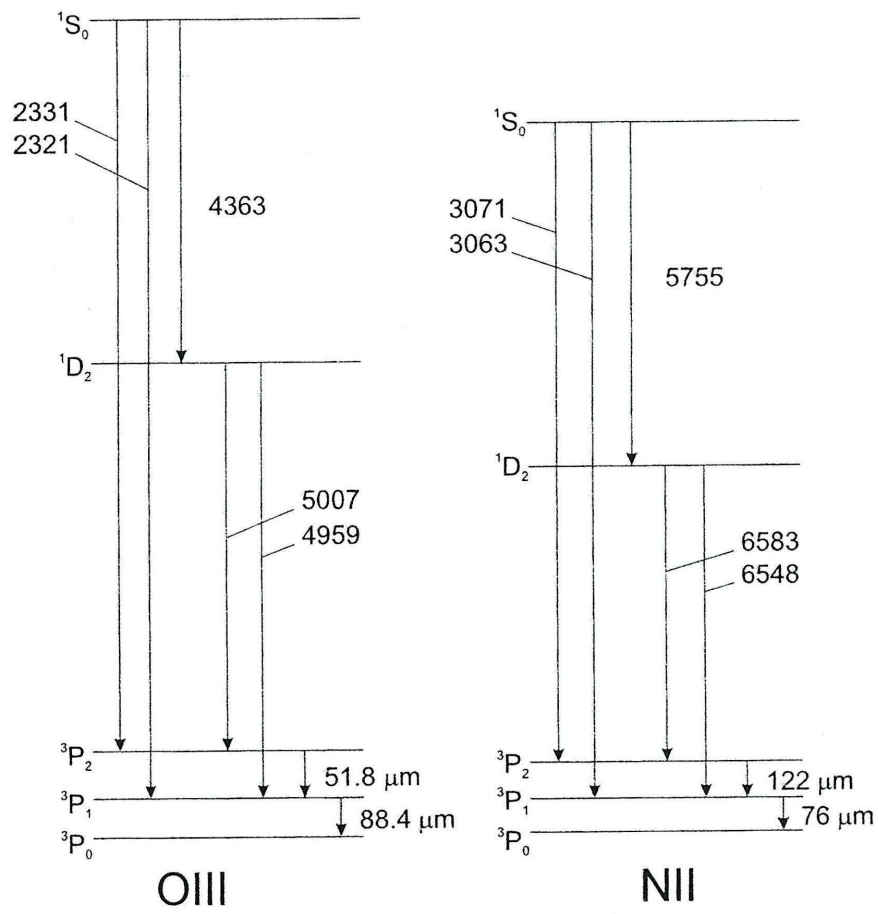

Figura 2.4: Diagrama de níveis para os íons OIII e NII.

É possível mostrar que existe a seguinte relação entre o coeficiente de desexcitação colisional $\gamma_{k j}$ e a intensidade de colisão $\Omega_{j k}$ (Maciel, 2002a, p. 128)

$$
\gamma_{k j}=\frac{h^{2} \Omega_{j k}}{g_{k}\left(2 \pi m_{e}\right)^{3 / 2}(k T)^{1 / 2}} .
$$

Substituindo a equação 2.10 na equação 2.11 e usando a relação da equação 2.12, obtém-se

$$
\frac{I(500.7+495.9 \mathrm{~nm})}{I(436.3 \mathrm{~nm})}=\frac{\Omega_{12}}{\Omega_{13}}\left(\frac{\nu_{21}}{\nu_{32}}\right) \frac{A_{31}+A_{32}}{A_{32}} e^{E_{32} / k T} .
$$

Esta equação é valida somente para baixas densidades. No caso mais geral, para densidades mais altas, introduz-se um fator de correção para desexcitação colisional. Tal fator de correção é expressado por $\frac{A_{21}}{\gamma_{21}+A_{21}}$.

Utilizando este fator de correção, encontra-se

$$
\frac{I_{495.9}+I_{500.7}}{I_{436.3}}=\frac{\Omega_{12}}{\Omega_{13}} \frac{A_{31}+A_{32}}{A_{32}} \frac{\nu_{21}}{\nu_{32}}\left\{\frac{A_{21}}{h^{2} \Omega_{12} /\left[g_{2}\left(2 \pi m_{e}\right)^{3 / 2}(k T)^{1 / 2}\right]+A_{21}}\right\} e^{E_{32} / k T} .
$$

Esta equação depende essencialmente de parâmetros atômicos e da temperatura e, portanto, pode ser utilizada para obter a temperatura eletrônica através da razão das 
intensidades das linhas do [OIII] $\lambda 495.9,500.7 / 436.3 \mathrm{~nm}$. Substituindo os valores dos parâmetros atômicos e constantes físicas, a equação 2.14 resulta em

$$
\frac{I_{495.9}+I_{500.7}}{I_{436.3}}=\frac{7.73 \times e^{3.29 \times 10^{4} / T}}{1+4.45 \times 10^{-4} n_{e} / T^{1 / 2}} .
$$

Um procedimento análogo leva à seguinte relação com a temperatura para o NII

$$
\frac{I_{654.8}+I_{658.3}}{I_{575.5}}=\frac{6.91 \times e^{2.50 \times 10^{4} / T}}{1+2.5 \times 10^{-3} n_{e} / T^{1 / 2}} .
$$

O cálculo dos parâmetros físicos foi realizado através da sub-rotina temden, provida pelo pacote externo STSDAS do IRAF. Esta sub-rotina deriva a temperatura eletrônica $T$ dada uma densidade eletrônica $n_{e}$, ou $n_{e}$ dado $T$, de um gás nebular ionizado através da aproximação de N-níveis. Os parâmetros físicos obtidos para as NPs observadas são mostrados na tabela 2.2 .

Tabela 2.2 - Parâmetros físicos dos objetos observados em 2006 e 2007. As colunas mostram, respectivamente, o excesso de cor, a densidade eletrônica em número obtida através das linhas do enxofre, a temperatura eletrônica calculada pelas linhas do nitrogênio, e a temperatura eletrônica calculada pelas linhas do oxigênio.

\begin{tabular}{lcccc}
\hline \hline \multicolumn{1}{c}{ Nome } & $\mathrm{E}(\mathrm{B}-\mathrm{V})$ & $\begin{array}{c}n_{e}([\mathrm{SII}]) \\
10^{3} \mathrm{~cm}^{-3}\end{array}$ & $\begin{array}{c}T([\mathrm{NII}]) \\
10^{4} \mathrm{~K}\end{array}$ & $\begin{array}{c}T([\mathrm{OIII}]) \\
10^{4} \mathrm{~K}\end{array}$ \\
\hline H 1-17 & & & & \\
H 1-28 & 0.67 & 0.73 & 0.86 & 1.19 \\
H 1-37 & 0.48 & 1.22 & 1.02 & 1.28 \\
H 1-6 & 1.02 & 0.83 & 1.03 & 1.40 \\
H 1-8 & 1.42 & 7.79 & 0.80 & 1.55 \\
H 1-9 & 0.98 & 13.26 & 1.85 & 1.54 \\
H 1-60 & 0.26 & 5.00 & 1.08 & 1.08 \\
H 2-1 & 0.48 & 5.28 & 1.29 & 1.83 \\
H 2-10 & 1.57 & 6.83 & 1.77 & 1.29 \\
H 2-35 & 0.63 & 0.24 & 1.02 & 1.19 \\
H 2-45 & 1.18 & 5.55 & 1.24 & 1.24 \\
He 2-207 & 0.29 & 0.53 & 1.02 & 1.30 \\
Hen 2-155 & 0.56 & 1.22 & 1.01 & 1.01 \\
Hen 2-169 & 2.00 & 1.24 & 1.25 & 1.82 \\
Hen 2-186 & 0.52 & 3.52 & 1.11 & 1.34 \\
Hf 2-1 & 0.53 & 0.61 & 1.31 & 1.27 \\
IC 4663 & 0.42 & 1.39 & 1.29 & 1.15 \\
IC 4699 & 0.16 & 3.81 & 1.30 & 1.30 \\
K 3-11 & 1.88 & 8.96 & 0.79 & 0.79 \\
Contin & & & \\
\hline
\end{tabular}

Continua na próxima página... 
Tabela 2.2 - Continuação

\begin{tabular}{|c|c|c|c|c|}
\hline Nome & $\mathrm{E}(\mathrm{B}-\mathrm{V})$ & $\begin{array}{c}n_{e}([\mathrm{SII}]) \\
10^{3} \mathrm{~cm}^{-3}\end{array}$ & $\begin{array}{c}T([\mathrm{NII}]) \\
10^{4} \mathrm{~K}\end{array}$ & $\begin{array}{c}T([\mathrm{OIII}]) \\
10^{4} \mathrm{~K}\end{array}$ \\
\hline M 1-39 & 1.66 & 33.88 & 0.69 & 0.69 \\
\hline M 1-45 & 1.33 & 8.06 & 0.66 & 0.66 \\
\hline M 1-46 & 0.19 & 2.00 & 1.41 & 1.75 \\
\hline M 1-47 & 0.30 & 3.06 & 1.14 & 1.14 \\
\hline M 1-55 & 0.11 & 9.77 & 0.71 & 0.71 \\
\hline M 1-60 & 1.21 & 6.84 & 1.15 & 1.06 \\
\hline M 2-40 & 0.82 & 5.04 & 1.05 & 1.20 \\
\hline M 3-29 & 0.10 & 0.76 & 0.87 & 1.04 \\
\hline M 1-24 & 0.86 & 4.49 & 1.29 & 1.10 \\
\hline M 2-21 & 0.23 & 5.84 & 1.57 & 1.25 \\
\hline M 2-22 & 0.69 & 1.77 & 1.52 & 1.25 \\
\hline M 2-37 & 0.43 & 0.34 & 1.36 & 9.45 \\
\hline M 3-23 & 0.86 & 0.87 & 1.59 & 1.47 \\
\hline M 3-24 & 0.86 & 2.15 & 1.25 & 0.99 \\
\hline M 3-28 & 1.21 & 1.88 & 1.07 & 1.32 \\
\hline M 3-40 & 1.52 & 8.99 & 0.66 & 0.66 \\
\hline M 3-49 & 0.35 & 0.24 & 0.90 & 1.32 \\
\hline M 3-53 & 2.06 & 5.44 & 1.24 & 6.05 \\
\hline MA 3 & 1.21 & 1.11 & 1.49 & 1.19 \\
\hline MaC 1-16 & 0.20 & 0.57 & 0.90 & 1.06 \\
\hline Mewe 1-7 & 0.92 & 0.26 & 1.45 & 1.45 \\
\hline Pc 21 & 0.38 & 0.79 & 1.56 & 1.44 \\
\hline Pe 1-15 & 0.89 & 1.56 & 1.50 & 0.90 \\
\hline Pe 1-6 & 1.26 & 1.03 & 1.68 & 1.31 \\
\hline Pe 2-13 & 0.12 & 3.09 & 1.79 & 1.79 \\
\hline Sa $1-5$ & 0.95 & 3.59 & 1.44 & 1.18 \\
\hline Sa $2-230$ & 0.69 & 0.68 & 1.67 & 1.30 \\
\hline StWr 2-21 & 0.17 & 1.87 & 1.12 & 1.23 \\
\hline StWr 4-10 & 0.66 & 5.00 & 1.22 & 1.22 \\
\hline Th 4-11 & 1.55 & 1.28 & 1.90 & 1.90 \\
\hline Th3-25 & 1.60 & 5.21 & 1.32 & 1.57 \\
\hline Th3-26 & 1.12 & 2.26 & 1.32 & 1.56 \\
\hline Vd 1-3 & 0.82 & 0.71 & 0.90 & 0.90 \\
\hline Vd 1-4 & 0.83 & 7.48 & 1.46 & 1.34 \\
\hline Vd 1-5 & 1.07 & 0.81 & 1.75 & 1.28 \\
\hline Vd 1-8 & 1.84 & 10.11 & 1.96 & 1.92 \\
\hline Vd 1-9 & 1.92 & 5.48 & 1.83 & 1.19 \\
\hline Wray 16-385 & 0.08 & 3.53 & 0.94 & 0.94 \\
\hline
\end{tabular}




\subsection{Cálculo das abundâncias}

Existem duas distintas famílias de métodos de determinação de abundâncias nebulares: i) os métodos empíricos, onde se calculam as abundâncias iônicas das espécies presentes no espectro através de um modelo atômico simples e a seguir estimam-se as abundâncias elementais correspondentes com a aplicação de Fatores de Correção de Ionização para levar-se em conta os íons não observados; ii) os modelos de fotoionização, onde o espectro observado é comparado com uma grade de modelos nebulares teóricos, e as abundâncias são obtidas através da derivação de um "melhor ajuste" entre os modelos teóricos e o espectro observado. Neste projeto é usado o método empírico, que desde os anos 80 vem sendo empregado por nosso grupo, com melhorias sucessivas nos programas de análise e incorporando sempre modelos atômicos mais completos e dados atômicos atualizados. Com este método obtém-se um tratamento homogêneo de conjuntos grandes de objetos com resultados satisfatórios, como pode ser visto, por exemplo, em Costa et al. (2004), Escudero et al. (2004) e referências aí citadas.

\subsubsection{Abundâncias iônicas}

As abundâncias iônicas, relativas ao $H^{+}$, podem ser calculadas a partir da razão da intensidade das linhas proibidas observadas relativas à emissividade $H \beta$. Alexander e Balick (1997) fornecem uma relação empírica conveniente para a determinação das abundâncias iônicas, obtidas através de simulações numéricas:

$$
\frac{N^{+}}{H^{+}}=\frac{I(658.4)}{I(H \beta)} 1.341 \times 10^{-6} \frac{e^{(26485 / T)}}{1+1.2224 \times 10^{-3} x},
$$

sendo $x=n_{e} / \sqrt{T}$.

$$
\begin{gathered}
\frac{O^{0}}{H^{+}}=\frac{I(630.0)}{I(H \beta)} 4.80 \times 10^{-6}\left(0.383+1.2 \times 10^{-4}-5.443 \times 10^{-9} T^{2}\right) \times e^{(37076 / T)} \\
\frac{O^{+}}{H^{+}}=\frac{I(372.8)}{I(H \beta)} 4.684 \times 10^{-7}\left(1.14-1.156 \times 10^{-5} T\right) \times e^{(43706 / T)} \times \\
\times\left(1.05+1.534 \times 10^{-4} n_{e}-2.54 \times 10^{-10} n_{e}^{2}\right)
\end{gathered}
$$




$$
\frac{O^{+}}{H^{+}}=\frac{I(732.5)}{I(H \beta)} 4.20 \times 10^{-6}\left[0.612+0.405 \frac{e^{-z}-\left(1.1-0.9 \times 10^{-5} T\right) e^{z}}{\left(e^{-z}+e^{z}\right)}\right] \times e^{(6545 / T)},
$$

onde $z=\log n_{e}-3.04$.

$$
\begin{gathered}
\frac{O^{++}}{H^{+}}=\frac{I(500.7)}{I(H \beta)} 1.152 \times 10^{-6} \frac{e^{(34609 / T)}}{1+1.2487 \times 10^{-4} x} \\
\frac{S^{+}}{H^{+}}=\frac{I(671.7+673.1)}{I(H \beta)} 1.660 \times 10^{-7}\left(1.03+1.89 \times 10^{-4} n_{e}\right) \times e^{(25079 / T)} \\
\frac{S^{++}}{H^{+}}=\frac{I(631.2)}{I(H \beta)} 3.1 \times 10^{-6} \frac{e^{(43250 / T)}}{1+6.93 \times 10^{-3} x^{0.54}} \\
\frac{A r^{++}}{H^{+}}=\frac{I(713.6)}{I(H \beta)} 8.189 \times 10^{-7} e^{(24243 / T)} \\
\frac{N e^{++}}{H^{+}}=\frac{I(386.9)}{I(H \beta)} 1.33 \times 10^{-6} e^{(41250 / T)}
\end{gathered}
$$

Tais expressões são usadas no software Abundância Química desenvolvido por Escudero (2005) para determinar os parâmetros físicos de nebulosas fotoionizadas.

A derivação das abundâncias iônicas do hélio requer cuidados especiais devido à presença de efeitos colisionais (Escudero e Costa, 2001). Aqui é adotada a teoria de recombinação para o HeI e HeII, usando os coeficientes de recombinação de Pequignot et al. (1991). A abundância do HeI foi também corrigida dos efeitos colisionais usando os termos de correção de Kingdon e Ferland (1995).

\subsubsection{Abundâncias elementais}

Os ICFs obtidos por Kingsburgh e Barlow (1994) são usados para encontrar as abundâncias elementais a partir das abundâncias iônicas previamente determinadas.

Para o caso do hélio em particular, temos a determinação do $\mathrm{He}^{+}$e $\mathrm{He}^{++}$. De acordo com os critérios definidos por Torres-Peimbert e Peimbert (1977), não há contribuição substancial do hélio neutro na abundância total do hélio quando $\log O^{+} / O<-0.4$, podendo ser desprezada esta componente. Neste caso, a abundância total do hélio pode ser 
escrita como

$$
\frac{H e}{H}=\frac{H e^{+}}{H^{+}}+\frac{H e^{++}}{H^{+}} .
$$

A abundância total do oxigênio pode ser determinada a partir da soma das abundâncias dos íons $\mathrm{O}^{+}$e $\mathrm{O}^{++}$corrigida pela razão entre a abundância de $\mathrm{He}$ com $\mathrm{He}^{+}$

$$
\frac{O}{H}=\left(\frac{O^{++}}{H^{+}}+\frac{O^{+}}{H^{+}}\right) \frac{H e}{H e^{+}} .
$$

O cálculo da abundância química total do nitrogênio é feito a partir das similaridades entre os potenciais de ionização do nitrogênio e oxigênio

$$
\frac{N}{H}=\frac{N^{+}}{H^{+}} \frac{O}{O^{+}}
$$

A abundância química do enxofre é obtida de

$$
\frac{S}{H}=\left(\frac{S^{++}}{H^{+}}+\frac{S^{+}}{H^{+}}\right)\left(1-\left(1-\frac{O^{+}}{O}\right)^{3}\right)^{-1 / 3} .
$$

O argônio, juntamente com o enxofre, é um dos elementos com menor precisão na determinação dos dados. Sua determinação em nebulosas planetárias é feita a partir de uma única linha $\left(A r^{++}\right)$

$$
\frac{A r}{H}=1.34 \times \frac{A r^{++}}{H^{+}} \frac{O}{O^{++}}
$$

O fator de correção para o neônio é baseado na semelhança entre o potencial de ionização do oxigênio, e é um dos menos estudados e determinados na literatura. Sua expressão é

$$
\frac{N e}{H}=\frac{N e^{++}}{H^{+}} \frac{O}{O^{++}}
$$

As abundâncias químicas obtidas por estas expressões estão na tabela 2.3. 
Tabela 2.3 - Abundâncias químicas dos objetos observados utilizando $\epsilon(\mathrm{X})=\log (\mathrm{X} / \mathrm{H})+12$, e os respectivos desvios padrões.

\begin{tabular}{|c|c|c|c|c|c|c|c|c|c|c|c|c|}
\hline Nome & $\mathrm{He} / \mathrm{H}$ & $\sigma_{H e}$ & $\epsilon(N)$ & $\sigma_{N}$ & $\epsilon(O)$ & $\sigma_{O}$ & $\epsilon(S)$ & $\sigma_{S}$ & $\epsilon(A r)$ & $\sigma_{A r}$ & $\epsilon(N e)$ & $\sigma_{N e}$ \\
\hline H1-17 & 0.104 & 0.001 & 8.21 & 0.06 & 7.07 & 0.23 & 8.41 & 0.18 & 6.36 & 0.17 & 7.80 & 0.06 \\
\hline H1-37 & 0.152 & 0.007 & 8.40 & 0.05 & 8.54 & 0.08 & 6.86 & 0.06 & 6.71 & 0.08 & 8.14 & 0.03 \\
\hline H1-6 & 0.224 & 0.023 & 8.42 & 0.04 & 8.62 & $\ldots$ & 7.26 & 0.12 & 7.14 & 0.21 & 8.11 & 0.60 \\
\hline H1-60 & 0.114 & $\cdots$ & 8.02 & $\ldots$ & 6.66 & $\ldots$ & 8.45 & $\ldots$ & 6.00 & $\ldots$ & 7.82 & $\ldots$ \\
\hline $\mathrm{H} 2-10$ & 0.088 & 0.002 & 7.57 & 0.39 & 6.50 & 0.21 & 8.24 & 0.06 & 5.77 & 0.02 & 7.85 & 0.11 \\
\hline $\mathrm{H} 2-35$ & 0.089 & 0.002 & 8.24 & 0.02 & 8.34 & 0.16 & 6.61 & 0.06 & 6.39 & 0.12 & 7.89 & 0.13 \\
\hline $\mathrm{H} 2-45$ & 0.095 & 0.002 & 7.42 & $\ldots$ & 8.27 & 0.04 & 6.46 & 0.07 & 5.62 & 0.01 & 7.63 & 0.04 \\
\hline He 2-207 & 0.137 & 0.005 & 8.48 & 0.04 & 8.84 & 0.02 & 7.02 & 0.02 & 6.97 & 0.01 & 8.18 & 0.05 \\
\hline Hen 2-155 & 0.130 & 0.003 & 8.09 & 0.13 & 8.60 & 0.03 & 6.74 & 0.08 & 6.22 & 0.03 & 8.11 & 0.03 \\
\hline Hen 2-169 & 0.249 & 0.010 & 8.85 & 0.3 & 8.57 & 0.30 & 7.66 & 0.18 & 6.93 & 0.07 & 7.88 & $\ldots$ \\
\hline Hen $2-186$ & 0.132 & 0.014 & 8.60 & 0.07 & 8.65 & 0.04 & 6.92 & 0.07 & 6.53 & 0.07 & 8.04 & 0.07 \\
\hline Hf2-1 & 0.129 & 0.002 & 8.87 & 0.15 & 8.82 & 0.08 & 7.13 & 0.03 & 6.87 & 0.08 & 8.23 & 0.08 \\
\hline IC 4663 & 0.120 & 0.008 & 8.44 & 0.19 & 8.85 & 0.01 & 7.03 & 0.14 & 6.87 & $\ldots$ & 8.36 & 0.06 \\
\hline IC 4699 & 0.103 & $\ldots$ & $\ldots$ & $\ldots$ & 8.42 & $\ldots$ & 5.540 & $\ldots$ & 5.70 & $\ldots$ & 7.81 & $\ldots$ \\
\hline M 2-40 & 0.152 & $\cdots$ & 7.98 & $\ldots$ & 8.47 & $\ldots$ & 6.30 & $\cdots$ & 7.14 & $\ldots$ & 7.98 & $\ldots$ \\
\hline M1-24 & 0.052 & 0.006 & 7.81 & 0 & 8.16 & 0.08 & 6.50 & 0.06 & 6.25 & 0.08 & 7.72 & 0.20 \\
\hline M1-47 & 0.097 & 0.010 & $\cdots$ & $\cdots$ & 6.37 & 0.02 & 8.48 & 0.01 & 5.75 & 0.02 & 7.87 & $\cdots$ \\
\hline M2-21 & 0.107 & 0.003 & 8.47 & 0.14 & 7.10 & 0.76 & 8.48 & 0.09 & 5.92 & 0.10 & 7.53 & 0.26 \\
\hline M2-22 & 0.147 & $\cdots$ & 8.95 & $\cdots$ & 8.27 & $\cdots$ & 6.75 & $\ldots$ & 6.37 & $\cdots$ & 7.84 & $\ldots$ \\
\hline M2-37 & 0.162 & $\ldots$ & 6.91 & $\ldots$ & 6.87 & $\ldots$ & 5.49 & $\ldots$ & 5.47 & $\ldots$ & 6.80 & $\ldots$ \\
\hline M3-23 & 0.120 & 0.003 & 8.64 & 0.09 & 8.79 & 0.07 & 7.11 & 0.30 & 6.78 & 0.11 & 8.25 & 0.08 \\
\hline M3-24 & 0.150 & 0.005 & 8.54 & 0.1 & 8.47 & 0.05 & 6.91 & 0.10 & 6.43 & 0.02 & 8.08 & 0.05 \\
\hline M3-28 & 0.137 & 0.005 & 8.87 & 0.49 & 8.44 & 0.08 & 7.04 & 0.23 & 6.52 & 0.07 & 7.82 & 0.01 \\
\hline MA 3 & 0.090 & 0.016 & 7.25 & 0.33 & 8.10 & 0.09 & 6.17 & 0.37 & 5.95 & 0.04 & 7.54 & 0.35 \\
\hline Mewe 1-7 & 0.152 & 0.006 & 6.87 & 0.08 & 8.29 & 0.64 & 5.96 & 0.65 & 6.19 & 0.47 & 8.23 & 1.99 \\
\hline Pc 21 & 0.132 & 0.001 & 7.52 & 0.04 & 8.48 & 0.02 & 6.55 & 0.06 & 6.37 & 0.01 & 7.91 & 0.05 \\
\hline Pe1-15 & 0.123 & 0.010 & 8.44 & 0.31 & 8.65 & 0.25 & 7.03 & 0.01 & 6.40 & 0.16 & 8.08 & 0.31 \\
\hline Pe1-6 & 0.165 & 0.014 & 7.50 & 0.28 & 8.26 & 0.30 & 6.28 & 0.05 & 6.23 & 0.24 & 7.92 & 0.19 \\
\hline Pe2-13 & 0.217 & 0.026 & 8.51 & $\cdots$ & 8.18 & 0.24 & 6.98 & $\ldots$ & 6.50 & 0.02 & 7.39 & 0.17 \\
\hline Sa $1-5$ & 0.104 & 0.009 & 7.80 & 0.01 & 8.41 & 0.01 & 6.62 & 0.01 & 5.94 & $\cdots$ & 7.74 & 0.11 \\
\hline Sa 2-230 & 0.159 & 0.004 & 7.88 & 0.27 & 8.64 & 0.18 & 6.93 & 0.04 & 6.62 & 0.09 & 8.15 & 0.17 \\
\hline StWr 2-21 & 0.105 & 0.001 & 7.71 & 0.28 & 8.58 & 0.12 & 6.52 & 0.14 & 6.28 & 0.13 & 8.01 & 0.12 \\
\hline StWr 4-10 & 0.096 & 0.009 & $\cdots$ & $\ldots$ & 8.22 & 0.08 & 5.90 & $\cdots$ & 5.77 & 0.02 & 7.66 & 0.11 \\
\hline Th 4-11 & 0.119 & 0.006 & 6.93 & 0.07 & 6.86 & 0.13 & 5.52 & 0.14 & 4.80 & 0.13 & 7.15 & 0.19 \\
\hline Th3-26 & 0.123 & 0.023 & 8.47 & 0.08 & 8.52 & 0.21 & 7.08 & 0.23 & 6.51 & 0.42 & 7.83 & $\ldots$ \\
\hline Vd 1-4 & 0.106 & 0.003 & 7.66 & 0.04 & 8.30 & 0.03 & 6.27 & 0.05 & 5.93 & 0.03 & 7.73 & 0.05 \\
\hline $\operatorname{Vd} 1-5$ & 0.112 & 0.002 & 7.87 & 0.08 & 8.52 & $\ldots$ & 6.48 & 0.08 & 6.04 & 0.01 & 7.85 & 0.06 \\
\hline $\operatorname{Vd} 1-8$ & 0.094 & 0.003 & 7.92 & 0.35 & 8.18 & 0.35 & 6.33 & 0.50 & 5.82 & 0.20 & 7.57 & 0.25 \\
\hline $\mathrm{Vd} 1-9$ & 0.100 & 0.031 & 7.96 & 0.50 & 8.30 & 0.09 & 6.53 & 0.35 & 6.10 & 0.04 & 7.81 & $\ldots$ \\
\hline H1-8 & 0.073 & $\cdots$ & 8.09 & $\cdots$ & 8.54 & $\ldots$ & 7.19 & $\ldots$ & 7.02 & $\ldots$ & 8.15 & $\cdots$ \\
\hline H1-9 & 0.061 & 0.010 & 7.04 & 0.09 & 7.50 & 0.10 & 6.22 & 0.06 & 5.95 & 0.19 & 6.84 & 0.18 \\
\hline
\end{tabular}

Continua na próxima página... 
Tabela 2.3 - Continuação

\begin{tabular}{lcccccccccccc}
\hline \hline \multicolumn{1}{c}{ Nome } & He/H & $\sigma_{H e}$ & $\epsilon(N)$ & $\sigma_{N}$ & $\epsilon(O)$ & $\sigma_{O}$ & $\epsilon(S)$ & $\sigma_{S}$ & $\epsilon(A r)$ & $\sigma_{A r}$ & $\epsilon(N e)$ & $\sigma_{N e}$ \\
H1-28 & 0.185 & 0.001 & 8.38 & 0.09 & 8.41 & 0.04 & 6.87 & 0.07 & 6.69 & 0.02 & 8.08 & 0.18 \\
H2-1 & 0.059 & 0.001 & 7.06 & 0.03 & 7.61 & 0.15 & 5.91 & 0.13 & 6.20 & 0.15 & 7.09 & 0.24 \\
K3-11 & 0.009 & 0.001 & 7.89 & 0.27 & 8.36 & 0.66 & 7.93 & 0.49 & $\ldots$ & $\ldots$ & 10.60 & $\ldots$ \\
M 1-39 & 0.091 & 0.000 & 8.22 & 0.09 & 8.93 & 0.46 & 7.28 & 0.45 & 7.58 & 0.35 & 9.24 & 0.66 \\
M1-45 & 0.017 & 0.001 & 8.21 & 0.08 & 7.79 & 0.68 & 8.85 & 0.06 & 7.73 & $\ldots$ & 10.39 & $\ldots$ \\
M1-46 & 0.165 & 0.036 & 7.54 & 0.50 & 6.41 & 0.66 & 8.05 & 0.95 & 7.13 & 0.87 & 7.19 & $\ldots$ \\
M 1-55 & 0.005 & 0.003 & 8.00 & 0.11 & 8.64 & 0.26 & 7.47 & 0.17 & 7.74 & 0.12 & 10.40 & 0.10 \\
M 3-29 & 0.088 & 0.004 & 7.69 & 0.06 & 8.49 & 0.18 & 6.23 & 0.07 & 6.28 & 0.19 & 8.26 & 0.19 \\
M3-40 & 0.020 & 0.001 & 8.36 & $\ldots$ & 8.62 & 0.59 & 7.77 & 0.27 & $\ldots$ & $\ldots$ & $\ldots$ & $\ldots$ \\
M3-49 & 0.118 & 0.018 & 8.24 & 0.01 & 8.45 & 0.10 & 7.40 & 0.05 & 6.67 & 0.06 & 7.93 & 0.23 \\
M3-53 & 0.133 & 0.032 & 8.22 & 0.37 & 8.18 & 0.16 & 7.55 & 0.01 & 6.53 & 0.07 & $\ldots$ & $\ldots$ \\
MaC 1-16 & 0.166 & 0.008 & 8.41 & 0.03 & 8.92 & 0.02 & 6.92 & 0.03 & 7.02 & 0.03 & 8.55 & 0.02 \\
Th3-25 & 0.096 & 0.011 & 7.18 & 0.01 & 7.86 & 0.16 & 6.23 & 0.09 & 5.84 & 0.18 & 7.28 & 0.10 \\
Vd 1-3 & 0.096 & 0.005 & 7.69 & 0.16 & 8.45 & 0.40 & 7.00 & 0.16 & 6.80 & 0.26 & $\ldots$ & $\ldots$ \\
Wray 16-385 & 0.134 & 0.054 & $\ldots$ & $\ldots$ & 8.75 & 0.17 & 4.83 & $\ldots$ & 6.16 & $\ldots$ & 7.98 & $\ldots$ \\
& & & & & & & & & & &
\end{tabular}

Como foi feita mais de uma exposição para cada objeto, foi possível estimar o desvio padrão obtido a partir da média das exposições de um mesmo objeto.

Os objetos abaixo da linha horizontal traçada na tabela 2.3 possuem $\log O^{+} / O>-0.4$, indicando que há uma fração não desprezível de hélio neutro na abundância total do hélio. As abundâncias do hélio para esses objetos devem ser consideradas cautelosamente. 
Capítulo 3

\section{Resultados observacionais}

Neste capítulo são descritos os resultados observacionais deste projeto. É feita uma comparação com abundâncias químicas previamente publicadas por outros autores, e são analisadas as correlações entre as abundâncias químicas derivadas neste trabalho.

\subsection{Distribuição da amostra}

A amostra selecionada pelos critérios discutidos na seção 2.1 possui a distribuição no plano do céu mostrada na figura 3.1.

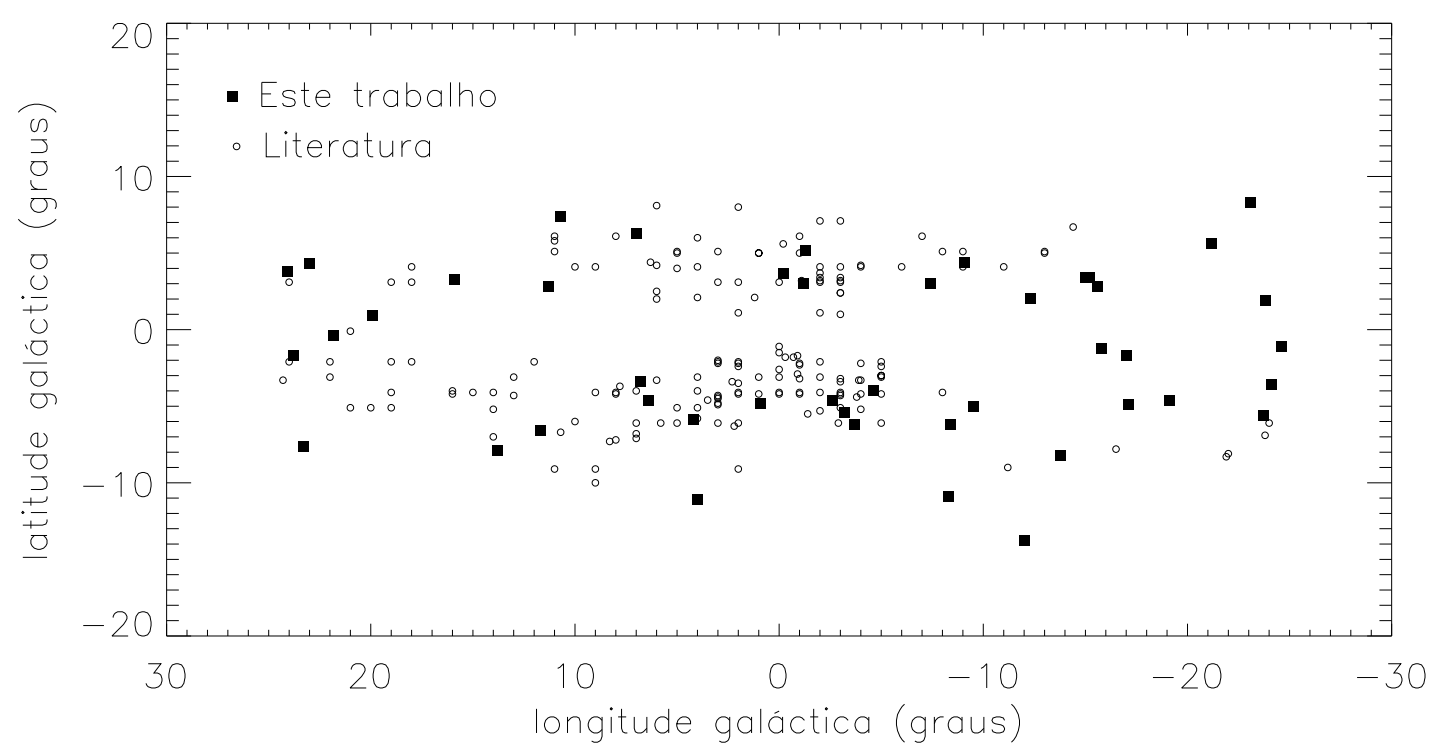

Figura 3.1: Distribuição das NPs observadas neste projeto, juntamente com as NPs da literatura.

Nesta figura, é comparada a distribuição dos objetos observados neste projeto com 
uma amostra selecionada da literatura. Esta amostra foi obtida a partir dos objetos que possuíam distâncias heliocêntricas publicadas nos seguintes catálogos: Maciel (1984), Cahn, Kaler e Stanghellini (1992), e Zhang (1995). As abundâncias químicas das NPs da literatura foram retiradas dos seguintes trabalhos: Exter, Barlow e Walton (2004) (29 objetos), Górny et al. (2004) (33 objetos), Escudero, Costa e Maciel (2004) (39 objetos), Ratag et al. (1997) (26 objetos), Cuisinier, Acker e Köppen (1996) (11 objetos), Perinotto, Morbidelli e Scatarzi (2004) (8 objetos), de Freitas Pacheco, Maciel e Costa (1992) (8 objetos), Köppen, Acker e Stenholm (1991) (6 objetos), Samland et al. (1992) (4 objetos), e Cuisinier et al. (2000) (3 objetos).

A figura mostra que os objetos deste trabalho estão bem distribuídos na região do bojo Galáctico, evitando tendências na análise das abundâncias introduzidas por uma cobertura de determinadas regiões do bojo, como acontece em Escudero e Costa (2001), onde objetos concentrados numa região com latitude maior que 5 graus apresentam abundâncias menores em aproximadamente 0.5 dex (ou 0.8 dex para o nitrogênio), exceto para o hélio, cuja abundância é maior por 0.125 dex, se comparadas às abundâncias obtidas por Ratag et al. (1997), Cuisinier et al. (2000), Stasińska, Richer e McCall (1998).

\subsection{Análise das abundâncias químicas}

Nesta seção são analisadas as abundâncias químicas obtidas neste projeto e comparadas com dados da literatura. Estes dados foram retirados dos seguintes trabalhos: Ratag et al. (1997); Exter, Barlow e Walton (2004); Górny et al. (2004); e Escudero, Costa e Maciel (2004). A escolha destes trabalhos para comparação com a nossa amostra ocorreu, pois, a região de estudo é a mesma e, além disso, possuem uma amostra significativa e homogênea. Além destes, foram utilizados os seguintes trabalhos para analisar as abundâncias obtidas, comparando-as com resultados previamente publicados: Perinotto (1991); Cuisinier, Acker e Köppen (1996); Cuisinier et al. (2000); e Girard, Köppen e Acker (2007). A seguir é feita uma breve descrição de cada artigo mencionado.

Perinotto (1991), publicou um catálogo de abundâncias compiladas da literatura contendo 209 NPs onde pelo menos duas abundâncias entre os elementos He, N, O, S, Ar, e Ne existiam. 
Cuisinier, Acker e Köppen (1996), que será citado aqui como CAK1996, apresentam as abundâncias para uma amostra de 62 NPs obtidas através de dados espectrofotométricos. Utilizaram o mesmo método empírico empregado neste trabalho, e derivaram as abundâncias com o próprio esquema de ICF deles. Para o N, S e Ne os ICFs são de Kingsburgh e Barlow (1994), assim como os nossos.

Ratag et al. (1997), citado como RPDM1997, derivaram as abundâncias de uma amostra de 45 NPs do bojo com base em modelos teóricos de fotoionização para prever os ICFs de cada NP usados para estimar os estágios de ionização não observado. Também reanalisaram os dados de 50 NPs do bojo previamente publicados.

Cuisinier et al. (2000), citado como CMKAS2000, derivaram abundâncias para 30 NPs do bojo a partir de dados espectrofotométricos, assim como é feito neste trabalho. Os ICFs são os mesmos que os utilizados em CAK1996.

Exter, Barlow e Walton (2004), citado como EBW2004, publicaram as abundâncias químicas de 45 NPs do bojo usando o método empírico, o mesmo utilizado neste trabalho. Utilizam os ICFs de Kingsburgh e Barlow (1994), enquanto que aqui são utilizados os ICFs para o oxigênio e nitrogênio sugeridos por Torres-Peimbert e Peimbert (1977), e para o argônio o ICF de de Freitas-Pacheco et al. (1993).

Górny et al. (2004), citado como GSEC2004, observaram 44 NPs na direção do bojo galáctico, derivando as abundâncias com o método empírico. Utilizaram as temperaturas obtidas do [NII] para calcular as abundâncias dos íons de baixa ionização e as temperaturas do [OIII] $\lambda 436.3 / 500.7$ para os íons com alto potencial de ionização. Adotaram como abundância do íon $\mathrm{O}^{+}$a média das abundâncias obtidas para este íon através das linhas [OII] $\lambda 372.7$ e [OII] $\lambda 732.0,733.0$.

Girard, Köppen e Acker (2007), citado como GKA2007, analisam as propriedades químicas de NPs ao redor de estrelas centrais do tipo [WC] e [WR]. Derivam as abundâncias de 48 NPs e reanalisam os espectros publicados de outras 167 NPs não WR. São usados os ICFs publicados por Aller (1984) que, exceto pelo ICF do argônio, são iguais aos empregados neste trabalho. 


\subsubsection{Hélio}

As estrelas de massa intermediária $\left(0.8\right.$ a $\left.8 M_{\odot}\right)$ como as que são progenitoras das nebulosas planetárias, têm um enriquecimento de hélio através da queima de hidrogênio que ocorre nas camadas próximas ao núcleo de hélio. Além disto, queimam hélio após deixar a seqüência principal e entrar no ramo das gigantes, restando um núcleo inerte de $\mathrm{C}$ e $\mathrm{O}$ circundado por camadas sucessivas de queima de $\mathrm{H}$ e He, quando atingem o ramo assintótico das gigantes. O resultado global da evolução dessas estrelas é um aumento na abundância de He (Maeder, 1992; Pagel, 1997).

Uma comparação entre as abundâncias químicas do hélio obtidas neste trabalho e as abundâncias compiladas da literatura pode ser visualizada na figura 3.2. A distribuição da abundância do hélio é comparada com os trabalhos de Exter, Barlow e Walton (2004), na figura referido como EBW2004; Górny et al. (2004), GSEC2004 na figura; Escudero, Costa e Maciel (2004), ECM2004 na figura; e RPDM1997 como Ratag et al. (1997).

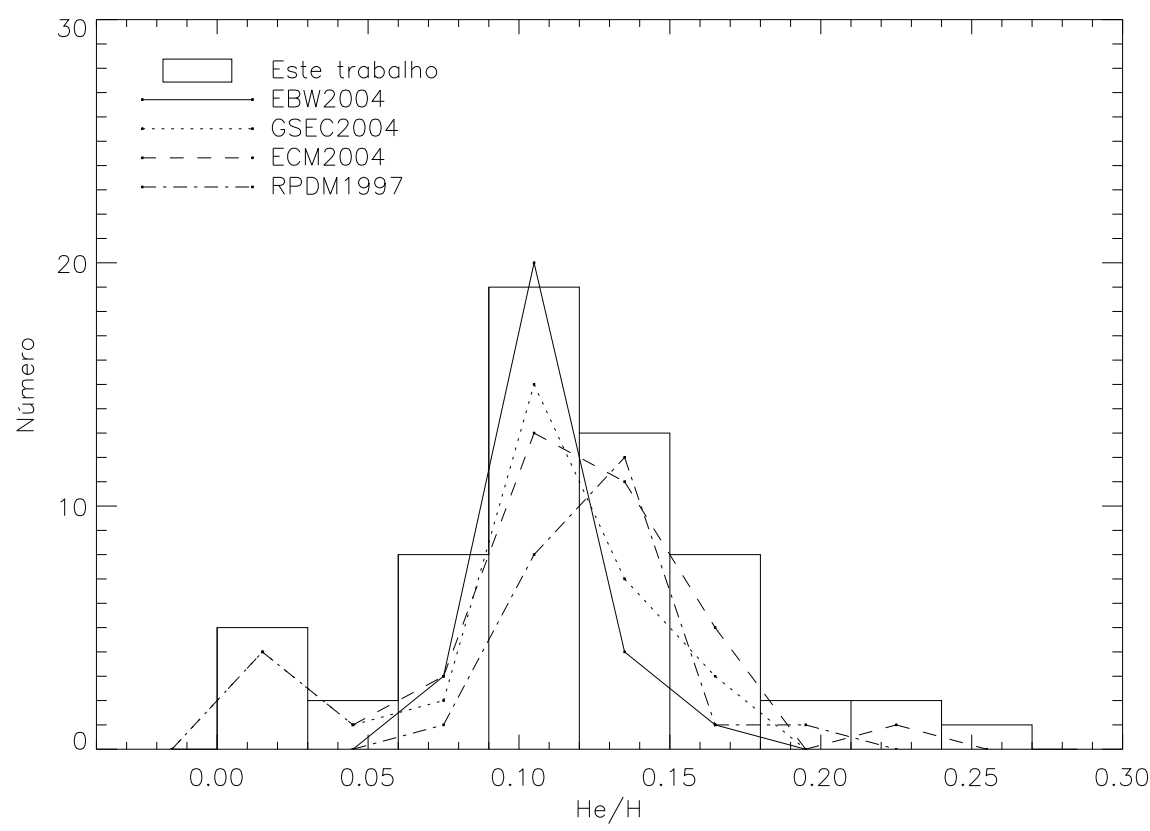

Figura 3.2: Comparação entre as distribuições das abundâncias de hélio obtidas neste trabalho e das abundâncias retiradas da literatura.

A distribuição das abundâncias encontradas para o hélio é muito semelhante às obtidas da literatura. Os histogramas apresentam uma distribuição larga, resultado das diferentes massas e idades das estrelas progenitoras das NPs. Os objetos com baixa abundância de 
hélio devem ser considerados cautelosamente, pois o método de derivação das abundâncias químicas empregado neste trabalho não resulta em abundâncias adequadas para estas NPs, já que a fração de He neutro não foi considerada, como discutido na seção 2.4.2. A distribuição das abundâncias de hélio tem um pico em 0.105, exceto a amostra de Ratag et al. (1997), que possui o pico da distribuição em 0.135.

Dos objetos com abundâncias químicas determinadas neste trabalho, 10 são comuns com outros trabalhos, provendo a oportunidade de comparar diretamente as abundâncias obtidas neste trabalho com dados publicados na literatura. A comparação para o hélio pode ser vista na figura 3.3. O eixo horizontal corresponde às abundâncias de hélio em número determinadas neste trabalho, enquanto que o eixo vertical corresponde aos valores retirados de outros trabalhos. A legenda no canto inferior direito mostra de onde foram retiradas as abundâncias da literatura.

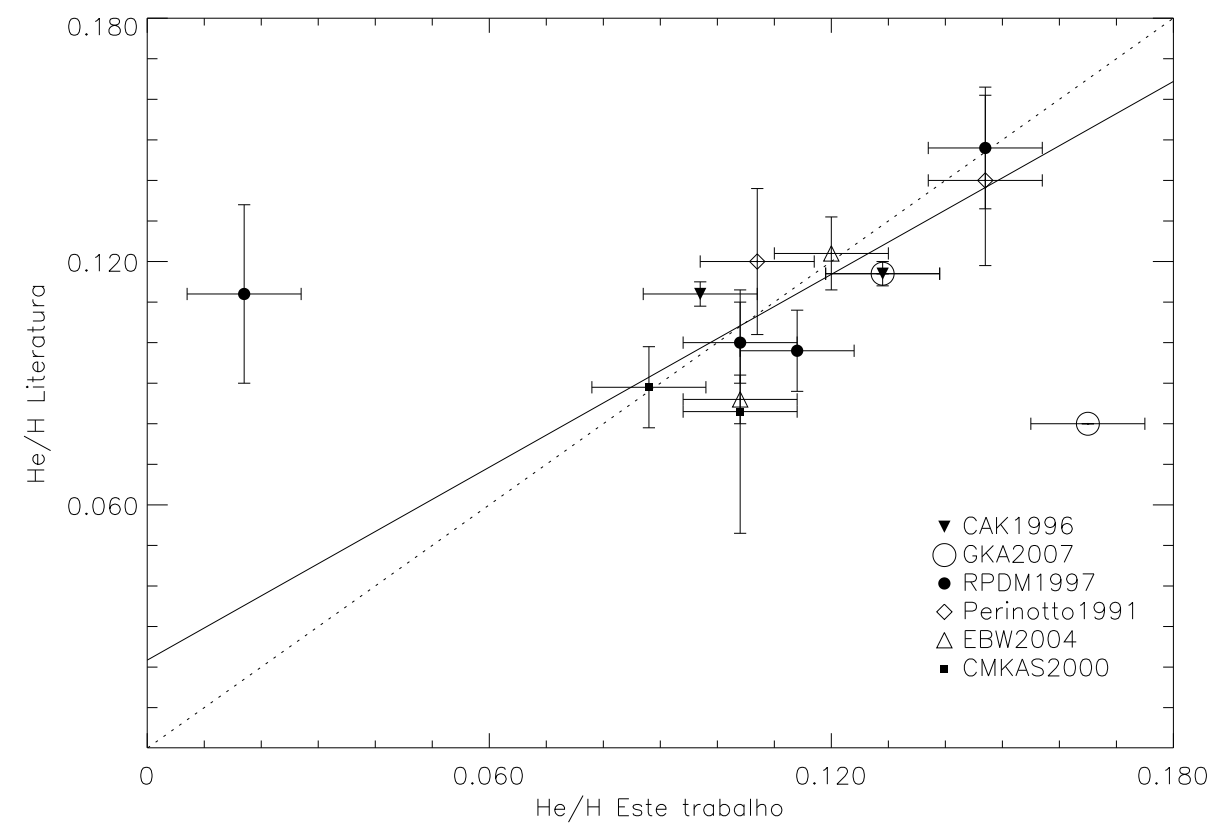

Figura 3.3: Comparação entre as abundâncias de hélio obtidas neste trabalho e as abundâncias retiradas da literatura. A linha tracejada indica onde os dados comparados são iguais, e a linha contínua é um ajuste linear dos dados.

Aos pontos foi feito um ajuste linear, mostrado através da linha contínua na figura. $\mathrm{O}$ coeficiente angular deste ajuste é igual a $0.8 \pm 0.2$ e o coeficiente linear é igual a $0.02 \pm 0.02$. O coeficiente de correlação para estes dados é 0.80 . Em toda esta seção foi realizada uma 
média das abundâncias químicas para os objetos com abundâncias publicadas por trabalhos distintos. Para o ajuste, foram excluídos os dois pontos que estão mais distantes da linha tracejada, os quais correspondem aos objetos M1-45 e M1-46.

A NP M1-45 teve a abundância de hélio determinada por nós igual a 0.017. Esta nebulosa planetária possui $\log O^{+} / O=-0.06 \mathrm{e}$, portanto, a abundância calculada é apenas um limite inferior, explicando a discrepância entre o valor obtido neste trabalho e o valor 0.112 determinado por RPDM1997.

A abundância de hélio da NP M1-46 determinada neste trabalho foi 0.165 , enquanto que GKA2007 obtiveram 0.080. O espectro desta NP apresenta o espectro de uma estrela do campo sobreposto. As linhas de absorção do espectro da estrela podem alterar o fluxo das linhas de emissão da nebulosa, introduzindo erros na determinação das abundâncias.

Excluindo estas duas NPs, as abundâncias de hélio derivadas neste trabalho concordam com as obtidas da literatura, dentro dos erros envolvidos.

\subsubsection{Nitrogênio}

Assim como a abundância do hélio, a abundância do nitrogênio em nebulosas planetárias também é alterada pela evolução da estrela progenitora. A ocorrência de episódios de dragagem (dredge up) em estrelas do ramo assintótico das gigantes, aumenta a abundância de ${ }^{4} \mathrm{He}$ e converte C e O em ${ }^{14} \mathrm{~N}$. Van den Hoek e Groenewegen (1997) estimam uma aumento de $28 \%$ na abundância do nitrogênio para uma estrela de $1 M_{\odot}$ e $37 \%$ para uma estrela com massa $\geq 3 M_{\odot}$. Portanto, a abundância de nitrogênio de NPs originadas de estrelas com massas acima desse valor, não reflete a abundância química do meio interestelar do qual a estrela se formou. Desta forma, a abundância do nitrogênio em NPs sem nenhum correção não pode ser usada como vínculo aos modelos de evolução química da Galáxia. Porém, como a produção de hélio e nitrogênio é maior em estrelas de grande massa, as abundâncias destes elementos são indicativas da massa da estrela progenitora.

Na figura 3.4 é mostrada a distribuição de abundâncias de nitrogênio obtida neste trabalho juntamente com as distribuições das abundâncias compiladas da literatura. A distribuição de abundâncias obtidas neste trabalho não apresenta um pico claro, e, assim como as outras distribuições comparadas na figura, apresenta um perfil bastante largo, indo de 7.0 dex a 9.0 dex. Tal espalhamento na distribuição das abundâncias de nitrogênio 


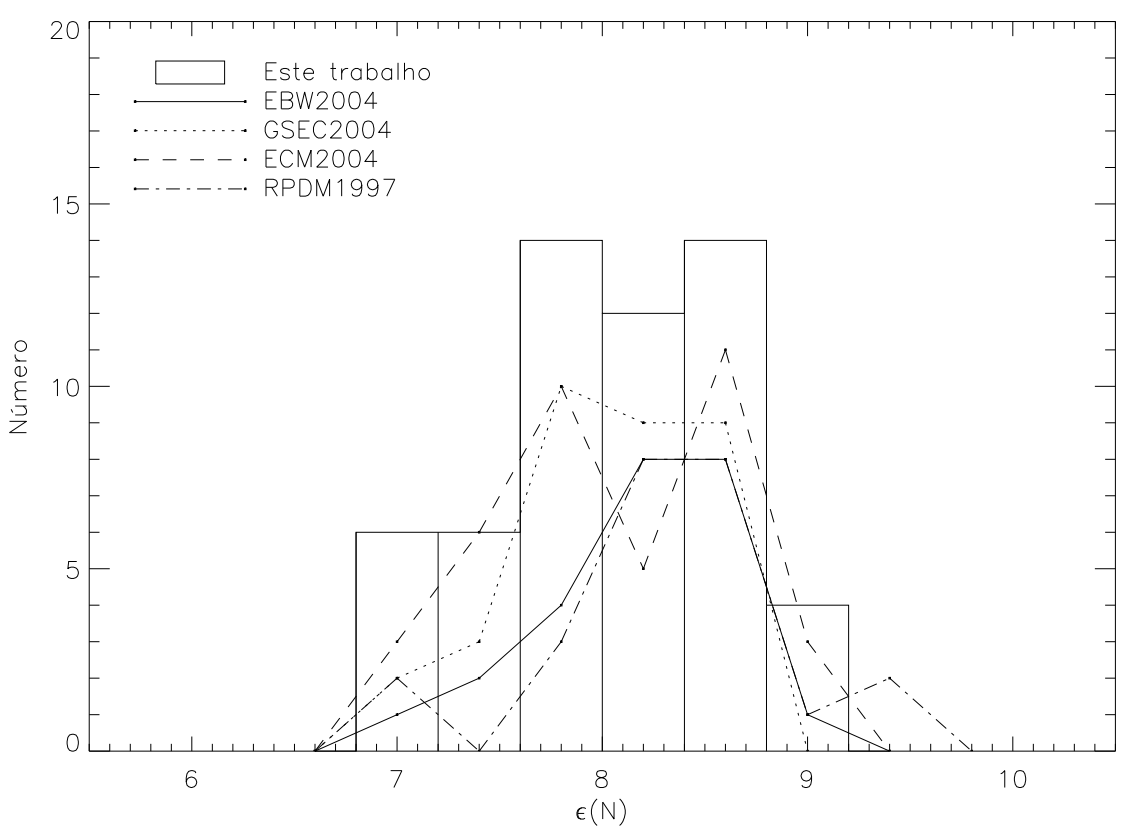

Figura 3.4: Histogramas comparando as distribuições das abundâncias de nitrogênio para diferentes amostras.

reflete a amplitude de massas das estrelas progenitoras de NPs. Incertezas na determinação das abundâncias também podem causar este espalhamento. Apesar das linhas do íon $\mathrm{N}^{+}$serem bastante intensas nas NPs, a determinação da abundância do nitrogênio depende da abundância do íon $\mathrm{O}^{+}$através do ICF. Portanto, imprecisões na determinação na abundância do $\mathrm{O}^{+}$se propagam na determinação da abundância do nitrogênio.

Uma comparação entre as abundâncias de nitrogênio obtidas neste trabalho com dados previamente publicados é feita na figura 3.5.

O ajuste linear tem como parâmetros: coeficiente linear igual a $(0.4 \pm 0.1) \times 10^{1}$ dex, e coeficiente angular igual a $0.6 \pm 0.1$. O coeficiente de correlação entre os dados, assumindo uma correlação linear, é 0.67 .

A dispersão do nitrogênio ao redor da linha onde as abundâncias comparadas seriam iguais é grande, mas está relativamente dentro dos erros. Os dados obtidos de EBW2004 e Perinotto (1991) são os que mais diferem dos nossos dados. EBW2004 usam o ICF do nitrogênio de Kingsburgh e Barlow (1994), o que pode explicar a diferença encontrada. A NP H1-17 em comum com EBW2004 também foi observada por CMKAS2000 e RPDM1997. Se comparada com estes trabalhos, a abundância de nitrogênio difere da nossa por 0.13 e 
-0.11 dex , respectivamente, dentro do erro de 0.16 dex esperado para o nitrogênio. As abundâncias dos dois objetos de Perinotto (1991) foram compilados de Webster (1988) e Aller e Keyes (1987). Em particular a NP M2-21 tem coordenadas galácticas $0.7^{\circ}$ e $-2.7^{\circ}$, ou seja, está localizada em uma região de grande extinção, portanto erros na correção da extinção interestelar podem causar erros na determinação da temperatura eletrônica, que se propagam para as abundâncias. Além disto, estas NPs são de alta ionização, pois apresentam linhas intensas de HeII $\lambda$ 468.6. Neste tipo de NP, tipicamente a fração de $\mathrm{N}^{+}$ pode ser muito menor que 10\%, e a abundância total de nitrogênio pode ter um erro muito grande, maior que $50 \%$.

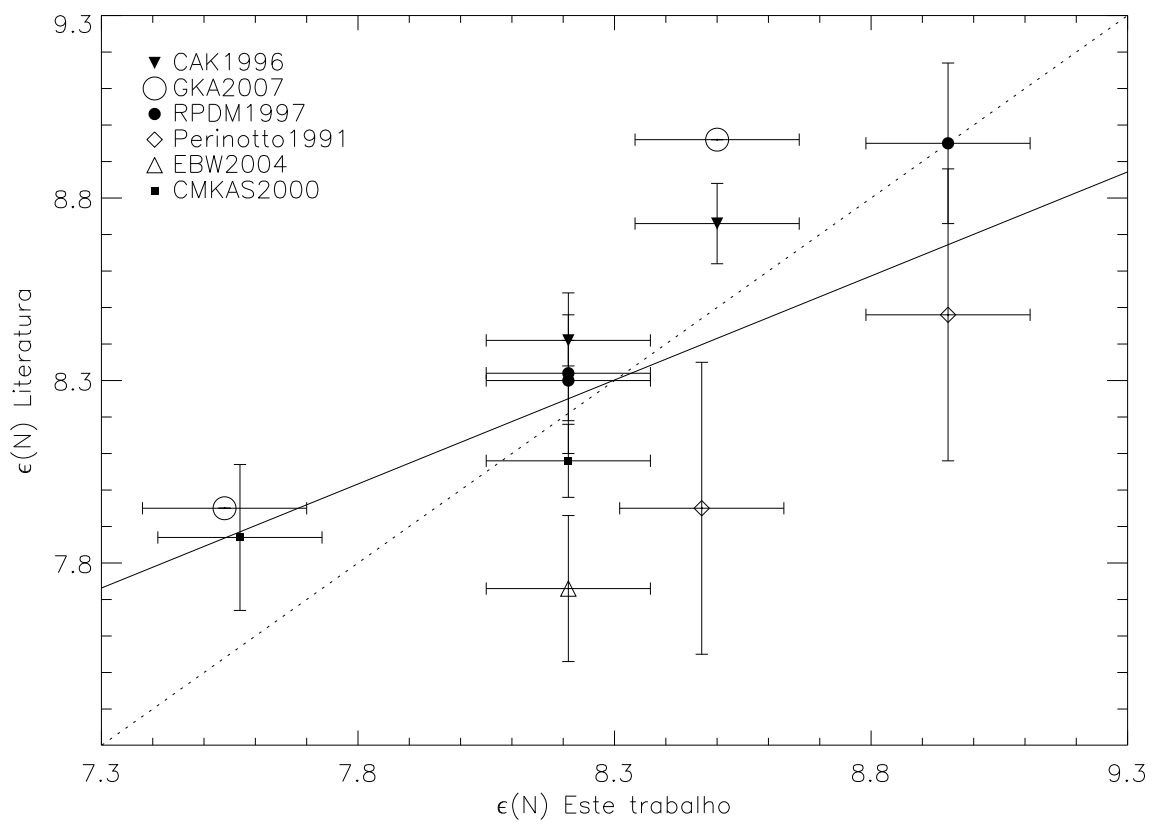

Figura 3.5: Comparação das abundâncias de nitrogênio com dados da literatura.

\subsubsection{Oxigênio}

De acordo com teorias de evolução estelar e cálculos de nucleossíntese (ver por exemplo Renzini e Voli, 1981; Lattanzio e Forestini, 1999), não se espera uma grande alteração da abundância do oxigênio em estrelas de massa pequena e intermediária. Deste modo, a abundância de oxigênio reflete a abundância do meio interestelar na época de formação da estrela progenitora da NP. 
A distribuição da abundância do oxigênio para a nossa amostra é mostrada na figura 3.6.

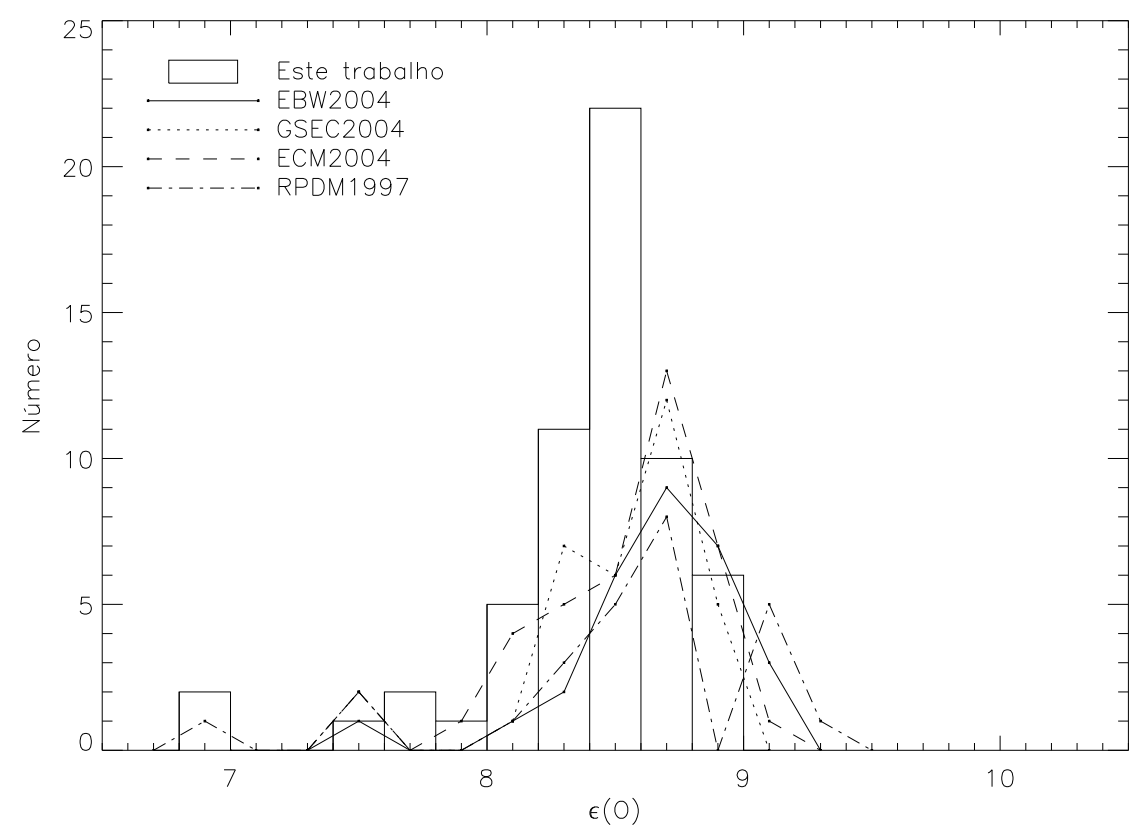

Figura 3.6: Comparação entre a distribuição das abundâncias de oxigênio obtidas neste trabalho com a distribuição dos dados da literatura.

A abundância de oxigênio tem uma tendência sistemática de ser mais baixa em aproximadamente 0.20 dex se comparado com os dados da literatura. Como a incerteza na determinação da abundância do oxigênio é da ordem de 0.20-0.30 dex, não se pode afirmar que esta é uma característica da amostra. Além disto, o bojo é formado por diferentes populações, em sua maioria estrelas com idade $10 \pm 2.5$ Ganos (Ortolani et al., 1995; Zoccali et al., 2003), porém há indícios de uma população mais jovem formada por estrelas $\mathrm{OH} / \mathrm{IR}$, estrelas variáveis AGB, etc, que parecem estar em sua maioria confinada no plano Galáctico (ver por exemplo van Loon et al., 2003). Tal composição de idades faz com que as NPs do bojo apresentem um grande espalhamento nas abundâncias químicas do oxigênio e elementos produzidos por captura $\alpha$ em geral.

Pode ser visto na figura que há um número significativo de NPs com abundâncias no intervalo de 8 a 9 dex, mostrando que a população de NPs do bojo foi originada em diversas épocas. O que pode sugerir diversos episódios de formação do bojo, como discutido por Costa e Maciel (2006). 
CAK1996 não obtiveram a temperatura eletrônica do NII para a NP M1-60. Eles utilizaram a temperatura do OIII para calcular a abundância do íon $\mathrm{O}^{+}$. Além disto, a temperatura do OIII está subestimada em comparação com a obtida neste trabalho. Tal fato aumenta as abundâncias dos íons $\mathrm{O}^{+} \mathrm{e}^{++}$, superestimando a abundância de oxigênio. Esta NP teve abundância de oxigênio determinada por GKA2007, que obtiveram um valor 0.25 dex maior que o obtido neste trabalho, relativamente dentro do erro esperado para o oxigênio.

A NP M1-46, que apresentou uma superabundância de hélio, também tem divergências com a abundância de oxigênio. GKA2007 estimaram a abundância de oxigênio sendo 8.87 dex, enquanto nós obtivemos 8.05 dex. Eles não obtiveram a temperatura eletrônica do OIII, usando a temperatura eletrônica do NII para calcular as abundâncias íons com grau de excitação maior que 2. Além disto, a temperatura eletrônica do NII obtida por eles é menor que a calculada por nós, superestimando as abundâncias. A sobreposição do espectro da NP com o espectro de uma estrela do campo inviabiliza uma estimativa mais precisa das abundâncias para esta NP.

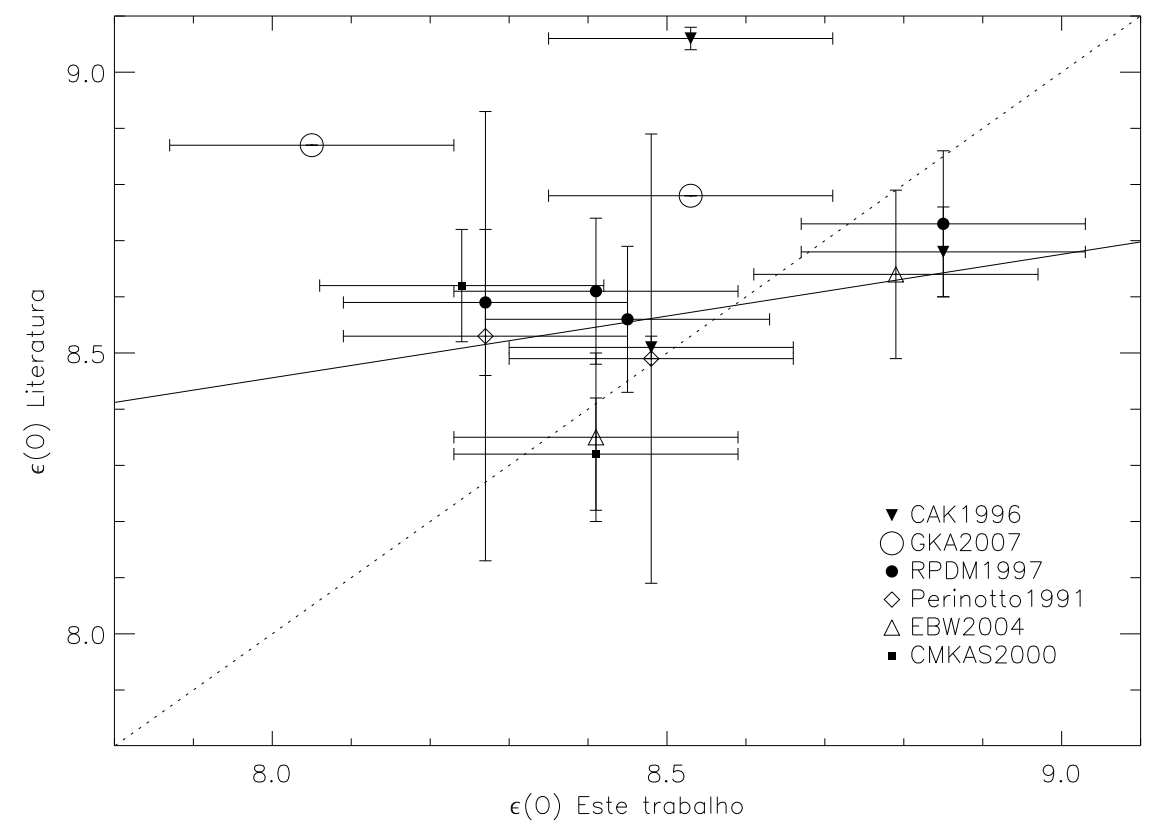

Figura 3.7: Comparação da abundância de oxigênio obtida neste trabalho com dados da literatura.

Estas duas NPs foram excluídas do ajuste linear mostrado na figura 3.7. O espalha- 
mento dos dados, que está dentro do erro esperado para o oxigênio, e a concentração de objetos com abundâncias ao redor de 8.5 dex, dificultam o ajuste linear. Os parâmetros deste ajuste são: coeficiente linear igual a $(0.7 \pm 0.3) \times 10^{1}$ dex, coeficiente angular igual a $0.2 \pm 0.3$. O coeficiente de correlação para o ajuste linear é 0.54. Os motivos citados anteriormente fazem com que os dados apresentem uma baixa correlação.

\subsubsection{Enxofre}

Assim como o oxigênio, o enxofre não é sintetizado em estrelas de massa pequena e intermediária, sendo possível utilizá-lo em estudos de evolução química da Galáxia. Comparando as abundâncias de enxofre com dados da literatura (figura 3.8), vê-se que os resultados encontrados neste trabalho concordam razoavelmente bem com as amostras selecionadas da literatura, sendo que tanto as abundâncias obtidas neste trabalho quanto as obtidas da literatura apresentam um grande espalhamento na distribuição.

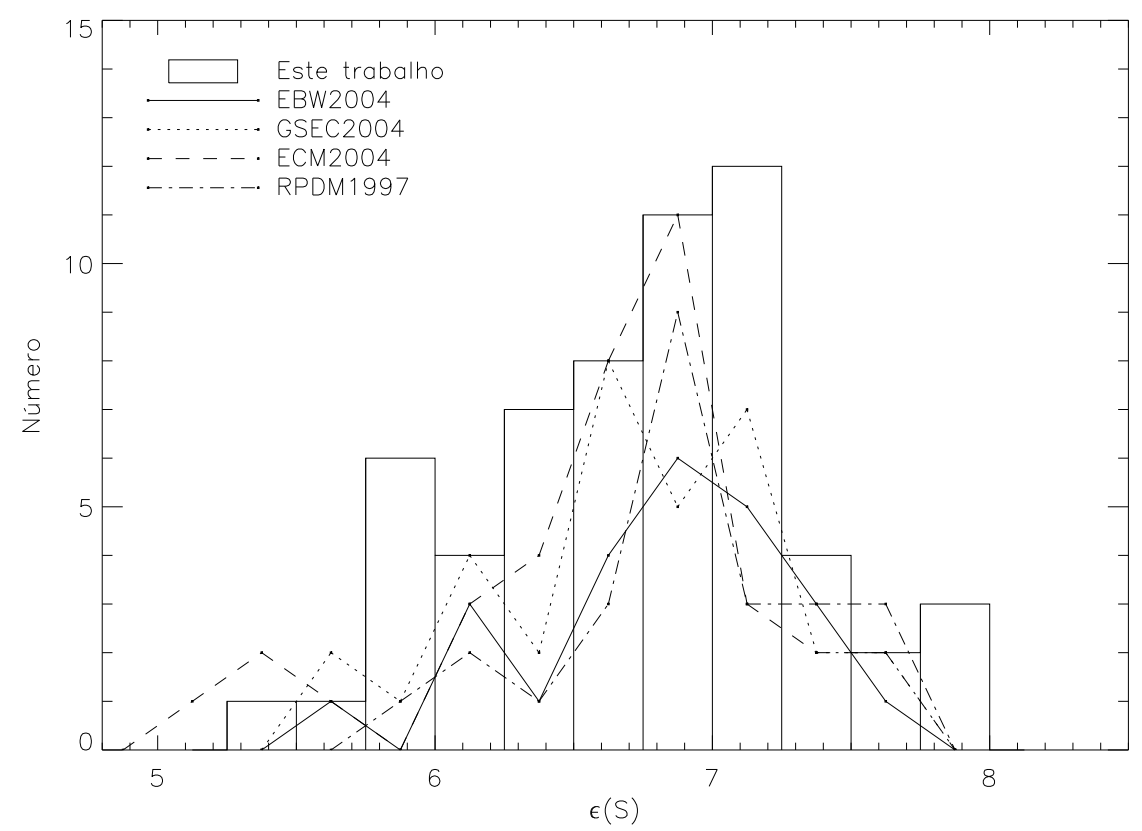

Figura 3.8: Distribuição das abundâncias químicas do enxofre encontradas neste trabalho comparadas com resultados compilados da literatura.

A abundância elemental de enxofre é calculada a partir das linhas do $\mathrm{S}^{+} \lambda 671.7,673.1$ $\mathrm{nm}$, e também a partir da linha do $\mathrm{S}^{+2} \lambda 631.2 \mathrm{~nm}$. A incerteza na determinação da abundância de enxofre se dá principalmente pelo fato de que geralmente não são observados 
os íons $\mathrm{S}^{+2}$ e $\mathrm{S}^{+3}$, os quais contêm a maior parte do enxofre em NPs (Pottasch et al., 1986). A linha do íon $\mathrm{S}^{+2}$ em $\lambda 631.2 \mathrm{~nm}$ apresenta baixo sinal ruído $(\mathrm{S} / \mathrm{N})$ nos espectros obtidos neste trabalho, resultando em imprecisões na determinação da abundância de enxofre. $\mathrm{O}$ íon $\mathrm{S}^{+}$, relativamente bem observado, contribui com aproximadamente $10 \%$ da abundância total do enxofre, e portanto necessita de um grande ICF, se este for o único íon observado.

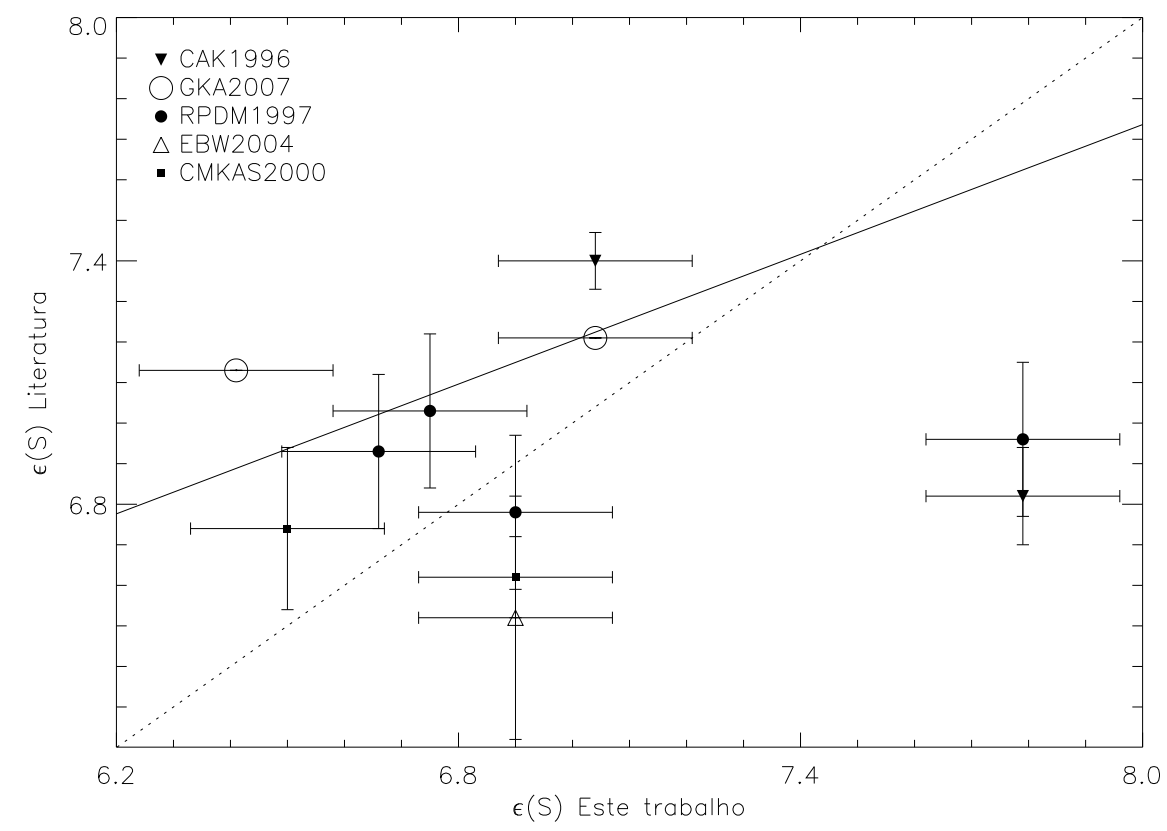

Figura 3.9: Abundâncias químicas do enxofre encontradas neste trabalho comparadas com resultados compilados da literatura.

Na figura 3.9 é mostrada uma comparação entre as abundâncias de enxofre que são comuns a outros trabalhos da literatura. Os dados apresentam uma baixa correlação, sendo o coeficiente de correlação igual a -0.13. O coeficiente angular do ajuste é $(0.8 \pm 0.2) \times 10^{1}$ dex e o coeficiente linear é $-0.1 \pm 0.2$.

Os pontos a direita da figura são da NP M1-45, que tem problemas na abundância do hélio, como discutido anteriormente. Os pontos com abundância de enxofre por volta de 6.9 dex são da NP H1-17. Em vista da diferença exprimida entre o nosso resultado e os da literatura para esta NP, cuja razão não ficou clara, optamos por excluir este ponto do ajuste.

Excluindo estas NPs, o ajuste linear resulta em um coeficiente linear igual a $(0.3 \pm 0.2) \times 10^{1} \mathrm{dex}$, e um coeficiente angular igual a $0.5 \pm 0.3$. O coeficiente de corre- 
lação para o ajuste linear é 0.69. Portanto, após a exclusão destas NPs os parâmetros do ajuste tornaram-se mais coerentes com o resultado esperado, ou seja, a linha que representa a igualdade dos dados comparados. Apesar do baixo número de pontos, pode-se dizer que, dentro dos erros envolvidos, os resultados encontrados para a abundâncias de enxofre concordam com os previamente publicados na literatura.

\subsubsection{Argônio}

No método utilizado no presente trabalho, a abundância de argônio é calculada apenas a partir da linha $713.6 \mathrm{~nm}$ do íon $\mathrm{Ar}^{++}$. Esta linha não apresenta uma alta razão S/N, introduzindo erros na determinação da abundância de argônio. Em NPs de baixa excitação os íons de $\mathrm{Ar}^{+}$podem dominar a abundância de argônio, o que exigiria grandes ICFs e, desta forma, aumentando a incerteza na determinação de sua abundância.

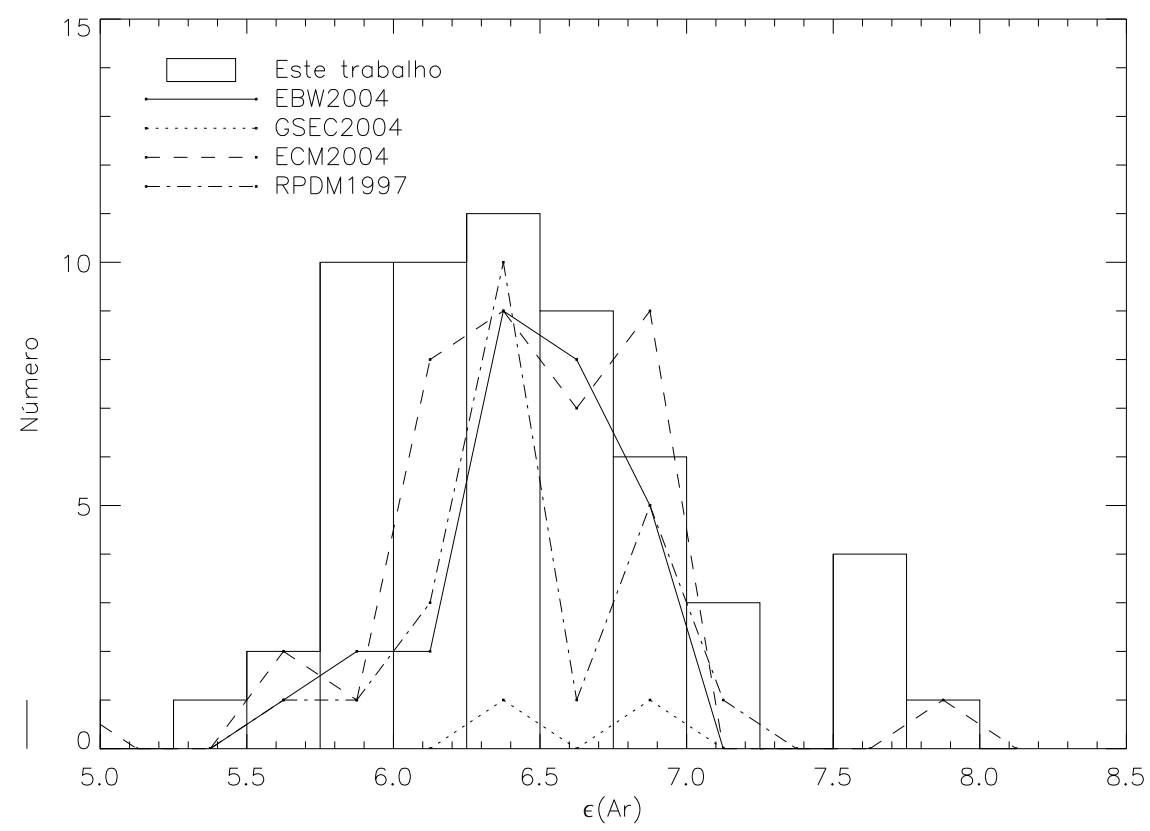

Figura 3.10: Distribuição da abundância de argônio obtida neste trabalho comparada com dados da literatura.

Tais erros se refletem na distribuição das abundâncias de argônio mostrada na figura 3.10. A figura mostra uma distribuição bastante larga e nos trabalhos de Ratag et al. (1997) e Escudero, Costa e Maciel (2004) a distribuição é bimodal. A amostra de Górny et al. (2004) não contém dados suficientes a respeito da abundância de argônio para uma 
comparação com as outras amostras.

Na figura 3.11 é mostrada a correlação entre as abundâncias de argônio obtidas neste trabalho com dados previamente publicados. A NP M1-46 teve a abundância de argônio obtida por GKA2007 e, se comparada com a determinada no presente trabalho, apresenta uma abundância muito baixa. Como mencionado anteriormente, há uma estrela do campo na fenda cujo espectro está sobreposto ao espectro desta NP, alterando o fluxo das linhas de emissão da nebulosa. Esta NP foi excluída do ajuste linear mostrado na figura. Os parâmetros deste ajuste são: coeficiente linear igual a $(-0.1 \pm 0.1) \times 10^{1}$ dex, e coeficiente angular igual a $1.1 \pm 0.2$. O coeficiente de correlação entre os dados é 0.78 .

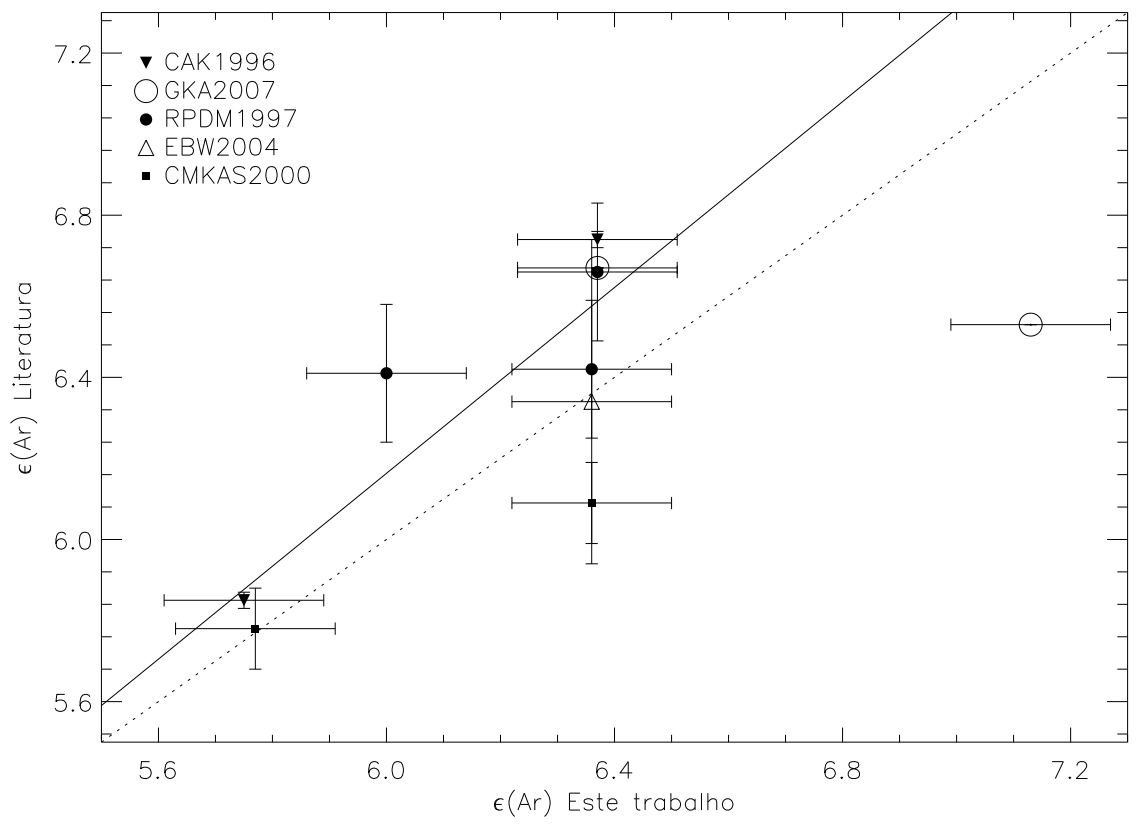

Figura 3.11: Comparação entre a abundância de argônio obtida neste trabalho com dados da literatura.

Constata-se que, exceto pela NP M1-46, há um bom acordo entre os dados obtidos neste trabalho e os dados da literatura. 


\subsubsection{Neônio}

A abundância de neônio em NPs é determinada a partir da linha 386.9 nm do íon $\mathrm{Ne}^{++}$. Por estar no extremo azul da cobertura espectral, esta linha nem sempre apresenta uma boa razão $\mathrm{S} / \mathrm{N}$ e, além disto, muitas vezes está sobreposta com linhas vizinhas, apesar de que a linha do íon $\mathrm{Ne}^{++}$é usualmente dominante.

A distribuição de abundância de neônio, apesar da incerteza em sua determinação, é similar se comparada com outros trabalhos, como pode ser visto na figura 3.12. A distribuição de neônio é bastante larga, indo de 6.5 a 9.0 dex, aproximadamente. O pico da distribuição está localizado em 7.9 dex.

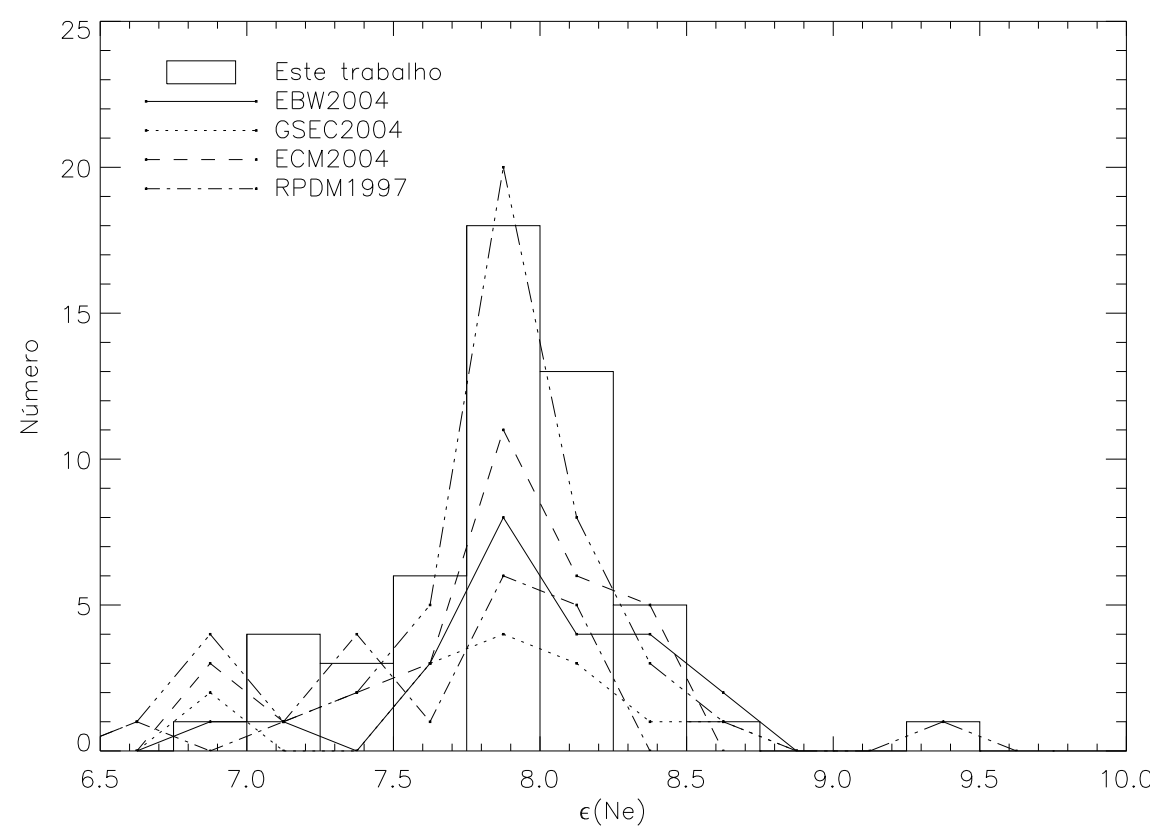

Figura 3.12: Histograma das abundâncias de neônio obtidas neste trabalho comparado com histogramas da literatura.

Na figura 3.13 é mostrada a correlação entre as abundâncias obtidas neste trabalho com dados da literatura. Em Perinotto (1991), CAK1996, e CMKAS2000 não havia a abundância de neônio publicada para uma comparação com as abundâncias obtidas aqui.

Apesar do pequeno número de pontos, os dados estão bem correlacionados, com coeficiente de correlação igual a 0.74 . O coeficiente linear da reta ajustada é $(0.1 \pm 0.4)$ dex, e o coeficiente angular é $0.8 \pm 0.5$. 


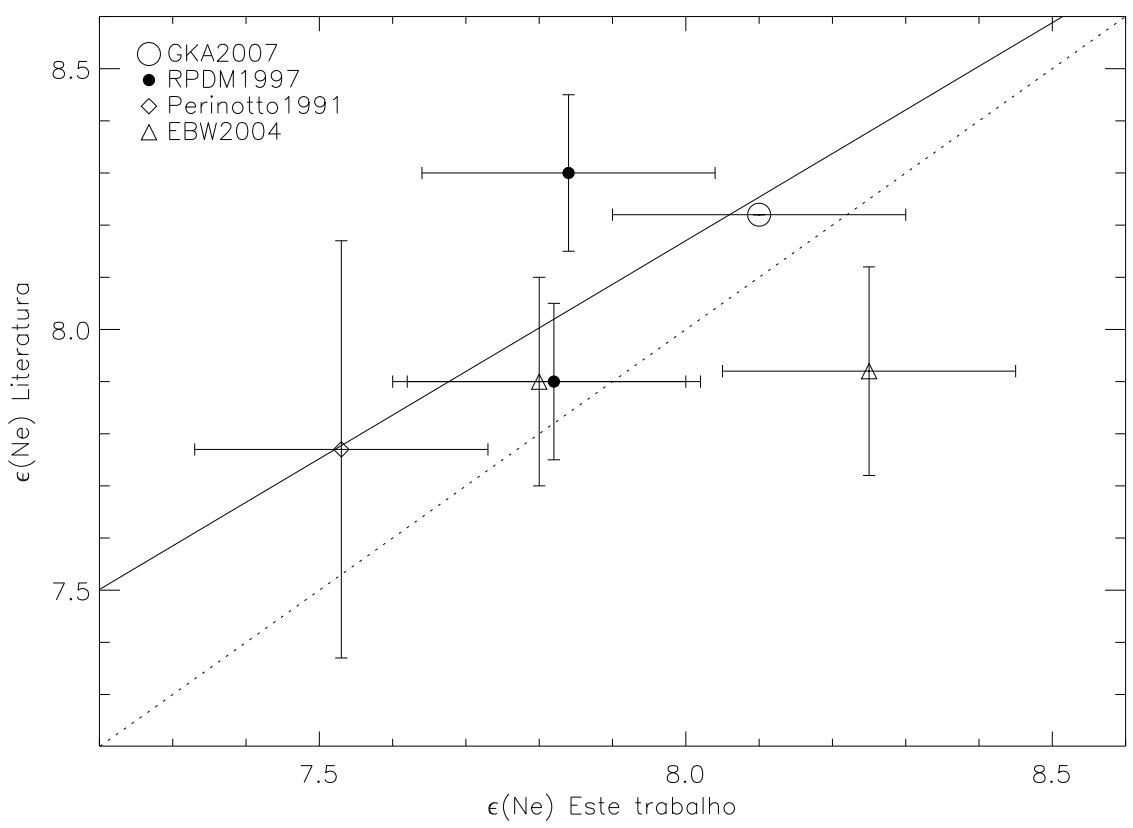

Figura 3.13: Correlação entre a abundância de neônio obtida neste trabalho com dados previamente publicados.

\subsection{Correlações entre elementos químicos}

O estudo da correlação entre as abundâncias dos diferentes elementos químicos é uma ferramenta importante para entender a evolução das estrelas centrais das NPs, provendo vínculos observacionais para os modelos de evolução estelar. As correlações entre os elementos não sintetizados pela estrela progenitora trazem importantes informações a respeito da formação e evolução da Galáxia, como pode ser visto em Ballero et al. (2007).

\subsubsection{Correlação entre N/O e hélio}

Uma vez que os elementos hélio e nitrogênio têm suas abundâncias químicas alteradas durante a evolução da estrela progenitora da NP, em um gráfico como o mostrado na figura 3.14, onde é analisada a correlação entre $\log (\mathrm{N} / \mathrm{O})$ e a abundância de hélio, a razão N/O deve crescer com o aumento da abundância de hélio, pois as NPs com as maiores razões He/H e N/O são originadas de estrelas mais massivas.

Na figura é possível ver que o espalhamento dos dados é maior que o erro estimado das abundâncias, e provavelmente é real. Deve-se notar que tanto os nossos dados como os da 


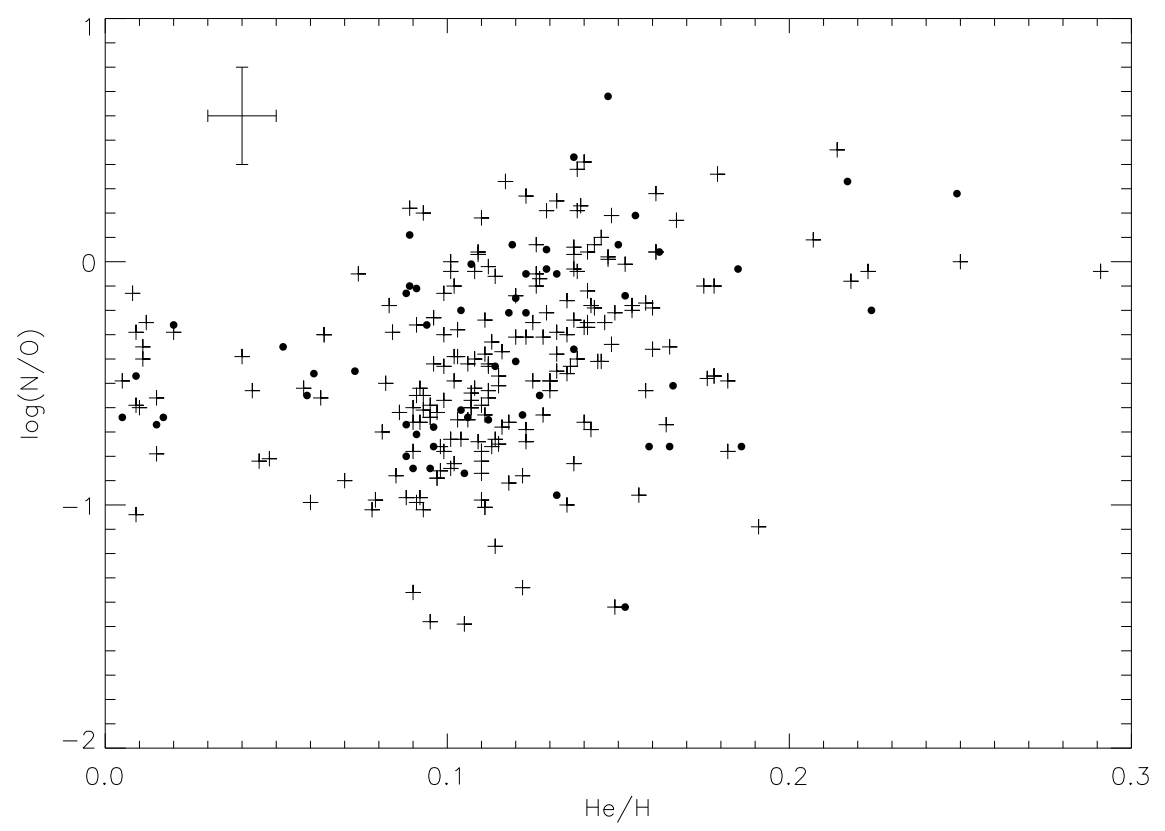

Figura 3.14: $\log (N / O)$ como função de He/H. Os círculos fechados são nosso dados e as cruzes são dados da literatura. A barra de erro no canto superior esquerdo indica o erro médio esperado.

literatura apresentam grande dispersão. Os nossos dados apresentam correlação de média para baixa, sendo o coeficiente de correlação igual a 0.30. Os pontos com He/H menor que 0.050 foram excluídos da análise de correlação por apresentarem abundâncias menor do que a abundância primordial do hélio produzida no Big Bang.

É esperado que o enriquecimento de nitrogênio não seja tão acentuado especialmente em NPs não tipo I, as quais constituem aproximadamente $80 \%$ da população de NPs da Galáxia (Ballero et al., 2007). Os dados obtidos neste trabalho, mostrados na figura 3.14, assim como alguns objetos da literatura, apresentam a razão N/O baixa, a não ser por um pequeno número de objetos com razão N/O ao redor de 0.5. Os objetos desta região podem ter sido originados de estrelas massivas, indicando uma formação estelar recente. Contudo, os erros envolvidos não permitem uma conclusão definitiva.

Cuisinier et al. (2000) mostrou que a razão N/O é mais baixa para os objetos do bojo se comparados com os do disco. Se confirmadas as abundâncias de nitrogênio e oxigênio destas NPs que possuem a razão N/O acima do esperado para objetos do bojo, então estas NPs podem estar situadas na transição entre o bojo e o disco. Por outro lado, o método 
empregado neste trabalho para excluir os objetos do disco não é $100 \%$ efetivo, podendo haver uma contaminação destes objetos na amostra.

\subsubsection{Correlação entre nitrogênio e oxigênio}

Examinando a relação entre as abundâncias de nitrogênio e oxigênio, mostrada na figura 3.15, uma correlação positiva pode ser observada. O coeficiente de correlação é 0.68. Esta correlação positiva está de acordo com as teorias de evolução estelar e de evolução química da Galáxia, pois, uma vez que a eficiência na produção de nitrogênio é maior em estrelas mais massivas e existe uma relação entre idade e metalicidade na Galáxia (RochaPinto e Maciel, 1997, e referências aí citadas), então as estrelas com maior abundância de nitrogênio devem ter uma maior abundância de oxigênio. Os dados parecem mostrar que esta relação não é linear, mas o espalhamento é grande para se poder afirmar isto.

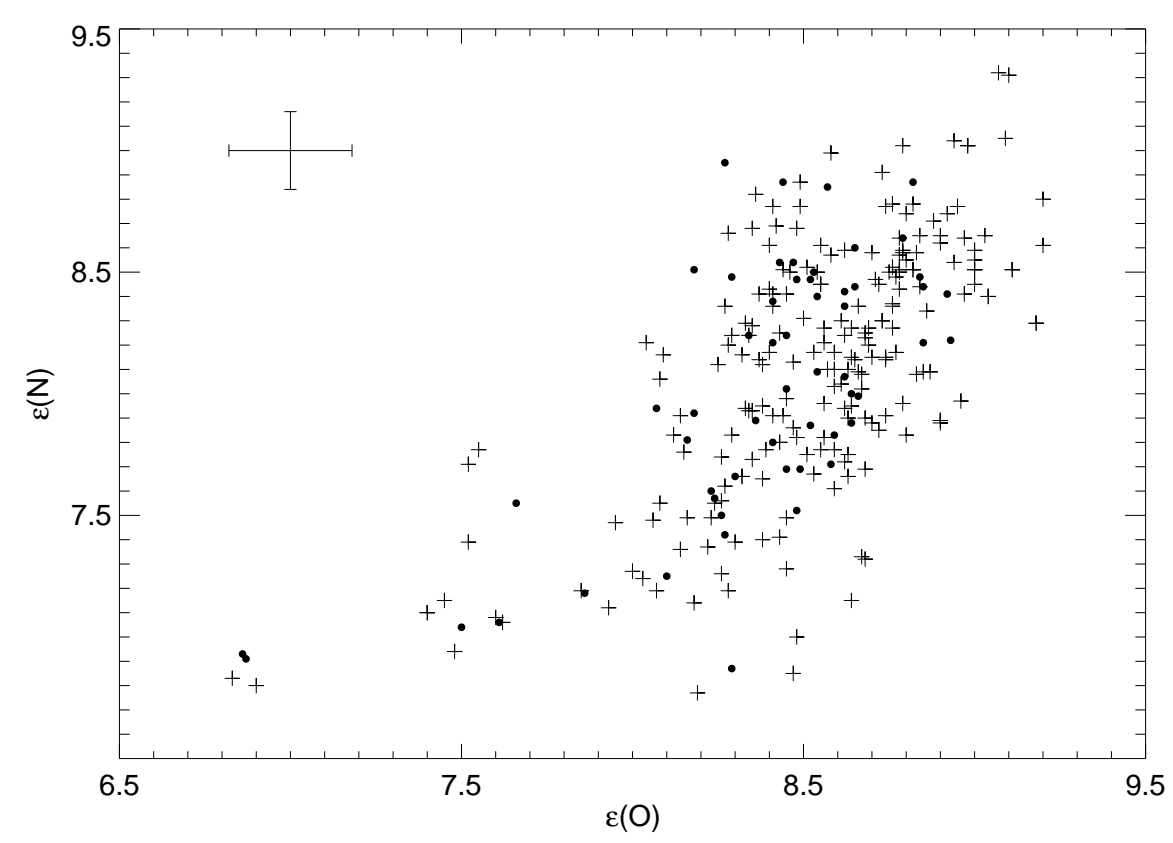

Figura 3.15: Variação da abundância de nitrogênio com a abundância de oxigênio.

\subsubsection{Correlação entre $(S, A r, N e)$ e oxigênio}

Como estes elementos não são produzidos na estrela progenitora da NP, e sim são gerados em explosões de supernovas tipo II, espera-se uma correlação positiva entre o 
enxofre, argônio, neônio e o oxigênio em NPs. Na figura 3.16 é mostrada correlação entre as abundâncias de enxofre e oxigênio. Dentro dos erros envolvidos, pode-se ver que esta correlação é praticamente linear, tanto para os nossos dados quanto para os da literatura. O coeficiente de correlação para as abundâncias obtidas neste trabalho é 0.72 , indicando uma grande correlação entre os dados.

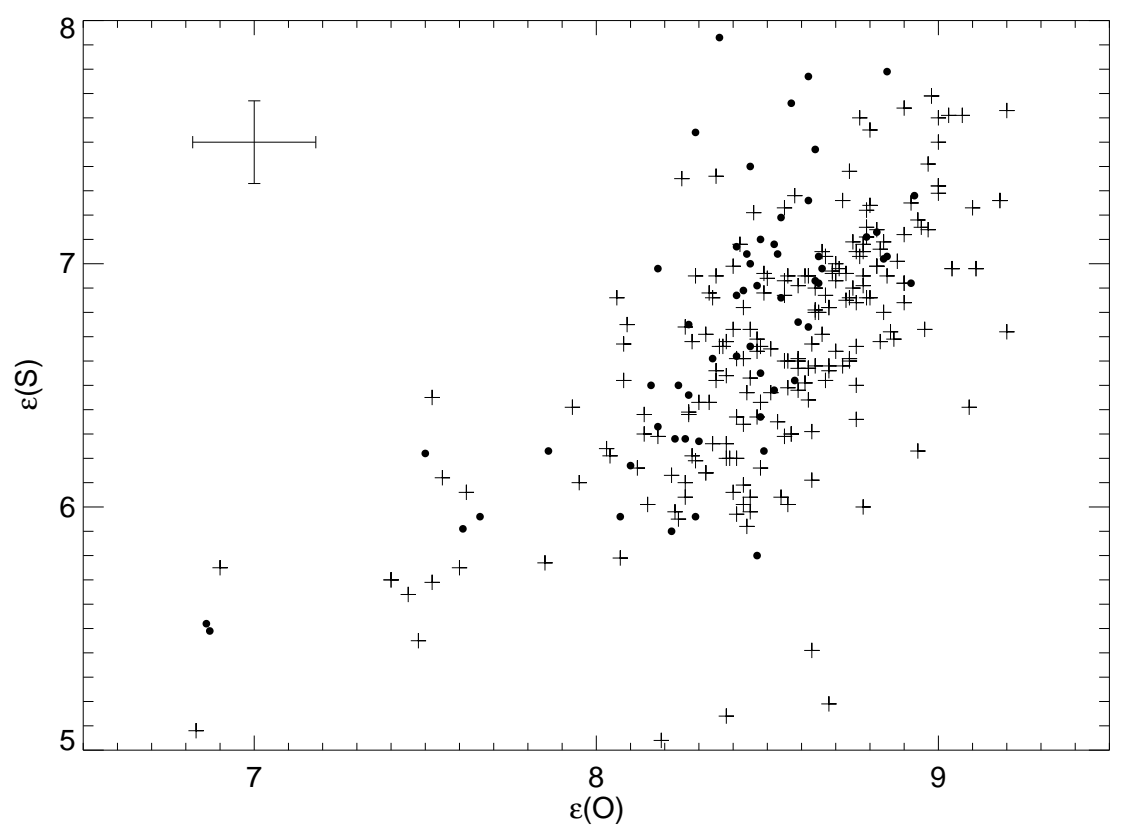

Figura 3.16: Correlação entre as abundâncias de oxigênio e neônio.

Assim como a correlação entre as abundâncias de enxofre e oxigênio, a correlação entre as abundâncias de argônio e oxigênio apresenta um certo espalhamento, como pode ser visualizado na figura 3.17. Apesar deste espalhamento a correlação é boa, com coeficiente igual a 0.68 . Os dados obtidos neste projeto concordam com os dados retirados da literatura, que também apresentam um certo espalhamento.

A correlação entre as abundâncias de neônio e oxigênio é mais bem definida se comparada com as correlações das abundâncias de enxofre e argônio com oxigênio. Os dados compilados da literatura apresentam um maior espalhamento do que os dados obtidos neste projeto, porém foram compilados de diferentes trabalhos e, portanto, as diferenças dos métodos contribuem para este espalhamento. O coeficiente de correlação para a nossa amostra é 0.80, o maior entre todas as correlações feitas anteriormente. 


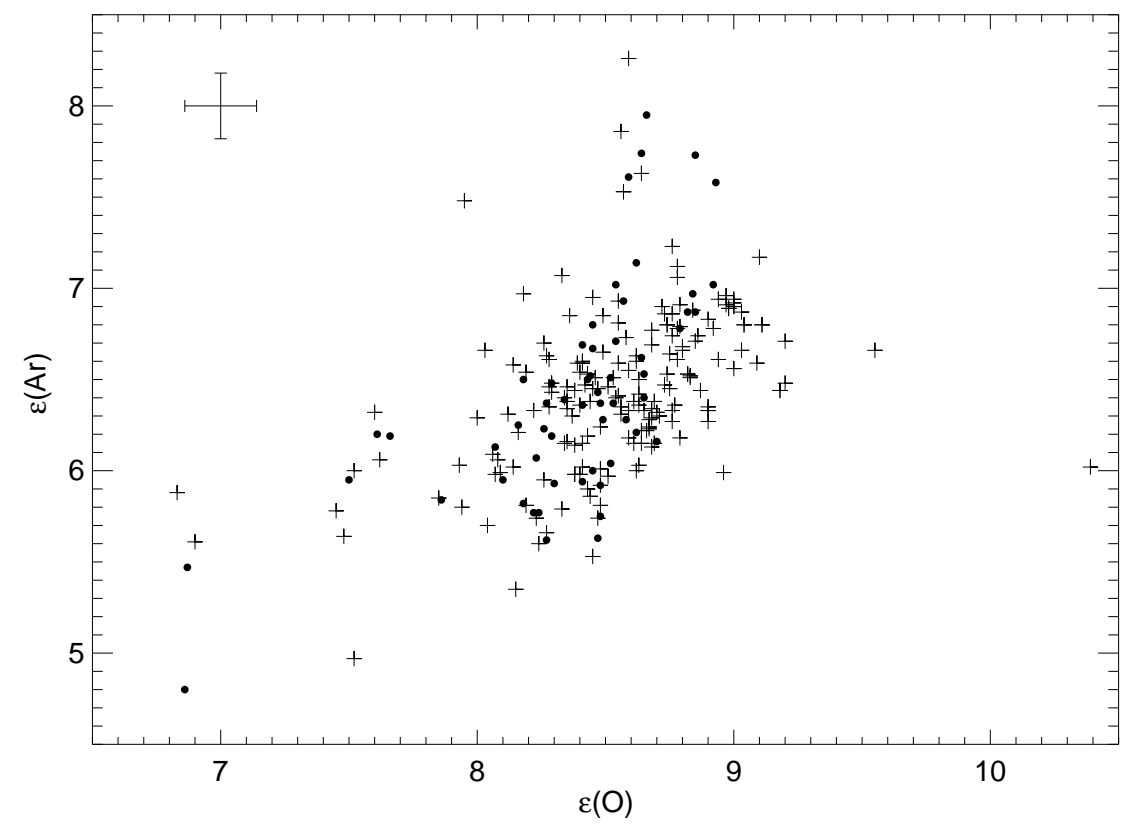

Figura 3.17: Correlação entre as abundâncias de argônio e oxigênio.

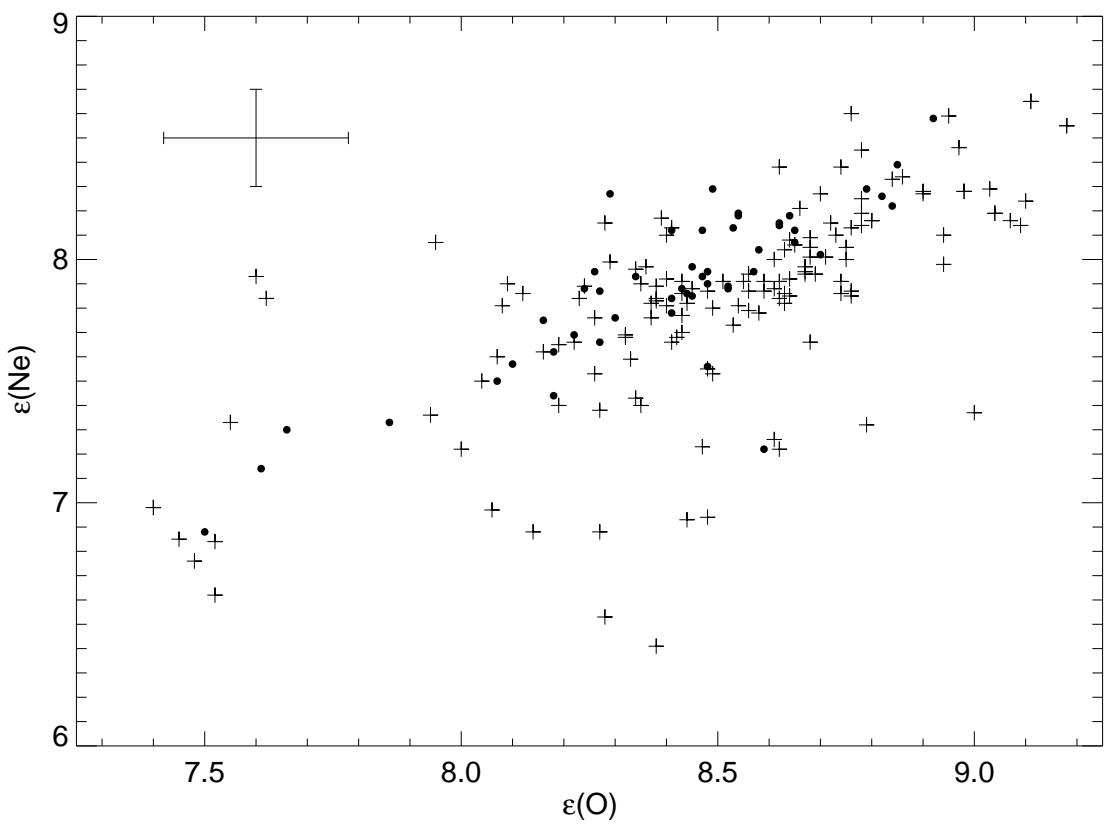

Figura 3.18: Correlação entre as abundâncias de neônio e oxigênio. 
Capítulo 4

\section{Distâncias estatísticas e abundâncias químicas}

O fato das estrelas na seqüência principal apresentarem uma relação bem definida entre a luminosidade e o tipo espectral permite a utilização da paralaxe espectroscópica como uma ferramenta para determinar distâncias na Galáxia. Porém, tratando-se de NPs, suas estrelas centrais apresentam brilho superficial baixo e em muitos casos não podem ser observadas. Além disto, enquanto que durante a seqüência principal a posição das estrelas no diagrama HR não varia muito, as estrelas centrais das NPs estão sujeitas a grandes mudanças em suas temperaturas e luminosidades durante o curto tempo de vida delas. Apesar de suas massas não mudarem significativamente, suas abundâncias superficiais sofrem mudanças devido à queima nuclear. Como resultado, qualquer derivação de distâncias a partir das propriedades estelares é necessariamente dependente de modelo.

Exceto por alguns casos de NPs próximas onde é possível empregar o método de paralaxe trigonométrica, ou em casos onde há uma companheira binária na seqüência principal, a maior parte das distâncias das NPs tem que ser estimadas através das propriedades nebulares. Fazendo-se certas hipóteses sobre a estrutura nebular, as distâncias podem ser derivadas medindo-se os fluxos, tamanhos angulares, densidades eletrônica, e assim por diante. Estes métodos são coletivamente chamados de distâncias estatísticas.

Uma escala de distância bem determinada para as NPs faz-se necessária para a investigação da distribuição espacial das NPs na Galáxia e, por conseqüência, a distribuição dos elementos químicos ejetados pela estrela progenitora. Infelizmente, após muitos anos de esforços, as distâncias das NPs permanecem controversas.

Neste capítulo descrevemos algumas escalas de distância utilizadas no presente trabalho, baseadas no fluxo em rádio e tamanho angular óptico. 


\subsection{Escala de distância de Shklovsky}

O método mais utilizado para a determinação de distâncias é o método de Shklovsky (ver por exemplo Gurzadyan, 1997). Neste método, Shklovsky assume que todas as nebulosas planetárias possuem a mesma massa, e a distância é obtida através da observação do fluxo nebular (por exemplo o fluxo $H_{\beta}$ ) e o tamanho angular.

A massa ionizada da nebulosa planetária é relacionada à densidade eletrônica da seguinte maneira (Kwok, 2000)

$$
M_{i}=\frac{4 \pi}{3} n_{e} \mu_{e} m_{H} \epsilon R^{3},
$$

onde $\mu_{e}$ é o peso molecular médio por elétron e $\epsilon$ é o fator de preenchimento, introduzido por Osterbrock e Flather (1959) para especificar qual a fração do volume nebular é preenchido por gás ionizado. Para emissão livre-livre, assumindo uma distribuição de velocidades maxwelliana dos elétrons na nebulosa, a densidade eletrônica está relacionada com o fluxo em $5 \mathrm{GHz}$ por (Kwok, 2000)

$$
\left.n_{e}=4.8 \times 10^{3}\left[F_{5 G H z}(\mathrm{mJy})\right]^{1 / 2} \epsilon^{-1 / 2}[\theta(\operatorname{arcsec})]^{-3 / 2}[D(\mathrm{kpc})]\right)^{-1 / 2} \mathrm{~cm}^{-3},
$$

sendo $\theta=R_{i} / D$ o raio angular. Substituindo a equação 4.2 na equação 4.1 , temos

$$
M_{i}=7 \times 10^{-5}\left[F_{5 G H z}(\mathrm{mJy})\right]^{1 / 2} \epsilon^{1 / 2}[\theta(\operatorname{arcsec})]^{3 / 2}[D(\mathrm{kpc})]^{5 / 2} M_{\odot} .
$$

Portanto, a distância pode ser determinada conhecendo-se o fluxo e o tamanho angular:

$$
D=46\left[F_{5 G H z}(\mathrm{mJy})\right]^{-1 / 5} \epsilon^{-1 / 5}[\theta(\operatorname{arcsec})]^{-3 / 5}\left(M_{i} / M_{\odot}\right)^{2 / 5} \mathrm{kpc} .
$$

Tipicamente a massa ionizada e o fator de preenchimento das NPs são (Boffi e Stanghellini, 1994) $M_{i}=0.2 M_{\odot}$ e $\epsilon=0.3$, respectivamente.

Na seção 2.1 do capítulo 2 foi dito que excluindo as NPs com diâmetro angular óptico maior que 12" e fluxo em 5 GHz acima de 100 mJy, excluem-se as NPs que estão na direção do bojo, porém localizadas na vizinhança solar. Se adotarmos esses valores para o fluxo e o diâmetro angular, a equação 4.4 fornece uma distância de aproximadamente 4 kpc como um limite inferior para os objetos que possuem estas características.

Eisenhauer et al. (2003) a partir de observações astrométricas e espectroscópicas de estrelas orbitando o buraco negro central da Galáxia, determinaram a distância do Sol ao centro da Galáxia como sendo $R_{0}=(7.94 \pm 0.42) \mathrm{kpc}$. Outros estudos suportam esta 
distância de $\sim 8$ kpc como por exemplo Reid (1993). Alguns outros estudos indicam uma distância menor tal como Nishiyama et al. (2006). Como as observações sugerem uma distância mais curta que a adotada pela IAU de $8.5 \mathrm{kpc}$, optamos neste trabalho por usar uma distância de 8 kpc do Sol ao centro da Galáxia.

Estes resultados indicam que, com o presente método de seleção, são excluídas as NPs cuja distância ao centro Galáctico for maior que 4 kpc. Segundo discutido por Stasińska et al. (1991), estes critérios devem eliminar cerca de 90 a 95\% das NPs que estão na direção do bojo, porém próximas ao Sol.

\subsection{Escala de distância de Maciel e Pottasch}

O método de Shklovsky, como discutido anteriormente, postula que a massa do gás ionizado na nebulosa é constante, e igual a $0.2 M_{\odot}$. Tal hipótese é a maior fonte de erro nas distâncias. Maciel e Pottasch (1980) (aqui referido como MP80) descobriram um método indireto para determinar a distância através da derivação de uma relação envolvendo a massa e outras propriedades físicas da nebulosa.

A distância obtida por Shklovsky é essencialmente dada por

$$
d_{0}=\text { constante } M_{0}^{2 / 5}(\theta / \operatorname{arcsec})^{-3 / 5}\left[F_{5 G H z}(\mathrm{mJy})\right]^{-1 / 5},
$$

onde $M_{0}=0.16 M_{\odot}$.

Assumindo um modelo esférico de nebulosa planetária contendo hidrogênio e hélio, a massa ionizada pode ser escrita como

$$
M=\frac{4}{3} \pi R^{3} \epsilon m_{H} N_{e} \frac{1+4 y}{1+x y}
$$

onde $\mathrm{R}$ é o raio ionizado, $\epsilon$ é o fator de preenchimento, $y$ é a abundância de hélio em número, e $x=\left[N\left(H e^{+}\right)+2 N\left(H e^{++}\right)\right] /\left[N\left(H e^{+}\right)+N\left(H e^{++}\right)\right]$.

Como esta equação sugere, deve existir algum tipo de relação entre a massa e o raio. MP80 buscaram obter esta relação empiricamente, encontrando uma correspondência do tipo

$$
M\left(M_{\odot}\right)=a R(\mathrm{pc})+b
$$

com $a=1.225$ e b=-0.0123. Esta equação é uma aproximação de primeira ordem, mas é melhor que a aproximação de ordem zero que Shklovsky utilizou em seu método. Portanto, 
se a massa ionizada não for considerada constante, as distâncias calculadas pelo método de MP80 são dadas por

$$
d=d_{0}\left(M / M_{0}\right)^{2 / 5}
$$

Considerando as equações $4.7,4.8$, juntamente com $R=\theta d$, é possível eliminar a massa, o que torna a distância uma função apenas de parâmetros que podem ser determinados. Este método foi aplicado nas medidas de fluxo em $5 \mathrm{GHz}$ de NPs austrais obtidos por Milne e Aller (1975), e Milne (1979), resultando em 202 distâncias. Estas distâncias podem ser encontradas em Maciel e Pottasch (1980). Um outro catálogo baseado neste mesmo método foi publicado por Maciel (1984), contendo 468 NPs com distâncias determinadas. No presente trabalho utilizamos este catálogo para estudar a distribuição química de nebulosas planetárias na conexão bojo-disco.

Inicialmente aplicamos o método descrito no capítulo 2, seção 2.1 para excluir as NPs que não estão na direção do bojo, e aquelas que estão na direção do bojo, porém localizadas na vizinhança solar. Na figura 4.1 são mostrados os histogramas da distribuição de NPs em função da distância heliocêntrica para diferentes campos de visão na direção do centro Galáctico.

O gráfico superior à esquerda indica um campo de 50 graus em longitude galáctica por 20 graus em latitude galáctica. A média do ajuste gaussiano é $3.2 \pm 0.1 \mathrm{kpc}$ e a largura de $3.5 \pm 0.2 \mathrm{kpc}$. Diminuindo o campo de visão, encontra-se a distribuição mostrada no gráfico superior à direita, com um campo de 20 graus em longitude e 20 graus em latitude. O ajuste fornece uma média de $3.23 \pm 0.09 \mathrm{kpc}$ e uma largura de $3.3 \pm 0.2 \mathrm{kpc}$. Diminuindo ainda mais o campo, tem-se a distribuição mostrada no gráfico inferior, com um campo de 10 graus de longitude por 10 graus de latitude. A média e a largura da gaussiana ajustada são, respectivamente, $2.7 \pm 0.2 \mathrm{kpc}$ e $3.2 \pm 0.2 \mathrm{kpc}$. Observe que a distância média diminui com a diminuição do campo de visão. Este fato contraria o que se espera, pois diminuindo o campo de visão, em princípio, excluem-se ainda mais os objetos do disco, limitando a amostra aos objetos do bojo. Isto faria com que a distância média da distribuição dos objetos do bojo aumentasse. Contudo, a extinção pela poeira no plano do disco faz com que os objetos do bojo sejam de difícil observação próximos a este plano. De fato, as NPs do bojo Galáctico são melhor observadas na região do bojo acima e abaixo do disco, como pode ser visto na figura 4.2, que mostra a distribuição dos objetos da amostra de Maciel 

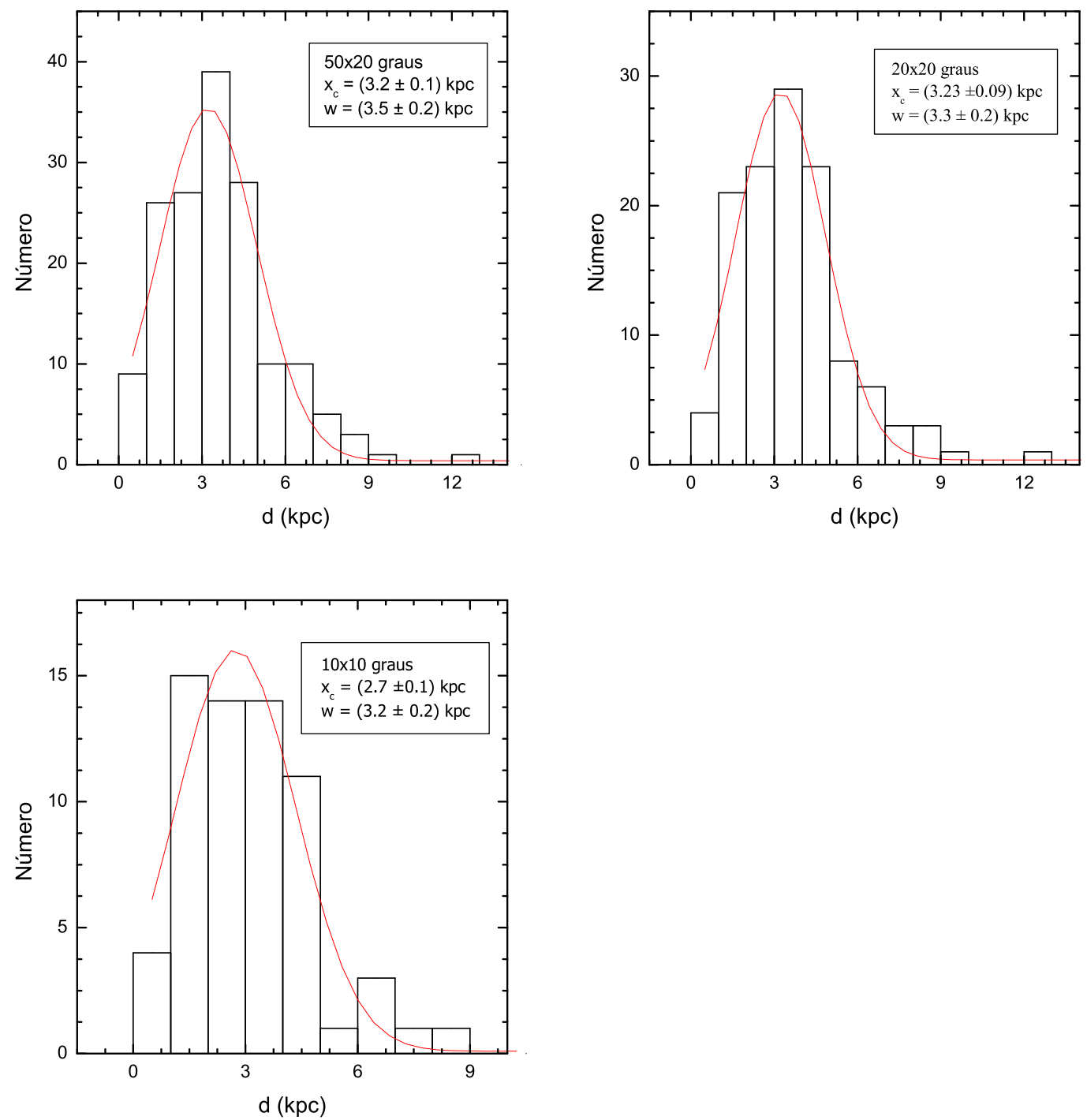

Figura 4.1: Histograma da distância de MP80 para as NPs selecionadas através do fluxo em $5 \mathrm{GHz}$ e diâmetro angular óptico.

(1984) com coordenadas galácticas compreendendo o intervalo $|\ell| \leq 25$ graus e $|b| \leq 10$ graus.

A extinção pela poeira do disco faz com que a amostra seja dividida em duas faixas ao redor do eixo com $b=0$. Portanto, ao diminuir a janela de observação, restringe-se a amostra a esta região de alta extinção e, devido ao efeito de seleção causado pela extinção, observam-se os objetos mais próximos.

No catálogo publicado por Maciel (1984), existem vários objetos que possuem raio fora do intervalo $0.01-0.4$ pc estabelecido por MP80 e objetos para os quais o fluxo e/ou 


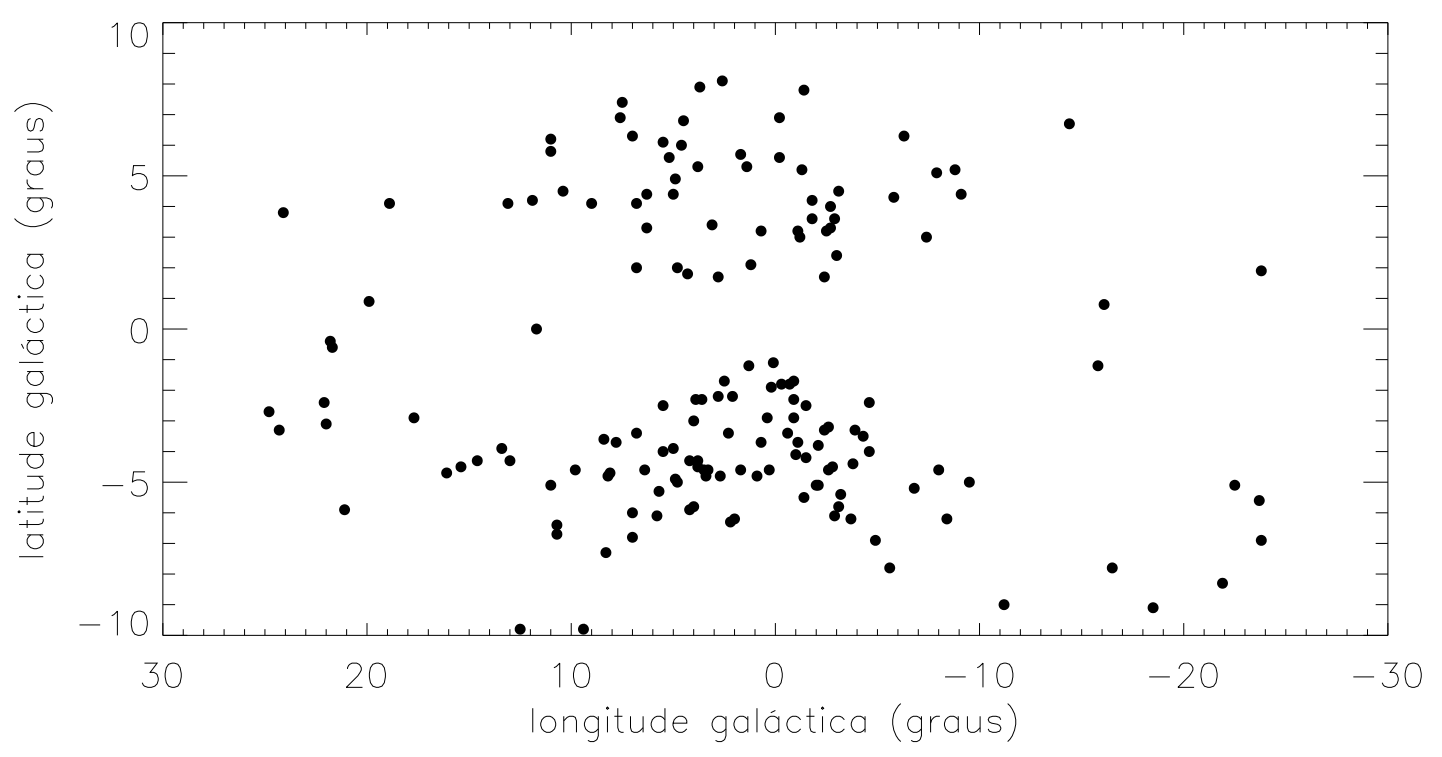

Figura 4.2: Distribuição no plano do céu dos objetos da amostra de Maciel (1984). Os eixos mostram as coordenadas galácticas.

o tamanho angular estão perto ou abaixo do limite de deteç̧ão. Estas NPs possuem distâncias com uma marca do tipo LL (lower limit) e UL (upper limit). Para melhorar a análise, foram excluídas as NPs que possuem distâncias dadas por um limite inferior, resultando nos gráficos da figura 4.3.
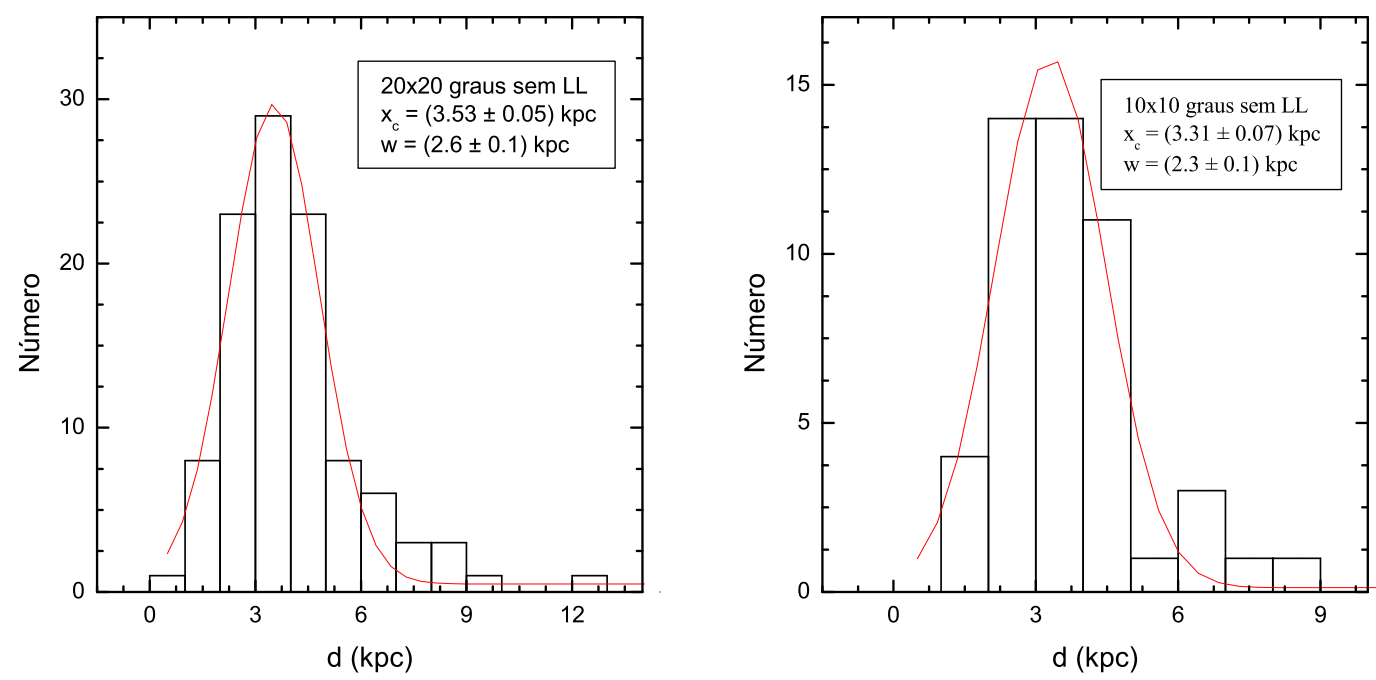

Figura 4.3: Histograma da amostra selecionada do catálogo de Maciel (1984) excluídas as NPs cujas distâncias são um limite inferior.

Nesta figura, o histograma foi deslocado para a direita, aumentando a média e dimi- 
nuindo a largura do ajuste gaussiano. Em um gráfico como este, espera-se uma distribuição gaussiana com média igual à distância do centro Galáctico $(8 \mathrm{kpc})$. Porém não é o que mostram os histogramas da figura 4.3, pois as distâncias encontradas estão em torno de 3 kpc. Como os objetos foram selecionados a partir do fluxo em rádio e diâmetro angular óptico, o que excluiria os objetos do disco, então esta só pode ser uma característica desta escala. Isto mostra que a escala de distância de MP80 é uma escala curta, ou seja, as distâncias obtidas por este método são subestimadas.
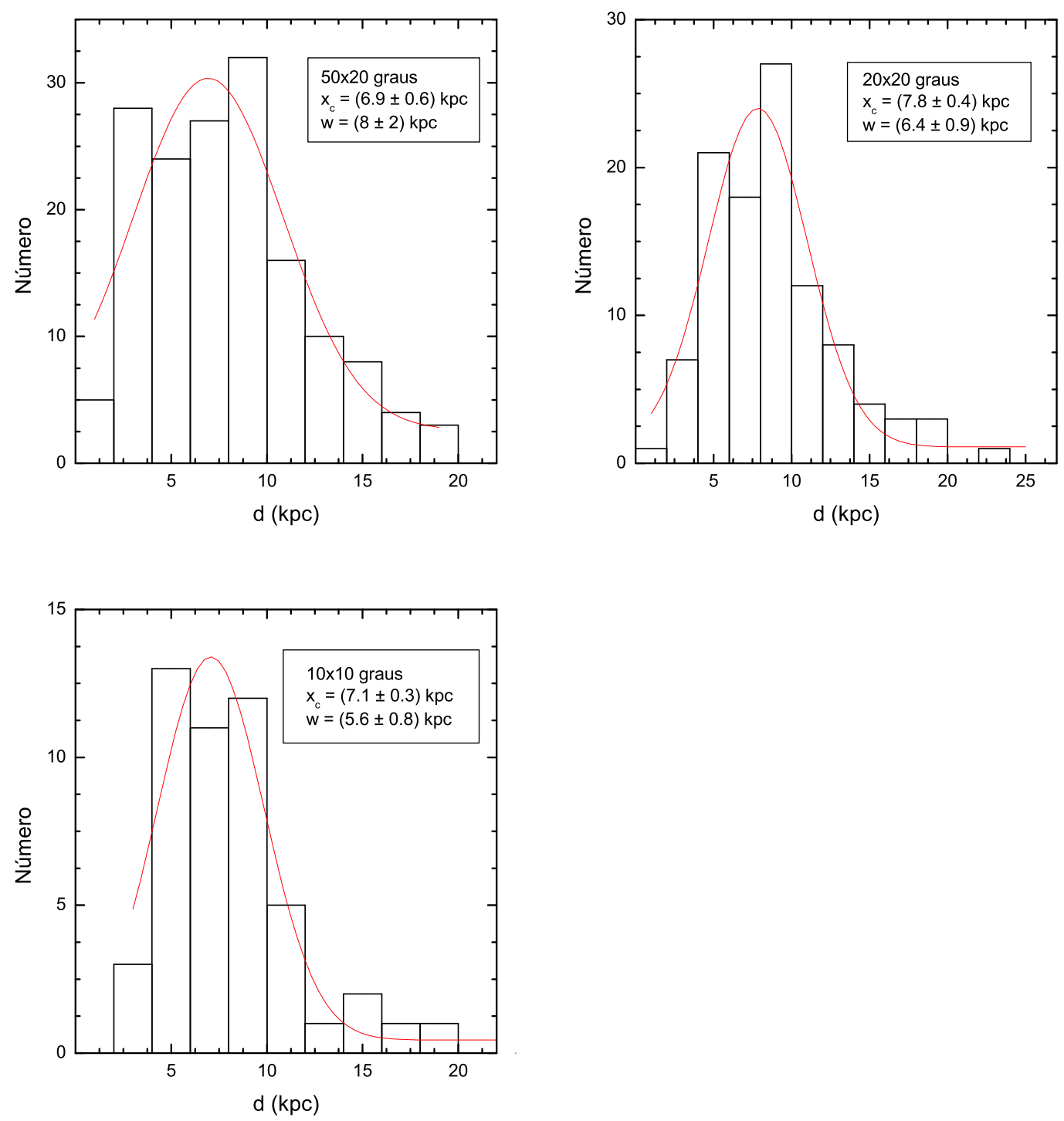

Figura 4.4: Distribuição das distâncias de MP80 multiplicadas por um fator de escala para reproduzir a distância média do bojo. 
Para adequar a escala de MP80 as outras escalas, multiplicamos as distâncias de MP80 por um fator de escala, com o objetivo de obter uma distribuição com média igual distância do bojo. Tal fator de escala foi obtido a partir da razão das distâncias médias da escala de Zhang (1995) e de MP80. O fator de escala encontrado por este método é 2.25. A distribuição das distâncias de MP80 escalonadas pode ser vista na figura 4.4. Uma gaussiana com média $6.9 \pm 0.2 \mathrm{kpc}$ e desvio padrão $(0.8 \pm 0.2) \times 10^{-1} \mathrm{kpc}$ é mostrada no gráfico superior à esquerda da figura 4.4, que possui os objetos com coordenadas $|\ell| \leq 25$ graus e $|b| \leq 10$ graus. O gráfico superior à direita mostra uma gaussiana com média $7.8 \pm 0.4$ kpc e desvio padrão $6.4 \pm 0.9 \mathrm{kpc}$, para os objetos com $|\ell| \leq 10$ e $|b| \leq 10$. Os objetos com $|\ell| \leq 5$ graus e $|b| \leq 5$ graus possuem uma distribuição com ajuste gaussiano com média $7.1 \pm 0.3 \mathrm{kpc}$ e desvio padrão $5.6 \pm 0.8 \mathrm{kpc}$, como pode ser visto no gráfico inferior da figura. A introdução do fator de escala aumentou a largura das gaussianas ajustadas, mas também deslocou a média das gaussianas para um valor próximo à distância do centro Galáctico.

\subsection{Escala de distância de Zhang}

$\mathrm{Na}$ escala de distância estatística de Shklovsky assume-se que todas as nebulosas planetárias têm a mesma massa e são opticamente finas a radiação ionizante. Este cenário não é muito realista, pois as estrelas centrais das NPs evoluem rapidamente com o tempo, e a nebulosa é ativa tanto radiativamente quanto dinamicamente (Kwok, 1994). Além disso, as NPs são o produto da evolução de estrelas que compreendem um grande intervalo de massas $\left(0.8\right.$ a $\left.8 M_{\odot}\right)$.

Somando-se ao problema das hipóteses envolvidas na determinação da distância, as escalas de distância tradicionais também sofrem com a falta de calibradores adequados. As distâncias estatísticas de centenas de NPs foram freqüentemente computadas com base em apenas um pequeno número (10 ou mais) de NPs com distâncias bem determinadas até então, ver por exemplo Daub (1982); Maciel e Pottasch (1980); Cahn, Kaler e Stanghellini (1992). Atualmente a situação não é muito diferente, com aproximadamente 30 NPs com distâncias determinadas através da paralaxe ou observações diretas das estrelas centrais (Hajian, 2006). Motivado por estes problemas, Zhang (1995) propôs uma nova escala de distância baseada na correlação entre a massa ionizada e o raio e na correlação entre a 
temperatura de brilho superficial no contínuo de rádio e o raio nebular.

Dada a distância $D$ e o tamanho angular $\theta$ da uma nebulosa planetária, seu raio é encontrado através da relação

$$
R=\frac{D \theta(\operatorname{arcsec})}{206.265}
$$

Para uma nebulosa opticamente fina em $5 \mathrm{GHz}$, a massa ionizada pode ser escrita a partir da equação 4.4

$$
M_{i}=\frac{1}{46}\left[F_{5 G H z}(\mathrm{mJy})\right]^{1 / 2} \epsilon^{1 / 2}[\theta(\operatorname{arcsec})]^{3 / 2}[D(\mathrm{kpc})]^{5 / 2} M_{\odot} .
$$

Zhang observou a seguinte correlação entre a massa ionizada e o raio da nebulosa

$$
\log M_{i}=1.3077( \pm 0.07) \log R+0.3644( \pm 0.09)
$$

Substituindo as equações 4.9 e 4.10 na relação empírica da equação 4.11 e assumindo um fator de preenchimento $\epsilon=0.6$, Zhang obteve a seguinte relação

$$
\log D_{M i}=1.458-0.161 \log \theta-0.419 \log F_{5 G H z}
$$

onde $D_{M i}$ é a distância obtida através da relação massa-raio em kpc.

Para obter uma melhor calibração de sua escala de distância, Zhang investigou a correlação entre a temperatura de brilho $\left(\mathrm{T}_{b}\right)$ e o raio das NPs, encontrando a relação empírica

$$
\log R=-0.32( \pm 0.02) \log T_{b}-0.56( \pm 0.05)
$$

A escala de distância $D_{T_{b}}$ obtida da relação $T_{b}$ vs. $R$ é derivada substituindo-se a equação 4.13 na equação 4.9, resultando

$$
\log D_{T_{b}}=1.748-0.31 \log T_{b}-\log \theta .
$$

A escala de distância final adotada por Zhang foi a média dos logaritmos das distâncias obtidas pelas relações massa-raio e temperatura de brilho-raio

$$
\log D_{f}=\left(\log D_{M i}+\log D_{T_{b}}\right) / 2
$$

Adotamos esta distância final para estudar a distribuição das abundâncias químicas das NPs na conexão bojo-disco. Para realizar tal estudo, foram selecionadas as NPs do catálogo de Zhang (1995) com base nos critérios definidos na seção 2.1. Tais critérios resultaram em uma amostra com distribuição no plano do céu dada pela figura 4.5. 


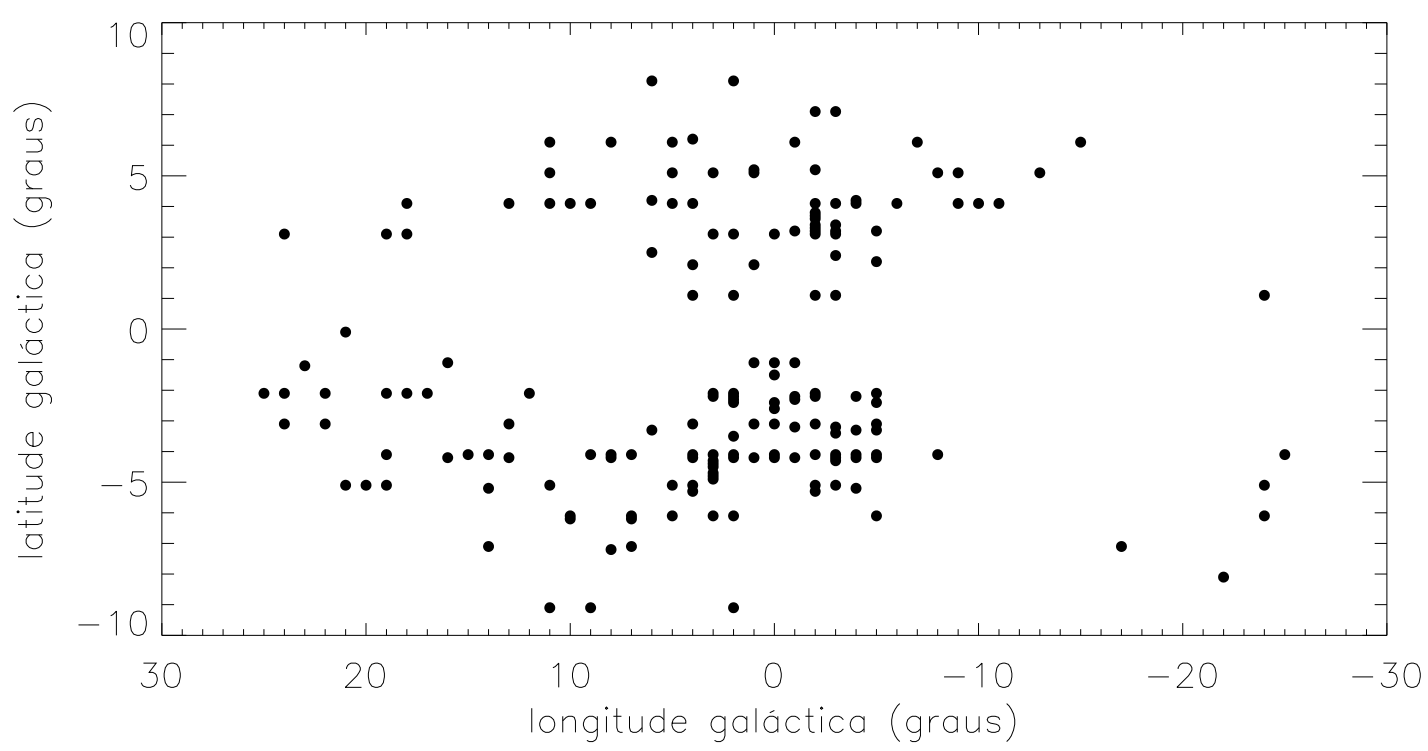

Figura 4.5: Distribuição no plano do céu dos objetos selecionados da amostra de Zhang (1995). São mostradas as NPs com $|\ell| \leq 25$ graus e $|b| \leq 10$ graus.

Novamente é possível notar a influência da extinção pela poeira no plano do disco. Com relação à distância heliocêntrica, obteve-se a distribuição de NPs mostrada na figura 4.6. No gráfico superior à esquerda está representado a distribuição dos objetos para um campo de 50x20 graus. O gráfico também mostra um ajuste gaussiano com média $7.2 \pm 0.2 \mathrm{kpc}$ e desvio padrão $4.3 \pm 0.5 \mathrm{kpc}$. O gráfico superior à direita mostra a distribuição das NPs em função da distância heliocêntrica para um campo de 20x20 graus. A gaussiana ajustada possui média igual a $7.5 \pm 0.2 \mathrm{kpc}$ e largura igual a $4.1 \pm 0.4 \mathrm{kpc}$. Para um campo de 10x10 graus temos o histograma mostrado no gráfico inferior. O ajuste gaussiano fornece uma média e desvio padrão igual a $7.6 \pm 0.1 \mathrm{kpc}$ e $4.1 \pm 0.4 \mathrm{kpc}$, respectivamente. A média e o desvio padrão para cada campo de visão não alteram-se significativamente, mostrando que a amostra selecionada representa a população do bojo Galáctico.

Os histogramas da figura 4.6 são bem representados pela gaussiana ajustada, a qual é mais larga do que os desvio padrão esperado de $1.2 \mathrm{kpc}$ para o bojo. Como discutido por Zhang (1995), esta dispersão é uma convolução da provável distribuição gaussiana do bojo com uma gaussiana representando o espalhamento extra introduzido pela relação massa-raio. Mesmo com tal dispersão, esta escala de distância reproduz bem a distância do centro Galáctico dentro de um erro de $10 \%$. Isto não quer dizer que esta é a incerteza nesta escala de distância. Zhang (1995) estima uma incerteza da ordem de $28 \%$ para esta escala. 

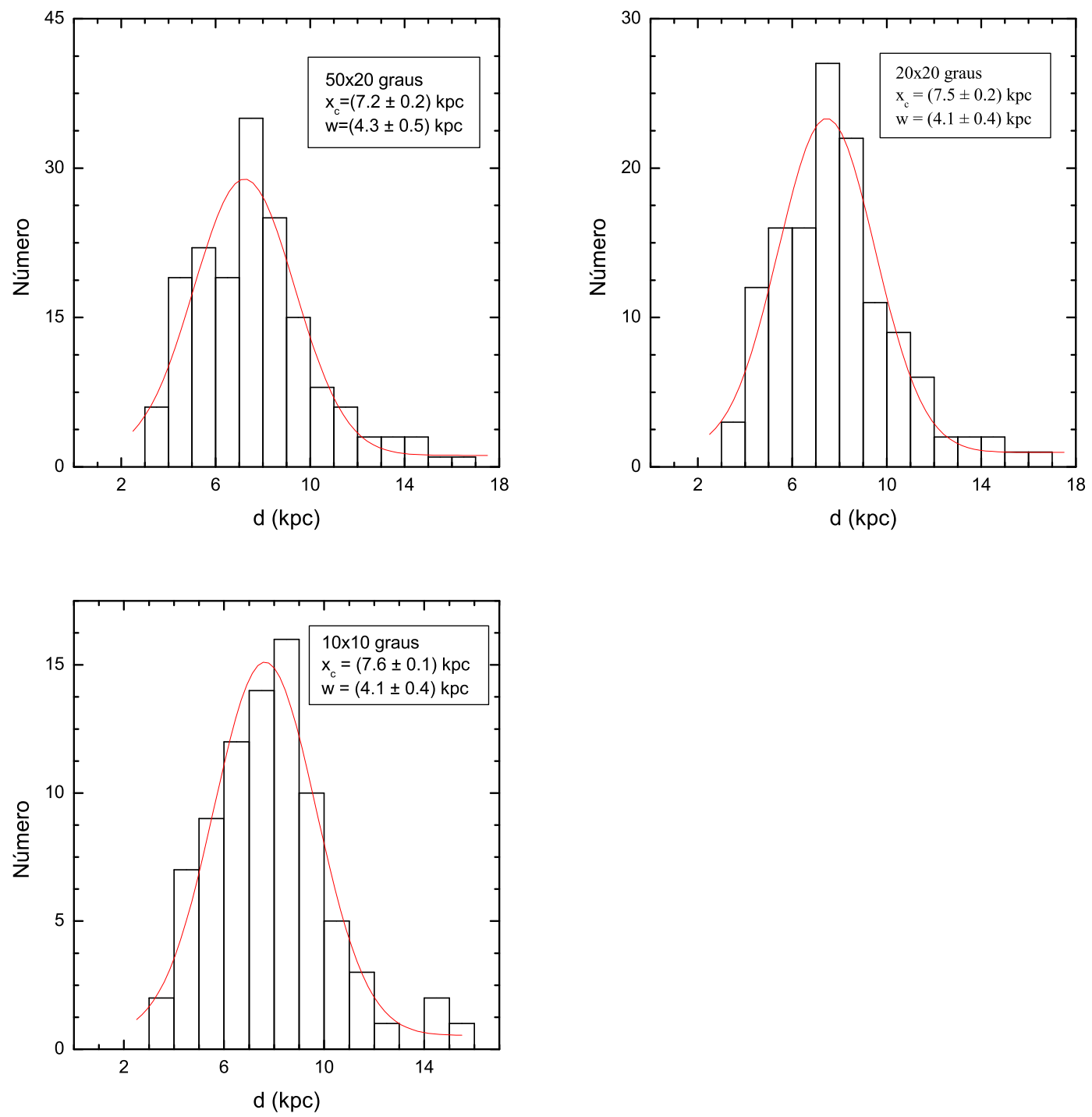

Figura 4.6: Histograma da distância heliocêntrica obtida através da escala de Zhang1995 das NPs localizadas no bojo da Galáxia. Nos gráficos são mostrados o ajuste de uma gaussiana, juntamente com os parâmetros obtidos do ajuste para cada campo de visão do bojo Galáctico.

\subsection{Escala de distância de Cahn}

A escala de distância proposta por Cahn, Kaler e Stanghellini (1992) (aqui referido como CKS92) tem como base o método de Shklovsky aplicado a um extensivo catálogo produzido por eles. Para obter tal escala, eles seguem o método de Daub (1982). Este método consiste em definir uma massa

$$
\mu=\sqrt{2.266 \times 10^{-21} d^{5} \theta^{3} F_{5 G H z}}
$$


onde $d$ é a distância em pc, $\theta$ é o raio angular em segundos de arco e $F_{5 G H z}$ é o fluxo em rádio em 5 GHz. Eles definem ainda um parâmetro de espessura óptica $T$ dado por

$$
T=\log \frac{4 \theta^{2}}{F_{5 G H z}} .
$$

A distância é encontrada através de uma relação entre o raio $R$, a massa $M$ e o parâmetro $T:$

$$
\log R=\frac{M}{2.5}-1.306+0.2 T
$$

usando

$$
d=206265 \frac{R}{\theta}
$$

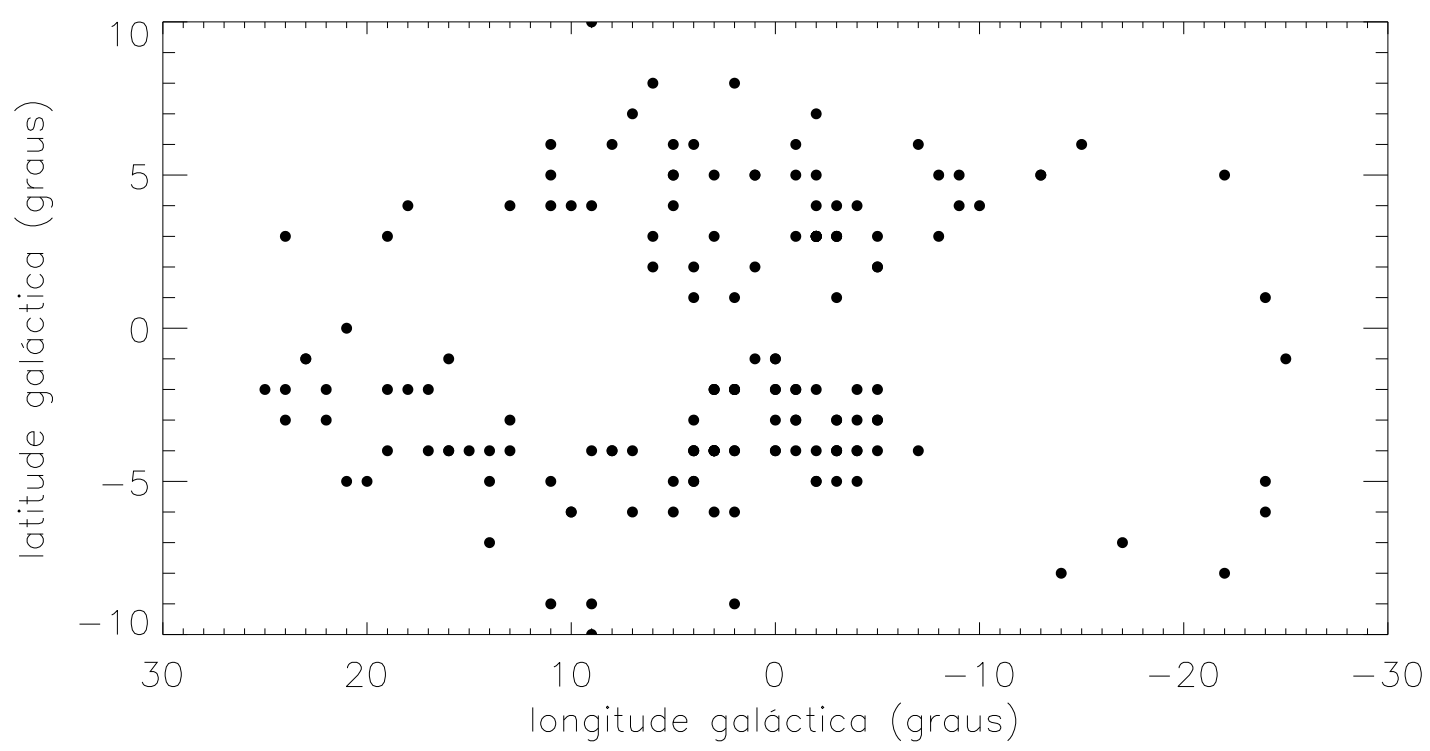

Figura 4.7: Distribuição no plano do céu dos objetos selecionados da amostra de CKS92. São mostradas as NPs com $|\ell| \leq 25$ graus e $|b| \leq 10$ graus.

A distribuição no plano do céu das NPs do catálogo de CKS92 é mostrada na figura 4.7. Os mesmos critérios descritos anteriormente foram aplicados para selecionar estes objetos. 
Na figura 4.8 são mostrados os histogramas do número de objetos em função da distância heliocêntrica em kpc para cada campo.
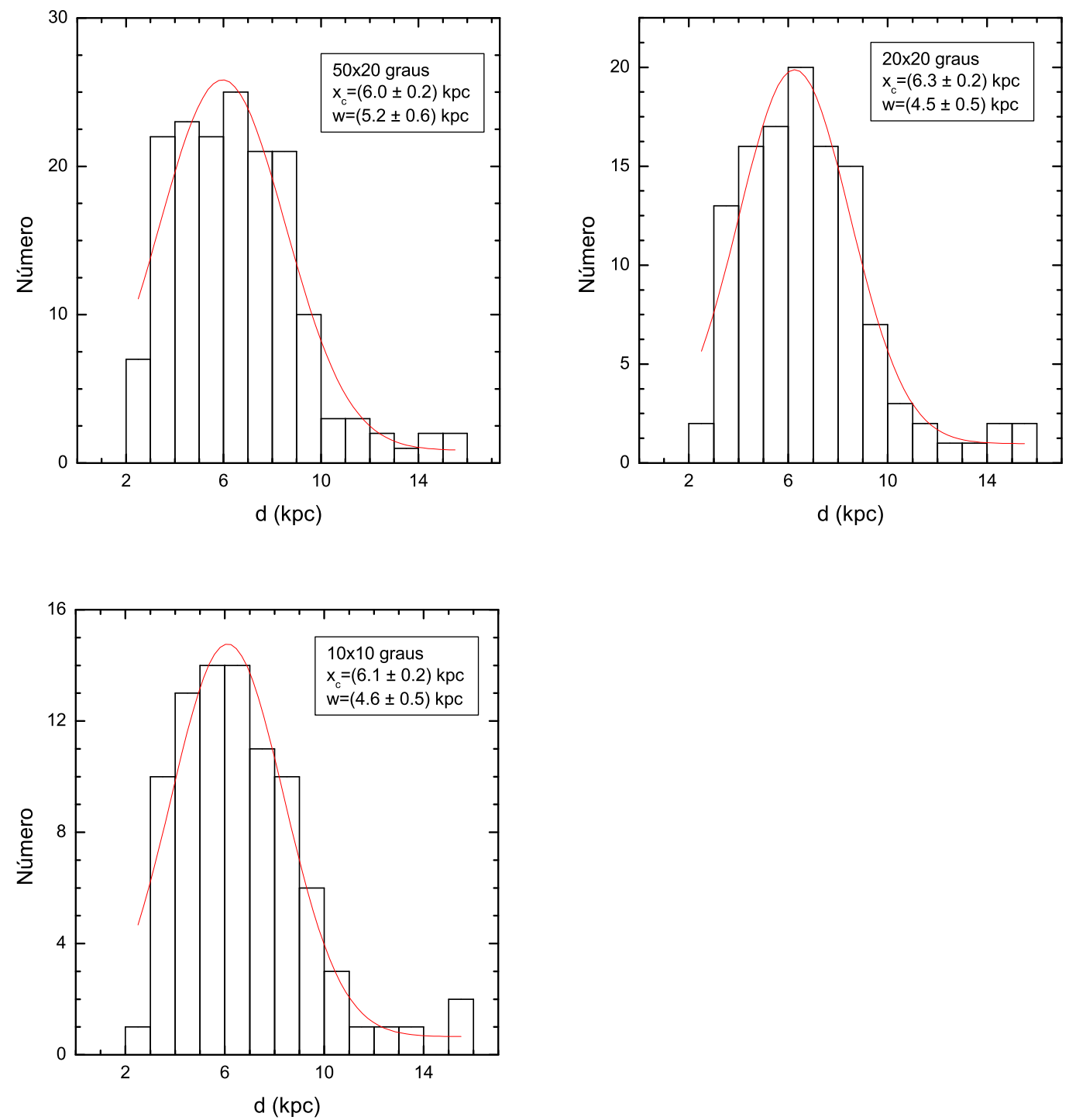

Figura 4.8: Distribuição da distância obtida através do método de CKS92. Nos gráficos também é mostrado o ajuste gaussiano para cada distribuição.

No gráfico superior à esquerda vê-se que a média da gaussiana ajustada é $6.0 \mathrm{kpc}$. Restringindo a longitude e latitude galáctica para $|\ell| \leq 10$ graus e $|b| \leq 10$ graus, tem-se que a distância média aumenta para $6.3 \mathrm{kpc}$. Diminuindo o campo para $|\ell| \leq 5$ graus e $|b| \leq 5$ graus, a distância média permanece quase inalterada $(6.1 \mathrm{kpc})$ dentro dos erros envolvidos. 
Isto mostra que boa parte dos objetos são do bojo (ou próximos), pois a medida que o campo de visão é diminuído, a média das gaussianas não muda significativamente. Esta constatação justifica utilizar a escala de CKS92 para o estudo da distribuição das abundâncias das nebulosas planetárias na conexão bojo-disco.

\subsection{Abundâncias na conexão bojo-disco}

As escalas de distâncias mencionadas anteriormente podem ser utilizadas para o estudo da distribuição das abundâncias químicas no disco interno da galáxia e no bojo. Como estas escalas de distâncias são estatísticas e, freqüentemente, são dependentes do modelo adotado ou do método usado para calibrá-las, é importante a utilização de duas ou mais escalas, a fim de comparar os resultados obtidos para as diferentes escalas. Além disto, as propriedades químicas podem variar com o campo de visão adotado, pois a amostra pode conter objetos de diferentes populações dependendo do campo de visão. Assim, nesta seção são utilizadas as três escalas de distâncias introduzidas no começo deste capítulo, as quais são as escalas de Maciel e Pottasch (1980); Cahn, Kaler e Stanghellini (1992); Zhang (1995), além dos três campos estudados anteriormente, ou seja, 50x20, 20x20, e 10x10 graus.

Nesta seção é utilizada a distância galactocêntrica ao invés da distância heliocêntrica, sendo que a conversão entre estas distâncias foi feita através da seguinte relação:

$$
R=\sqrt{R_{0}^{2}+(d \cos b)^{2}-2 R_{0} d \cos b \cos \ell},
$$

onde $d$ é a distância heliocêntrica do objeto, $R_{0}$ é a distância do Sol ao centro da galáxia (adotada como sendo 8 kpc, Reid (1993); Eisenhauer et al. (2003)), b e $\ell$ são as latitude e longitude galácticas, respectivamente.

O método implementado para estudar a distribuição de abundâncias químicas na conexão bojo-disco é similar ao empregado por Maciel, Lago e Costa (2006), que estimaram a variação temporal do gradiente radial de abundâncias químicas a partir de NPs. Basicamente, é fixada uma distância galactocêntrica e a amostra de NPs anteriormente selecionada é dividida em dois grupos. O grupo I, constituído das NPs que possuem distância ao centro galáctico menor que o limite previamente estabelecido, e o grupo II, composto das 
NPs que possuem distância galactocêntrica maior que este limite. Após esta divisão da amostra, computa-se a média das abundâncias químicas dos objetos pertencentes a cada grupo. Como não se sabe ao certo qual é a distância que separa estes grupos, de tal forma que o grupo I seja composto por objetos pertencentes ao bojo da Galáxia, e o grupo II seja formado por objetos pertencentes ao disco interno da Galáxia, varia-se esta distância que divide a amostra e calcula-se novamente as médias das abundâncias químicas das NPs de cada grupo. Portanto, repetindo-se este procedimento é possível comparar as abundâncias das NPs do grupo I com as NPs do grupo II para cada distância galactocêntrica que define a fronteira de separação dos dois grupos. A seguir são apresentados os resultados obtidos a partir deste método.

\subsubsection{Escala de Maciel}

Uma característica desta escala de distância é ser uma escala curta, característica esta que pode ser vista no gráfico 4.1. Para uma melhor comparação dos resultados obtidos com esta escala e as outras estudadas neste trabalho, foi analisada a distribuição das abundâncias químicas com a escala de MP80 escalonada.

Nos gráficos da figuras 4.9, 4.10 e 4.11, são realizadas comparações entre as abundâncias dos grupos I e II para diferentes campos de visão: 50x20, 20x20, e 10x10 graus, respectivamente. As barras de erro apresentadas são o erro padrão da média, calculada para cada média das abundâncias de cada grupo, e para cada distância galactocêntrica fixada.

No campo de 50x20 graus em média as abundâncias das NPs do grupo I são maiores que as do grupo II para os elementos alfa. Porém estas diferenças são da ordem de 0.1 dex, ou seja, menor que o erro estimado para as abundâncias. Para o nitrogênio a ordem é invertida, sendo que o grupo II apresenta média das abundâncias superior ao grupo I. Novamente a diferença é da ordem de 0.1 dex, e desta forma não se pode afirmar que há de fato uma separação entre os dois grupos. O hélio apresenta uma diferença de 0.013 em número, para distâncias galactocêntricas menores que $1 \mathrm{kpc}$, permanecendo o grupo II com médias superiores ao grupo I. Esta diferença está dentro do erro estimado para a abundância de hélio.

Estas diferenças se tornam menos claras a medida que o campo de visão é diminuído, como pode ser visto nas figuras 4.10 e 4.11 . 
A influência do fator de escala introduzido pode ser vista na figura 4.12, a qual mostra que não há uma distinção clara entre as abundâncias de cada grupo para a escala de MP80 sem o fator de escala. É provável que existam poucos objetos do bojo no catálogo de Maciel (1984), o que implicaria em se observar poucos objetos a grandes distâncias heliocêntricas e, portanto, não seriam vistas as propriedades químicas destes objetos nestes gráficos.

Portanto a escala de distância de MP80 não é uma escala de distância adequada para se estudar as propriedades químicas das NPs localizadas a grandes distâncias do Sol. 

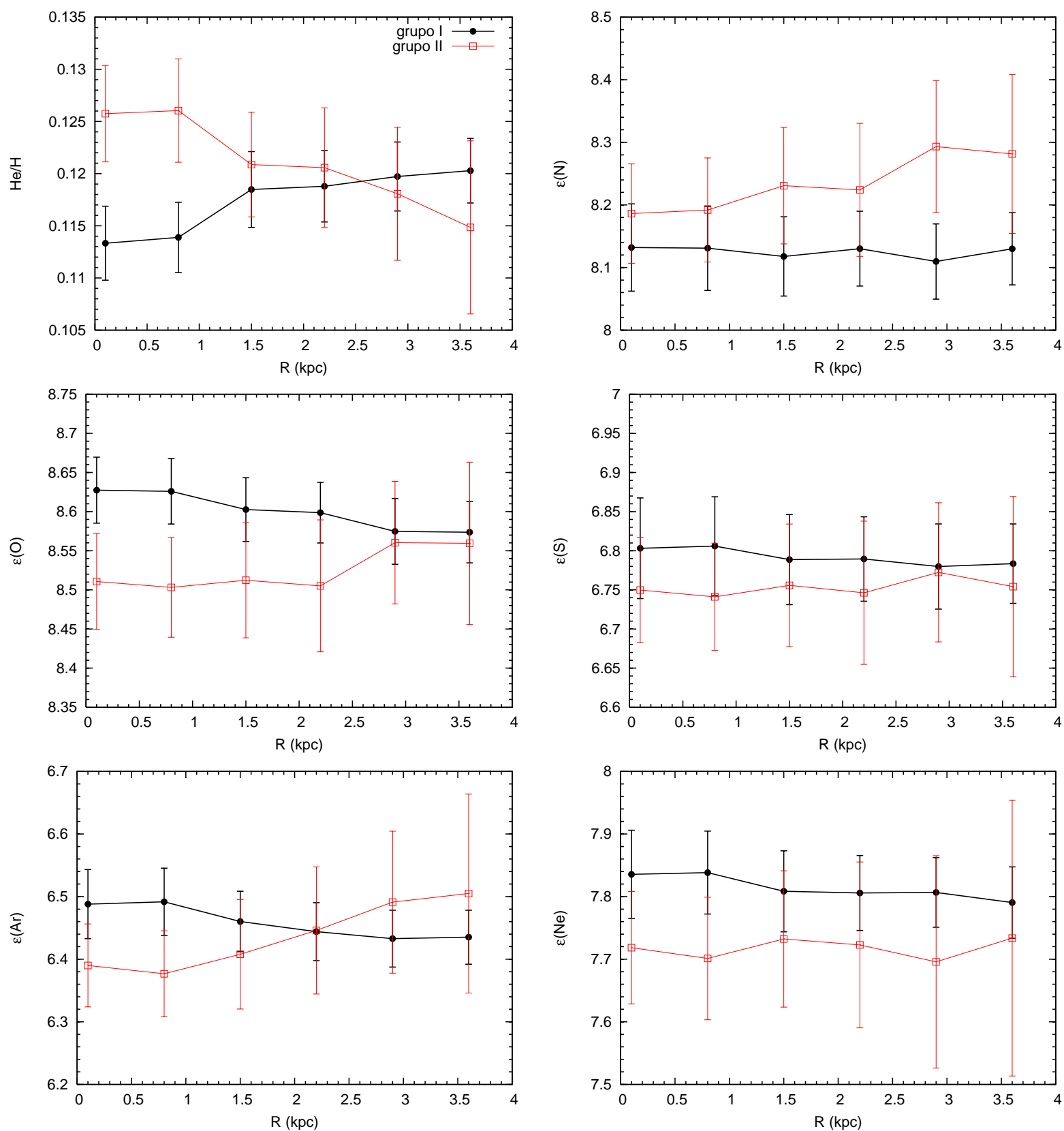

Figura 4.9: Distribuição radial das abundâncias químicas das nebulas planetárias localizadas nos primeiros kpc da Galáxia baseada na escala de distância de MP80. Um campo de visão de 50x20 graus foi utilizado. A curva preta indica a média das abundâncias das NPs do grupo I, e a curva vermelha indica a média das abundâncias das NPs do grupo II. 

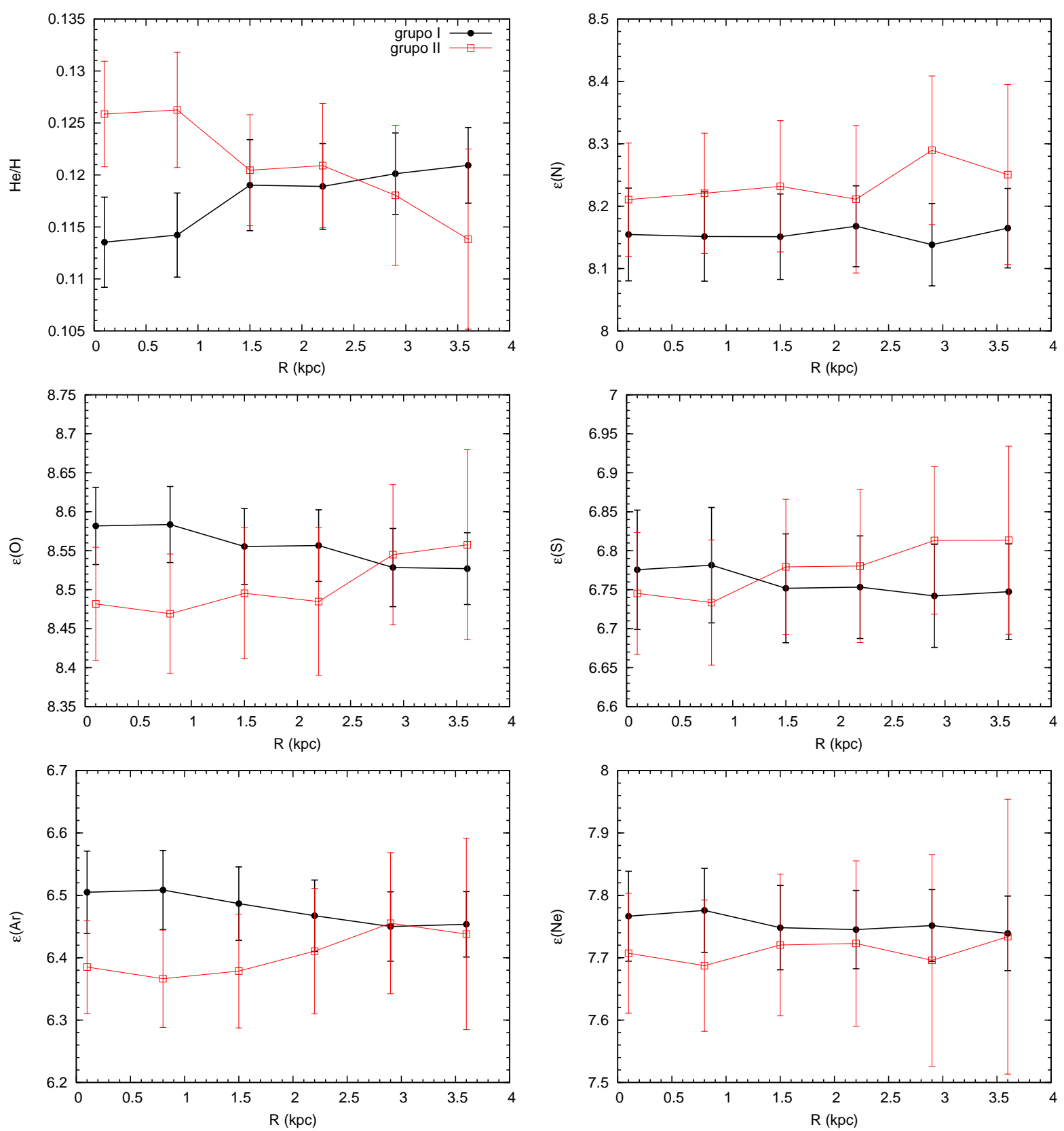

Figura 4.10: Distribuição das abundâncias para a escala de MP80 utilizando um campo de 20x20 graus. 

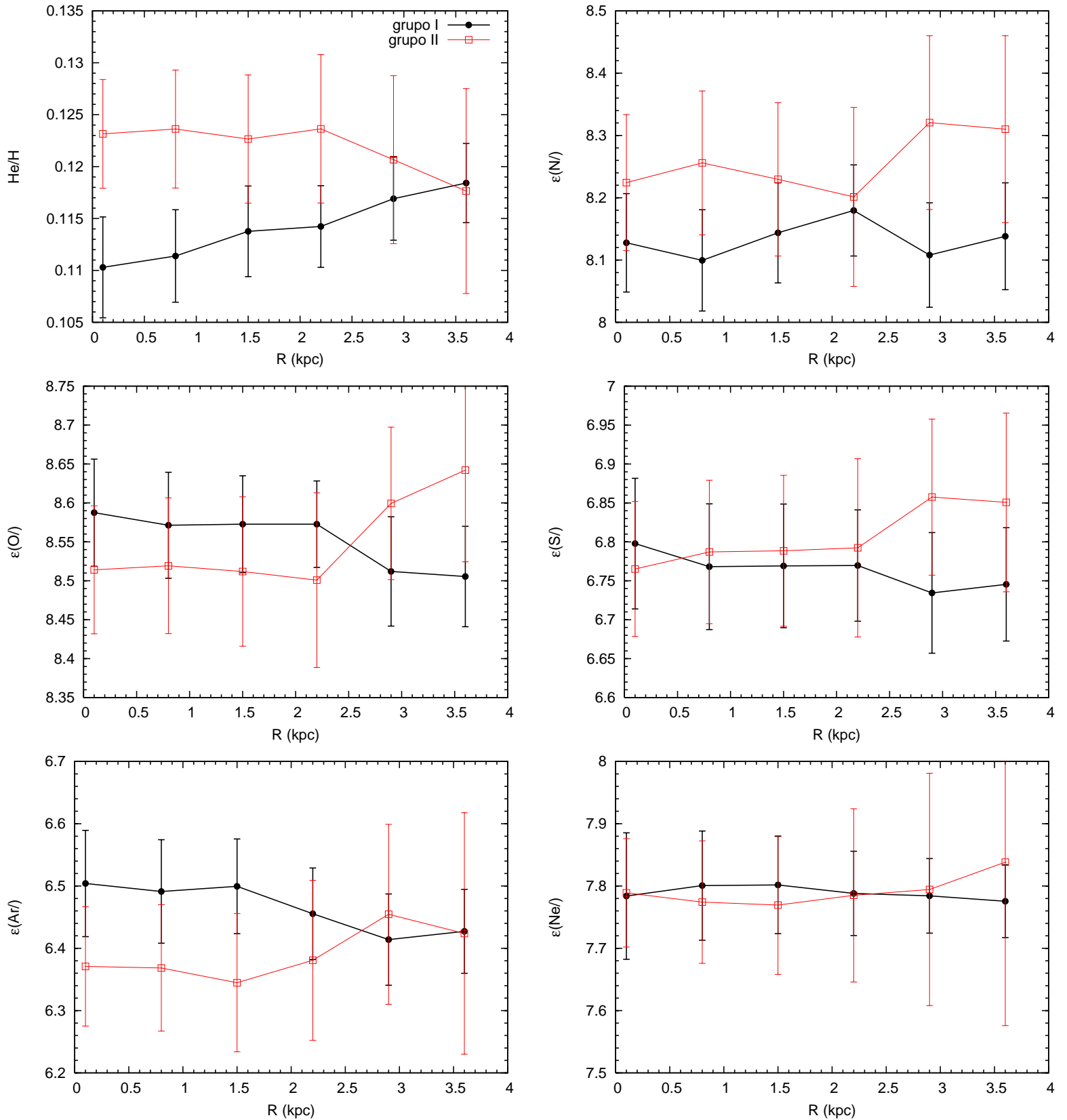

Figura 4.11: Distribuição das abundâncias para a escala de MP80 e um campo de 10x10 graus. 

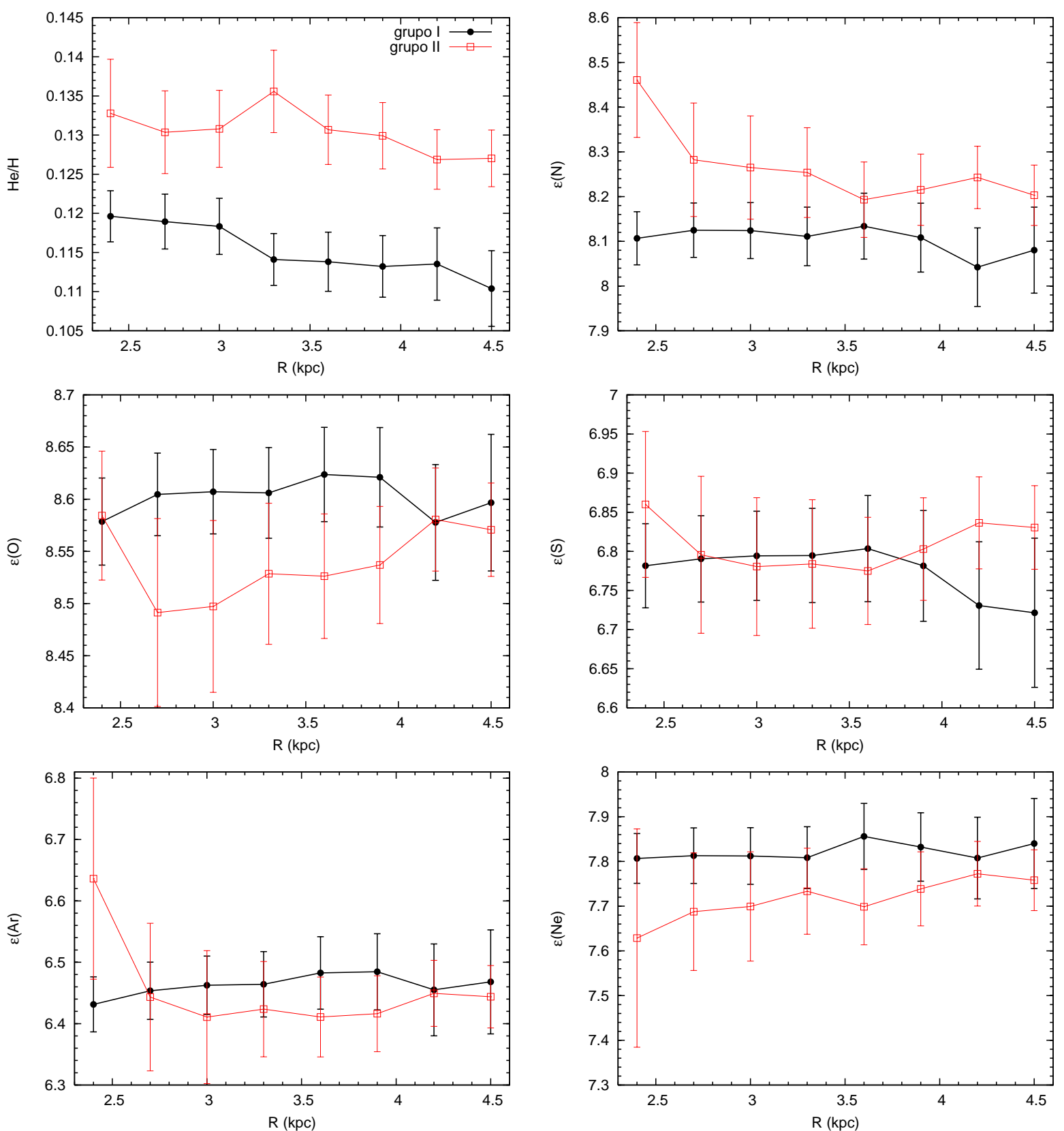

Figura 4.12: Distribuição das abundâncias para a escala de MP80 sem o fator de escala. O campo utilizado foi de 50x20 graus. 


\subsubsection{Escala de Zhang}

Na figuras 4.13, 4.14, e 4.15 são mostradas a variação das abundâncias das NPs nos primeiros $4 \mathrm{kpc}$ centrais da Galáxia, para diferentes campos de visão: 50x50, 20x20, e 10x10 graus, respectivamente. As curvas para os diferentes campos de visão são similares, mas os menores campos apresentam uma diferença entre os grupos I e II um pouco superior para os elementos alfa. O comportamento da abundância de neônio se destaca das demais, pois há uma separação entre as abundâncias dos grupos I e II, não importando onde está localizado a fronteira que divide os dois grupos.

Para os outros elementos, é possível constatar uma pequena diferença entre as médias das abundâncias químicas do grupo I e do grupo II, sendo que as NPs do grupo I apresentam uma abundância menor do que as do grupo II. Porém há várias superposições das barras de dispersão, principalmente para distâncias maiores que $2 \mathrm{kpc}$.

A abundância de hélio é maior no grupo II antes dos $3 \mathrm{kpc}$, característica que se inverte após esta distância, passando o grupo I a ter uma maior abundância média. As barras de dispersão são muito grandes e se sobrepõem nesta região, não mostrando uma separação clara. A maior separação entre os grupos corre em 0.8 kpc, sendo a diferença de 0.010 em número para o campo de 50x20 graus. Para os outros elementos a separação é sempre da ordem de 0.15 dex, exceto pelo neônio, que apresenta uma diferença de 0.20 dex. 

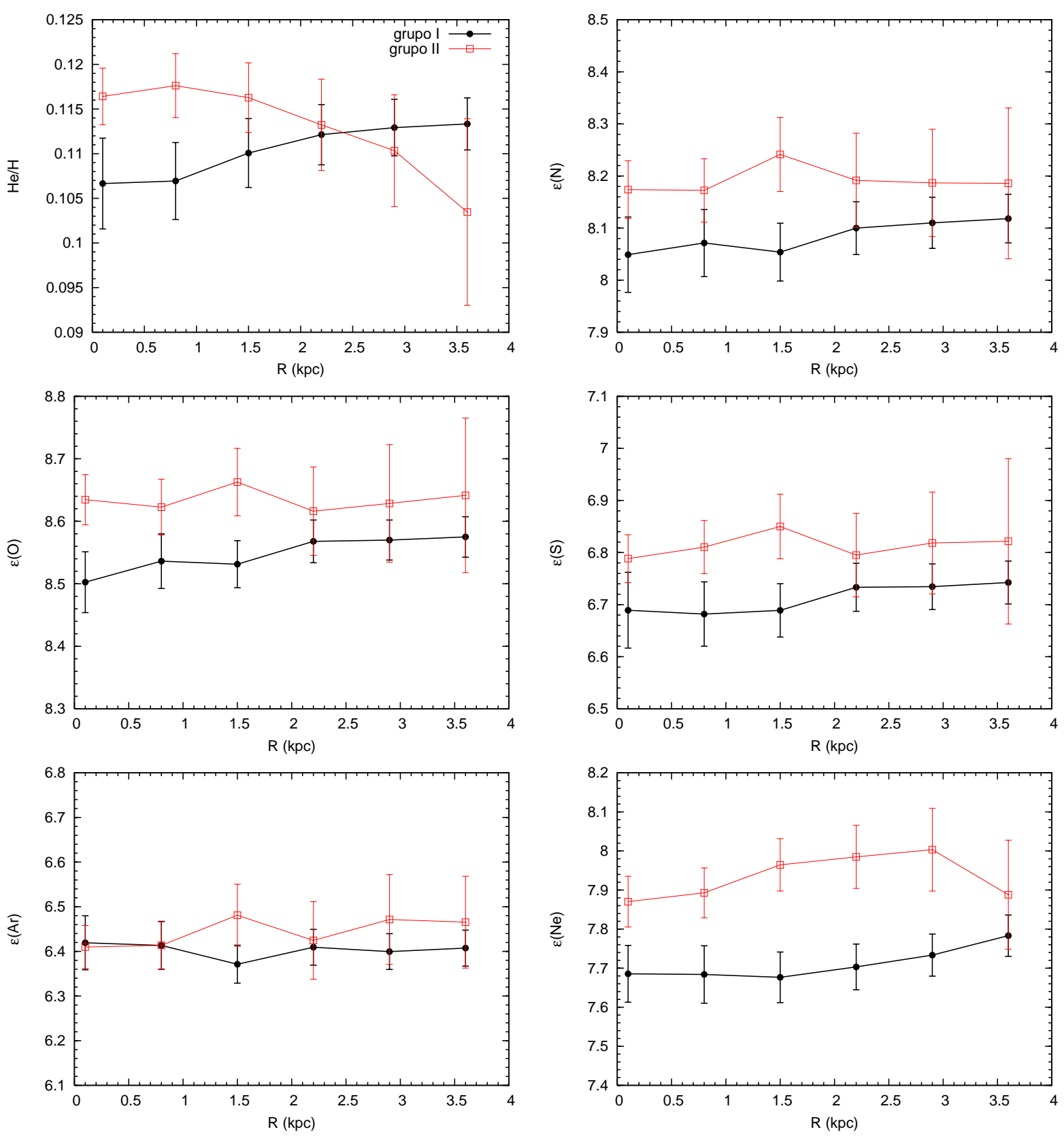

Figura 4.13: Distribuição das abundâncias dos grupos I e II em função da distância que separa os dois grupos. Foi utilizada a escala de Zhang95 com um campo de visão de 50x20 graus. 

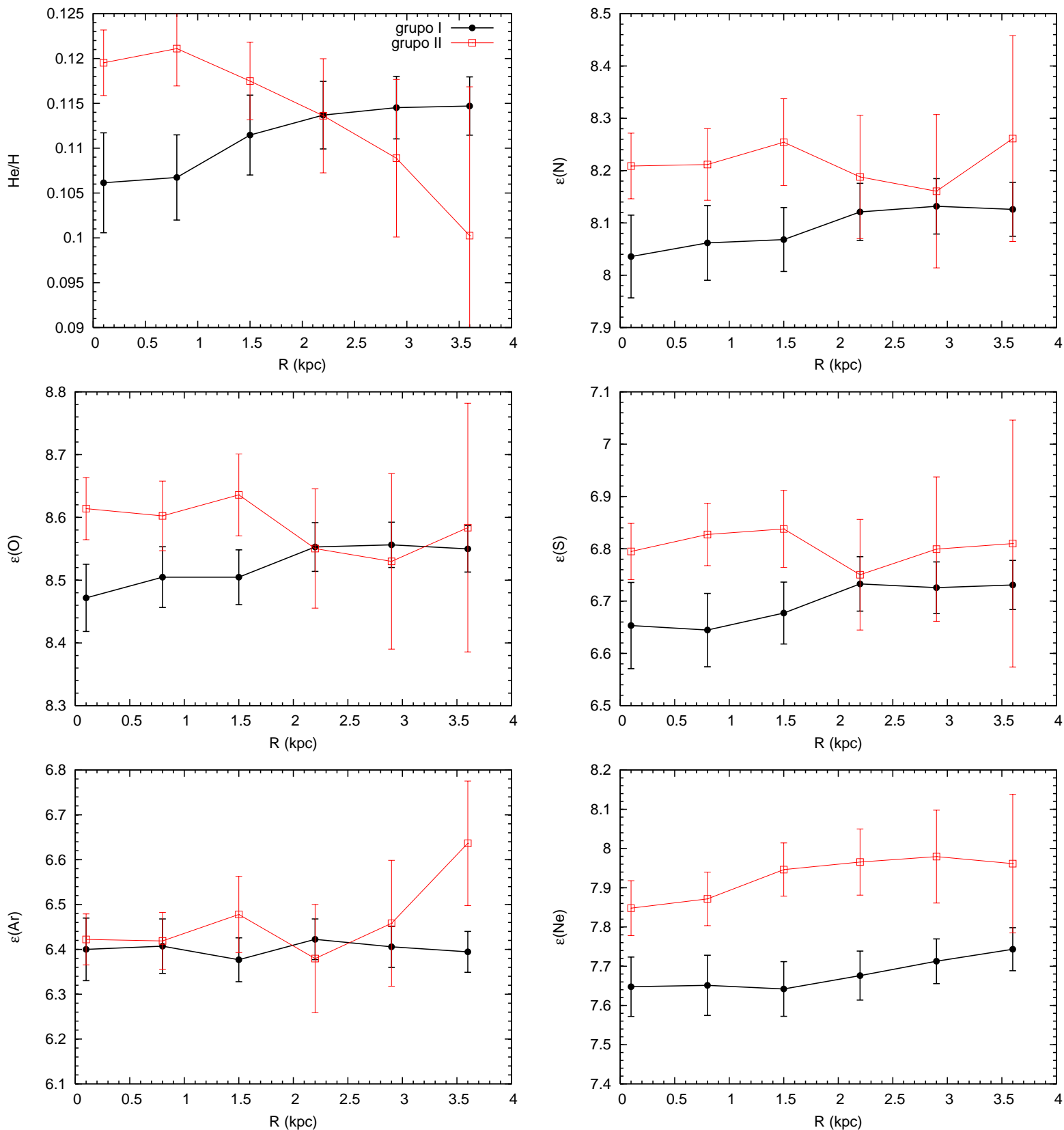

Figura 4.14: Abundâncias médias dos grupos I e II em função da distância de separação dos grupos para a escala de Zhang95 com um campo de visão de 20x20 graus. 

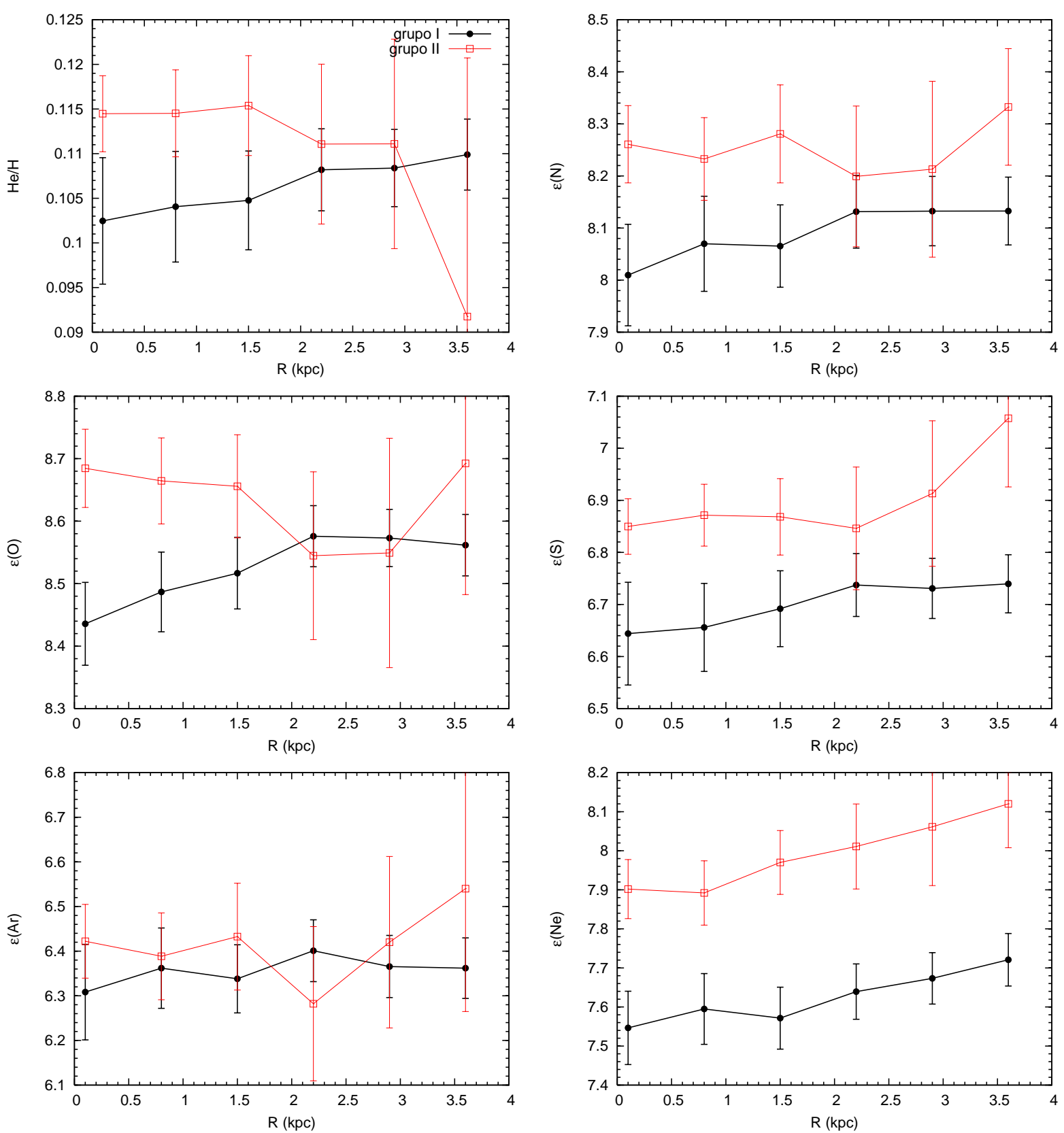

Figura 4.15: Variação das abundâncias dos grupos I e II para a escala de Zhang95 e um campo de visão de $10 x 10$ graus. 


\subsubsection{Escala de Cahn}

Como a escala proposta por CKS92 é uma escala de distância longa, espera-se obter melhores resultados com esta escala se comparados à escala de MP80. Os resultados estão nas figuras 4.16, 4.17 e 4.18, que mostram a distribuição da média das abundâncias em função da distância galactocêntrica que define a fronteira de separação dos dois grupos, para diferentes campos de visão: 50x20, 20x20, e 10x10 graus, respectivamente.

Os resultados encontrados para a escala de CKS92 concordam com aqueles obtidos através da escala de Zhang95, no sentido de que em média as abundâncias do grupo II são maiores que as do grupo I.

O argônio não apresenta uma distinção entre as abundâncias dos dois grupos, e a abundância média do neônio para os dois grupos se mostra a mais distinta entre os elementos alfa.

Assim como acontece na escala de Zhang95, a abundância de hélio média apresenta uma inversão entre os grupos ao redor de $1 \mathrm{kpc}$, sendo que antes de $1 \mathrm{kpc}$ a abundância média do grupo II é maior que a do grupo I, e a partir de $1 \mathrm{kpc}$ a abundância média do grupo I passa a ser maior. Note que a diferença está dentro da barra de erro, não sendo clara a separação.

Para o campo de 50x20 graus as abundâncias de nitrogênio e oxigênio diferem entre os grupos em 0.15 dex, aproximadamente. A abundância de enxofre não apresenta grande distinção entre os grupos, sendo a diferença da ordem de 0.1 dex, porém a abundância do grupo II está sempre acima da abundância do grupo I.

A separação das abundâncias médias de cada grupo é similar para os diferentes campos de visão porém, a medida que é diminuído, a separação se torna um pouco mais clara, especialmente para o nitrogênio, oxigênio e neônio. Note que para os elementos alfa esta diferença entre os grupos é um pouco superior a 0.1 dex, sendo o erro na determinação das abundâncias superior a este valor. 

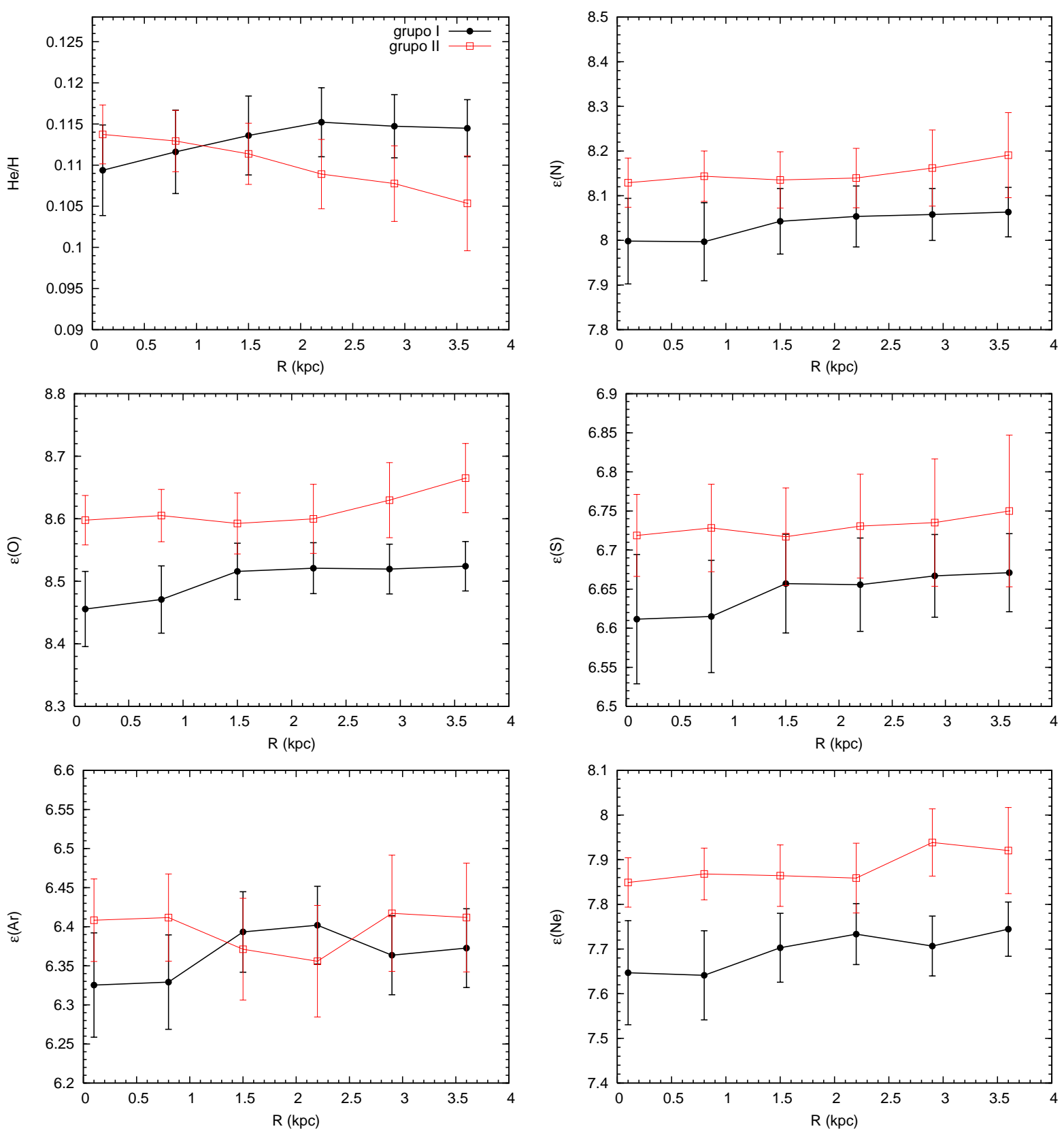

Figura 4.16: Variação das abundâncias químicas dos grupos I e II em função da distância galactocêntrica que separa os grupos. Utilizou-se escala de CKS92 e um campo de 50x20 graus. 

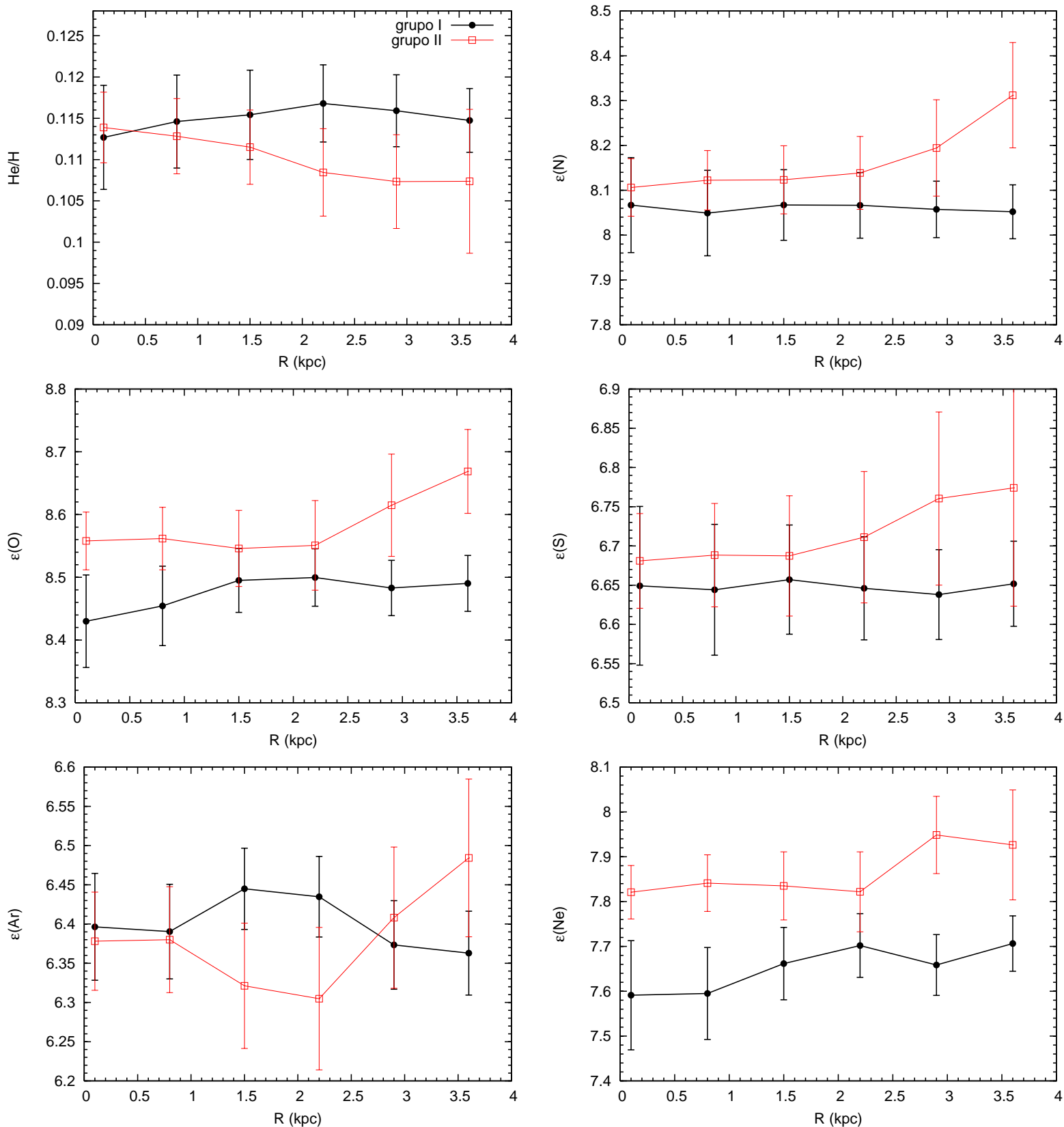

Figura 4.17: Abundâncias médias dos grupos I e II para a escala de CKS92 e um campo de 20x20 graus. 

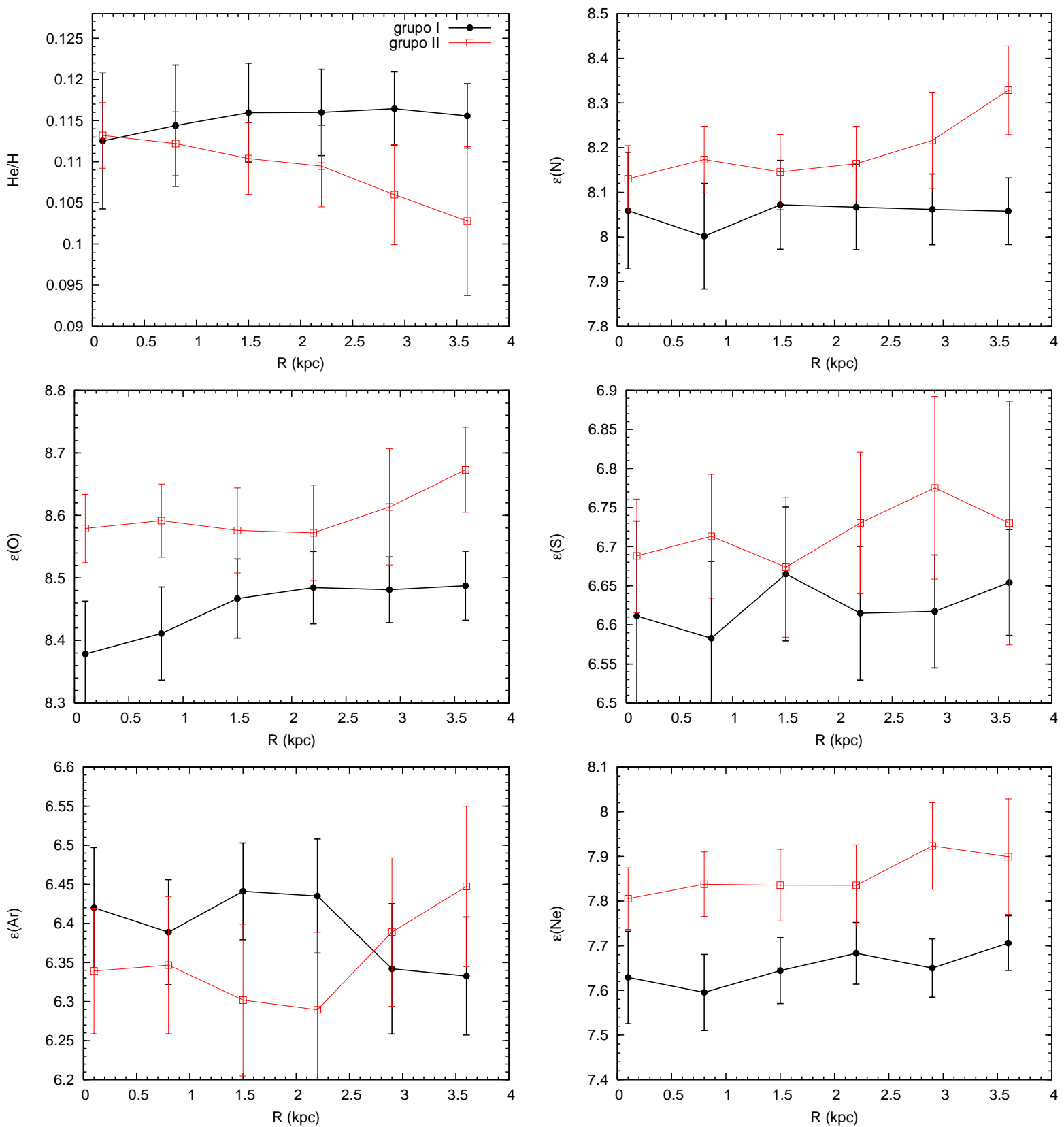

Figura 4.18: Abundâncias médias dos grupos I e II para a escala de CKS92 e um campo de 10x10 graus. 


\subsection{Teste de Kolmogorov-Smirnov}

O teste de dois lados de Kolmogorov-Smirnov (teste KS), ver por exemplo Press et al. (1992), foi aplicado para encontrar qual é a distância galactocêntrica que separa os grupos I e II, de tal maneira que as populações de cada grupo sejam as mais distintas possíveis. Uma baixa probabilidade neste teste indica que as amostras foram originadas de distribuições distintas. Nas figuras 4.19, 4.20, e 4.21 são apresentados os resultados obtidos com o teste KS aplicado à escala de distância de Zhang95 para diferentes campos de visão. O eixo vertical mostra a probabilidade de os dois grupos serem originados da mesma distribuição. O eixo horizontal mostra a distância que separa a amostra nos grupos I e II.

Entre os elementos alfa, o neônio é o elemento que tem as mais baixas probabilidades, independente da distância galactocêntrica que define a fronteira de separação dos grupos. Para os outros elementos as menores probabilidades estão concentradas para as distâncias menores que $1.5 \mathrm{kpc}$. Entende-se aqui menores probabilidades como valores menores que $10 \%$.

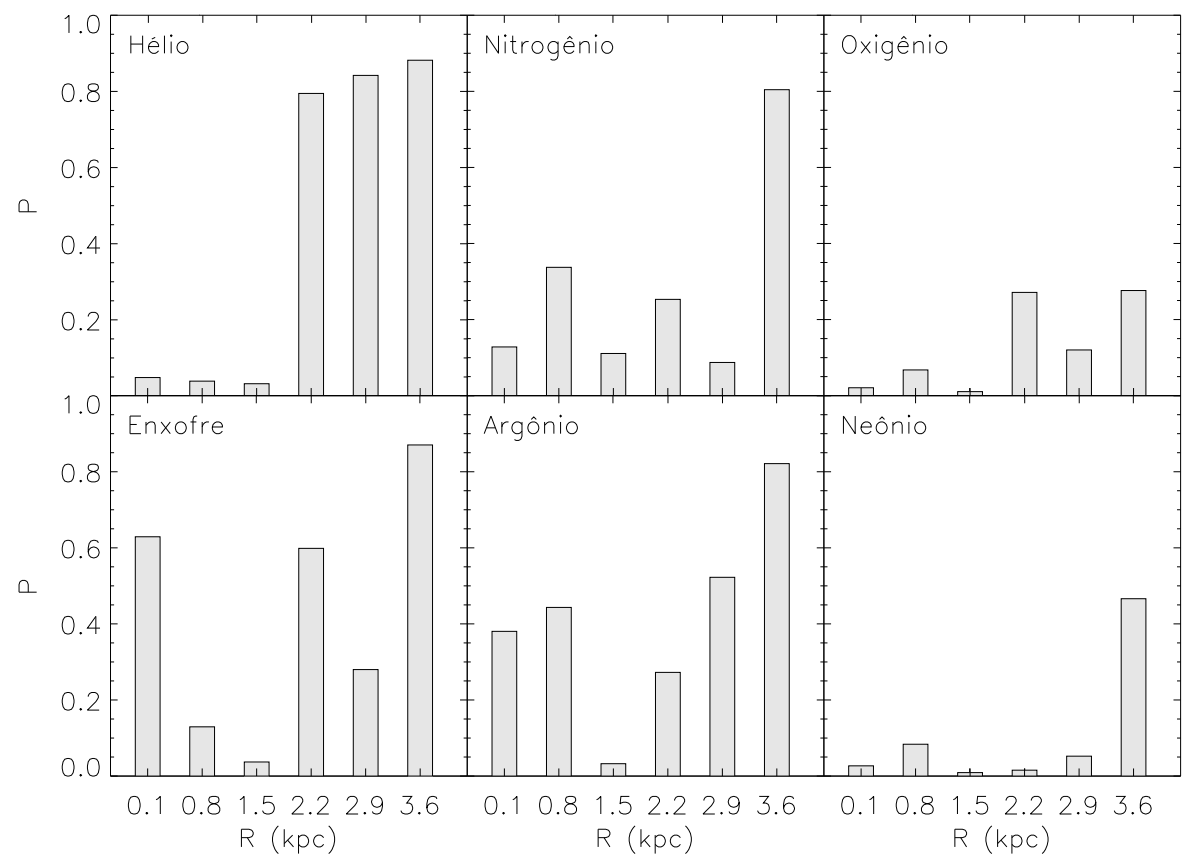

Figura 4.19: Teste KS aplicado à escala de Zhang95 para um campo de 50x20 graus. 


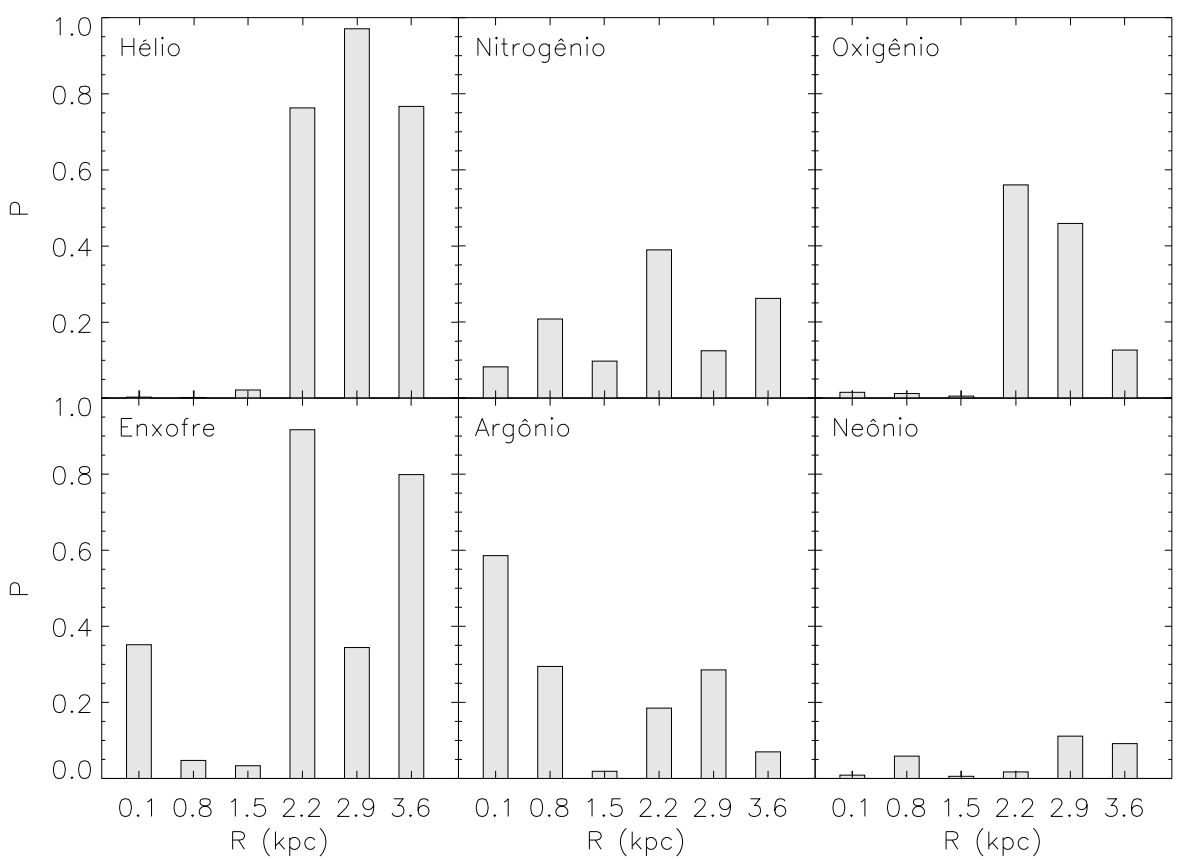

Figura 4.20: Teste KS aplicado à escala de Zhang95 para um campo de 20x20 graus.

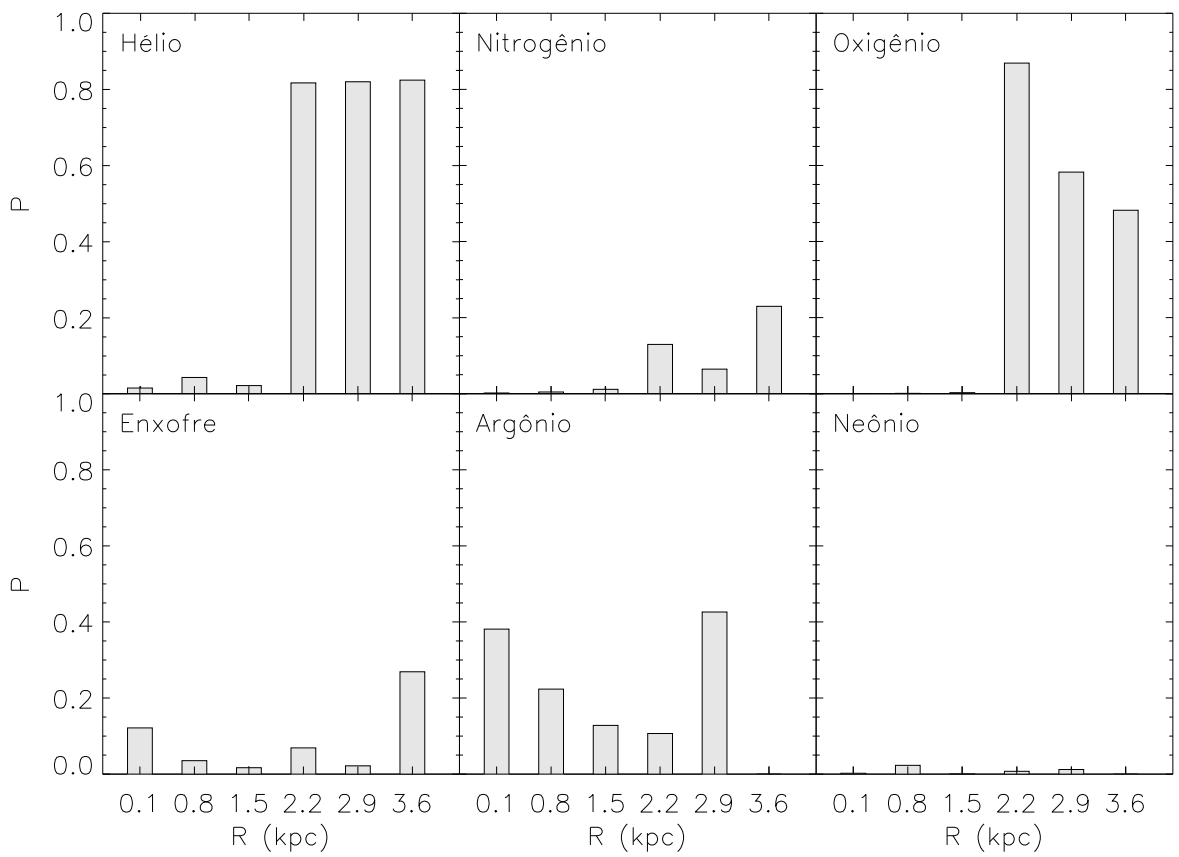

Figura 4.21: Teste KS aplicado à escala de Zhang95 para um campo de 10x10 graus. 
As figuras 4.22, 4.23, e 4.24 mostram o teste KS aplicado à escala de distância de CKS92 para diferentes campos de visão: 50x20, 20x20, e 10x10 graus, respectivamente. Estes gráficos não são tão conclusivos quanto os obtidos a partir da escala de Zhang95, mas é possível analisar alguns aspectos dos mesmos.

O oxigênio mostra baixas probabilidades, independentemente do campo de visão e portanto não serve como critério de separação. O neônio apresenta probabilidades inferiores a $20 \%$, sendo que para o campo de 10x10 graus as probabilidades são inferiores a 10\%, exceto para a distância de $0.8 \mathrm{kpc}$, que apresenta uma probabilidade de $18 \%$.

O hélio tem probabilidades maiores que $45 \%$ em todos os campos, a não ser para a distância de $0.8 \mathrm{kpc}$, para a qual a probabilidade é menor que $20 \%$ para os campos de $50 \times 20$ e 20x20 graus.

As menores probabilidades do argônio estão situadas ao redor de 2.2 e $2.9 \mathrm{kpc}$, sendo sempre menores que 20\%. O enxofre não apresenta uma distância para a qual a probabilidade é mínima em todos os campos. As menores probabilidades para o nitrogênio aparecem no campo de 10x10 graus, apresentando um mínimo em 1.5 kpc e outro em 2.9 $\mathrm{kpc}$.

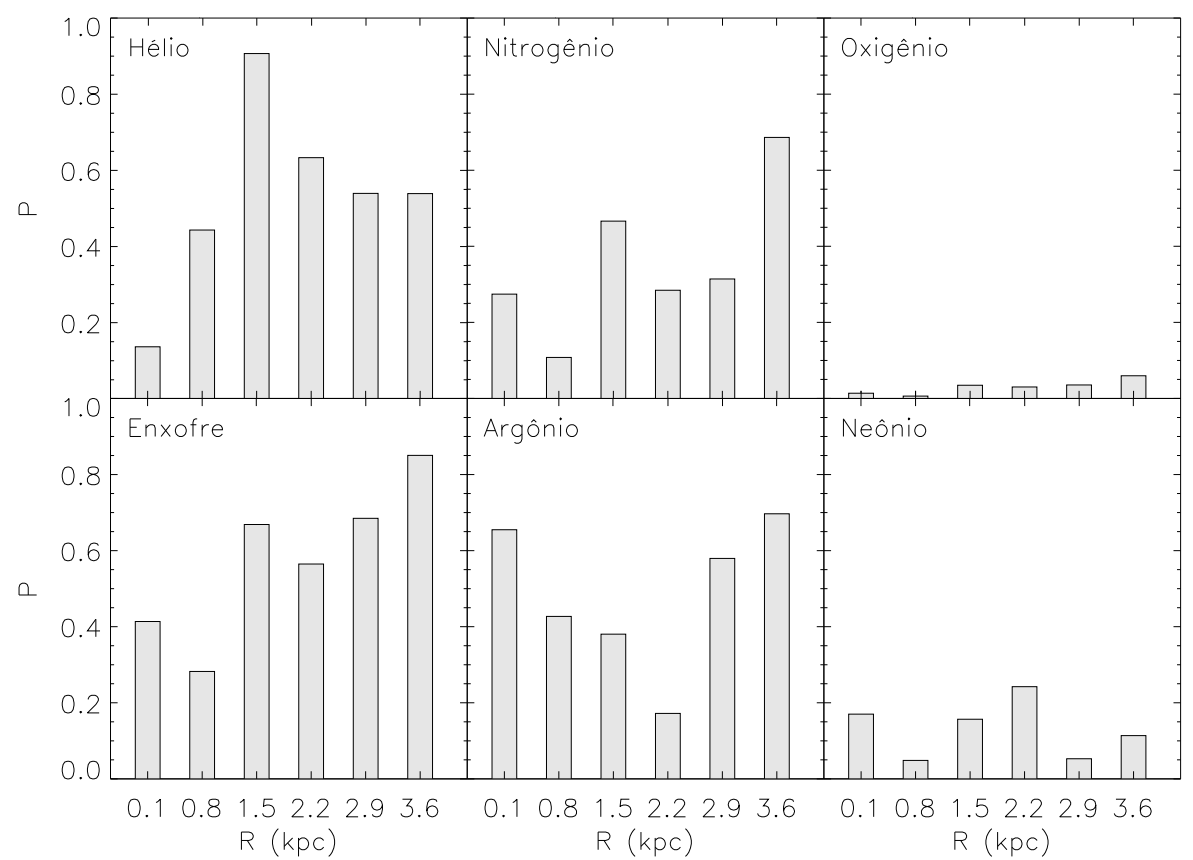

Figura 4.22: Teste KS aplicado à escala de CKS92 para um campo de 50x20 graus. 


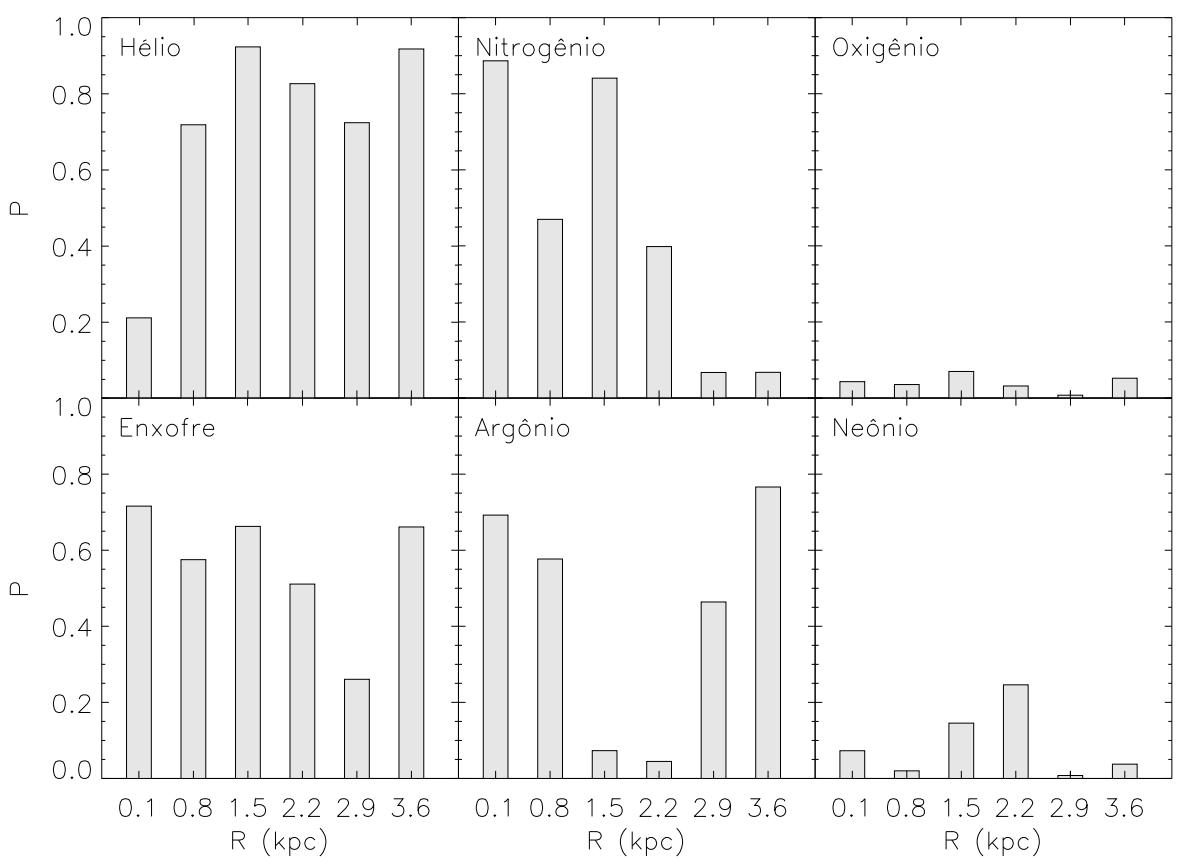

Figura 4.23: Teste KS aplicado à escala de CKS92 para um campo de 20x20 graus.

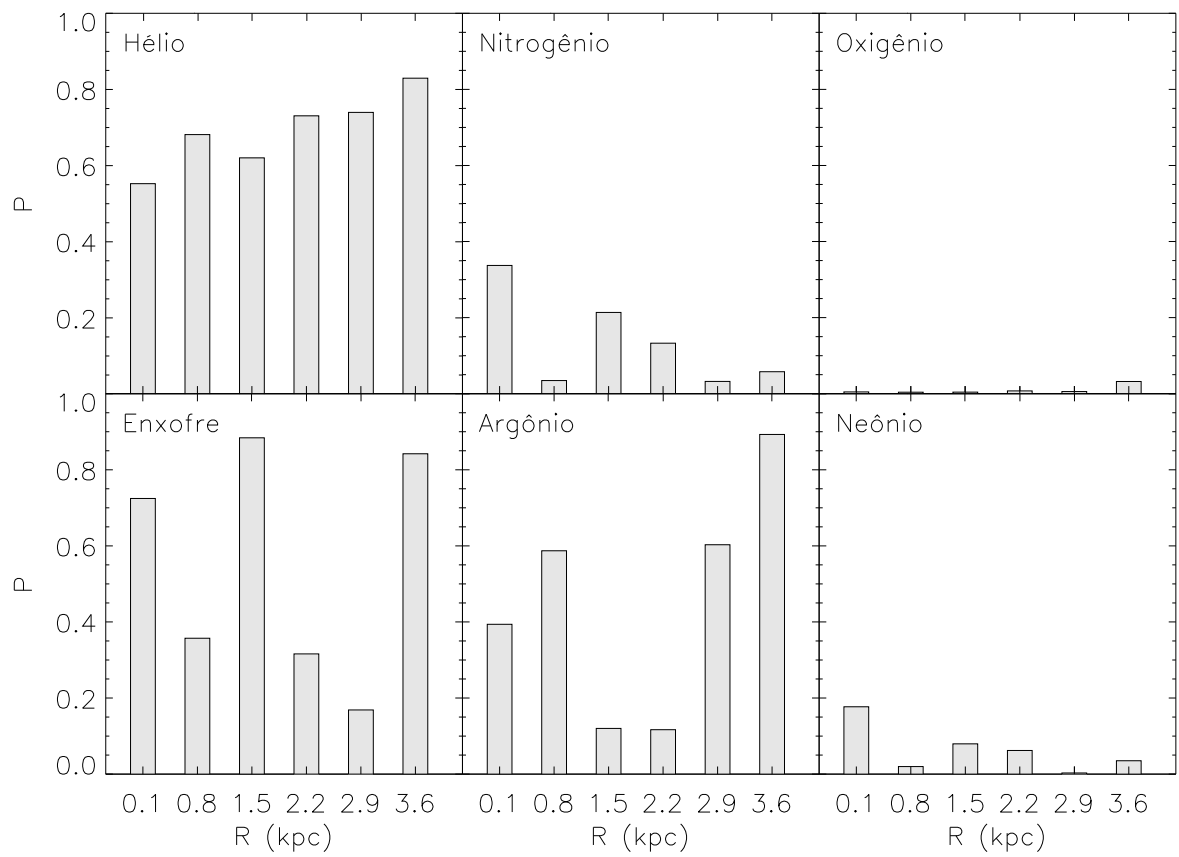

Figura 4.24: Teste KS aplicado à escala de CKS92 para um campo de 10x10 graus. 
Nos gráficos das figuras 4.25, 4.26, e 4.27 são apresentados a aplicação do teste KS à escala de distância de MP80 para diferentes campos: 50x20, 20x20, e 10x10 graus. A escala de MP80 mostra uma grande probabilidade dos grupos serem originados da mesma distribuição, independentemente da distância e do campo de visão adotados.

O hélio apresenta probabilidades inferiores a $16 \%$ para as distâncias de 0.1 e 0.8 kpc. O nitrogênio apresenta um mínimo das probabilidades em 2.9 kpc para todos os campos, sendo o valor deste mínimo da ordem de 10\%. Nos campos de 50x20 e 20x20 graus, as probabilidades são menores que $10 \%$ e 25\%, respectivamente, para o oxigênio considerando distâncias menores que $1.5 \mathrm{kpc}$.

As altas probabilidades encontradas para a escala de MP80 mostram que não há uma grande distinção das distribuições que originaram os grupos I e II, ou seja, estes grupos não são distintos do ponto de vista estatístico.

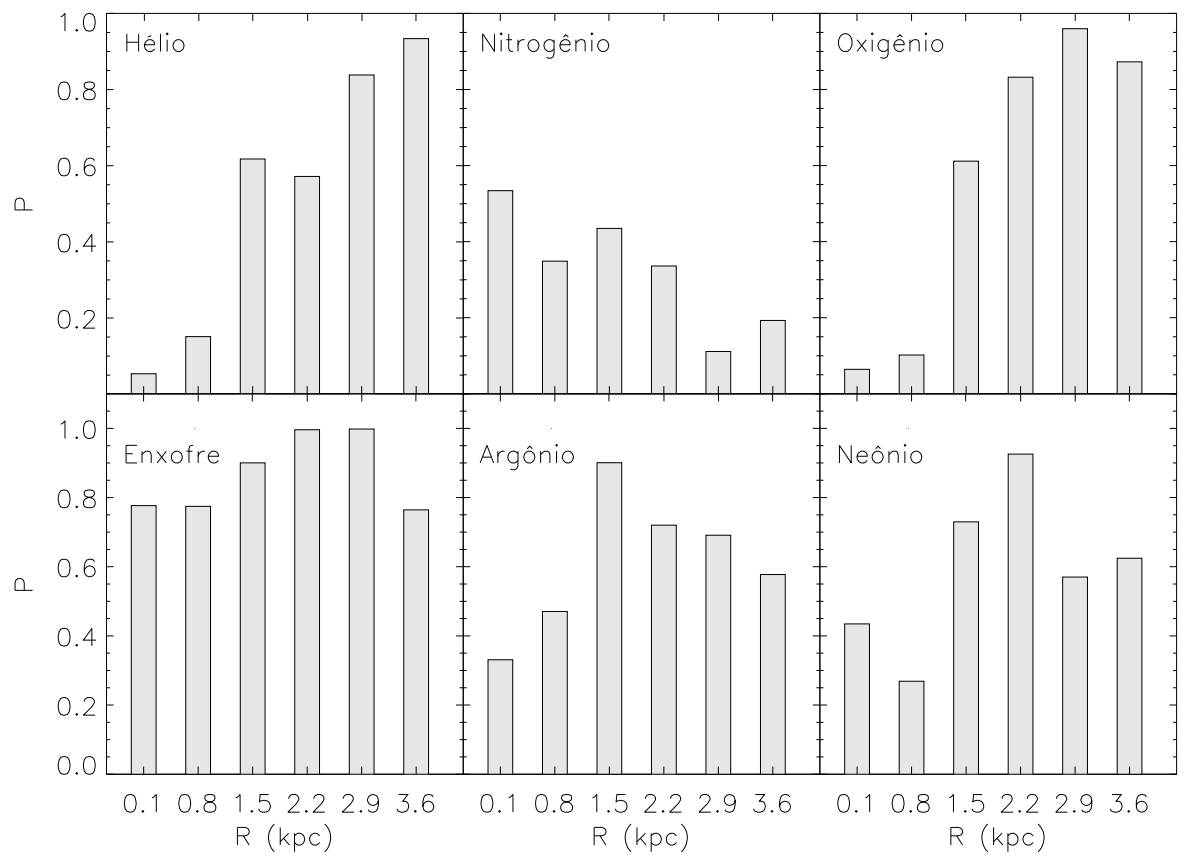

Figura 4.25: Teste KS aplicado à escala de MP80 para um campo de 50x20 graus. 


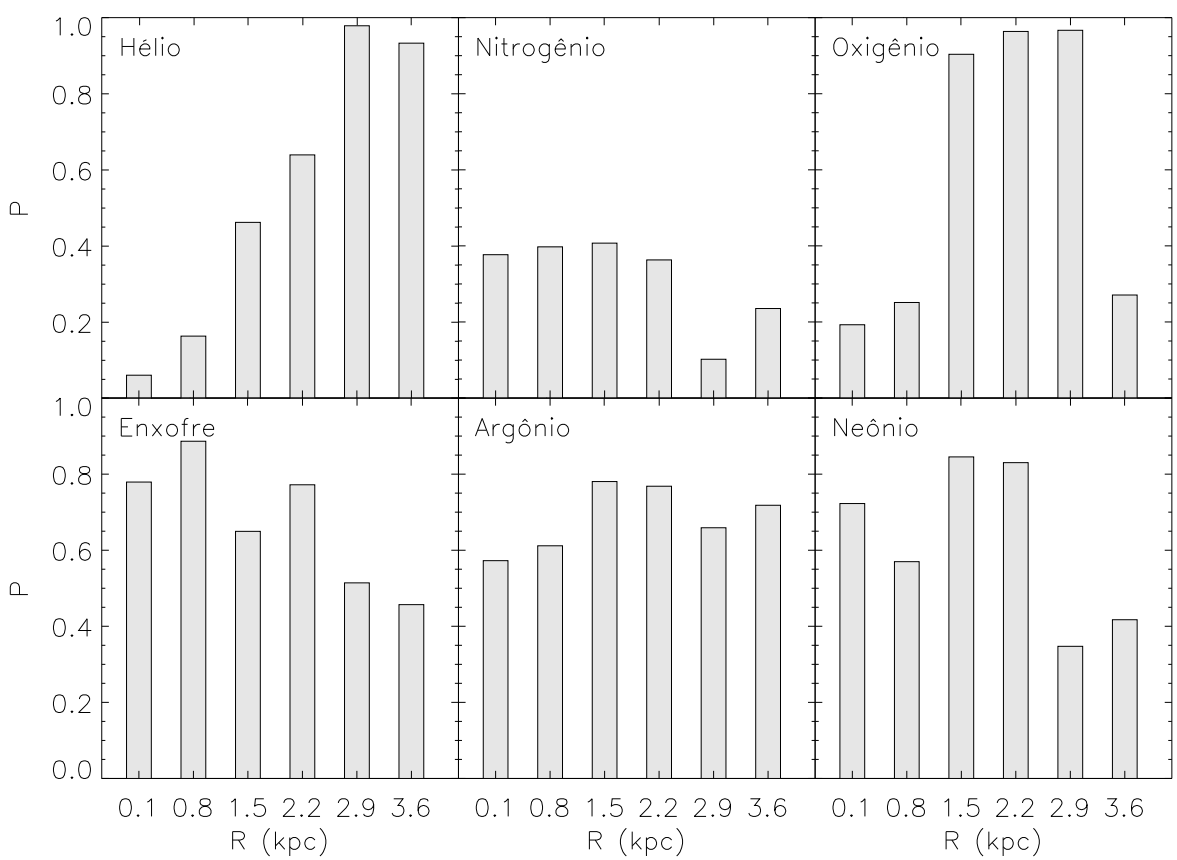

Figura 4.26: Teste KS aplicado à escala de MP80 para um campo de 20x20 graus.

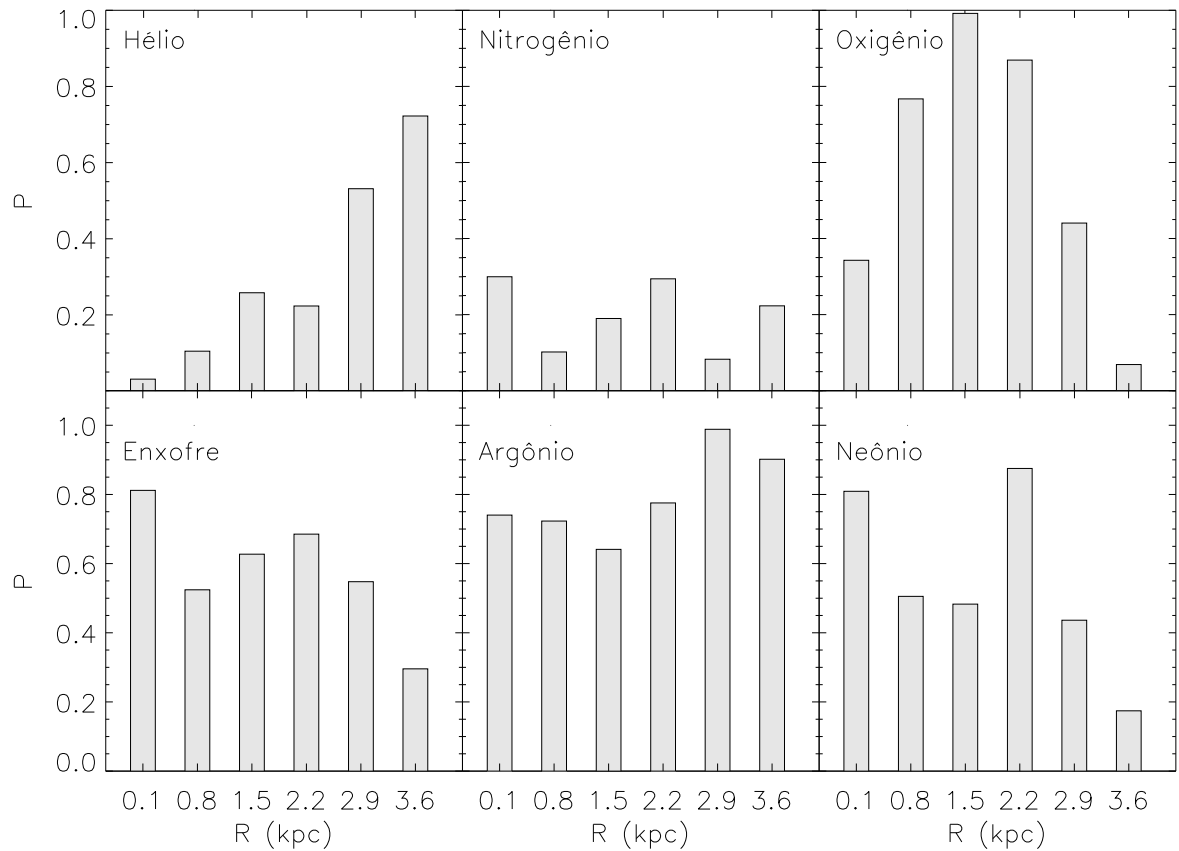

Figura 4.27: Teste KS aplicado à escala de MP80 para um campo de 10x10 graus. 


\subsection{Distribuição das abundâncias}

O teste KS foi conclusivo a respeito da escala de distância de Zhang95, mostrando que a maior diferença entre as abundâncias dos grupos I e II ocorre para distâncias menores que 1.5 kpc. A escala de CKS92 mostrou que esta diferença ocorre para distâncias entre 2.2 e 2.9 kpc. Optou-se pela distância de 2.9 kpc, já que apenas o argônio apresenta o mínimo em 2.2 kpc nos campos de 20x20 e 10x10 graus. Desta forma, serão adotas as distâncias de 1.5 e 2.9 kpc, para as escalas de Zhang95 e CKS92, respectivamente, definindo-se assim a fronteira de separação dos grupos, com o objetivo de estudar o comportamento da distribuição das abundâncias químicas entre os grupos I e II. Os histogramas das distribuições das abundâncias químicas nos grupos I e II são mostrados a seguir.

Analisando as figuras 4.28, 4.29, e 4.30 constata-se que para o oxigênio a distribuição das abundâncias do grupo I é mais larga que as do grupo II. Além disto, o grupo I contém mais objetos com abundâncias maiores que 9.0 dex, enquanto que o grupo II favorece abundâncias mais altas que 8.5 dex. Isto se reflete nas médias das abundâncias de cada grupo, sendo que o grupo I apresenta as médias 8.53, 8.50, e 8.52 dex e o grupo II tem como médias os valores 8.66, 8.64, e 8.63 dex, para os campos de visão 50x20, 20x20, e 10x10 graus, respectivamente. 

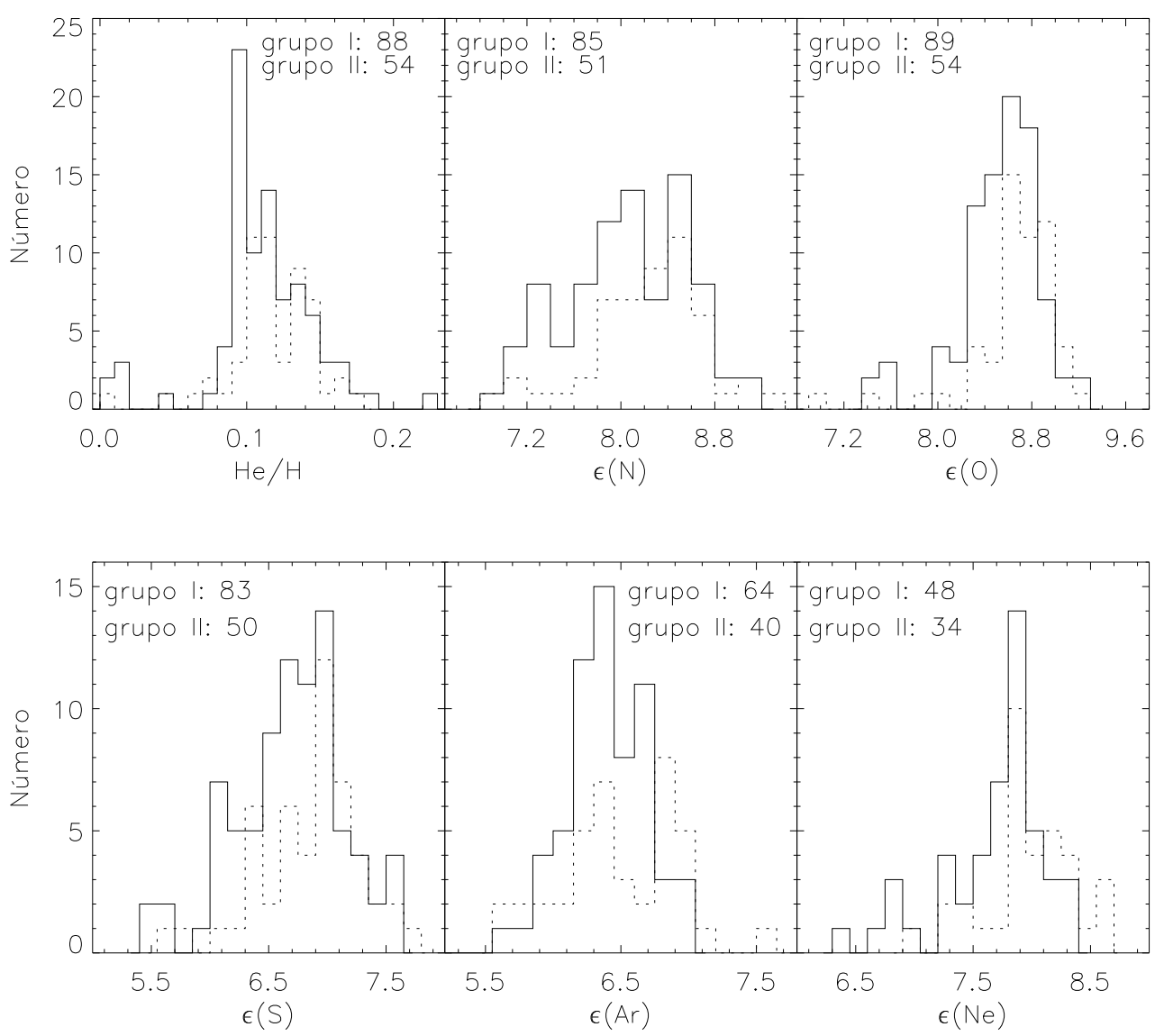

Figura 4.28: Comparação entre as abundâncias das NPs dos grupos I e II para a escala de distância de Zhang95 e um campo de 50x20 graus. A linha contínua representa a distribuição das abundâncias das NPs do grupo I, e a tracejada as do grupo II. O número acompanhado do grupo indica o número de NPs pertencentes a cada grupo. A fronteira entre os dois grupos foi definida em $1.5 \mathrm{kpc}$ do centro galáctico.

Este favorecimento de abundâncias mais altas para o grupo II pode ser visto nos outros elementos alfa. Os picos das distribuições, em geral, coincidem, porém os objetos do grupo I mostram favorecer abundâncias mais baixas que os objetos do grupo II. Contudo, esta diferença não é superior ao erro nas abundâncias químicas. Comparado aos demais elementos alfa, o neônio apresenta a maior diferença entre as distribuições das abundâncias dos grupos I e II, sendo que as NPs do grupo II favorecem uma maior abundância de neônio.

Para o nitrogênio, as distribuições das abundâncias das NPs dos grupos I e II são similares e ambas são mais largas que os erros, cobrindo o intervalo de 6.8 a 9.2 dex. No campo de 10x10 graus as abundâncias de nitrogênio das NPs do grupo II estão, em sua 

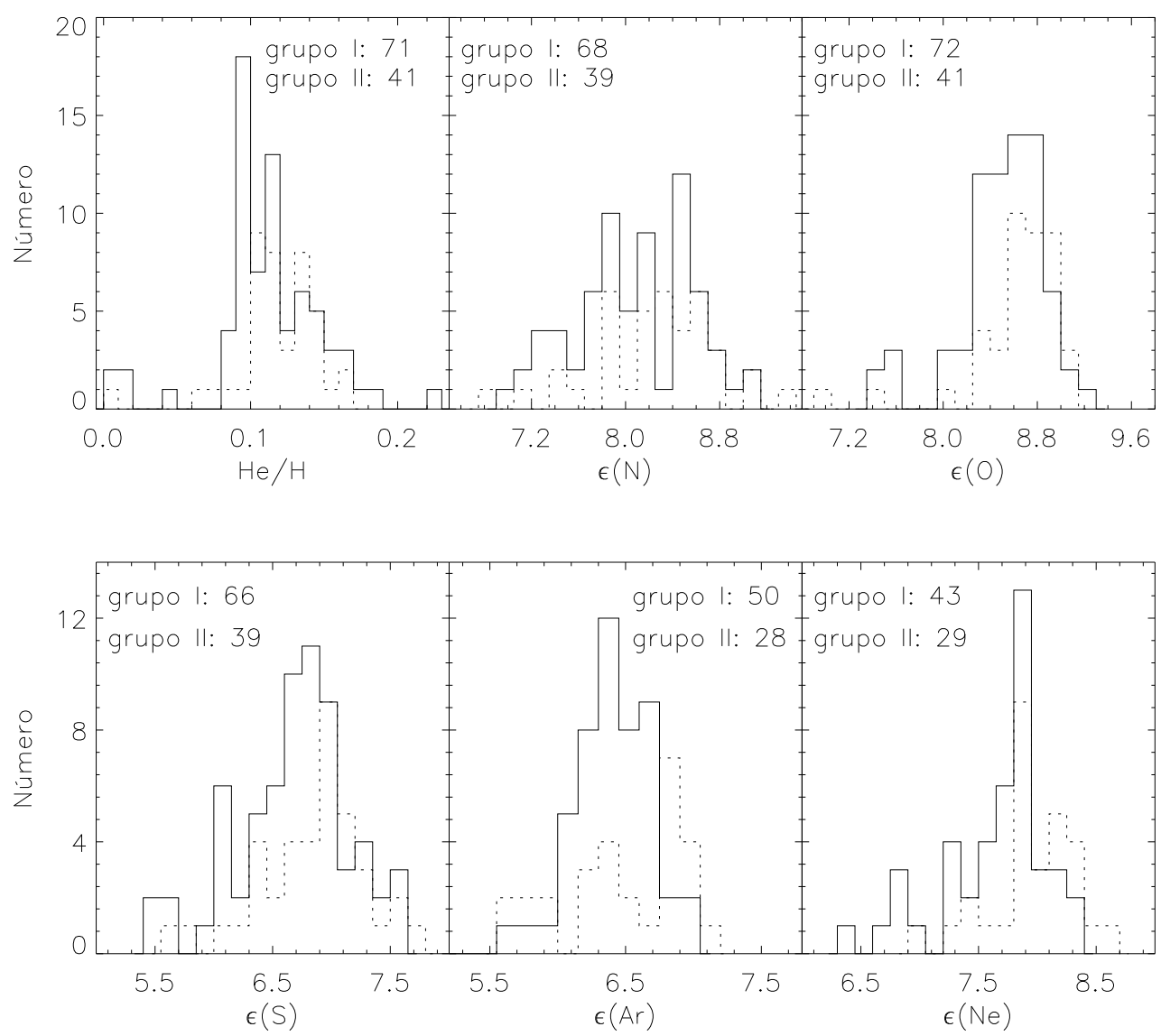

Figura 4.29: Distribuição das abundâncias das NPs do grupo I (linha contínua) e do grupo II (linha tracejada) para a escala de distância de Zhang95 e um campo de 20x20 graus.

maioria, acima de 7.8 dex, enquanto que as abundâncias das NPs do grupo I se estendem até 7.0 dex. As médias das abundâncias das NPs pertencentes ao grupo I são 8.05, 8.07, e 8.06, para os campos de 50x20, 20x20, e 10x10 graus, respectivamente. O grupo II apresenta as médias 8.24, 8.25, 8.28, respectivamente.

O hélio apresenta distribuição de abundâncias similares para os grupos I e II, não sendo possível identificar alguma tendência da distribuição do hélio em função do campo de visão. As abundâncias médias de hélio em número para o grupo I são 0.110, 0.114 e 0.104 , considerando os campos 50x20, 20x20, e 10x10 graus, respectivamente. Para o grupo II as abundâncias médias são 0.116, 0.117, e 0.115 . 

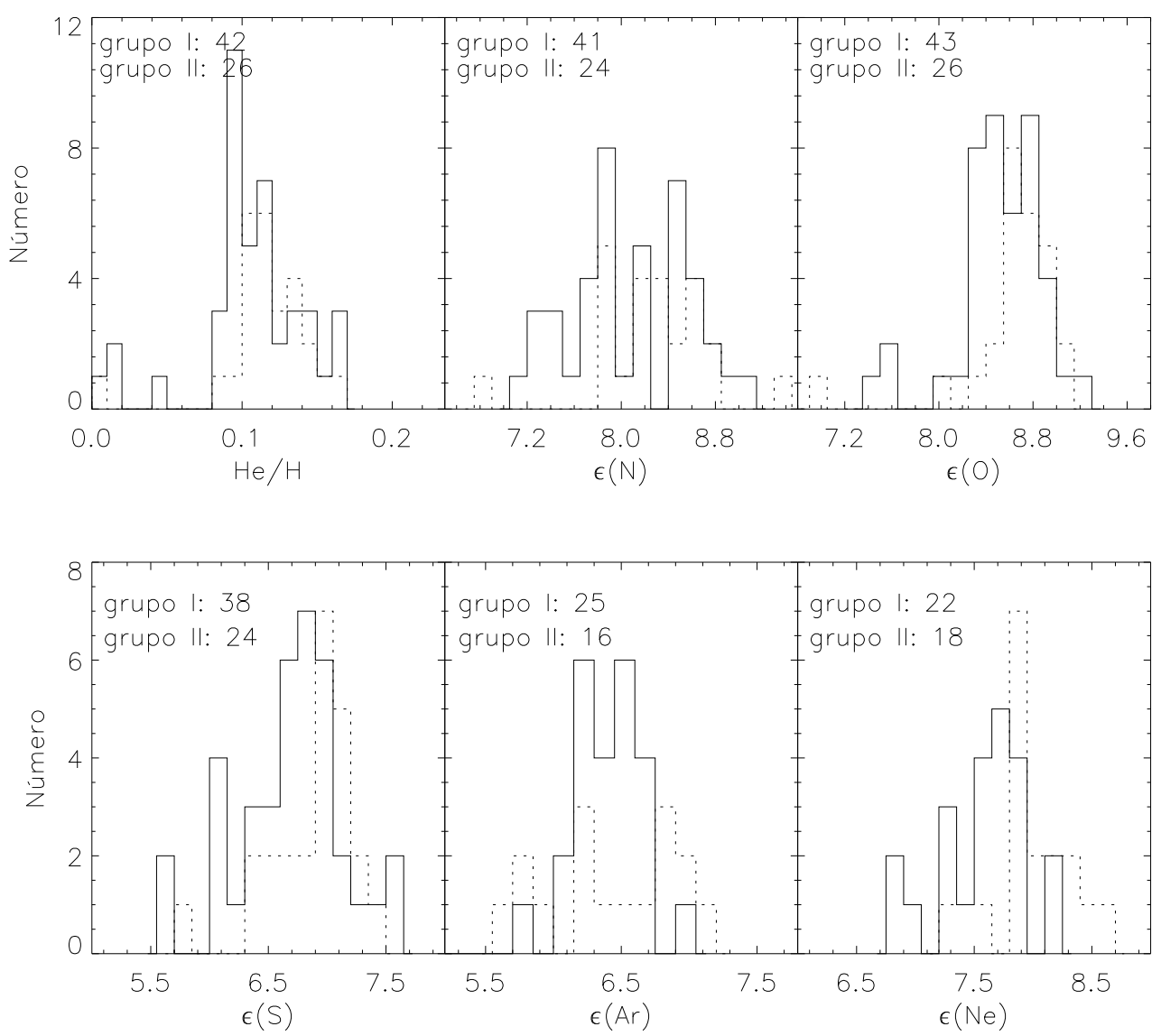

Figura 4.30: Distribuição das abundâncias das NPs do grupo I (linha contínua) e do grupo II (linha tracejada) para a escala de distância de Zhang95 e um campo de 10x10 graus.

As figuras 4.31, 4.32, e 4.33 mostram as distribuições de abundâncias para as NPs dos grupos I e II, utilizando a escala de distância de CKS92. Foi utilizada a distância de 2.9 kpc como a distância galactocêntrica que define a fronteira de separação dos grupos I e II, obtida através do teste KS.

Os picos das distribuições de oxigênio estão localizados em torno de 8.6 dex para todos os campos, sendo que as distribuições dos grupos I e II são comparáveis. O grupo II apresenta um número maior de NPs com abundâncias superiores a 9.0 dex, se comparado ao grupo I. Este apresenta uma distribuição mais larga, compreendendo abundâncias na faixa de 8.0 a 9.3 dex. As médias das abundâncias do grupo I são 8.52, 8.48, e 8.48, e as do grupo II são 8.63, 8.61, 8.61, não mostrando uma diferença significante. O teste KS retorna os seguintes valores: $0.035,0.007$, e 0.006, mostrando que a diferença entre as distribuições cumulativas dos grupos I e II são significativamente diferentes. 

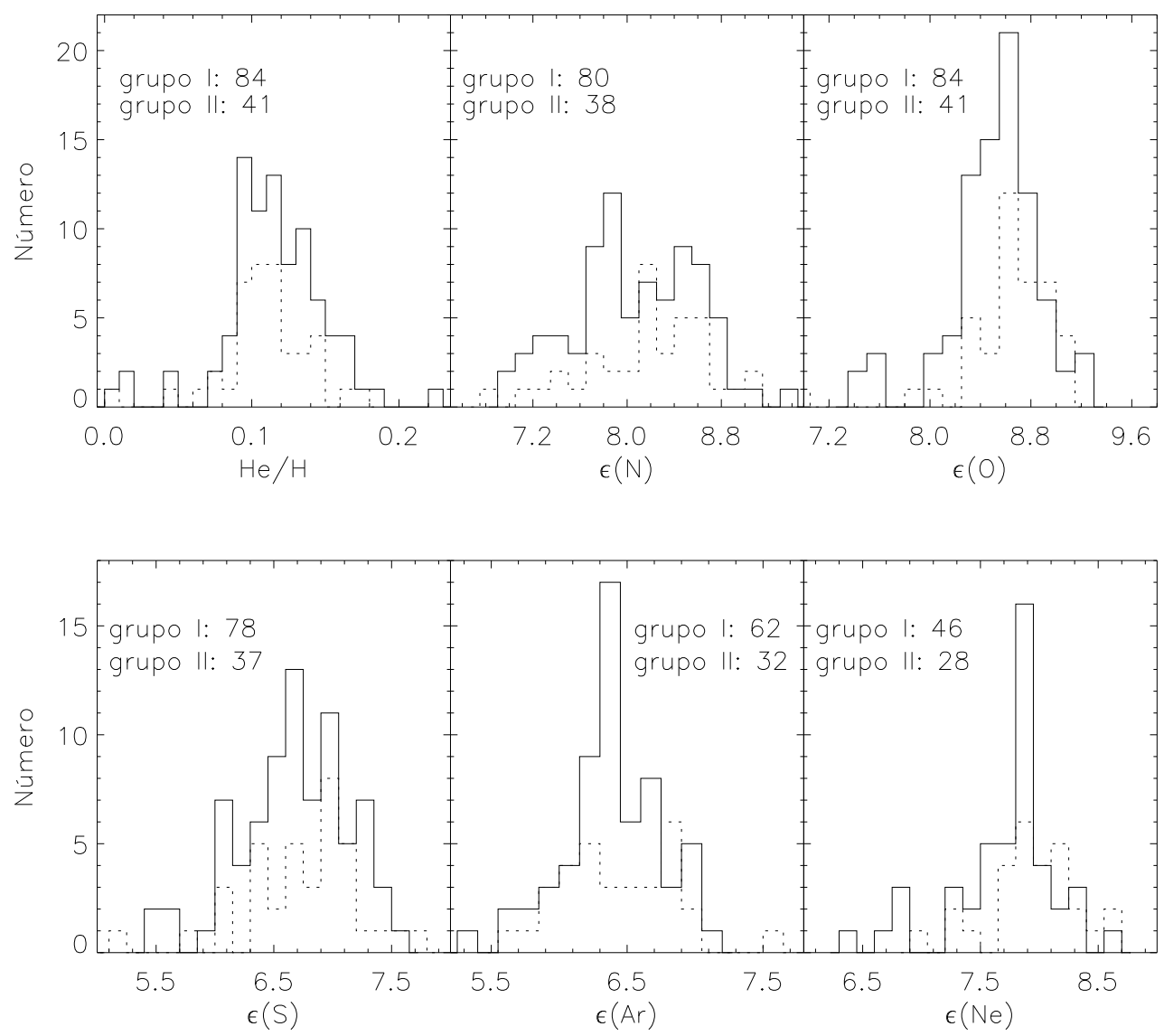

Figura 4.31: Distribuição das abundâncias das NPs do grupo I (linha contínua) e do grupo II (linha tracejada) para a escala de distância de CKS92 e um campo de 50x20 graus. A distância galactocêntrica que define a fronteira entre os grupos foi fixada em $2.9 \mathrm{kpc}$.

As distribuições do grupo II para os demais elementos alfa apresentam uma tendência para maiores abundâncias se comparadas as do grupo I, principalmente para os menores campos.

O teste estatístico aplicado às distribuições de nitrogênio não permite concluir se há uma diferença entre as distribuições dos grupos I e II, sendo a probabilidade das amostras serem iguais maior que 50\% para os campos de 50x20 e 20x20 graus, e 21\% para o campo de 10x10 graus.

O hélio não apresenta grandes distinções entre as distribuições dos grupos I e II. As distribuições são largas, cobrindo o intervalo de 0.60 a 0.190 em número. As médias para o grupo I são 0.114, 0.116, e 0.116, e para as do grupo II são 0.108, 0.107, e 0.106. Isto mostra que, em média, as abundâncias de hélio das NPs do grupo I são maiores que as do 
grupo II, porém o teste KS não mostra uma diferença entre as distribuições cumulativas dos grupos I e II, com a probabilidade delas serem iguais superior a $70 \%$ para os campos de 20x20 e 10x20 graus, e da ordem de 50\% para o campo de 50x20 graus.
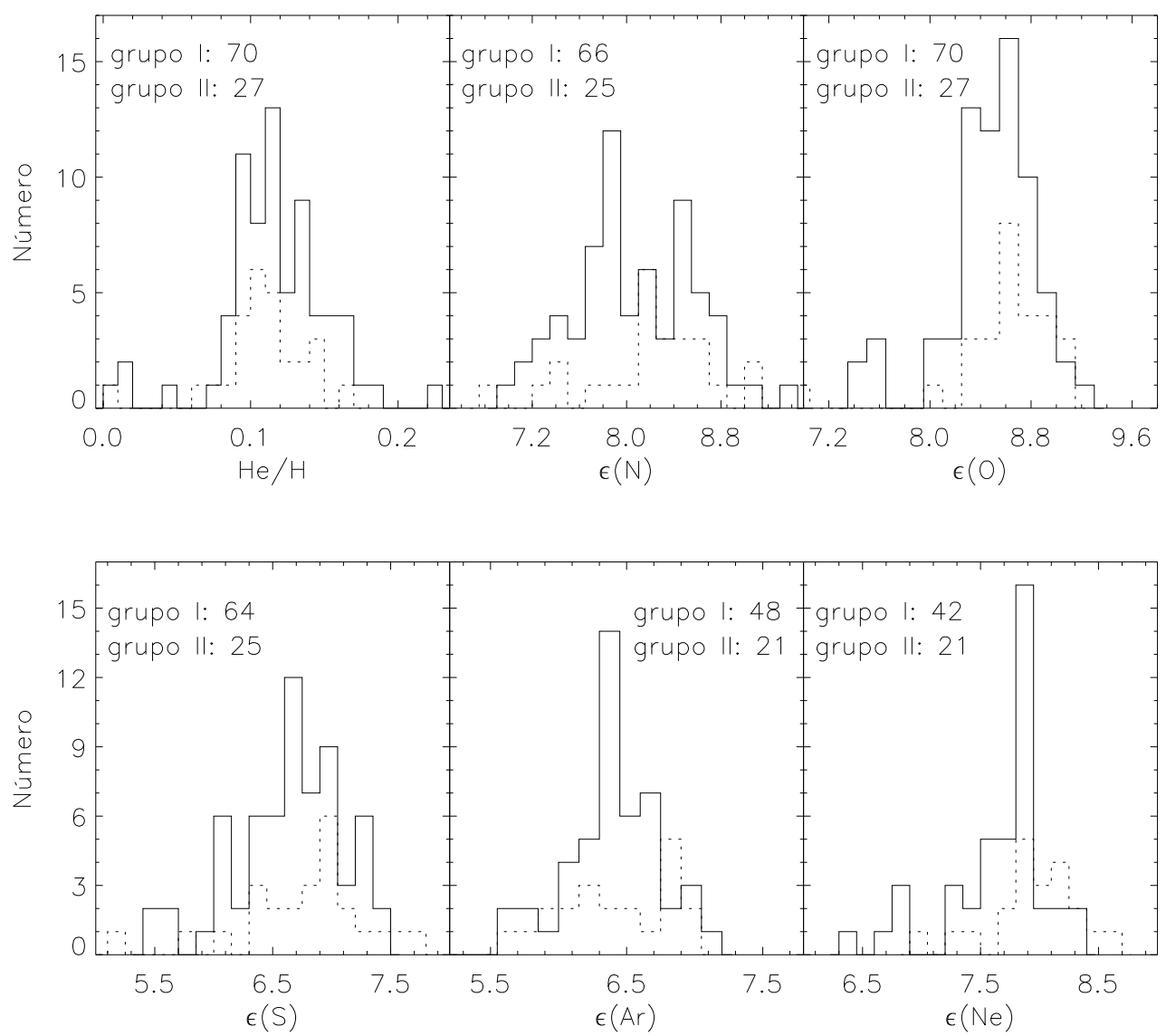

Figura 4.32: Distribuição das abundâncias das NPs do grupo I (linha contínua) e do grupo II (linha tracejada) para a escala de distância de CKS92 e um campo de 20x20 graus. 

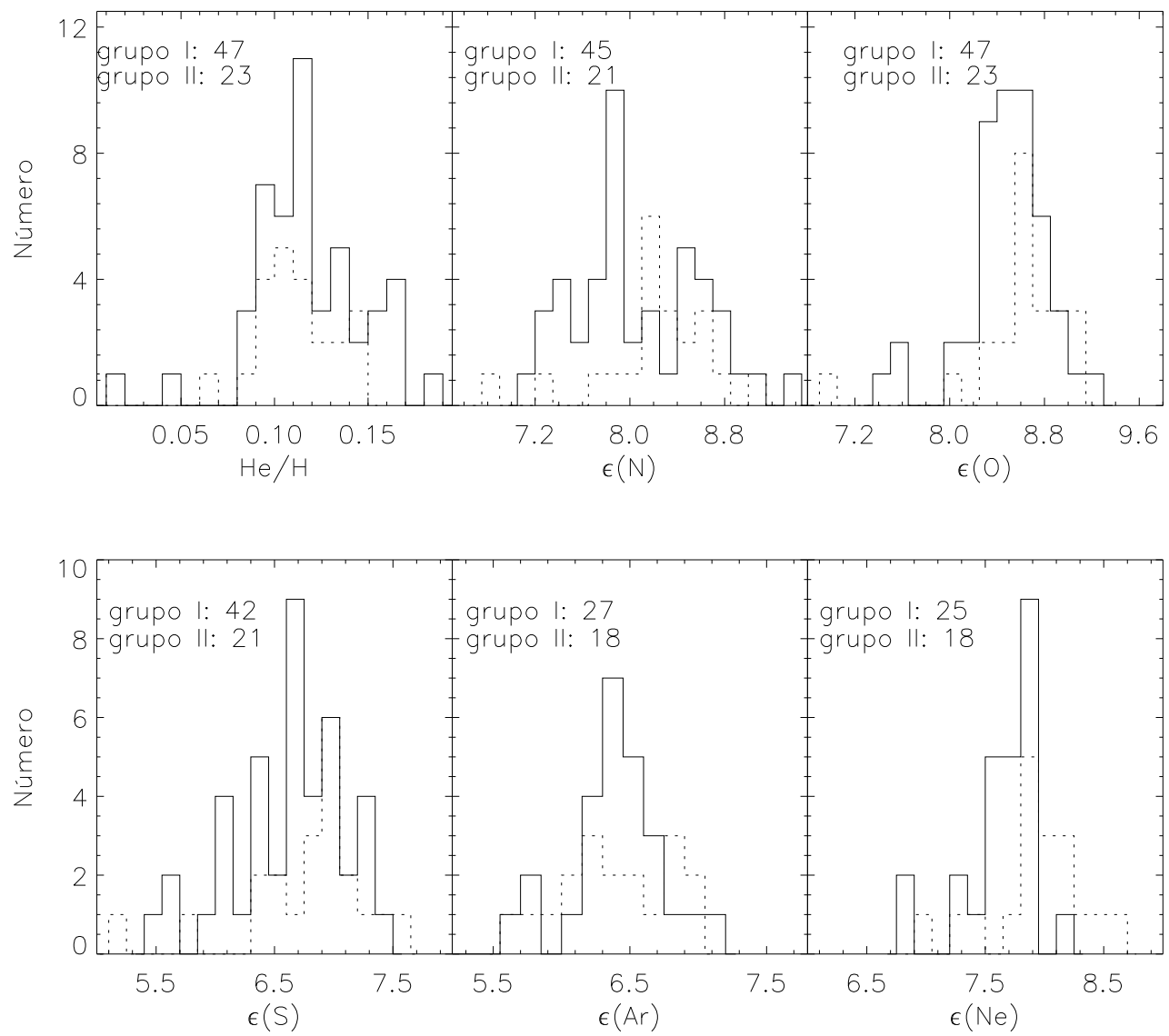

Figura 4.33: Distribuição das abundâncias das NPs do grupo I (linha contínua) e do grupo II (linha tracejada) para a escala de distância de CKS92 e um campo de 10x10 graus.

As distribuições das abundâncias para a escala de MP80 podem ser visualizadas nas figuras 4.34, 4.35, e 4.36. Como o teste KS não foi conclusivo a respeito da escala de MP80, optou-se por utilizar a distância de $1.5 \mathrm{kpc}$ encontrada através da aplicação deste teste na escala de Zhang95. Nestas figuras, as distribuições das abundâncias dos grupos I e II são similares. De fato, o teste KS retorna como probabilidades dos grupos serem originados da mesma distribuição cumulativa valores superiores a $50 \%$ para os elementos alfa, independentemente do campo de visão adotado.

As abundâncias médias de oxigênio para o grupo I são um pouco superiores as do grupo II. Para o primeiro grupo as médias encontradas foram $8.60,8.56$, e 8.57 dex, e para o segundo grupo foram 8.51, 8.50, e 8.51 dex.

O teste KS aplicado às abundâncias de hélio e nitrogênio retorna probabilidades menores que as dos elementos alfa. Para o hélio, a probabilidade encontrada para o campo 
de 10x10 graus é 26\%. Para os outros campos as probabilidades são maiores que $50 \%$. As médias das abundâncias do grupo I são inferiores as do grupo II, sendo que o primeiro grupo apresenta como médias os valores 0.118 , 0.119, e 0.114, e o grupo II os valores 0.121, 0.120, e 0.123, todas as abundâncias em número.

Assim como para as outras escalas de distância, há uma grande dispersão na distribuição de abundâncias do nitrogênio. O teste KS fornece probabilidades da ordem de $40 \%$ para os campos maiores, enquanto que para o campo de 10x10 graus a probabilidade cai para $19 \%$. Os valores médios das abundâncias para o grupo I são 8.12, 8.15, e 8.14 dex, enquanto que para o grupo II a média resultou em 8.23 dex para todos os campos.
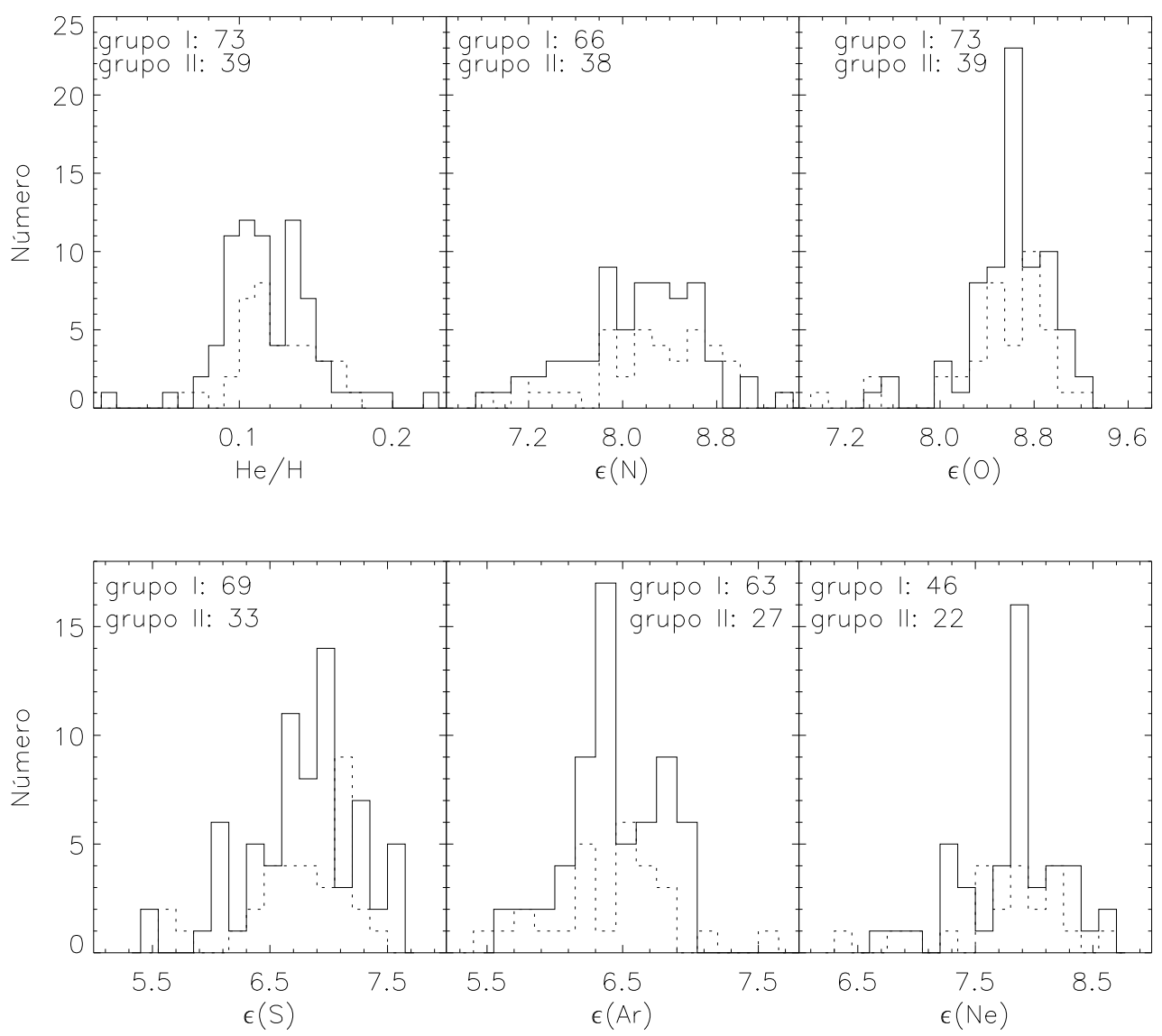

Figura 4.34: Distribuição das abundâncias das NPs do grupo I (linha contínua) e do grupo II (linha tracejada) para a escala de distância de MP 80 e um campo de 50x20 graus. A fronteira que define a separação dos grupos foi fixada em $1.5 \mathrm{kpc}$. 

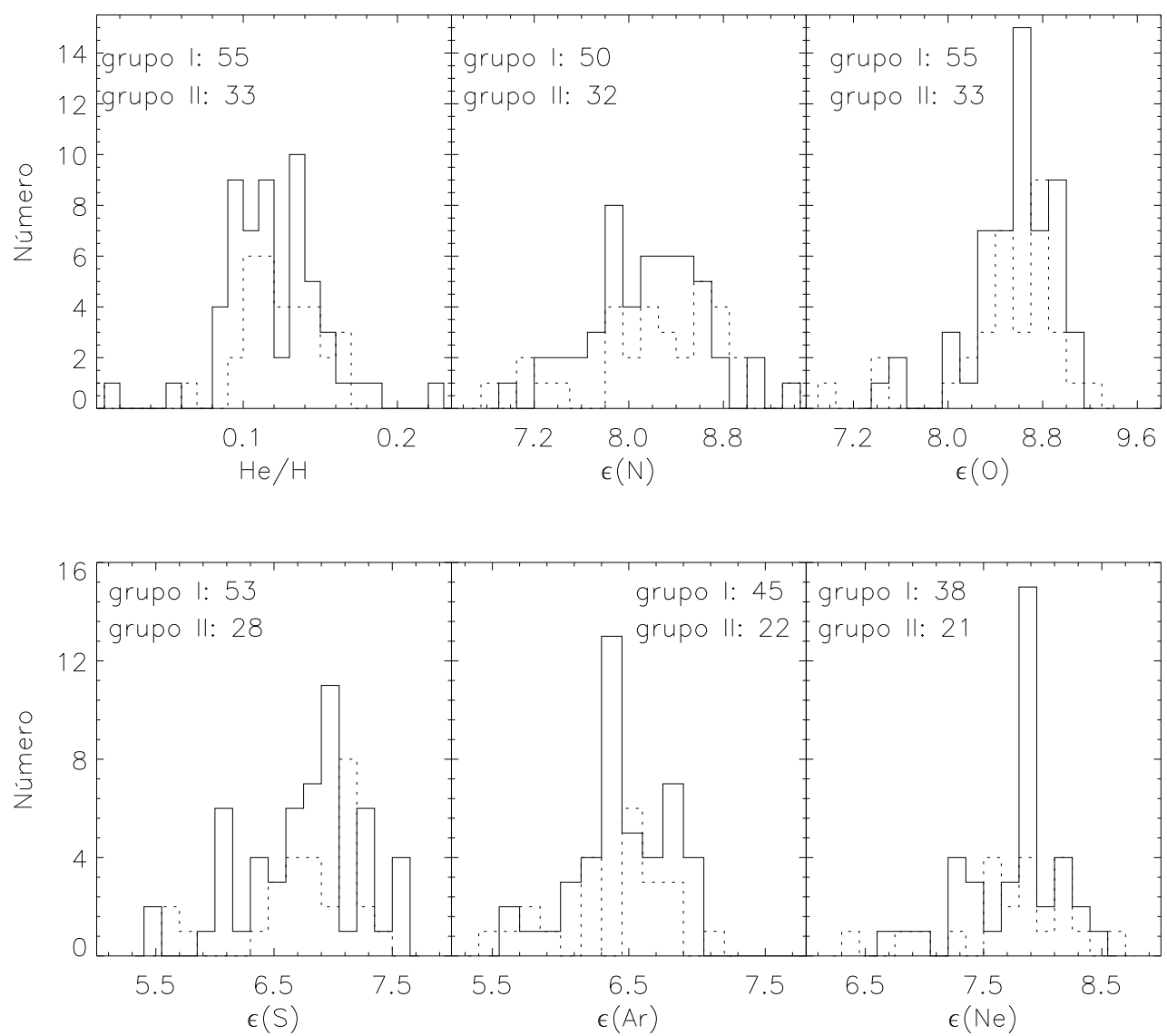

Figura 4.35: Distribuição das abundâncias das NPs do grupo I (linha contínua) e do grupo II (linha tracejada) para a escala de distância de MP 80 e um campo de 20x20 graus. 

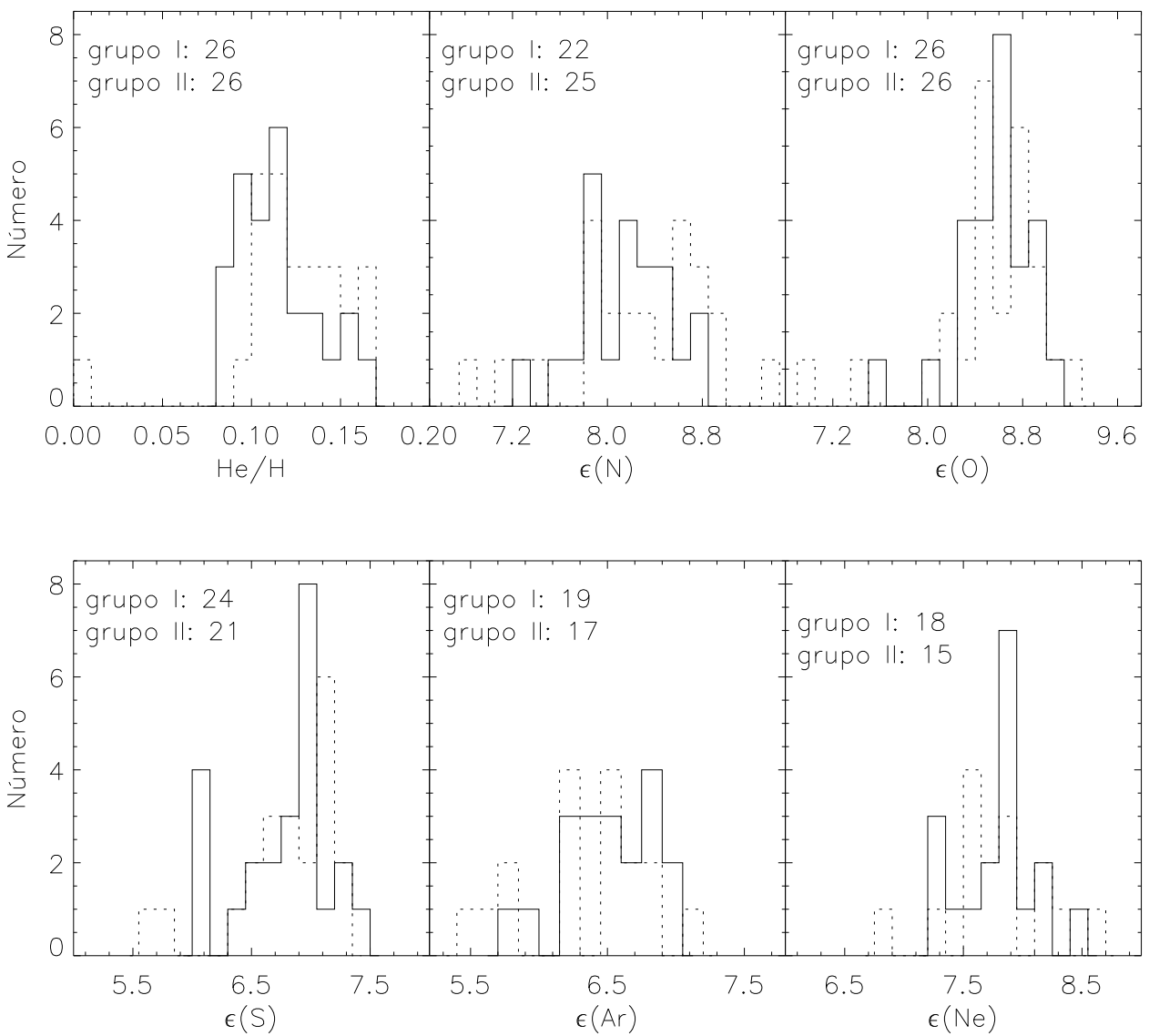

Figura 4.36: Distribuição das abundâncias das NPs do grupo I (linha contínua) e do grupo II (linha tracejada) para a escala de distância de MP 80 e um campo de 10x10 graus.

Em síntese, o que se observa para as escalas de distância de Zhang95 e CKS92 é uma subabundância para os elementos alfa das NPs pertencentes ao grupo I, comparadas às NPs pertencentes ao grupo II. Para a escala de Zhang95, o oxigênio, que é um típico representante dos elementos alfa, e apresenta uma boa precisão na determinação das abundâncias, mostra uma diferença entre as abundâncias médias de cada grupo de 0.15 dex. Para a escala de CKS92 esta diferença é menor, sendo de 0.13 dex. Estas diferenças são pequenas e, em muitos casos, o erro na determinação das abundâncias as supera. Porém, o que as duas escalas mostram é a tendência do grupo II apresentar NPs com maiores abundâncias que as NPs do grupo I.

Sobre a escala de MP80, não há diferenças significativas entre as abundâncias das NPs dos grupos I e II. Contudo, em média as NPs do grupo I apresentam maiores abundâncias que as do grupo II para os elementos alfa. Como a análise das abundâncias para esta 
escala apresenta propriedades distintas se comparadas às escalas de Zhang95 e CKS92, estes resultados devem ser considerados cautelosamente.

O estudo das distribuições das abundâncias químicas de cada grupo para os diferentes campos de visão mostra que não há uma grande distinção do comportamento destas distribuições em função do campo adotado. De fato, para as escalas de CKS92 e Zhang95 o número de NPs em cada grupo diminui basicamente pelo mesmo fator, a medida que o campo de visão é diminuído. Isto não ocorre para a escala de MP80, onde na transição do campo de 50x20 para o de 10x10 graus, o número de objetos do grupo I diminui em 64 $\%$, enquanto que o do grupo II diminui em 33\%. Porém, há um sutil acréscimo na diferença entre as abundâncias dos grupos I e II para o menor campo. Isto pode ser causado devido as diferentes populações estelares do disco. A mudança de inclinação no logaritmo da distribuição vertical de densidade em $\sim 700$ pc (Cabrera-Lavers, Garzón e Hammersley, 2005), é usualmente explicada como a assinatura da transição entre duas populações distintas: os discos fino e espesso. Para uma distância de $8 \mathrm{kpc}$, o campo de $5 \times 5$ graus apresenta uma altura de 700 pc. Entende-se que o disco espesso seja composto por uma população mais antiga que o disco fino, com metalicidades compatíveis com aquelas dos aglomerados globulares do disco (Vallenari, Bertelli e Schmidtobreick, 2000). Portanto, a exclusão da NPs do disco espesso na análise da distribuição das abundâncias para o menor campo, implica numa comparação direta entre as abundâncias das NPs do bojo e do disco fino, aumentando a diferença entre as distribuições dos grupos I e II.

As distâncias galactocêntricas de 1.5 e 2.9 kpc definem o limite de separação dos grupos I e II para as escalas de Zhang95 e CKS92, respectivamente, de tal maneira que se tem a maior diferença entre as populações dos grupos acusada pelo teste KS. Uma vez que, o bojo e o disco apresentam propriedades químicas distintas, estas distâncias podem ser interpretadas como sendo o raio que divide as populações do bojo e do disco interno com base nas propriedades químicas. Desta forma, as NPs contidas no grupo I seriam NPs pertencentes ao bojo da Galáxia, e as NPs do grupo II seriam NPs pertencentes ao disco interno da Galáxia. De fato, observações no infravermelho do bojo galáctico, como a mostrada na figura 2.2, corroboram esta afirmação. Nesta figura o raio nuclear do bojo está entre 10 e $15^{\circ}$. Para uma distância galactocêntrica de 8 kpc, que é a distância do Sol ao centro da Galáxia usada neste trabalho, o raio do bojo está entre 1.4 e 2.1 kpc para o 
eixo mais alongado. Como as escalas de distância utilizadas possuem grandes incertezas (da ordem ou maiores que 30\%), as distâncias encontradas estão razoavelmente dentro deste intervalo que as observações no infravermelho mostram.

\subsection{Comparação com outros trabalhos}

Tiede e Terndrup (1999) fizeram observações fotométricas e espectroscópicas de 503 estrelas gigantes em quatro janelas na direção do bojo, com coordenadas $(\ell, b)$ iguais a $\left(-28.8^{\circ},-6^{\circ}\right),\left(-8.7^{\circ},-6.0^{\circ}\right),\left(8.4^{\circ},-6.0^{\circ}\right)$, e $\left(24.4^{\circ}, 6.1^{\circ}\right)$. Neste trabalho, usam o módulo de distância para analisar a distribuição radial das metalicidades. Para comparar os resultados obtidos por eles com este trabalho, foi realizada a conversão de módulo de distância para distância galactocêntrica utilizando a relação

$$
d(p c)=10^{(5+m-M) / 5}
$$

para converter o módulo de distância em distância heliocêntrica, e em seguida utilizou-se a equação 4.20, para converter a distância heliocêntrica em distância galactocêntrica.

A metalicidade das estrelas em função da distância galactocêntrica é mostrada na figura 4.37. As distâncias foram divididas em bins de $0.5 \mathrm{kpc}$, e para cada bin foi feita a média das abundâncias. As barras de erro indicam o erro padrão da média.

Nota-se no gráfico que as estrelas que estão a mais de $2 \mathrm{kpc}$ possuem abundância de ferro superior àquelas situadas a menos de $2 \mathrm{kpc}$ do centro galáctico. Os autores argumentam que a diferença encontrada é superior a quaisquer viés na seleção da amostra ou erros nas abundâncias. Atribuem esta diferença a diferentes populações ao longo da linha de visada.

Smartt et al. (2001) obtiveram espectros de alta resolução para quatro estrelas jovens tipo-B localizadas entre 2.5-5 kpc do centro Galáctico. As abundâncias fotosféricas obtidas a partir destas estrelas são representativas do material interestelar do qual a estrela nasceu devido à sua relativa juventude. As distribuições de abundâncias encontradas por este grupo vão ao encontro com as características encontradas neste trabalho. A abundância de oxigênio parece diminuir para distâncias menores que $3 \mathrm{kpc}$ do centro da Galáxia, contudo as barras de erro são grandes, podendo-se afirmar apenas que as abundâncias não seguem o gradiente do disco em direção ao centro da Galáxia, pois estão 0.3 a 0.4 dex abaixo do que se esperaria dada a posição Galáctica das estrelas e o gradiente de Rolleston 


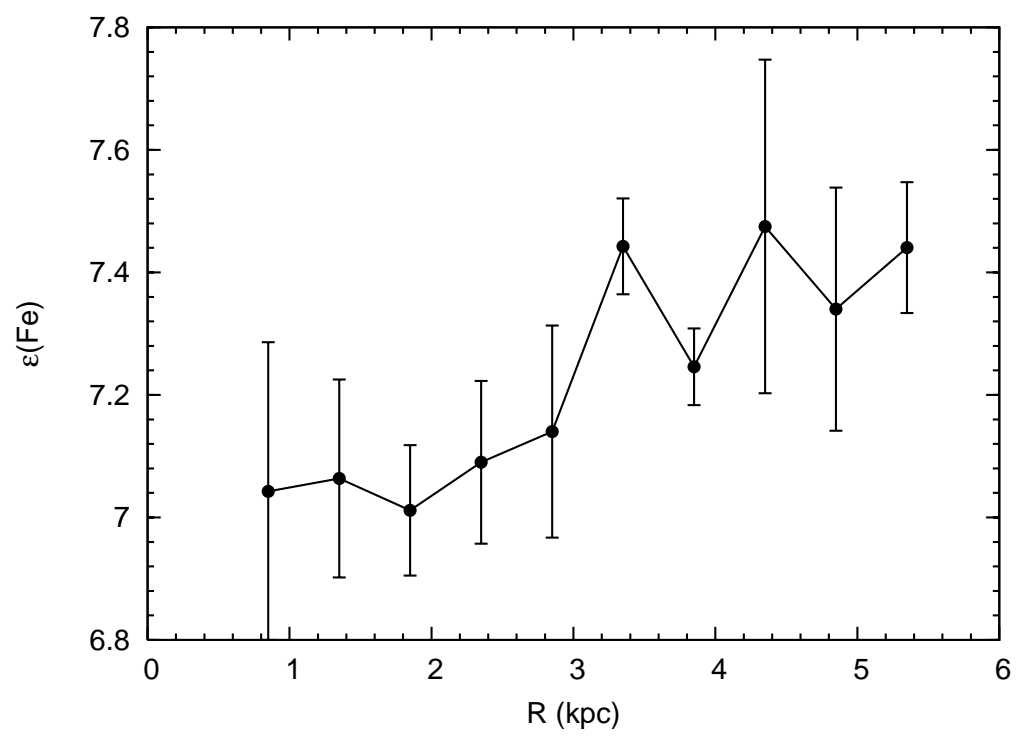

Figura 4.37: Distribuição das metalicidades de estrelas em função da distância galactocêntrica para a amostra de Tiede e Terndrup (1999). As barras de erro indicam o desvio padrão da média para cada distância galactocêntrica fixada.

et al. (2000).

Portinari e Chiosi (1999) estudaram a distribuição da taxa de formação estelar (SFR) ao longo do disco galáctico, e a relacionaram com modelos de evolução química. Na figura 4.38 é mostrada a distribuição da SFR, normalizada pela SFR na vizinhança solar, em função da distância galactocêntrica. Esta distribuição foi obtida a partir da distribuição de restos de supernovas, pulsares, fótons do contínuo Lyman e da distribuição de nuvens moleculares, segundo as fontes mencionadas na figura.

$\mathrm{Na}$ figura, pode-se ver um decréscimo da SFR para regiões internas do disco. Tal decréscimo se reflete nas abundâncias químicas dos elementos alfa em NPs, pois uma menor SFR limita a massa total ejetada pelas estrelas e, conseqüentemente, diminui o enriquecimento químico do meio interestelar através das sucessivas gerações de estrelas.

Existem inúmeras evidências da existência de uma barra nos primeiros 3 kpc da Galáxia (ver por exemplo Gerhard, 2002). A idéia foi originalmente sugerida para explicar a cinemática do gás atômica e molecular próximo ao centro Galáctico (Mulder e Liem, 1986, e referências aí contidas). Portinari e Chiosi (1999) apontam que a influência dinâmica da barra galáctica parece explicar o pico dos perfis da SFR e densidade de gás ao redor de 4 kpc, o qual os modelos de evolução química estáticos são incapazes de reproduzirem 


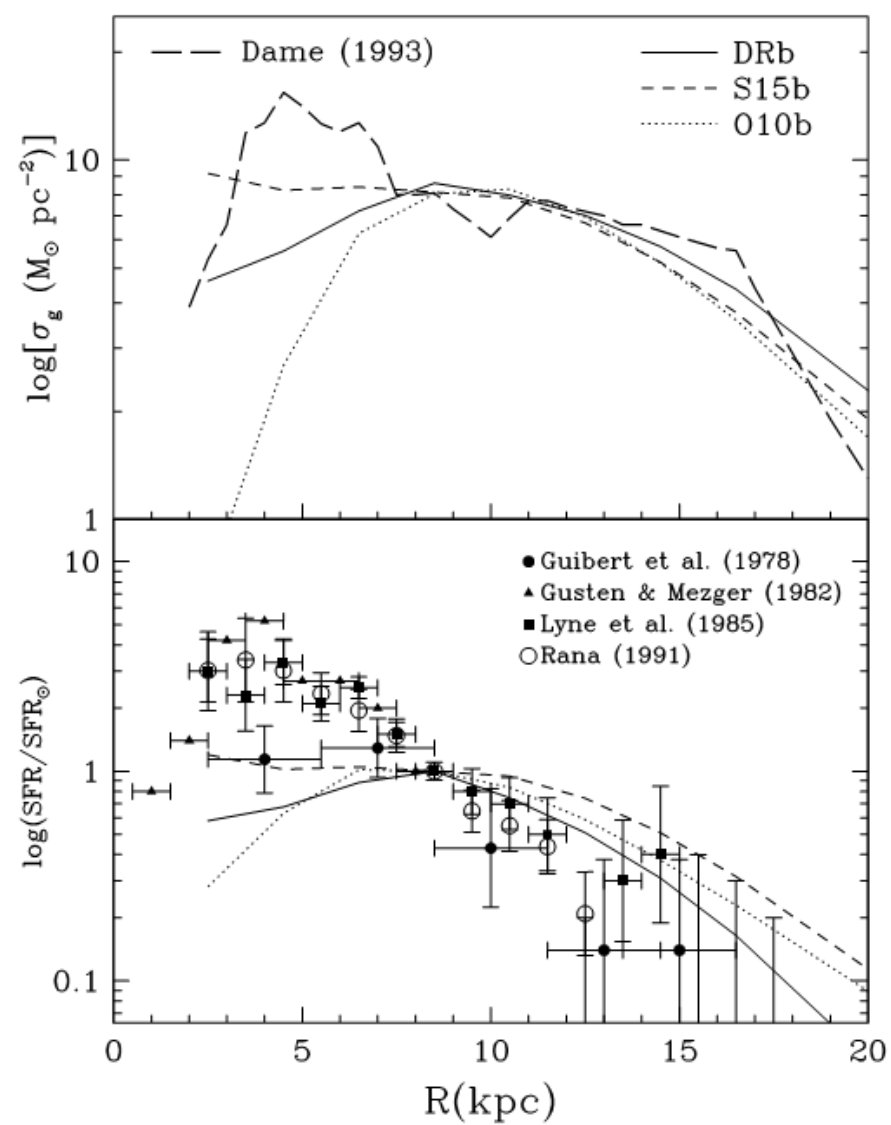

Figura 4.38: Densidade radial de gás observada e distribuição da SFR ao longo do disco galáctico, em termos da SFR local. A figura foi obtida de Portinari e Chiosi (1999).

se outros vínculos observacionais são impostos, tais como o gradiente radial de metalicidades. De fato, torques gravitacionais de um potencial barrado, ou não axi-simétrico, são indutores de acumulação de gás e formação de anéis nas correspondentes ressonâncias de Lindblad (ver por exemplo Schwarz, 1981, 1984). Os autores mostraram que fluxos induzidos por uma barra retiram gás do raio de corrotação da mesma, aproximadamente onde a barra termina, expulsando-o na direção das ressonâncias de Lindblad interna e externa. Portinari e Chiosi (2000) desenvolveram um modelo químico com fluxos radiais para reproduzir este efeito da barra sobre a distribuição de gás, através da simulação de convenientes perfis de velocidade do fluxo. Os resultados obtidos por eles mostram que é possível reproduzir a distribuição da densidade de gás, além do próprio gradiente de metalicidades, através de fluxos com velocidades tanto lentas quanto rápidas. O gradiente de abundância de oxigênio e a distribuição radial de gás podem ser vistos na figura 4.39.

O modelo proposto por Portinari e Chiosi (2000) prevê uma diminuição da abundância 


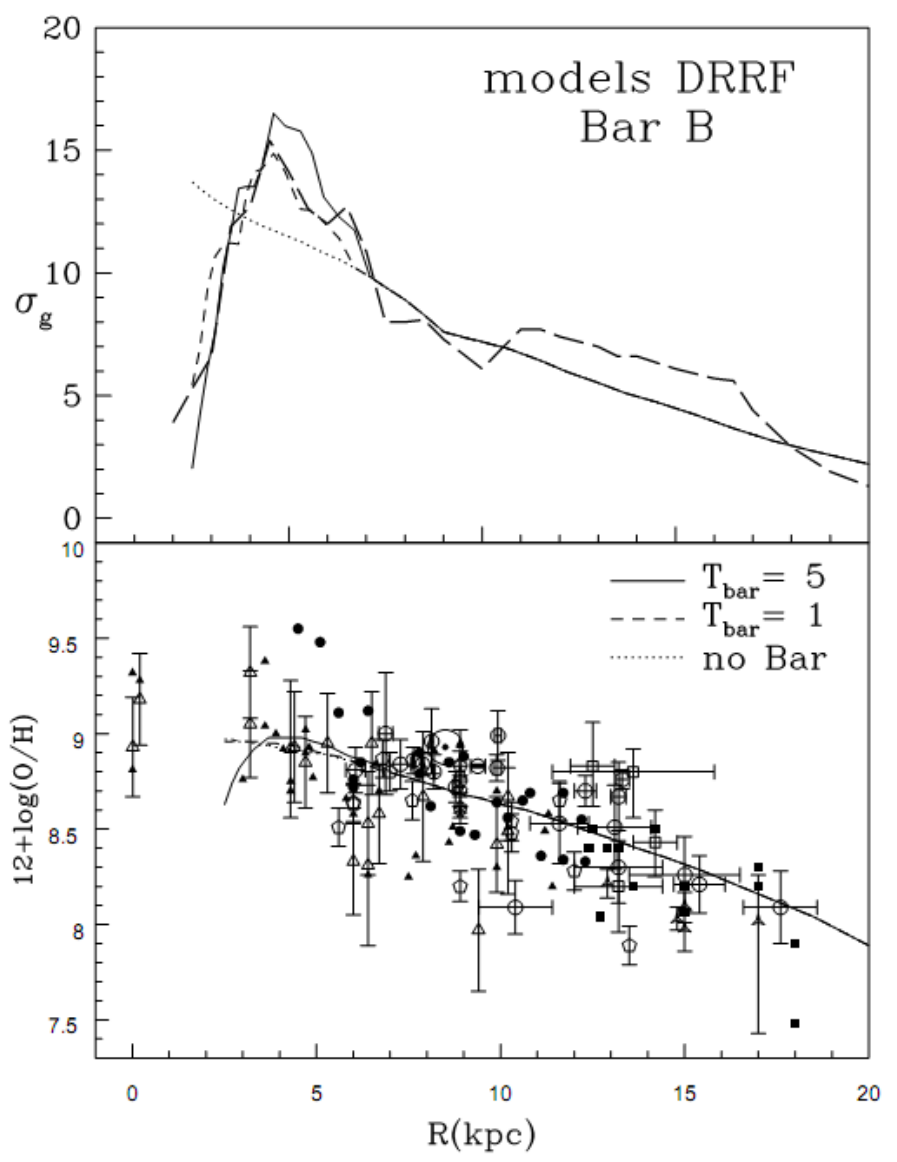

Figura 4.39: Densidade radial de gás observada e distribuição da abundância de oxigênio ao longo do disco galáctico. A figura foi obtida de Portinari e Chiosi (2000).

de oxigênio para distâncias menores que $4 \mathrm{kpc}$, porém a falta de objetos para estas distâncias dificulta a comparação com dados observacionais.

Mishurov, Lépine e Acharova (2002) estudaram a influência da corrotação na distribuição química dos elementos na Galáxia. Neste trabalho, os autores aplicam os efeitos dos braços espirais em uma teoria de enriquecimento químico para explicar as propriedades das abundâncias observadas. No disco galáctico ocorrem ressonâncias para determinados raios de órbitas, para as quais durante uma volta completa de uma estrela, no referencial em rotação com velocidade angular $\Omega_{p}$ (velocidade de rotação do padrão espiral; note que neste modelo o padrão espiral gira como um corpo rígido com $\Omega_{p}=$ constante), estas apresentam um número inteiro de máximos de elongação, devido ao movimento epicicloidal. Em particular, existem duas ressonâncias onde $\Omega_{p}=\Omega-\kappa / 2$ e $\Omega_{p}=\Omega+\kappa / 2$ denominadas ressonâncias interna e externa de Lindblad, respectivamente. $\kappa$ é a freqüência 
epicíclica. Nesta teoria, os braços são indutores de formação estelar e somente podem se formar na chamada zona de onda, localizada entre as ressonâncias de Lindblad interna e externa. Portanto, a taxa de formação estelar é nula fora destes limites, o que diminuiria a abundância observada. A ressonância interna aconteceria em 3.5 kpc, aproximadamente. 
Capítulo 5

\section{Conclusões}

\subsection{Síntese das conclusões}

Este trabalho constituiu-se da análise de abundâncias químicas de nebulosas planetárias localizadas na conexão bojo-disco. Novas abundâncias foram derivadas a partir de observações espectrofotométricas no telescópio Perkin-Elmer de 1.60 m do Laboratório Nacional de Astrofísica (LNA) em Minas Gerais, Brasil. Foram observadas nebulosas planetárias selecionadas através da localização na direção do centro da Galáxia, diâmetro angular no óptico e fluxo em rádio. Os espectros foram reduzidos através dos procedimentos padrões de redução, utilizando-se para isto o pacote IRAF. Após a redução, obteve-se os parâmetros físicos densidade e temperatura eletrônica a partir da análise das linhas de emissão observadas no espectro óptico. Posteriormente, foram calculadas as abundâncias químicas através de um método empírico, onde se calculam as abundâncias iônicas das espécies presentes no espectro através de um modelo atômico simples e a seguir estimamse as abundâncias elementais correspondentes através da aplicação de Fatores de Correção de Ionização para levar-se em conta os íons não observados.

Foi feita uma comparação entre as abundâncias obtidas neste trabalho com outros trabalhos da literatura. As distribuições das abundâncias são compatíveis, apenas o oxigênio apresentando uma tendência sistemática para abundâncias mais baixas, se comparado com as distribuições da literatura. No entanto esta diferença é de 0.2 dex, não sendo significativa pois os erros na determinação das abundâncias do oxigênio são da ordem de 0.2-0.3 dex. Alguns objetos observados em comum com outros trabalhos puderam ser utilizados para uma comparação direta entre os diferentes métodos empregados nestes trabalhos e os resultados obtidos aqui. A comparação mostrou um bom acordo entre os métodos, obtendo 
coeficientes de correlação sempre acima de 0.5. As correlações entre os elementos químicos obtidos neste trabalho se mostraram compatíveis com os dados da literatura.

Para o estudo da distribuição das abundâncias químicas na conexão bojo-disco utilizouse as escalas de distância de Maciel e Pottasch (1980) (MP80), Cahn, Kaler e Stanghellini (1992) (CKS92), e Zhang (1995) (Zhang95). Dentre estas escalas, a de MP80 se mostrou uma escala curta, resultando em uma distância heliocêntrica média para as nebulosas planetárias do bojo da ordem de $3 \mathrm{kpc}$. Com base neste fato, optou-se por recalibrar esta escala com base na distância média do bojo para a escala de Zhang95.

A distribuição das abundâncias na conexão bojo-disco foi estudada dividindo-se a amostra de cada escala em dois grupos. O grupo I representado pelas nebulosas planetárias com distâncias galactocêntricas menores que um limite estabelecido, e o grupo II representado por aquelas com distâncias maiores que este limite. Após esta divisão da amostra, computou-se a média das abundâncias químicas dos objetos pertencentes a cada grupo. Como não era conhecida a distância que separa estes grupos, de tal forma que o grupo I fosse composto por objetos pertencentes ao bojo da Galáxia, e o grupo II fosse formado por objetos pertencentes ao disco interno da Galáxia, variou-se esta distância que divide a amostra e calculou-se novamente as médias das abundâncias químicas das NPs de cada grupo. Tal separação mostrou que em média as nebulosas planetárias do grupo I apresentam menores abundâncias se comparadas as do grupo II, para as escalas de Zhang95 e CKS92. Contudo esta separação não é superior aos erros na obtenção das abundâncias, indicando apenas uma tendência. De fato, os histogramas das distribuições mostraram que existe esta tendência entre os grupos e que existe uma distância galactocêntrica para a qual o teste estatístico de Kolmogorov-Smirnov indica um máximo entre a diferença das distribuições cumulativas que originaram os grupos. Esta distância é de $1.5 \mathrm{kpc}$ para a escala de Zhang95 e de 2.9 kpc para a escala de CKS92. A escala de MP80 não apresentou resultados conclusivos a respeito da distribuição das abundâncias dos grupos I e II.

Estas distâncias encontradas podem ser interpretadas como a separação entre as propriedades químicas do bojo e o disco da Galáxia, para as respectivas escalas de distância. A distância de $2.9 \mathrm{kpc}$ encontrada para a escala de CKS92 concorda com dados de outros grupos como os de Tiede e Terndrup (1999), que não mostraram de uma forma explicita em seu trabalho que para distâncias menores que 3 kpc há uma diminuição da abundância 
média de ferro, como pode ser visto na figura 4.37. De acordo com a relação de Pagel (1989), para o intervalo de metalicidades $6.65 \leqslant \epsilon(\mathrm{O}) \leqslant 7.75$ vale a relação

$$
[\mathrm{Fe} / \mathrm{H}]=2 \epsilon(\mathrm{O})-17.40
$$

Portanto é possível comparar os resultados obtidos por Tiede e Terndrup (1999) com os obtidos neste projeto. A distância de separação das propriedades químicas das estrelas do bojo e do disco encontrada através da amostra deles coincide com a encontrada através da escala de CKS92. Dado que o erro nas distâncias estatísticas geralmente é superior a $30 \%$, estes resultados estão em excelente acordo, mostrando que o resultado para a escala de CKS92 é mais compatível com os de outros grupos.

A explicação da diminuição das abundâncias nesta região interna do disco ainda não está clara. O modelo de Portinari e Chiosi (2000) aponta para a influência da barra central da Galáxia no fluxo de gás desta região. Conseqüentemente há uma diminuição da taxa de formação estelar, implicando em metalicidades menores na região interna do disco. O modelo de Mishurov, Lépine e Acharova (2002) mostra que uma taxa de formação estelar associada ao padrão de rotação do disco pode diminuir a taxa de formação estelar na região mais interna do disco, antes da ressonância interna de Lindblad. Cabe ressaltar que estes modelos não se excluem mutuamente.

\subsection{Perspectivas}

Nesta seção são apresentadas algumas perspectivas que podem complementar os resultados encontrados neste projeto.

\subsubsection{Cinemática}

A abordagem do problema do encontro do bojo com o disco através da cinemática dos objetos é de grande importância. As propriedades cinemáticas do bojo indicam uma forte dependência com a metalicidade: Rich (1992) já havia observado que a dispersão de velocidades aumenta para objetos de menor metalicidade, baseando-se em uma amostra de gigantes K medidas na Janela de Baade. Pode-se estender este estudo para região de conexão do bojo com o disco utilizando-se nebulosas planetárias pois, por terem linhas de 
emissão intensas, suas velocidades radiais são fáceis de se medir.

\subsubsection{Modelos Quimiodinâmicos}

A descoberta de uma barra na região central da Galáxia dificulta os estudos desta região com base apenas em modelos de evolução química clássicos. A influência dos efeitos dinâmicos da barra na distribuição das abundâncias químicas na região central da Galáxia precisa ser melhor investigada. Neste contexto entram os modelos quimiodinâmicos, que têm sido utilizados para distinguir as propriedades químicas das diferentes estruturas da Galáxia (ver por exemplo Bekki e Chiba, 2001).

\subsubsection{Novos catálogos}

A recente publicação do catálogo Macquaire/AAO/Strasbourg (MASH) de nebulosas planetárias (Parker et al., 2006) abre uma perspectiva nova. Mais de 900 novos objetos são nele identificados, dos quais cerca de 500 na região do bojo. Tais objetos fornecem uma base de dados muito mais ampla como vínculo observacional das propriedades cinemáticas da região central da Galáxia. Peyaud et al. (2006) descrevem um uso desta base dados na determinação das propriedades cinemáticas do bojo, porém sem abordar o problema de sua interconexão com as outras estruturas presentes na região central da Galáxia. Adicionalmente, esta nova base de dados abre uma perspectiva de ampliação considerável da amostra de abundâncias químicas de nebulosas planetárias nesta região.

O acesso aos movimentos próprios de uma grande quantidade de objetos da região central obtidos a partir do experimento OGLE-II, tal como descrito por Sumi et al. (2004) constitui-se também numa base de dados de grande importância para a derivação das propriedades cinemáticas das distintas populações da região central da Galáxia.

\subsubsection{Espectrógrafo Goodman - SOAR}

Para o segundo semestre de 2008 está previsto entrar em operação o espectrógrafo Goodman, que será acoplado ao telescópio SOAR. Este instrumento trará grandes perspectivas para a obtenção de abundâncias químicas de nebulosas planetárias próximas ao centro da Galáxia, numa região de difícil observação devido à extinção interestelar. 


\subsubsection{Gaia}

A missão Gaia, com início previsto para dezembro de 2011, irá conduzir um censo de 1 bilhão de estrelas na Via Láctea, através de observações nos modos fotometria, espectroscopia e astrometria. Tal projeto revolucionará a Astrofísica Galáctica, pois pela primeira vez será possível estudar a Galáxia em 3 dimensões com grande precisão. 


\section{Referências Bibliográficas}

Acker A., Marcout J., Ochsenbein F., Stenholm B., Tylenda R., Strasbourg - ESO catalogue of galactic planetary nebulae. Part 1; Part 2. Garching: European Southern Observatory, 1992

Alexander J., Balick B., Nebular Abundance Errors., AJ, 1997, vol. 114, p. 713

Aller L. H., Physics of Thermal Gaseous Nebulae. Astrophysics and Space Science Library v. 112, Dordrecht, Holanda, 1984

Aller L. H., Keyes C. D., A spectroscopic survey of 51 planetary nebulae, ApJS, 1987, vol. 65 , p. 405

Ballero S. K., Matteucci F., Chiappini C., The effects of Population III stars and variable IMF on the chemical evolution of the Galaxy, New Astronomy, 2006, vol. 11, p. 306

Ballero S. K., Matteucci F., Origlia L., Rich R. M., Formation and evolution of the Galactic bulge: constraints from stellar abundances, A\&A, 2007, vol. 467, p. 123

Bekki K., Chiba M., Formation of the Galactic Stellar Halo. I. Structure and Kinematics, ApJ, 2001, vol. 558, p. 666

Binney J., Gerhard O. E., Stark A. A., Bally J., Uchida K. I., Understanding the kinematics of Galactic centre gas, MNRAS, 1991, vol. 252, p. 210

Boffi F. R., Stanghellini L., Filling factors and ionized masses in planetary nebulae, A\&A, 1994, vol. 284 , p. 248 
Bureau M., Freeman K. C., The Nature of Boxy/Peanut-Shaped Bulges in Spiral Galaxies, AJ, 1999, vol. 118, p. 126

Cabrera-Lavers A., Garzón F., Hammersley P. L., The thick disc component of the Galaxy from near infrared colour-magnitude diagrams, A\&A, 2005, vol. 433, p. 173

Cahn J. H., Kaler J. B., Stanghellini L., A catalogue of absolute fluxes and distances of planetary nebulae, A\&AS, 1992, vol. 94, p. 399

Costa R. D. D., Maciel W. J., Planetary nebulae as probes for galactic chemical evolution. In Planetary Nebulae in our Galaxy and Beyond , vol. 234 of IAU Symposium, 2006, p. 243

Cuisinier F., Acker A., Köppen J., Spectrophotometric observations of planetary nebulae high above the Galactic plane., A\&A, 1996, vol. 307, p. 215

Cuisinier F., Maciel W. J., Köppen J., Acker A., Stenholm B., Observations of planetary nebulae in the Galactic Bulge, A\&A, 2000, vol. 353, p. 543

Cunha K., Sellgren K., Smith V. V., Ramirez S. V., Blum R. D., Terndrup D. M., Chemical Abundances of Luminous Cool Stars in the Galactic Center from High-Resolution Infrared Spectroscopy, ApJ, 2007, vol. 669, p. 1011

Daub C. T., A statistical survey of local planetary nebulae, ApJ, 1982, vol. 260, p. 612

de Freitas-Pacheco J. A., Barbuy B., Costa R. D. D., Idiart T. E. P., Type-I Planetary Nebulae in the Large Magellanic Cloud - Oxygen Sulphur and Argon Abundances as Tracers of Chemical Enrichment, A\&A, 1993, vol. 271, p. 429

de Freitas Pacheco J. A., Maciel W. J., Costa R. D. D., Chemical abundances of disk planetary nebulae, A\&A, 1992, vol. 261, p. 579

de Vaucouleurs G., Interpretation of velocity distribution of the inner regions of the Galaxy. In The Galaxy and the Magellanic Clouds, vol. 20 of IAU Symposium, 1964, p. 195

Eisenhauer F., Schödel R., Genzel R., Ott T., Tecza M., Abuter R., Eckart A., Alexander T., A Geometric Determination of the Distance to the Galactic Center, ApJ, 2003, vol. 597, p. L121 
Escudero A. V., Propriedades químicas e evolução da população de massa intermediária do bojo galáctico, São Paulo: Universidade de São Paulo, 2005, Tese de Doutorado, 142 p.

Escudero A. V., Costa R. D. D., Abundances of recently discovered planetary nebulae towards the galactic bulge, A\&A, 2001, vol. 380, p. 300

Escudero A. V., Costa R. D. D., Maciel W. J., New abundances of planetary nebulae in the Galactic Bulge, A\&A, 2004, vol. 414, p. 211

Exter K. M., Barlow M. J., Walton N. A., The abundance distributions of Galactic bulge and disc planetary nebulae, MNRAS, 2004, vol. 349, p. 1291

Faundez-Abans M., Maciel W. J., Abundance gradients from type II planetary nebulae, A\&A, 1986, vol. 158, p. 228

Faundez-Abans M., Maciel W. J., Neon, argon, and chlorine abundance gradients from type II planetary nebulae, Ap\&SS, 1987, vol. 129, p. 353

Fitzpatrick E. L., Correcting for the Effects of Interstellar Extinction, PASP, 1999, vol. 111, p. 63

Fulbright J. P., McWilliam A., Rich R. M., Abundances of Baade's Window Giants from Keck HIRES Spectra. II. The Alpha and Light Odd Elements, ApJ, 2007, vol. 661, p. 1152

Fux R., 3D self-consistent N-body barred models of the Milky Way. II. Gas dynamics, A\&A, 1999, vol. 345 , p. 787

Genzel R., Hollenbach D., Townes C. H., The nucleus of our Galaxy., Reports of Progress in Physics, 1994, vol. 57, p. 417

Gerhard O., The Galactic Bar. In The Dynamics, Structure and History of Galaxies: A Workshop in Honour of Professor Ken Freeman, vol. 273 of Astronomical Society of the Pacific Conference Series, 2002, p. 73

Girard P., Köppen J., Acker A., Chemical compositions and plasma parameters of planetary nebulae with Wolf-Rayet and wels type central stars, A\&A, 2007, vol. 463, p. 265 
Górny S. K., Stasińska G., Escudero A. V., Costa R. D. D., The populations of planetary nebulae in the direction of the Galactic bulge. Chemical abundances and Wolf-Rayet central stars, A\&A, 2004, vol. 427, p. 231

Gurzadyan G. A., The Physics and Dynamics of Planetary Nebulae. Springer-Verlag, Berlin Heidelberg New York, 1997

Hajian A. R., Distances to Planetary Nebulae. In Planetary Nebulae in our Galaxy and Beyond , vol. 234 of IAU Symposium, 2006, p. 41

Immeli A., Samland M., Gerhard O., Westera P., Gas physics, disk fragmentation, and bulge formation in young galaxies, A\&A, 2004, vol. 413, p. 547

Kingdon J., Ferland G. J., Collisional effects in He I: an observational analysis, ApJ, 1995, vol. 442 , p. 714

Kingsburgh R. L., Barlow M. J., Elemental abundances for a sample of southern galctic planetary nebulae., MNRAS, 1994, vol. 271, p. 257

Kwok S., Planetary nebulae: A modern view, PASP, 1994, vol. 106, p. 344

Kwok S., The Origin and Evolution of Planetary Nebulae. Cambridge ; New York, Cambridge University Press (Cambridge astrophysics series ; 31), 2000

Köppen J., Acker A., Stenholm B., Spectrophotometric survey of southern planetary nebulae. II - Chemical compositions, A\&A, 1991, vol. 248, p. 197

Lattanzio J., Forestini M., Nucleosynthesis in AGB Stars. In Asymptotic Giant Branch Stars , vol. 191 of IAU Symposium, 1999, p. 31

Lecureur A., Hill V., Zoccali M., Barbuy B., Gómez A., Minniti D., Ortolani S., Renzini A., Oxygen, sodium, magnesium, and aluminium as tracers of the galactic bulge formation, A\&A, 2007, vol. 465, p. 799

Maciel W. J., A catalogue of distances of planetary nebulae, A\&AS, 1984, vol. 55, p. 253

Maciel W. J., Astrofísica do Meio Interestelar. Edusp, São Paulo, 2002a 
Maciel W. J., Radial Gradients and Metallicities in the Galactic Disk. In Revista Mexicana de Astronomia y Astrofisica Conference Series, vol. 12 of Revista Mexicana de Astronomia y Astrofisica, vol. 27, 2002b, p. 207

Maciel W. J., Costa R. D. D., Uchida M. M. M., An estimate of the time variation of the O/H radial gradient from planetary nebulae, A\&A, 2003, vol. 397, p. 667

Maciel W. J., Lago L. G., Costa R. D. D., An estimate of the time variation of the abundance gradient from planetary nebulae. II. Comparison with open clusters, cepheids and young objects, A\&A, 2005, vol. 433, p. 127

Maciel W. J., Lago L. G., Costa R. D. D., An estimate of the time variation of the abundance gradient from planetary nebulae. III. O, S, Ar, and Ne: a comparison of PN samples, A\&A, 2006, vol. 453, p. 587

Maciel W. J., Pottasch S. R., Distances of planetary nebulae, A\&A, 1980, vol. 88, p. 1

Maeder A., Stellar yields as a function of initial metallicity and mass limit for black hole formation, A\&A, 1992, vol. 264, p. 105

McWilliam A., Rich R. M., The first detailed abundance analysis of Galactic bulge $K$ giants in Baade's window, ApJS, 1994, vol. 91, p. 749

Milne D. K., Radio Observations at 5 GHz of Southern Planetary Nebula II, A\&AS, 1979, vol. 36 , p. 227

Milne D. K., Aller L. H., Radio observations at $5 \mathrm{GHz}$ of southern planetary nebulae., A\&A, 1975, vol. 38, p. 183

Minniti D., Field Stars and Clusters of the Galactic Bulge: Implications for Galaxy Formation, ApJ, 1996, vol. 459, p. 175

Mishurov Y. N., Lépine J. R. D., Acharova I. A., Corotation: Its Influence on the Chemical Abundance Pattern of the Galaxy, ApJ, 2002, vol. 571, p. L113

Mulder W. A., Liem B. T., Construction of a global gas-dynamical model for our galaxy, A\&A, 1986, vol. 157, p. 148 
Nikolaev S., Weinberg M. D., A Rigorous Reanalysis of the IRAS Variable Population: Scale Lengths, Asymmetries, and Microlensing, ApJ, 1997, vol. 487, p. 885

Nishiyama S., Nagata T., Sato S., Kato D., Nagayama T., Kusakabe N., Matsunaga N., Naoi T., Sugitani K., Tamura M., The Distance to the Galactic Center Derived from Infrared Photometry of Bulge Red Clump Stars, ApJ, 2006, vol. 647, p. 1093

Ortolani S., Renzini A., Gilmozzi R., Marconi G., Barbuy B., Bica E., Rich R. M., Near Coeval Formation of the Galactic Bulge and Halo Inferred from Globular Cluster Ages, Nature, 1995, vol. 377, p. 701

Osterbrock D., Flather E., Electron Densities in the Orion NEBULA.II., ApJ, 1959, vol. 129 , p. 26

Osterbrock D. E., Astrophysics of gaseous nebulae and active galactic nuclei. University Science Books, Mill Valley, California, 1989, 422 p., 1989

Pagel B. E. J., The G-dwarf problem and radio-active cosmochronology. In Evolutionary Phenomena in Galaxies, 1989, p. 201

Pagel B. E. J., Nucleosynthesis and Chemical Evolution of Galaxies. Cambridge University Press, Cambridge, UK, 1997

Pagel B. E. J., Edmunds M. G., Abundances in stellar populations and the interstellar medium in galaxies, ARA\&A, 1981, vol. 19, p. 77

Parker Q. A., Acker A., Frew D. J., Hartley M., Peyaud A. E. J., Ochsenbein F., Phillipps S., Russeil D., Beaulieu S. F., Cohen M., Köppen J., Miszalski B., Morgan D. H., Morris R. A. H., Pierce M. J., Vaughan A. E., The Macquarie/AAO/Strasbourg Ho Planetary Nebula Catalogue: MASH, MNRAS, 2006, vol. 373, p. 79

Pequignot D., Petitjean P., Boisson C., Total and effective radiative recombination coefficients, A\&A, 1991, vol. 251, p. 680

Perinotto M., Chemical abundances in planetary nebulae - Basic data and correlations between elements, ApJS, 1991, vol. 76, p. 687 
Perinotto M., Morbidelli L., Scatarzi A., A reanalysis of chemical abundances in galactic PNe and comparison with theoretical predictions, MNRAS, 2004, vol. 349, p. 793

Peyaud A. E. J., Boily C., Acker A., Parker Q., Kinematics and Dynamics of the Galactic Bulge through Planetary Nebulae. In Planetary Nebulae in our Galaxy and Beyond, vol. 234 of IAU Symposium, 2006, p. 485

Portinari L., Chiosi C., On star formation and chemical evolution in the Galactic disc, A\&A, 1999, vol. 350, p. 827

Portinari L., Chiosi C., On radial gas flows, the Galactic Bar and chemical evolution in the Galactic Disc, A\&A, 2000, vol. 355, p. 929

Pottasch S. R., Mo J.-E., Kingma S., Preite-Martinez A., Olnon F. M., IRAS spectra planetary nebulae. III, A\&A, 1986, vol. 161, p. 363

Press W. H., Teukolsky S. A., Vetterling W. T., Flannery B. P., Numerical recipes in FORTRAN. The art of scientific computing. Cambridge: University Press, - c1992, 2nd ed., 1992

Ratag M. A., Pottasch S. R., Dennefeld M., Menzies J., Abundances in planetary nebulae near the galactic centre. I. Abundance determinations, A\&AS, 1997, vol. 126, p. 297

Ratag M. A., Pottasch S. R., Dennefeld M., Menzies J. W., Abundances in planetary nebulae near the galactic center. II - Abundance distributions, A\&A, 1992, vol. 255, p. 255

Reid M. J., The distance to the center of the Galaxy, ARA\&A, 1993, vol. 31, p. 345

Renzini A., Voli M., Advanced evolutionary stages of intermediate-mass stars. I-Evolution of surface compositions, A\&A, 1981, vol. 94, p. 175

Rich R. M., Spectroscopy and abundances of 88 K giants in Baade's Window, AJ, 1988, vol. 95 , p. 828

Rich R. M., Origlia L., The First Detailed Abundances for M Giants in Baade's Window from Infrared Spectroscopy, ApJ, 2005, vol. 634, p. 1293 
Rocha-Pinto H. J., Maciel W. J., The history of star formation in the local disc from the G dwarf metallicity distribution, MNRAS, 1997, vol. 289, p. 882

Rohlfs K., Kampmann H., Galactic Elliptical Streamlines and their Large-Scale Organization. In Back to the Galaxy, vol. 278 of American Institute of Physics Conference Series, 1993, p. 122

Rolleston W. R. J., Smartt S. J., Dufton P. L., Ryans R. S. I., The Galactic metallicity gradient, A\&A, 2000, vol. 363, p. 537

Samland M., Köppen J., Acker A., Stenholm B., Spectrophotometric survey of southern planetary nebulae. III - Automatic ionization modelling, A\&A, 1992, vol. 264, p. 184

Schwarz M. P., The response of gas in a galactic disk to bar forcing, ApJ, 1981, vol. 247, p. 77

Schwarz M. P., How bar strength and pattern speed affect galactic spiral structure, MNRAS, 1984, vol. 209, p. 93

Smartt S. J., Venn K. A., Dufton P. L., Lennon D. J., Rolleston W. R. J., Keenan F. P., Chemical abundances in the inner 5 kpc of the Galactic disk, A\&A, 2001, vol. 367, p. 86

Stasińska G., Richer M. G., McCall M. L., The planetary nebulae populations in five galaxies: abundance patterns and evolution, A\&A, 1998, vol. 336, p. 667

Stasińska G., Tylenda R., Acker A., Stenholm B., An extensive study of planetary nebulae in the Galactic bulge. II - Statistical properties of the nebular envelopes, A\&A, 1991, vol. 247 , p. 173

Sumi T., Wu X., Udalski A., Szymański M., Kubiak M., Pietrzyński G., Soszyński I., Woźniak P., Żebruń K., Szewczyk O., Wyrzykowski Ł., The Optical Gravitational Lensing Experiment: catalogue of stellar proper motions in the OGLE-II Galactic bulge fields, MNRAS, 2004, vol. 348, p. 1439

Tiede G. P., Terndrup D. M., Kinematics, Metallicities, and Stellar Distributions in the Inner Disk and Bulge of the Milky Way, AJ, 1999, vol. 118, p. 895 
Torres-Peimbert S., Peimbert M., Photoelectric photometry and physical conditions of planetary nebulae., Revista Mexicana de Astronomia y Astrofisica, 1977, vol. 2, p. 181

Vallenari A., Bertelli G., Schmidtobreick L., The Galactic disk: study of four low latitude Galactic fields, A\&A, 2000, vol. 361, p. 73

van den Hoek L. B., Groenewegen M. A. T., New theoretical yields of intermediate mass stars, A\&AS, 1997, vol. 123, p. 305

van Loon J. T., Gilmore G. F., Omont A., Blommaert J. A. D. L., Glass I. S., Messineo M., Schuller F., Schultheis M., Yamamura I., Zhao H. S., Infrared stellar populations in the central parts of the Milky Way galaxy, MNRAS, 2003, vol. 338, p. 857

Webster B. L., The abundances and mass distribution of planetary nebulae in the galactic bulge, MNRAS, 1988, vol. 230, p. 377

Weiland J. L., Arendt R. G., Berriman G. B., Dwek E., Freudenreich H. T., Hauser M. G., Kelsall T., Lisse C. M., Mitra M., Moseley S. H., Odegard N. P., Silverberg R. F., Sodroski T. J., Spiesman W. J., Stemwedel S. W., COBE diffuse infrared background experiment observations of the galactic bulge, ApJ, 1994, vol. 425, p. L81

Zhang C. Y., A statistical distance scale for Galactic planetary nebulae, ApJS, 1995, vol. 98, p. 659

Zoccali M., Lecureur A., Barbuy B., Hill V., Renzini A., Minniti D., Momany Y., Gómez A., Ortolani S., Oxygen abundances in the Galactic bulge: evidence for fast chemical enrichment, A\&A, 2006, vol. 457, p. L1

Zoccali M., Renzini A., Ortolani S., Greggio L., Saviane I., Cassisi S., Rejkuba M., Barbuy B., Rich R. M., Bica E., Age and metallicity distribution of the Galactic bulge from extensive optical and near-IR stellar photometry, A\&A, 2003, vol. 399, p. 931 
Apêndice 

Apêndice A

Tabelas de fluxos 
Tabela A.1 - Fluxos desavermelhados observados em junho de 2006 relativos a $\mathrm{H} \beta$, sendo $\mathrm{F}(\mathrm{H} \beta)=100$.

\begin{tabular}{|c|c|c|c|c|c|c|c|c|c|}
\hline & He $2-207$ & IC 4699 & M 1-55 & M 3-29 & M 1-39 & M 2-40 & MA 3 & $\mathrm{MaC} 1-16$ & Mewe 1-7 \\
\hline$[\mathrm{OII}] \lambda 3727.7$ & - & - & - & - & - & - & - & - & - \\
\hline$[\mathrm{NeIII}] \lambda 3868.7$ & 128.0 & 125.0 & - & 107.0 & - & - & 74.2 & 118.2 & 20.7 \\
\hline H6ג3889 & 21.5 & 19.0 & 11.8 & 37.1 & 32.1 & 36.4 & 39.3 & 26.3 & 40.6 \\
\hline$[\mathrm{NeIII}] \lambda 3967.4$ & 60.8 & 50.9 & 19.0 & 53.7 & 38.3 & 44.0 & 44.0 & 47.9 & 784.3 \\
\hline H5 $\lambda 3970.1$ & - & - & - & - & - & - & - & - & 68.1 \\
\hline $\mathrm{H} \delta \quad \lambda 4101.7$ & 27.1 & 27.0 & 24.6 & 34.5 & 34.9 & 41.9 & 36.5 & 29.4 & 42.6 \\
\hline $\mathrm{H} \gamma \lambda 4340.5$ & 49.4 & 47.2 & 50.1 & 46.0 & 57.6 & 55.5 & 53.3 & 45.2 & 64.4 \\
\hline [OIII] $\lambda 4363.2$ & 20.7 & 16.3 & - & 4.1 & - & 2.8 & 5.9 & 5.9 & 11.2 \\
\hline $\mathrm{HeI} \lambda 4471.5$ & 4.3 & 5.3 & - & 5.8 & 7.2 & 11.2 & 4.8 & 6.0 & 5.1 \\
\hline HeII $\lambda 4685.7$ & 67.0 & 29.7 & - & - & 3.3 & - & - & 17.0 & 61.1 \\
\hline$[\mathrm{ArIV}] \lambda 4711.2$ & 10.8 & 5.2 & 2.0 & - & - & - & 5.3 & 2.3 & 5.3 \\
\hline$[\mathrm{ArIV}] \lambda 4740.2$ & 7.5 & 4.6 & - & - & - & - & 3.3 & 1.3 & 3.7 \\
\hline $\mathrm{H} \beta \lambda 4861.3$ & 100.0 & 100.0 & 100.0 & 100.0 & 100.0 & 100.0 & 100.0 & 100.0 & 100.0 \\
\hline [OIII $] \lambda 4959.5$ & 505.2 & 401.7 & - & 189.6 & 17.1 & 87.5 & 191.9 & 257.0 & 206.6 \\
\hline [OIII] $\lambda 5007.6$ & 1531.0 & 1188.0 & 1.2 & 546.9 & 51.3 & 245.7 & 540.8 & 776.1 & 614.8 \\
\hline$[\mathrm{NI}] \lambda 5199.1$ & 5.0 & - & 1.6 & - & 1.7 & - & - & 11.2 & 1.0 \\
\hline$[\mathrm{CaV}] \lambda 5309.2$ & - & - & - & - & - & - & - & 1.9 & - \\
\hline $\operatorname{HeII} \lambda 5411.5$ & 5.9 & 2.2 & - & - & 0.4 & - & - & 1.8 & 5.7 \\
\hline$[\mathrm{CIIII}] \lambda 5517.7$ & 2.7 & - & - & - & - & - & - & - & - \\
\hline [CIIII] $\lambda 5537.9$ & 2.4 & - & - & - & - & - & - & - & - \\
\hline$[\mathrm{NII}] \lambda 5754.6$ & 6.7 & - & 1.4 & 0.8 & 3.0 & 2.7 & 0.6 & 8.5 & 0.8 \\
\hline $\operatorname{HeI} \lambda 5875.8$ & 11.5 & 8.4 & 0.8 & 12.6 & 13.4 & 23.5 & 12.7 & 22.2 & 13.6 \\
\hline$[\mathrm{OI}] \lambda 6300.3$ & 15.4 & 0.3 & 2.3 & 0.4 & 2.2 & 0.5 & 0.6 & 37.5 & 1.8 \\
\hline [SIII] $\lambda 6312.1$ & 7.4 & 0.4 & - & 0.7 & 0.8 & 1.2 & 0.8 & 2.2 & 0.8 \\
\hline$[\mathrm{OI}] \lambda 6363.8$ & 5.5 & - & 0.9 & 0.6 & 0.8 & 0.3 & - & 12.9 & 0.9 \\
\hline$[\mathrm{ArV}] \lambda 6434.7$ & 1.0 & 0.3 & - & 0.2 & 0.1 & - & - & - & 0.1 \\
\hline$[\mathrm{NII}] \lambda 6548.1$ & 138.3 & - & 73.5 & 22.0 & 114.7 & 217.5 & 3.0 & 226.8 & 2.0 \\
\hline $\mathrm{H} \alpha \lambda 6562.9$ & 285.0 & 285.0 & 285.0 & 285.0 & 285.0 & 285.0 & 285.0 & 284.9 & 285.2 \\
\hline$[\mathrm{NII}] \lambda 6583.5$ & 395.6 & - & 191.4 & 66.5 & 313.3 & 205.1 & 9.0 & 680.8 & 6.1 \\
\hline $\operatorname{HeI} \lambda 6678.2$ & 3.9 & 3.4 & 0.2 & 4.1 & 3.4 & 7.3 & 4.0 & 7.0 & 4.6 \\
\hline$[\mathrm{SII}] \lambda 6723$ & 104.4 & 1.1 & 30.9 & 7.8 & 14.5 & 11.6 & 1.6 & 137.7 & 3.2 \\
\hline$[\mathrm{ArV}] \lambda 7005.6$ & 2.0 & - & 0.2 & - & - & - & - & - & 1.5 \\
\hline HeI $\lambda 7065.5$ & 3.0 & 2.1 & 0.3 & 3.1 & 4.5 & 9.8 & 4.1 & 5.0 & 2.0 \\
\hline$[$ ArIII $] \lambda 7135.8$ & 48.5 & 4.1 & 0.5 & 9.8 & 10.5 & 34.0 & 9.8 & 27.6 & 11.3 \\
\hline$[\mathrm{ArIV}] \lambda 7170.5$ & - & 1.2 & - & - & - & - & - & - & 1.9 \\
\hline HeII $\lambda 7177.5$ & 1.4 & - & - & - & - & - & - & - & 0.6 \\
\hline$[\mathrm{ArIV}] \lambda 7238.1$ & 2.0 & - & - & - & 0.6 & 2.3 & - & - & 4.5 \\
\hline$[\mathrm{ArIV}] \lambda 7263$ & - & - & - & - & - & - & - & - & - \\
\hline$[\mathrm{OII}] \lambda 7325$ & 11.5 & 1.3 & 4.9 & 3.0 & 7.2 & 15.3 & 2.4 & 18.1 & 4.2 \\
\hline$[\mathrm{ArIII}] \lambda 7751.4$ & 16.8 & 4.8 & - & 6.8 & 2.5 & 19.7 & 2.7 & 12.3 & 8.6 \\
\hline
\end{tabular}


Tabela A.1 - Continuação

\begin{tabular}{|c|c|c|c|c|c|c|c|c|c|}
\hline & Pc 21 & Pe 1-6 & Sa $1-5$ & Sa $2-230$ & StWr 2-21 & StWr 4-10 & Th 4-11 & Vd 1-3 & Vd 1-4 \\
\hline$[\mathrm{OII}] \lambda 3727.7$ & - & - & - & - & - & - & - & - & - \\
\hline$[\mathrm{NeIII}] \lambda 3868.7$ & 76.4 & 88.2 & 108.1 & 104.6 & 97.9 & 86.2 & 67.0 & - & 132.0 \\
\hline H6ג3889 & 14.2 & 46.9 & 12.4 & 22.6 & 21.9 & 20.6 & 35.0 & 19.0 & 20.4 \\
\hline$[\mathrm{NeIII}] \lambda 3967.4$ & 40.4 & 63.3 & 46.6 & 56.6 & 56.4 & 39.7 & 45.5 & - & 43.8 \\
\hline H5 $\lambda 3970.1$ & - & - & 40.1 & - & - & - & - & - & - \\
\hline $\mathrm{H} \delta \quad \lambda 4101.7$ & 31.7 & 40.9 & 30.6 & 45.2 & 30.8 & 25.6 & 44.0 & 28.9 & 31.5 \\
\hline $\mathrm{H} \gamma \lambda 4340.5$ & 47.5 & 58.8 & 51.3 & 55.5 & 50.1 & 48.5 & 52.3 & 51.6 & 52.0 \\
\hline$[\mathrm{OIII}] \lambda 4363.2$ & 12.8 & 14.9 & 11.9 & 12.0 & 12.6 & 10.1 & 29.7 & - & 17.1 \\
\hline $\operatorname{HeI} \lambda 4471.5$ & 3.7 & 10.2 & 6.0 & 5.7 & 4.3 & 6.7 & 6.6 & 6.0 & 6.6 \\
\hline HeII $\lambda 4685.7$ & 102.4 & 32.2 & 2.6 & 115.4 & 41.3 & - & 8.4 & - & 4.8 \\
\hline$[\mathrm{ArIV}] \lambda 4711.2$ & 13.5 & 9.3 & 3.6 & 12.7 & 4.7 & - & 2.2 & - & 2.0 \\
\hline$[\mathrm{ArIV}] \lambda 4740.2$ & 10.2 & 4.5 & 3.6 & 9.7 & 3.8 & - & 1.3 & - & 2.2 \\
\hline $\mathrm{H} \beta \lambda 4861.3$ & 100.0 & 100.0 & 100.0 & 100.0 & 100.0 & 100.0 & 100.0 & 100.0 & 100.0 \\
\hline$[\mathrm{OIII}] \lambda 4959.5$ & 242.6 & 248.4 & 387.6 & 295.5 & 359.1 & 283.2 & 29.2 & 36.2 & 384.8 \\
\hline$[\mathrm{OIII}] \lambda 5007.6$ & 735.8 & 771.3 & 1113.2 & 879.8 & 1066.2 & 851.0 & 81.8 & 110.2 & 1125.7 \\
\hline$[\mathrm{NI}] \lambda 5199.1$ & 0.6 & - & - & 0.4 & 0.6 & - & 0.7 & 0.5 & 0.7 \\
\hline$[\mathrm{CaV}] \lambda 5309.2$ & - & - & - & - & - & - & 0.9 & - & - \\
\hline HeII $\lambda 5411.5$ & 9.5 & 2.8 & - & 9.7 & 3.9 & - & 0.9 & - & 0.5 \\
\hline$[\mathrm{ClIII}] \lambda 5517.7$ & 1.2 & - & - & 1.2 & 0.7 & - & 0.3 & - & - \\
\hline$[\mathrm{ClIII}] \lambda 5537.9$ & 0.9 & - & - & 0.9 & 0.7 & - & - & - & 0.7 \\
\hline$[\mathrm{NII}] \lambda 5754.6$ & 0.3 & 1.6 & 0.7 & 0.9 & 0.4 & - & 0.7 & 1.2 & 2.1 \\
\hline $\operatorname{HeI} \lambda 5875.8$ & 6.2 & 9.6 & 16.8 & 8.4 & 10.7 & 15.2 & 18.1 & 13.6 & 18.3 \\
\hline$[\mathrm{OI}] \lambda 6300.3$ & 0.7 & 0.2 & 2.0 & - & 2.3 & - & 0.8 & 5.0 & 9.4 \\
\hline$[\mathrm{SIII}] \lambda 6312.1$ & 2.1 & 0.5 & 1.4 & 3.3 & 1.7 & 0.6 & 0.6 & - & 1.4 \\
\hline$[\mathrm{OI}] \lambda 6363.8$ & 0.3 & - & 0.7 & 0.5 & 0.9 & - & 0.7 & 1.7 & 3.2 \\
\hline$[\mathrm{ArV}] \lambda 6434.7$ & 2.2 & - & - & 1.2 & 0.2 & - & 0.2 & - & - \\
\hline$[\mathrm{NII}] \lambda 6548.1$ & 2.7 & 6.0 & 5.9 & 5.1 & 15.1 & - & 4.7 & 50.4 & 23.5 \\
\hline $\mathrm{H} \alpha \lambda 6562.9$ & 284.7 & 285.0 & 285.0 & 285.0 & 284.6 & 285.0 & 285.0 & 285.0 & 285.0 \\
\hline$[\mathrm{NII}] \lambda 6583.5$ & 8.2 & 18.2 & 17.8 & 15.4 & 18.6 & - & 14.1 & 139.5 & 51.5 \\
\hline $\operatorname{HeI} \lambda 6678.2$ & 2.6 & 3.5 & 4.0 & 2.7 & 3.3 & 3.6 & 3.9 & 3.8 & 4.3 \\
\hline$[\mathrm{SII}] \lambda 6723$ & 3.9 & 3.6 & 4.2 & 7.6 & 6.4 & - & 1.6 & 48.8 & 5.0 \\
\hline$[\mathrm{ArV}] \lambda 7005.6$ & 4.8 & - & - & 2.2 & 0.5 & - & 0.4 & - & - \\
\hline HeI $\lambda 7065.5$ & 1.2 & 2.2 & 5.3 & 0.9 & 3.3 & 3.8 & 12.1 & 2.1 & 9.8 \\
\hline$[\mathrm{ArIII}] \lambda 7135.8$ & 12.3 & 16.5 & 9.4 & 20.0 & 12.6 & 7.3 & 1.3 & 8.3 & 11.0 \\
\hline$[\mathrm{ArIV}] \lambda 7170.5$ & 0.7 & - & - & - & - & - & 0.3 & - & 0.2 \\
\hline HeII $\lambda 7177.5$ & 1.9 & - & - & 1.3 & 0.7 & - & - & - & - \\
\hline$[\mathrm{ArIV}] \lambda 7238.1$ & 0.5 & 1.6 & - & 0.6 & 0.8 & - & 0.3 & - & 1.1 \\
\hline$[\mathrm{ArIV}] \lambda 7263$ & 0.5 & - & - & - & 0.3 & - & 0.2 & - & - \\
\hline$[\mathrm{OII}] \lambda 7325$ & 3.4 & 3.5 & 4.2 & 3.7 & 3.9 & - & 0.9 & 6.6 & 17.6 \\
\hline$[\mathrm{ArIII}] \lambda 7751.4$ & 5.1 & 3.2 & 2.6 & 5.8 & 4.9 & 2.1 & 0.3 & 3.0 & 2.9 \\
\hline
\end{tabular}


Tabela A.1 - Continuação

\begin{tabular}{|c|c|c|c|c|}
\hline & Vd 1-5 & Vd 1-8 & Vd 1-9 & Wray $16-385$ \\
\hline$[\mathrm{OII}] \lambda 3727.7$ & - & - & - & - \\
\hline$[\mathrm{NeIII}] \lambda 3868.7$ & 87.1 & 188.8 & 121.5 & 62.1 \\
\hline H6 23889 & 20.9 & 125.6 & 56.2 & - \\
\hline$[\mathrm{NeIII}] \lambda 3967.4$ & 70.9 & 73.4 & - & 58.8 \\
\hline Н5 23970.1 & - & - & - & - \\
\hline $\mathrm{H} \delta \lambda 4101.7$ & 32.1 & 33.1 & - & 13.5 \\
\hline $\mathrm{H} \gamma \lambda 4340.5$ & 46.2 & 85.0 & 49.5 & 38.8 \\
\hline$[\mathrm{OIII}] \lambda 4363.2$ & 17.3 & 47.4 & 7.6 & 6.2 \\
\hline HeI $\lambda 4471.5$ & 4.2 & 27.2 & 11.2 & 15.7 \\
\hline HeII $\lambda 4685.7$ & 39.7 & 15.0 & 4.5 & - \\
\hline$[\mathrm{ArIV}] \lambda 4711.2$ & 8.8 & 10.1 & 10.6 & 5.2 \\
\hline$[\mathrm{ArIV}] \lambda 4740.2$ & 8.3 & 14.0 & 2.8 & - \\
\hline $\mathrm{H} \beta \lambda 4861.3$ & 100.0 & 100.0 & 100.0 & 100.0 \\
\hline [OIII] $] 44959.5$ & 439.7 & 526.2 & 297.1 & 416.9 \\
\hline$[\mathrm{OIII}] \lambda 5007.6$ & 1316.0 & 1526.4 & 829.3 & 1208.4 \\
\hline$[\mathrm{NI}] \lambda 5199.1$ & 0.4 & 1.4 & 0.7 & - \\
\hline$[\mathrm{CaV}] \lambda 5309.2$ & 0.3 & - & - & 2.0 \\
\hline HeII $\lambda 5411.5$ & 3.8 & 2.3 & 0.3 & - \\
\hline [ClIII] $] \lambda 5517.7$ & - & - & - & - \\
\hline$[\mathrm{ClIII}] \lambda 5537.9$ & - & - & - & - \\
\hline$[\mathrm{NII}] \lambda 5754.6$ & 0.2 & 2.5 & 1.3 & 1.4 \\
\hline HeI $\lambda 5875.8$ & 11.1 & 18.5 & 18.8 & 19.9 \\
\hline$[\mathrm{OI}] \lambda 6300.3$ & 0.3 & 6.6 & 2.7 & 6.8 \\
\hline$[\mathrm{SIII}] \lambda 6312.1$ & 0.8 & 2.1 & 1.2 & - \\
\hline$[\mathrm{OI}] \lambda 6363.8$ & 0.1 & 2.1 & 1.1 & - \\
\hline$[\mathrm{ArV}] \lambda 6434.7$ & 0.6 & 0.4 & - & - \\
\hline$[\mathrm{NII}] \lambda 6548.1$ & 1.8 & 13.1 & 26.0 & - \\
\hline $\mathrm{H} \alpha \lambda 6562.9$ & 285.0 & 285.0 & 286.0 & 285.0 \\
\hline$[\mathrm{NII}] \lambda 6583.5$ & 5.2 & 39.7 & 26.9 & - \\
\hline $\mathrm{HeI} \lambda 6678.2$ & 3.2 & 3.8 & 4.7 & 5.0 \\
\hline$[\mathrm{SII}] \lambda 6723$ & 1.8 & 6.6 & 4.7 & 1.8 \\
\hline$[\mathrm{ArV}] \lambda 7005.6$ & 0.7 & 0.6 & - & 0.8 \\
\hline HeI $\lambda 7065.5$ & 2.7 & 6.4 & 7.7 & 3.1 \\
\hline$[$ ArIII] $] 7135.8$ & 10.2 & 12.8 & 13.6 & 11.5 \\
\hline$[$ ArIV $] \lambda 7170.5$ & 0.8 & 0.4 & - & - \\
\hline HeII $\lambda 7177.5$ & 0.7 & - & - & - \\
\hline$[\mathrm{ArIV}] \lambda 7238.1$ & - & 0.3 & 0.6 & - \\
\hline$[$ ArIV $] \lambda 7263$ & 0.4 & 0.3 & - & - \\
\hline$[\mathrm{OII}] \lambda 7325$ & 1.4 & 9.9 & 7.7 & - \\
\hline$[$ ArIII] $\lambda 7751.4$ & 3.0 & 2.9 & 3.3 & 23.8 \\
\hline
\end{tabular}


Tabela A.2 - Fluxos desavermelhados dos objetos observados em junho de 2007. Os fluxos são relativos a $\mathrm{H} \beta$ sendo $\mathrm{F}(\mathrm{H} \beta)=100$.

\begin{tabular}{|c|c|c|c|c|c|c|c|c|c|c|}
\hline & H1-60 & $\mathrm{H} 2-10$ & $\mathrm{H} 2-1$ & $\mathrm{H} 2-35$ & Hen 2-155 & M1-38 & M1-45 & M1-47 & M3-23 & H1-9 \\
\hline$[\mathrm{OII}] \lambda 3727.7$ & 5.05 & 41.14 & 133.13 & 76.59 & 61.03 & 110.91 & 87.4 & 9.53 & 15.27 & 100.03 \\
\hline$[\mathrm{NeIII}] \lambda 3868.7$ & 82.06 & 178.68 & 7.23 & 91.2 & 111.31 & - & - & 113.16 & 143.33 & 8.07 \\
\hline H6ג3889 & 16.24 & 31.81 & 16.51 & - & 18.91 & 19.13 & 30.96 & 18.49 & 8.44 & 23.68 \\
\hline$[\mathrm{NeIII}] \lambda 3967.4$ & 34.65 & 43.07 & 15.75 & 48.8 & 46.4 & 14.31 & 25.14 & 39.87 & 51.23 & 16.01 \\
\hline Н5 & - & - & - & - & - & - & - & - & - & - \\
\hline $\mathrm{H} \delta \lambda 4101.7$ & 27.62 & 38.99 & 23.52 & 31.28 & 26.73 & 24.17 & 37.3 & 26.44 & 33.14 & 30.66 \\
\hline $\mathrm{H} \gamma \lambda 4340.5$ & 46.97 & 53.7 & 42.65 & 48.35 & 46.18 & 43.38 & 53.47 & 45.18 & 53.28 & 48.76 \\
\hline$[\mathrm{OIII}] \lambda 4363.2$ & 7.6 & 13.12 & 2.34 & 7.79 & 6.76 & - & 3.88 & 11.52 & 19.99 & 3.35 \\
\hline $\operatorname{HeI} \lambda 4471.5$ & 7.63 & 8.28 & 3.21 & 7.89 & 4.96 & - & 4.49 & 6.53 & 2.81 & 4.73 \\
\hline HeII $\lambda 4685.7$ & 6.23 & 1.72 & 0.11 & 29.16 & 6.62 & - & 3.18 & 4.08 & 105.73 & - \\
\hline$[\mathrm{ArIV}] \lambda 4711.2$ & 3.94 & 2.83 & - & - & 3.14 & - & - & 3.45 & 22.33 & 2.76 \\
\hline$[\mathrm{ArIV}] \lambda 4740.2$ & 2.29 & 2.47 & - & - & 2.41 & - & - & 2.49 & 17.7 & - \\
\hline $\mathrm{H} \beta \lambda 4861.3$ & 100 & 100 & 100 & 100 & 100 & 100 & 100 & 100 & 100 & 100 \\
\hline [OIII] $] \lambda 4959.5$ & 317.02 & 345.79 & 27.51 & 247.32 & 343.11 & - & 1.26 & 399.31 & 387.45 & 55.61 \\
\hline$[\mathrm{OIII}] \lambda 5007.6$ & 924.59 & 949.38 & 82.74 & 725.56 & 996.26 & 2.06 & 1.97 & 1184.4 & 1106.41 & 153.12 \\
\hline$[\mathrm{NI}] \lambda 5199.1$ & - & - & 0.53 & 0.54 & 0.71 & 1.27 & 1.59 & - & - & 1.19 \\
\hline$[\mathrm{CaV}] \lambda 5309.2$ & 1.78 & - & - & 1.19 & 0.25 & - & - & - & - & - \\
\hline HeII $\lambda 5411.5$ & 1.02 & 0.27 & - & 2.1 & 0.82 & - & - & - & 7.33 & 0.97 \\
\hline [ClIII] $] \lambda 5517.7$ & - & - & - & - & - & - & - & - & - & - \\
\hline [CIIII] $]$ 5537.9 & - & - & - & - & - & - & - & - & - & - \\
\hline$[\mathrm{NII}] \lambda 5754.6$ & - & 0.62 & 2.94 & 1.43 & 0.66 & 1.18 & 1.26 & 0.2 & 0.59 & 5.49 \\
\hline HeI $\lambda 5875.8$ & 15.57 & 17.38 & 9.52 & 10.6 & 17.67 & 2.19 & 2.35 & 13.84 & 4.08 & 13.32 \\
\hline$[\mathrm{OI}] \lambda 6300.3$ & 0.72 & 1.84 & 2.01 & 1.53 & 1.58 & 2.23 & 1.51 & - & 0.34 & 2.57 \\
\hline$[\mathrm{SIII}] \lambda 6312.1$ & 0.61 & 1.07 & 1.55 & 0.9 & 1.23 & 0.23 & 0.19 & 0.61 & 3.62 & 2.7 \\
\hline$[\mathrm{OI}] \lambda 6363.8$ & 0.21 & 0.62 & 0.85 & 0.46 & 0.63 & 0.89 & 0.63 & - & 0.29 & 0.96 \\
\hline$[\mathrm{ArV}] \lambda 6434.7$ & 0.52 & 0.08 & 0.17 & - & - & - & 0.1 & - & 2.67 & - \\
\hline [NII] $\lambda 6548.1$ & 1.74 & 7.38 & 32.23 & 43.81 & 23.09 & 77.82 & 80.22 & - & 4.29 & 31.55 \\
\hline $\mathrm{H} \alpha \lambda 6562.9$ & 202.87 & 285 & 285 & 285 & 285 & 285 & 285 & 285 & 285 & 285 \\
\hline [NII] $\lambda 6583.5$ & 5.26 & 12.09 & 94.46 & 115.46 & 39.54 & 175.25 & 222.59 & - & 12.79 & 89.85 \\
\hline $\mathrm{HeI} \lambda 6678.2$ & 5.04 & 3.73 & 2.83 & 4.99 & 4.91 & 0.97 & 1.11 & 4.82 & 2.99 & 3.84 \\
\hline$[\mathrm{SII}] \lambda 6723$ & 0.82 & 1 & 2.29 & 18.05 & 4.26 & 10.29 & 7.98 & 0.29 & 3.72 & 0.87 \\
\hline$[\mathrm{ArV}] \lambda 7005.6$ & - & - & 0.57 & - & - & 0.75 & 0.25 & - & 7.06 & 0.8 \\
\hline HeI $\lambda 7065.5$ & 5.22 & 3.5 & 5.67 & 2.48 & 3.51 & 1.81 & 0.74 & 5.1 & 1.28 & 9.49 \\
\hline$[$ ArIII] $] \lambda 7135.8$ & 7.98 & 7.67 & 6.02 & 20.55 & 12.26 & 1.35 & 0.73 & 5.74 & 23.39 & 9.01 \\
\hline$[\mathrm{ArIV}] \lambda 7170.5$ & - & - & - & - & - & - & - & - & 2.55 & - \\
\hline HeII $\lambda 7177.5$ & - & - & - & - & - & - & - & - & - & - \\
\hline$[\mathrm{ArIV}] \lambda 7238.1$ & 2 & 0.27 & 0.35 & 1.04 & 0.63 & - & 0.77 & 2.23 & 1.77 & - \\
\hline$[\mathrm{ArIV}] \lambda 7263$ & - & 0.27 & - & - & - & - & - & - & 1.17 & - \\
\hline$[\mathrm{OII}] \lambda 7325$ & 3.54 & 4.51 & 37.03 & - & 2.92 & 6.22 & 1.7 & 0.98 & 2.16 & 87.4 \\
\hline$[\mathrm{ArIII}] \lambda 7751.4$ & 3.86 & 1.67 & 1.85 & 7.17 & 3.91 & 1.23 & - & 2.02 & 7.18 & 2.18 \\
\hline
\end{tabular}


Tabela A.2 - Continuação

\begin{tabular}{|c|c|c|c|c|c|c|c|c|c|c|}
\hline & K3-11 & $\mathrm{M} 2-22$ & M3-28 & M3-53 & Pe1-15 & Pe1-6 & Th3-25 & H1-17 & H1-6 & $\mathrm{H} 2-45$ \\
\hline$[\mathrm{OII}] \lambda 3727.7$ & 133.34 & 42.56 & 108.31 & - & 9.73 & 56.09 & 82.8 & 39.7 & - & - \\
\hline$[\mathrm{NeIII}] \lambda 3868.7$ & 66.06 & 104.06 & 116.08 & - & 64.93 & 142.29 & 53.65 & 120.79 & 130.87 & 94.35 \\
\hline H6 33889 & 68.55 & 23.34 & - & - & 14.41 & - & 34.62 & 26.18 & 25.42 & 20.95 \\
\hline$[\mathrm{NeIII}] \lambda 3967.4$ & 18.47 & 42.18 & 55.11 & - & 24.77 & 54.94 & 21.07 & 63.17 & 98.94 & 26.88 \\
\hline H5 23970.1 & - & - & - & - & - & - & 11.57 & - & - & - \\
\hline $\mathrm{H} \delta \lambda 4101.7$ & 193.01 & 36.02 & 40.2 & - & 28.08 & 49.59 & 42.42 & 36.15 & 11.44 & 26.91 \\
\hline $\mathrm{H} \gamma \lambda 4340.5$ & 61.77 & 58.24 & 51.55 & 258.63 & 42.04 & 54.35 & 52.59 & 50.75 & 42.74 & 49.69 \\
\hline$[\mathrm{OIII}] \lambda 4363.2$ & 13.78 & 9.04 & 17.95 & 121.3 & 3.32 & 10.55 & 9.62 & 23.83 & 19.9 & 11.81 \\
\hline $\mathrm{HeI} \lambda 4471.5$ & - & 9.03 & 11.28 & - & 6.97 & 12.48 & 10.78 & 11.18 & 23.12 & 11.14 \\
\hline HeII $\lambda 4685.7$ & 2.67 & 33.63 & 18.83 & - & 6.07 & 34.44 & - & 7.09 & 26.17 & - \\
\hline$[\mathrm{ArIV}] \lambda 4711.2$ & - & 7 & 13.5 & 40.73 & 2.06 & 5.96 & 1.68 & 5.68 & - & 3.06 \\
\hline$[\mathrm{ArIV}] \lambda 4740.2$ & - & 5.69 & 10.44 & 51.85 & 2.42 & 5.54 & 1.33 & 8.2 & - & 2.94 \\
\hline $\mathrm{H} \beta \lambda 4861.3$ & 100 & 100 & 100 & 100 & 100 & 100 & 100 & 100 & 100 & 100 \\
\hline$[\mathrm{OIII}] \lambda 4959.5$ & 2.9 & 267.15 & 418 & 402.76 & 250.06 & 250.42 & 166.08 & 496.26 & 243.81 & 328.16 \\
\hline$[\mathrm{OIII}] \lambda 5007.6$ & 2.11 & 770.17 & 1236.01 & 1042.18 & 734.67 & 736.43 & 438.36 & 1458.73 & 768.18 & 948.68 \\
\hline$[\mathrm{NI}] \lambda 5199.1$ & - & 3.72 & 4.76 & 32.54 & 0.81 & 2.03 & - & - & 8.74 & - \\
\hline$[\mathrm{CaV}] \lambda 5309.2$ & - & - & - & - & - & - & 0.53 & - & - & - \\
\hline HeII $\lambda 5411.5$ & - & 3.99 & 2.39 & - & - & 4.12 & - & 2.22 & 4.64 & 0.61 \\
\hline$[\mathrm{ClIII}] \lambda 5517.7$ & - & - & - & - & - & - & - & - & - & - \\
\hline$[\mathrm{ClIII}] \lambda 5537.9$ & - & - & - & - & - & - & - & - & - & - \\
\hline$[\mathrm{NII}] \lambda 5754.6$ & 1.94 & 4.63 & 10.88 & 15.32 & 0.73 & 3.01 & 1.35 & 6.42 & 14.06 & - \\
\hline $\mathrm{HeI} \lambda 5875.8$ & 1.17 & 13.11 & 17.59 & 21.53 & 18.18 & 20.72 & 15.91 & 23.1 & 28.5 & 15.15 \\
\hline [OI] $] 6300.3$ & 1.61 & 4.84 & 19 & 23.57 & 0.34 & 1.32 & 1.7 & 13.51 & 33.28 & 1.06 \\
\hline$[\mathrm{SIII}] \lambda 6312.1$ & 0.29 & 1.26 & 1.66 & 4.73 & 0.64 & 0.74 & 1.09 & 4.69 & 4.51 & 0.93 \\
\hline [OI] $] 6363.8$ & 0.8 & 1.55 & 6.31 & 8.59 & - & 0.83 & 0.52 & 4.59 & 13.76 & 0.49 \\
\hline$[\mathrm{ArV}] \lambda 6434.7$ & - & 0.62 & - & - & - & 0.47 & 0.15 & 0.42 & - & 0.29 \\
\hline$[\mathrm{NII}] \lambda 6548.1$ & 67.57 & 66.63 & 191.33 & 183.64 & 3.79 & 6.77 & 18.31 & 40.04 & 275.33 & 2.16 \\
\hline $\mathrm{H} \alpha \lambda 6562.9$ & 285 & 285 & 285 & 285 & 285 & 285 & 285 & 285 & 285 & 285 \\
\hline$[\mathrm{NII}] \lambda 6583.5$ & 186.46 & 176.44 & 556.59 & 529.83 & 11.3 & 19.98 & 41.61 & 100.15 & 811.49 & 6.4 \\
\hline $\mathrm{HeI} \lambda 6678.2$ & 0.72 & 6.42 & 5.49 & 7.48 & 5.47 & 6.2 & 4.04 & 6.23 & 10.03 & 3.48 \\
\hline$[\mathrm{SII}] \lambda 6723$ & 9.88 & 12.73 & 7.1 & 27.24 & 0.86 & 2.55 & 1.8 & 3.05 & 71 & 0.49 \\
\hline$[\mathrm{ArV}] \lambda 7005.6$ & 0.54 & 0.97 & 1.36 & 2.34 & - & - & - & 0.66 & 2.32 & - \\
\hline $\mathrm{HeI} \lambda 7065.5$ & 0.8 & 4.66 & 7.33 & 9.8 & 3.74 & 3.86 & 6.04 & 14.77 & 8.09 & 4.37 \\
\hline$[$ ArIII $] \lambda 7135.8$ & - & 19.63 & 34.54 & 38.92 & 13.99 & 16.61 & 8.73 & 30.24 & 57.79 & 5.2 \\
\hline$[$ ArIV] $] \lambda 7170.5$ & - & 0.97 & - & - & - & - & - & 0.95 & - & - \\
\hline HeII $\lambda 7177.5$ & - & - & - & - & - & - & - & - & - & - \\
\hline$[$ ArIV] $] \lambda 7238.1$ & - & 2.71 & 2.46 & - & 0.9 & 2.62 & 0.58 & 0.7 & 1.28 & 0.19 \\
\hline$[\mathrm{ArIV}] \lambda 7263$ & 1.15 & - & - & - & - & - & - & 0.49 & - & - \\
\hline$[\mathrm{OII}] \lambda 7325$ & 4.23 & 4.88 & 21.43 & 20.49 & 2.77 & 5.79 & 10.68 & 25.79 & 18.9 & 1.93 \\
\hline$[$ ArIII $] \lambda 7751.4$ & - & 7.03 & 10.43 & 9.36 & 3.22 & 4.44 & 2.06 & 8.31 & 11.61 & 1.22 \\
\hline
\end{tabular}


Tabela A.2 - Continuação

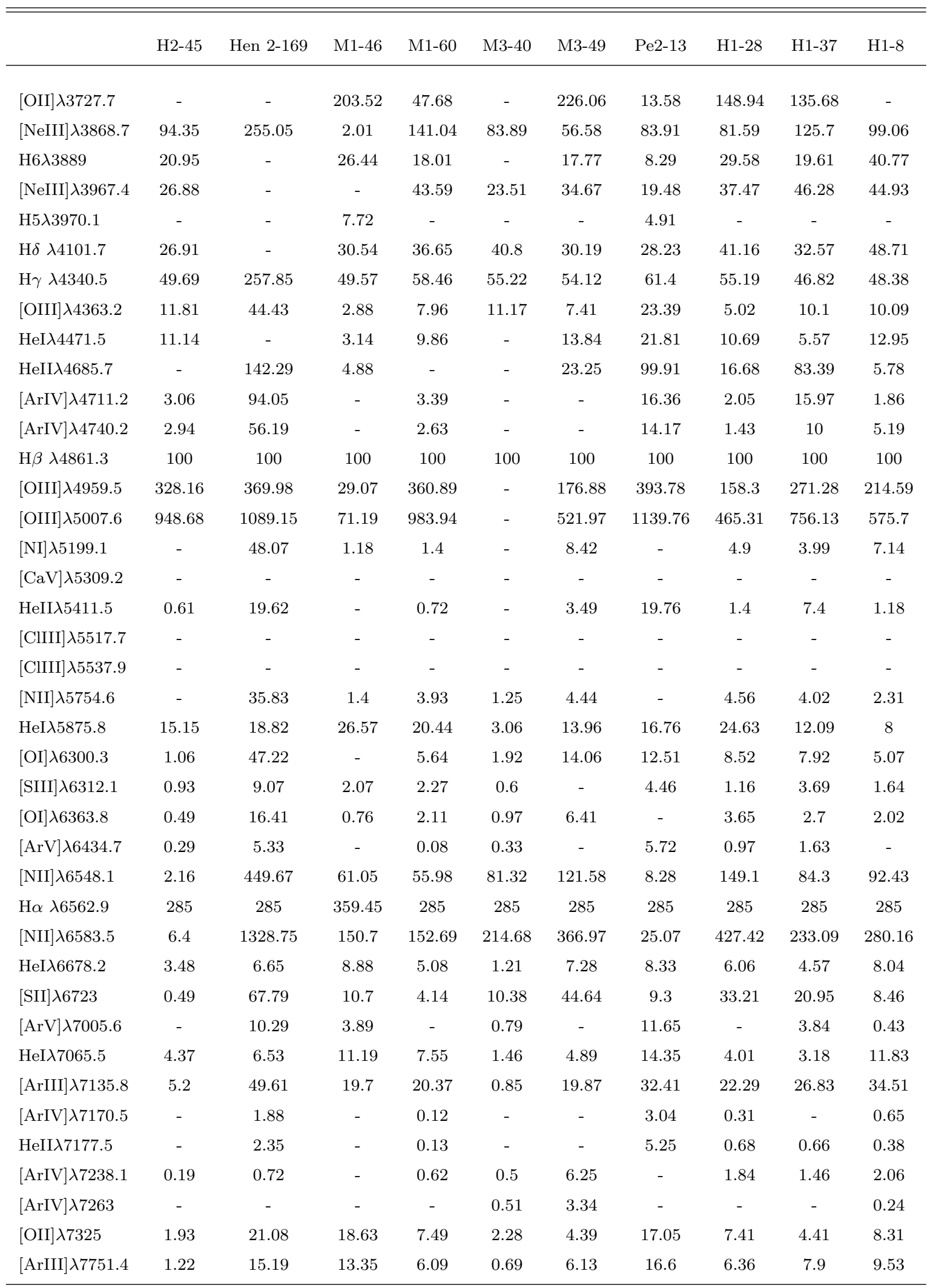


Tabela A.2 - Continuação

\begin{tabular}{|c|c|c|c|c|c|c|c|c|c|}
\hline & M1-24 & M2-21 & M2-37 & M3-24 & Th3-26 & H1-36 & Hen 2-186 & Hf2-1 & IC 4663 \\
\hline$[\mathrm{OII}] \lambda 3727.7$ & 31.43 & 12.97 & 43.58 & 35.37 & 54.06 & 61.34 & 111.18 & 52.28 & 57.17 \\
\hline$[\mathrm{NeIII}] \lambda 3868.7$ & 54.03 & 57.69 & 103.38 & 84.1 & 134.98 & 185.21 & 157.68 & 130.62 & 128.2 \\
\hline H6ג3889 & 27.08 & 18.07 & 30.65 & 17.65 & - & 15.53 & 11.89 & 33.21 & 16.91 \\
\hline$[\mathrm{NeIII}] \lambda 3967.4$ & 37.31 & 24.58 & 37.25 & 44.39 & 58.18 & 58.73 & 61.12 & 57.46 & 49.69 \\
\hline H5 23970.1 & - & - & - & - & - & - & - & - & - \\
\hline Н $\delta \lambda 4101.7$ & 33.76 & 14.09 & 27.15 & 24.82 & 27.01 & 28.42 & 27.84 & 31.89 & 37.55 \\
\hline $\mathrm{H} \gamma \lambda 4340.5$ & 49.5 & 39.13 & 49.96 & 44.52 & 73.75 & 52.02 & 49.52 & 49.8 & 58.09 \\
\hline$[\mathrm{OIII}] \lambda 4363.2$ & 4.26 & 16.5 & 13.84 & 4.02 & 20.67 & 50.06 & 23.45 & 17.33 & 10.15 \\
\hline $\mathrm{HeI} \lambda 4471.5$ & 6.76 & 5.7 & 17.45 & 6.73 & - & 2.73 & 5.05 & 1.93 & 5.13 \\
\hline HeII $\lambda 4685.7$ & - & 24.12 & - & 22.33 & 92.43 & 62.75 & 58.9 & 97.45 & 90.99 \\
\hline$[\mathrm{ArIV}] \lambda 4711.2$ & - & 3.93 & 1.36 & 4.04 & 28.53 & 12.27 & 10.76 & 17.25 & 11.58 \\
\hline$[$ ArIV] $] \lambda 4740.2$ & - & 4.27 & 1.96 & 2.73 & 17.57 & 10.47 & 8.48 & 10.21 & 7.75 \\
\hline $\mathrm{H} \beta \lambda 4861.3$ & 100 & 100 & 100 & 100 & 100 & 100 & 100 & 100 & 100 \\
\hline$[\mathrm{OIII}] \lambda 4959.5$ & 166.03 & 442.57 & 43.65 & 220.65 & 337.02 & 482 & 537.77 & 449.6 & 347.2 \\
\hline$[\mathrm{OIII}] \lambda 5007.6$ & 481.96 & 1294.29 & 108.19 & 650.85 & 961.6 & 1366.6 & 1557.67 & 1333.28 & 1028. \\
\hline$[\mathrm{NI}] \lambda 5199.1$ & - & 0.98 & 3.77 & 1 & 3.68 & 1.45 & 3.57 & 0.88 & - \\
\hline$[\mathrm{CaV}] \lambda 5309.2$ & - & - & - & - & - & 1.37 & - & - & - \\
\hline HeII $\lambda 5411.5$ & 0.31 & 2.17 & - & 2.39 & 7.72 & 6.33 & 4.6 & 6.46 & 5.51 \\
\hline$[\mathrm{ClIII}] \lambda 5517.7$ & - & - & - & - & - & - & - & - & - \\
\hline$[\mathrm{ClIII}] \lambda 5537.9$ & - & - & - & - & - & - & - & - & - \\
\hline$[\mathrm{NII}] \lambda 5754.6$ & 0.93 & 1.02 & 1.72 & 2.08 & 2.91 & 9.86 & 5.98 & 1.98 & 0.91 \\
\hline $\mathrm{HeI} \lambda 5875.8$ & 8.82 & 15.25 & 21.51 & 19.65 & 6.87 & 9.39 & 12.63 & 6.46 & 6.39 \\
\hline$[\mathrm{OI}] \lambda 6300.3$ & 0.64 & 5.05 & 1.24 & 1.88 & 5.91 & 33.86 & 19.79 & 3.31 & - \\
\hline$[\mathrm{SIII}] \lambda 6312.1$ & 0.9 & 4.53 & 1.77 & 1.09 & 7.89 & 8.86 & 4.23 & 3.97 & 2.63 \\
\hline$[\mathrm{OI}] \lambda 6363.8$ & 0.63 & 1.94 & - & 1.08 & - & 11.45 & 7.03 & 2.04 & - \\
\hline$[\mathrm{ArV}] \lambda 6434.7$ & 0.89 & - & - & - & 3.08 & 4.3 & 2.75 & 1.2 & 0.54 \\
\hline$[\mathrm{NII}] \lambda 6548.1$ & 19.03 & 8.08 & 30.36 & 31.75 & 48.62 & 39.25 & 95.68 & 35.77 & 19.71 \\
\hline $\mathrm{H} \alpha \lambda 6562.9$ & 285 & 285 & 285 & 285 & 285 & 285 & 285 & 285 & 285 \\
\hline$[\mathrm{NII}] \lambda 6583.5$ & 31.78 & 24.4 & 54.68 & 75.8 & 103.16 & 98.93 & 271.35 & 70.32 & 31.33 \\
\hline $\mathrm{HeI} \lambda 6678.2$ & 4.89 & 5.44 & 7.01 & 5.47 & 4.36 & 3.14 & 4.7 & 3.28 & 3.19 \\
\hline$[\mathrm{SII}] \lambda 6723$ & 1.96 & 1.96 & 5.87 & 6.4 & 10.1 & 3.87 & 15.26 & 13.73 & 5.42 \\
\hline$[\mathrm{ArV}] \lambda 7005.6$ & 0.18 & 1.31 & - & - & 5.03 & 9 & 4.94 & 2.15 & 1.15 \\
\hline $\mathrm{HeI} \lambda 7065.5$ & 4.77 & 8.43 & 4.01 & 3.93 & 3.65 & 5.72 & 6.52 & 1.71 & 1.43 \\
\hline$[$ ArIII] $\lambda 7135.8$ & 16.04 & 8.72 & 5.31 & 17.98 & 20.52 & 27.73 & 26.67 & 35.66 & 28.7 \\
\hline$[$ ArIV] $] \lambda 7170.5$ & - & 0.27 & - & 0.7 & 4.14 & 1.9 & 1.65 & 1.68 & 1.19 \\
\hline HeII $\lambda 7177.5$ & - & 0.52 & - & - & 0.41 & 0.91 & 0.76 & - & - \\
\hline$[\mathrm{ArIV}] \lambda 7238.1$ & 0.48 & 1 & 2.24 & 1.91 & 2.58 & 1.14 & 0.55 & 0.86 & 1.08 \\
\hline$[\mathrm{ArIV}] \lambda 7263$ & - & - & - & 0.27 & 0.94 & 1.19 & 0.62 & - & - \\
\hline$[\mathrm{OII}] \lambda 7325$ & 3.61 & 11.23 & 4.7 & 5.19 & 6.62 & 57.28 & 25.56 & 3.18 & 2.83 \\
\hline$[$ ArIII $] \lambda 7751.4$ & 4.78 & 2.44 & 3.34 & 3.78 & 7.49 & 7.61 & 9.43 & 8.24 & 6.1 \\
\hline
\end{tabular}

